\title{
Wales in Continental Guidebooks (1850-2013): A Country on the Imaginative Periphery
}

\author{
Dijkstra, Anna-Lou
}

How to cite:

Dijkstra, Anna-Lou (2017) Wales in Continental Guidebooks (1850-2013): A Country on the Imaginative Periphery. Doctoral thesis, Swansea University.

http://cronfa.swan.ac.uk/Record/cronfa39298

Use policy:

This item is brought to you by Swansea University. Any person downloading material is agreeing to abide by the terms of the repository licence: copies of full text items may be used or reproduced in any format or medium, without prior permission for personal research or study, educational or non-commercial purposes only. The copyright for any work remains with the original author unless otherwise specified. The full-text must not be sold in any format or medium without the formal permission of the copyright holder. Permission for multiple reproductions should be obtained from the original author.

Authors are personally responsible for adhering to copyright and publisher restrictions when uploading content to the repository.

Please link to the metadata record in the Swansea University repository, Cronfa (link given in the citation reference above.)

http://www.swansea.ac.uk/library/researchsupport/ris-support/ 


\section{Wales in Continental Guidebooks (1850-2013): A Country on the Imaginative Periphery}

Anna-Lou Dijkstra, BA, MA

Submitted to Swansea University in fulfilment of the requirements for the Degree of Doctor of Philosophy

Swansea University

2017 


\section{Summary}

This thesis examines the representations of Wales in German-, French- and Dutchlanguage travel guidebooks published between 1850 and 2013. The analysis focuses on the conceptualisation of the country in these texts within the framework of 'imaginative peripheries'. This framework is mainly based on the work of Edward Said and his model of 'imaginative geographies', which examines the perception of spaces through texts and discourses. In the thesis it is asserted that guidebooks have the power to significantly influence tourists' views of a destination, thus affecting the socio-spatial construction of the area in question. The thesis scrutinises how Wales is conceptualised as a cultural, linguistic, ethnographic, historical, geographical and political entity and how these representations influence the country's spatial realisation in the texts. In conclusion it is argued that during the course of the centuries under examination, Wales has been increasingly recognised as a distinct entity, but has simultaneously been moved to the periphery on a textual and conceptual level. Finally, these shifts not only provide insights into the way Wales is perceived in overseas travel guidebooks, but also reflect broader discourses concerning the changing balance of power in our globalising world. 


\section{Declarations and Statements}

\section{DECLARATION}

This work has not previously been accepted in substance for any degree and is not being concurrently submitted in candidature for any degree.

Signed (candidate)

Date

\section{STATEMENT 1}

This thesis is the result of my own investigations, except where otherwise stated. Where correction services have been used, the extent and nature of the correction is clearly marked in a footnote(s).

Other sources are acknowledged by footnotes giving explicit references. A bibliography is appended.

Signed (candidate)

Date

\section{STATEMENT 2}

I hereby give consent for my thesis, if accepted, to be available for photocopying and for inter-library loan, and for the title and summary to be made available to outside organisations.

Signed (candidate)

Date 


\section{Contents}

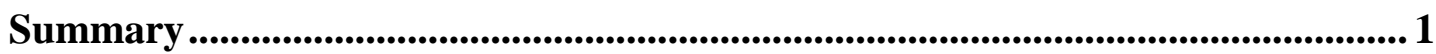

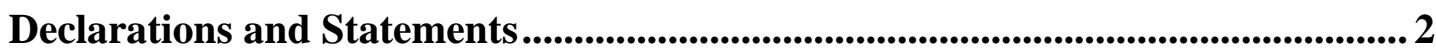

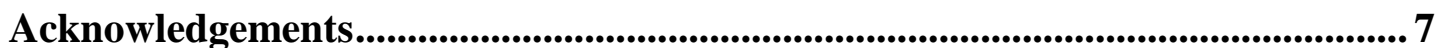

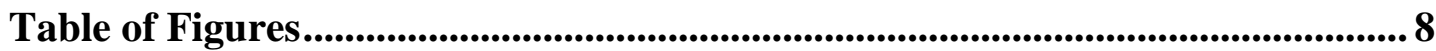

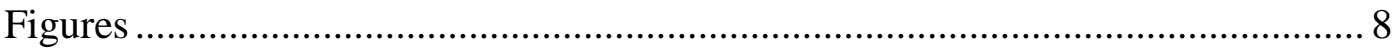

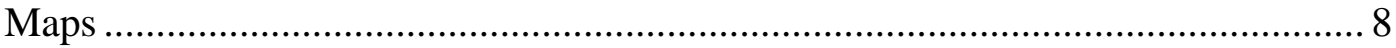

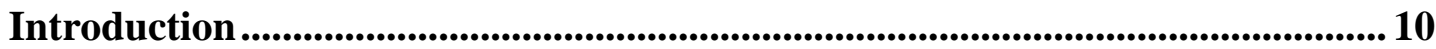

The Research Topic: Perceptions of Wales in Continental Guidebooks................ 10

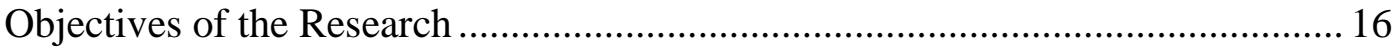

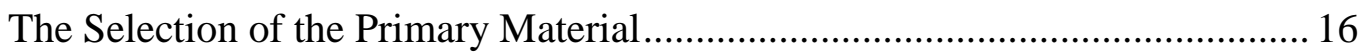

Methodological Approach, Theoretical Perspective and Research Questions ... 19

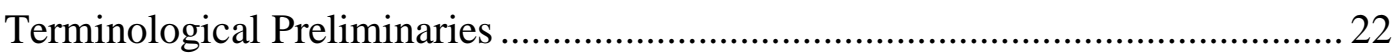

1 - The Guidebook ................................................................................................................. 31

1.1 The Historical Development of the Genre ................................................... 31

1.2 The Development of the Field: The Guidebook as an Object of Analysis....... 49

1.3 Guidebooks and the Socio-Spatial Construction of Destinations ...................5 59

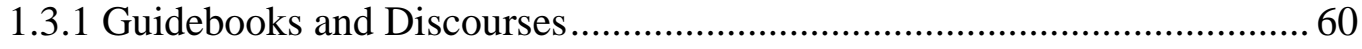

1.3.2 The Imaginative Conceptualisation of Places......................................... 64

1.4 The Correlation between Tourism, Peripherality and Guidebooks ................. 71

2 - Wales as a Travel Destination on the Imaginative Periphery .......................... 78

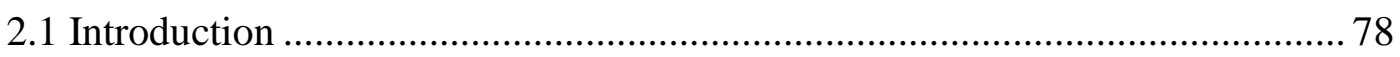

2.2 The Romantic Imaginations of Wales: A Discursive Prelude .......................... 80

2.2.1 The Welsh Landscape: From a Country of 'Horrid Rocks' to a Utopian

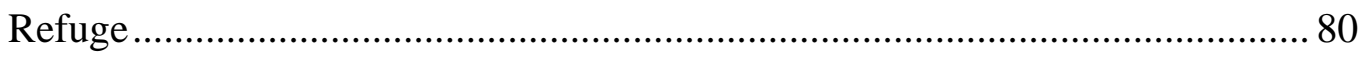

2.2.2 Celtic Tourism in Wales during the Romantic Period.............................. 89

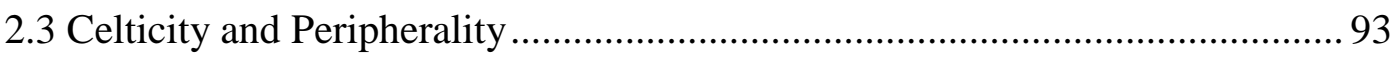


2.4 Continental Constructions of Wales 104

2.5 Concluding Remarks

3 - 1850-1900: Wales - Picturesque and Futuristic, With a Touch of Otherness

3.1 Introduction 113

3.2 Reaching Wales in the Nineteenth Century: Steamers and Railways 114

3.3 Obscuring Wales as a Travel Destination and Topographical Entity 121

3.4 Welsh Landscapes: Nature and Industry as Travel Incentives 128

3.4.1 The Aesthetic Ideals of the Picturesque and the Sublime. 129

3.4.2 Snowdonia: Viewing Wales Through a Swiss Lens 134

3.4.3 The Industrial Landscape: A Journey into the Future 138

3.5 Aspects of Welshness 150

3.5.1 German Views: Adding a Dash of Otherness 150

3.5.2 French Views: Celtomanic Wales 157

3.6 Concluding Remarks 161

4 - 1955-1975: The Emergence of Celtic Wales ........................................................ 163

4.1 Introduction 163

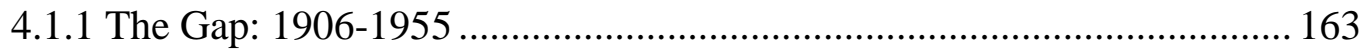

4.1.2 The Post-World War II Decades: The Rapid Growth of Tourism........... 167

4.1.3 The Corpus

4.2 First Impressions: Wales's Growing Distinctiveness as a Travel Destination.

4.3 German Views: Aestheticising and Racialising Wales

4.3.1 Continuation and Development of the Nineteenth-Century Discourse:

Picturesque and Industrial Landscapes

4.3.2 Moving towards the Periphery

4.3.2.1 Ethnographic Distinctions

4.3.2.2 Spatialising and Temporalising Welshness 
4.3.2.3 A Historical Sense of Difference: Aggressors, Heroes and Fair Rulers 189

4.3.2.4 The Welsh Language. 191

4.4 Diverging French Perceptions of Wales. 193

4.4.1 Continuation and Development of the Nineteenth-Century Discourse:

Picturesque and Industrial Landscapes 193

4.4.2 Contrasting Views........ 196

4.4.2.1 The Welsh Inhabitants: Manual Workers and Political Innovators .. 196

4.4.2.2 A Question of Perspective: The Anglo-Normans as Subjugators or

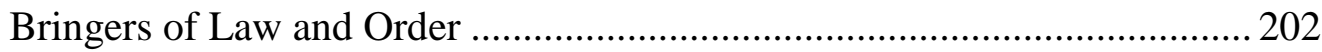

4.4.2.3 The Welsh Language..................................................................... 206

4.4.2.4 The Landscape as a Repository of Identity and Legend .................. 209

4.5 A Debut: The Dutch Material.................................................................... 212

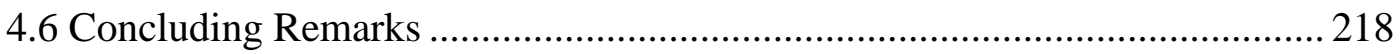

5 - 1995-2013: The Devolved Periphery .......................................................................... 221

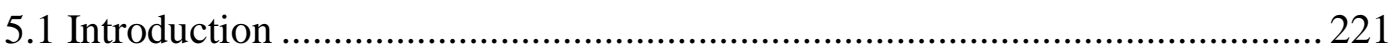

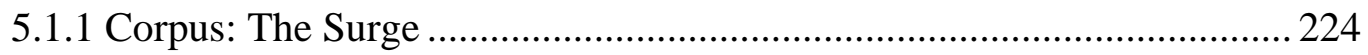

5.1.2 Overseas Tourism in Wales: Struggling against London-centrism ......... 226

5.2 Dutch Views: Wales as the Integral Other ................................................... 228

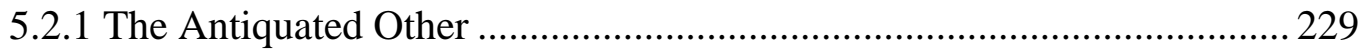

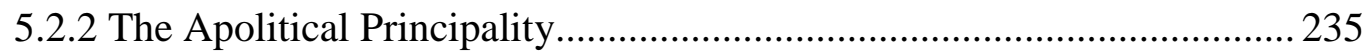

5.3 The German Construction of a Welsh Tryptich ......................................... 241

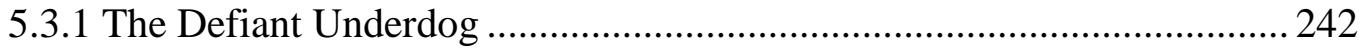

5.3.2 A Refuge from Globalisation and Modernisation.................................. 247

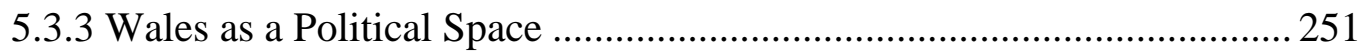

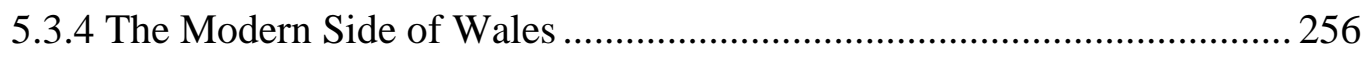

5.4 Wales as the Celtic Colony in French-Language Guidebooks ....................... 261

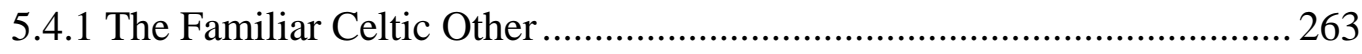




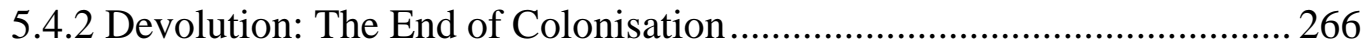

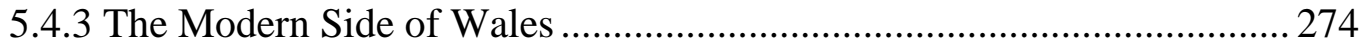

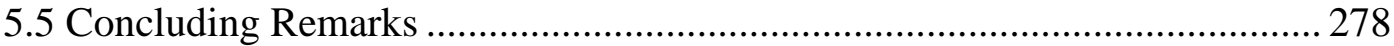

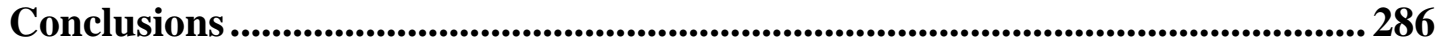

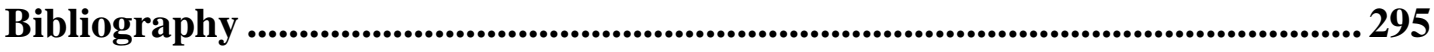

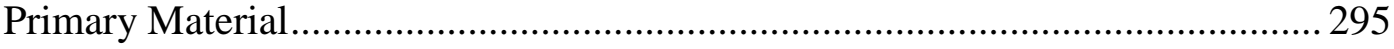

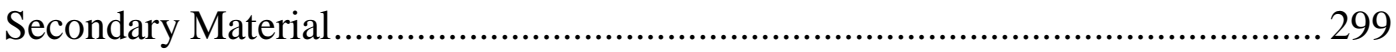




\section{Acknowledgements}

I would like to express my sincere gratitude to my first supervisor Dr Kathryn N. Jones for her continuous support of my research, her motivation and her patience. Her guidance helped me tremendously. She stimulated me to explore my potential as an academic even in the most difficult periods of the research when I was unable to see it. I would also like to thank my second supervisor, Professor Daniel Williams, for his suggestions concerning my work.

Overall, I am indebted to the AHRC-funded research-project 'European Travellers to Wales: $1750-2010$ ' for giving me the opportunity to join their team as a $\mathrm{PhD}$ student. Besides my first supervisor, my sincere thanks goes to the other researchers attached to this project; Professor Carol Tully, Dr Heather Williams and Dr Rita Singer, for reading and commenting on my thesis at various stages. By generously funding my tuition fees, my European archival tour and several international conferences, the project gave me the chance to develop myself academically as well as personally. Furthermore, I am grateful to the Dutch Prins Bernhard Cultuurfonds for supporting my research with additional funding in the year 2014-2015.

Most of all, however, I would like to thank my loving and caring husband, who supported me through the bleakest times and never gave up on me. Without him I would never have succeeded. Dankje allerliefste. 


\section{Table of Figures}

\section{Figures}

Figure 1: Chart showing the regional awareness of various parts of Great Britain amongst non-UK respondents (in: Visit Britain, Overseas Visitors to Britain, p. 46).

Figure 2: Statistical overview of the primary data that was discovered during the research. These figures include translated as well as untranslated titles........18

Figure 3: Plato Ahrens, 'Conway-Castle' (in: E.G. Ravenstein, Reisehandbuch für London, England und Schottland (Hildburghausen: Bibliographisches

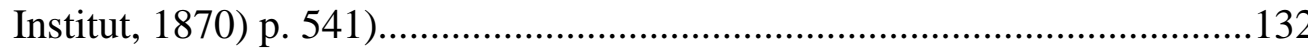

Figure 4: Richard Wilson, Conwy Castle (Conwy: Guildhall, 1714-1782). 132

Figure 5: The cover of Der Große Polyglott guide to Wales and England by Hans Lajta (1971).

\section{Maps}

Map 1: Leigh Shaw-Taylor and others, '1851 Britain: The Rail Network', Mapping the Rail Network, The Cambridge Group for the History of Population and Social Structure: Department of Geography and Faculty of History, <http://www.geog.cam.ac.uk/research/projects/occupations/britain19c/railwa ys/> [accessed 8 December 2014]

Map 2: Leigh Shaw-Taylor and others, '1881 Britain: The Rail Network', Mapping the Rail Network, The Cambridge Group for the History of Population and Social Structure: Department of Geography and Faculty of History, <http://www.geog.cam.ac.uk/research/projects/occupations/britain19c/railwa ys/> [accessed 8 December 2014].

Map 3: Karl Baedeker, 'Panorama from the Top of Snowdon' (in: Karl Baedeker, Grossbritannien: England (ausser London), Wales, Schottland und Irland (Leipzig: Karl Baedeker, 1899), p. 272) 
Map 4: 'L’Angleterre Touristique' (in: Élisabeth Halévy, Iles Britanniques: Angleterre, pays de Galles, Écosse, Eire, Irlande du Nord, Les Guides bleus

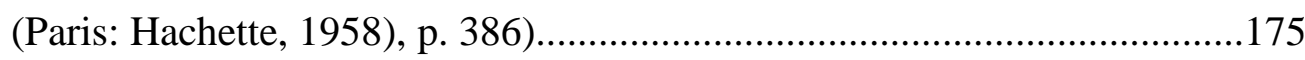

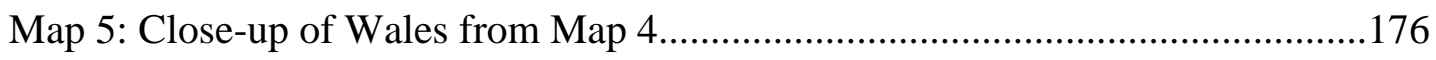

Map 6: Overview of itineraries (in: Reiswijzer voor Engeland, Wales en Schotland, ANWB Reiswijzer voor het buitenland ([n.p.]: Kon. Ned. Toeristenbond

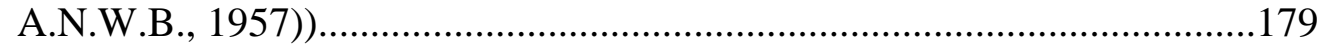

Map 7: Close-up of Wales from Map 6...............................................................180 


\section{Introduction}

\section{The Research Topic: Perceptions of Wales in Continental Guidebooks}

Wales - 'einen integrierenden Bestandteil des britischen Reichs' [an integral part of the British Empire], '[1]a campagne de la campagne anglaise' [the countryside of the English countryside], ${ }^{2}$ but also 'Land der Fremden' [land of strangers], 'Dorado für “Alternative", [El Dorado for 'counterculturists'], ${ }^{4}$ inhabited by '[f]eeën en monsters, trollen en heiligen' [fairies and monsters, trolls and saints]. ${ }^{5}$ The conceptualisations of this small country in Continental travel guidebooks are strikingly wide-ranging but at the same time show a remarkable level of similarity, both translinguistically and diachronically. This thesis examines the shifting representations of Wales in German-, Dutch- and French-language travel guidebooks published between 1850 and 2013. However, these texts are not created in a vacuum, but are part of our socio-cultural reality. They are consumer products and are thus part of the tourism industry through which they are disseminated and through which the guidebooks thereby distribute their constructions of the travel destination in question.

For many in the Western world, tourism has become an inherent and indispensable part of life. Modern infrastructure and rising affluence has enabled a growing number of people to reach far-away places, but also to make shorter trips to destinations which a century ago still seemed unreachable. International tourism has grown exponentially since the middle of the twentieth century and reached the number of almost one billion international tourists in $2016 .{ }^{6}$ On a par with this

\footnotetext{
${ }^{1}$ Karl Baedeker, Grossbritannien: England (ausser London), Wales, Schottland und Irland, Baedeker Handbuch für Reisende, 3rd edn (Leipzig: Karl Baedeker, 1899), p. xxix.

${ }^{2}$ Dominique Auzias and Jean-Paul Labourdette, Grande-Bretagne, Petit futé, 6th edn (Paris: Nouvelles éditions de l'université, 2006), p. 448.

${ }^{3}$ Karl Baedeker, London nebst Ausflügen nach Süd-England, Wales und Schottland sowie Reiserouten vom Continent nach England, Baedeker Handbuch für Reisende, 2nd edn (Koblenz: Karl Baedeker, 1866), p. 258; Ernst Georg Ravenstein, London, England, Schottland und Irland, ed. by H.J. Meyer, Meyers Reisebücher, 3rd edn (Leipzig: Bibliographisches Institut, 1876), p. 701. ${ }^{4}$ Petra Juling, Wales, DuMont Reise-Taschenbuch (Cologne: DuMont Buchverlag, 2000), p. 35.

${ }^{5}$ Midden Engeland en Wales, ANWB reisgidsen voor het buitenland ([n.p.]: ANWB, 1975), p. 219.

6 'Close to One Billion International Tourists in the First Nine Months of 2016', World Tourism Organization UNWTO Press Release, 7 November 2016 <http://media.unwto.org/press-release/201611-07/close-one-billion-international-tourists-first-nine-months-2016> [accessed 3 January 2017].
} 
development, Wales has also seen a gradual increase in the number of inbound travellers and experienced a record tourism year in $2014 .^{7}$ In a time of globalisation and growing internationalisation which seems to be dominated by larger industrialised world economies, smaller stateless nations also seem to be able to reap the benefits of these developments.

Although overseas tourism has expanded in Wales during the past decades, the country is still seriously lagging behind London, the rest of England and Scotland, as growth in Wales has been much less rapid. ${ }^{8}$ In their report Overseas Visitors to Britain, Visit Britain states that in 2009, ninety per cent of overseas visitors stayed in England and fifty per cent never even left London. Only four per cent travelled further west to visit Wales. The report subsequently concludes that there seems to be a strong focus on London as a travel destination amongst overseas visitors and that the regional spread of tourists outside of the capital city is much weaker compared to other large cities in Europe. ${ }^{9}$ In other words, tourism in Great Britain appears to be extremely London-centric: 'Even today, for many people, Britain is STILL perceived as LONDON versus THE COUNTRY/OTHER [...]. London dominates perceptions and is considered a different entity to Britain overall. There is little appreciation beyond London of a "modern Britain"”. ${ }^{10}$ Whilst London is regarded as a modern melting pot of cultures with an abundance of tourist attractions, the quoted study asserts that 'THE COUNTRY/OTHER' is perceived to be rural, depopulated, old-fashioned, picturesque and steeped in history and tradition. Most revealing, however, is the fact that even within this general lack of awareness of the rest of Great Britain outside of London, Wales proves to be the least wellknown of all (see Figure 1).

\footnotetext{
7 'More Visitors to Wales in 2014 as UK Enjoys a Record Tourism Year', Gov.uk Press Release, 17 July $2015<$ https://www.gov.uk/government/news/more-visitors-to-wales-in-2014-as-uk-enjoys-arecord-tourism-year> [accessed 3 January 2017].

${ }^{8}$ Visit Britain, Trends in Visits to Different Areas of Britain, Foresight, 127 (2014)

<https://www.visitbritain.org/nation-region-county-data> [accessed 21 August 2015], pp. 3-4.

${ }^{9}$ Visit Britain, Overseas Visitors to Britain: Understanding Trends, Attitudes and Characteristics (2010) <http://www.etoa.org/resources/reports/2010-overseas-visitors-to-britain-understandingtrends-attitudes-and-characteristics-by-visitbritain> [accessed 17 November 2015], p. 46.

${ }^{10}$ Visit Britain, Overseas Visitors to Britain, p. 46. Emphasis in original.
} 
Regional Awareness: Overall

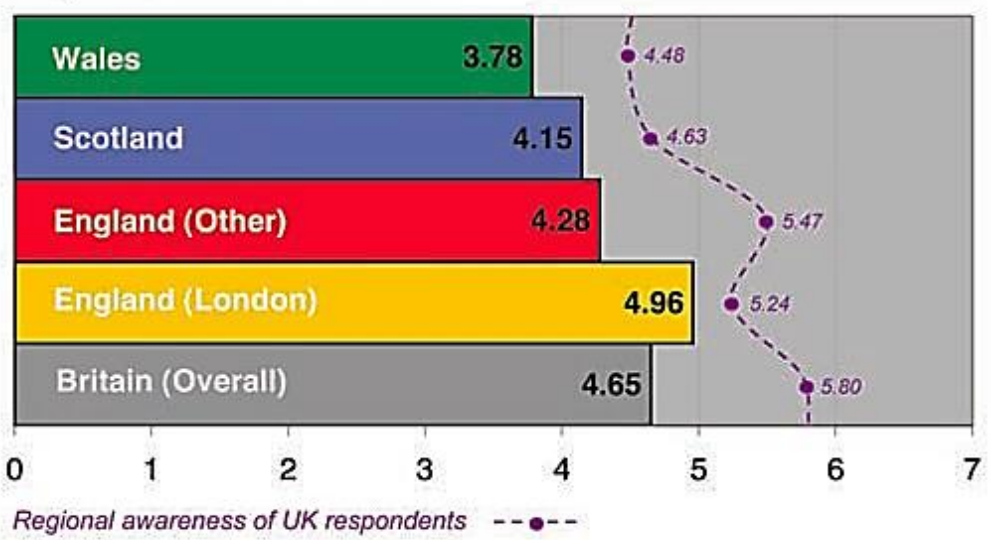

Figure 1: Measured on a scale from one to seven, the regional awareness of Wales amongst non-UK respondents is lowest compared to the other parts of Great Britain. This is represented by the bar graph, which is compared to the regional awareness amongst UK respondents, shown by the line graph. ${ }^{11}$

The main dilemma concerning Wales's overseas image is that tourists find it hard to distinguish Wales from England. Even as a devolved part of Great Britain, which, at the very least, should have increased Wales's political profile, the country has remained a peripheral and undistinguishable part of Great Britain in the eyes of most Europeans. Overseas visitors have difficulties in distinguishing Wales from the rest of the UK, and primarily see Wales as a part of England, whereas Ireland and Scotland are perceived as having well-established identities. ${ }^{12}$ In her book chapter 'Le pays de Galles: ni vu, ni connu', Anne Hellegouarc'h-Bryce refers to a survey conducted amongst French tourists undertaken in 1999, which indicated that Wales was the least well-known part of Britain. Most interviewees only associated Wales with its landscape, and twenty-five per cent did not have any image of the country at all. ${ }^{13}$ More recent surveys reveal that German and Dutch visitors also have a very limited understanding of Wales and Welshness. Remarks such as these can be regarded as representative: 'I don't really know exactly where Wales is... I don't

\footnotetext{
${ }^{11}$ Visit Britain, Overseas Visitors to Britain, p. 46.

${ }^{12}$ Nigel Morgan and Annette Pritchard, 'Promoting Niche Tourism Destination Brands', Journal of Promotion Management, 12 (2005), 17-33 (p. 25); Emlyn Sherrington, 'How Do You Sell a Nation?', Journal for the Study of British Cultures, 11 (2004), 183-94 (p. 183).

${ }^{13}$ Anne Hellegouarc'h-Bryce, 'Le pays de Galles: ni vu, ni connu', in Pays de Galles: quelle(s) image(s)? = What Visibility for Wales?, ed. by Anne Hellegouarc'h-Bryce, Gerry German and JeanYves Le Disez (Brest: Centre de recherche bretonne et celtique, Université de Bretagne Occidentale, 2009), pp. 251-65 (p. 255).
} 
even know how to get there', 14 'Wales equals England and furthermore there is Ireland and Scotland' ${ }^{15}$ In short, there seems to be a lack of awareness of Wales, its culture but also its geographical borders and distinctiveness as a separate entity within Great Britain. Hellegouarc'h-Bryce rightly mentions that this absence of an overseas profile exposes Wales to images projected by outsiders. ${ }^{16}$ As Wales is not recognised as having a clear identity, the country can be imagined in various ways and be used to conform to all kinds of wish-fulfilments.

This lack of awareness of Wales and the absence of a clear overseas profile have been a matter of concern for Wales's tourism organisations, as the relatively low number of visitors compared to other regions of the UK is generally linked to this issue. Annette Pritchard, director of the Welsh Centre for Tourism Research, has even claimed that the number of overseas visitors to Wales has fallen almost twentythree per cent over a ten-year period and identifies Wales's low visibility overseas as the main cause for these dwindling numbers. She describes Wales as 'Britain's best kept secret abroad', ${ }^{17}$ and criticises the work of tourist organisation Visit Wales for focusing its campaigns too much on the domestic market. ${ }^{18}$ Emlyn Sherrington, a Welsh historian, is also in search of a culprit for this deficient overseas profile and polemically blames the English: 'The causes of Wales' low profile outside Britain are to be found $[\ldots]$ in bureaucratic and institutional structures and can be summarised in one word - England' ${ }^{19}$ Both explanations are slightly too one-sided, and identifying one responsible party might prove to be impossible as well as unnecessary.

The perception of Wales amongst Continental Europeans has not been systematically examined up to this point, apart from a handful of tourism surveys mentioned above. These enquiries show that Wales often fails to evoke a strong

\footnotetext{
${ }^{14}$ GfK Consumer, Tipping Point Research Germany, Power Point Presentation ([n.p.]: Growth from Knowledge, 2006), p. 20.

${ }^{15}$ GfK Consumer, Tipping Point Research: Stage 2 the Netherlands, Power Point Presentation ([n.p.]: Growth from Knowledge, 2006), p. 24.

${ }^{16}$ Hellegouarc'h-Bryce, p. 252.

17 'Overseas Visitors to Wales Down 23\%, Prof Annette Pritchard Says', BBC News Wales, 1 April 2014 <http://www.bbc.co.uk/news/uk-wales-26834643> [accessed 17 November 2014].

${ }^{18}$ Although Visit Wales has responded to this by stating that they do market Wales in Ireland, Germany and the USA, since these markets have been identified as showing the most potential for growth, the Welsh government has cut the marketing budget for promoting Wales abroad by more than a million pounds. See: Daniel Davies, 'Row over Budget to Attract Overseas Tourists to Wales', BBC News, 13 January 2013 <http://www.bbc.co.uk/news/uk-wales-politics-20989259> [accessed 17 November 2015].

${ }^{19}$ Sherrington, p. 184.
} 
image, but for a long time there has been a substantial gap in research on Continental images of Wales as a political, cultural and geographical entity. Although the country has always been less frequented than London, Continental travellers have visited Wales through the ages and many did collect their experiences in travelogues, diaries and letters. Examining these testimonials would enable us to explore more profound European interactions with Wales, as well as their impressions of the country and its culture. Whereas British views of Wales have received an increasing amount of academic interest ${ }^{20}$ European perceptions of the country have been given little critical attention and the exploration of this topic has long been very limited. ${ }^{21}$ The AHRC-funded research project 'European Travellers to Wales: 1750-2010' is making a substantial pioneering contribution towards filling this gap. ${ }^{22}$ The project is a collaboration between Swansea and Bangor Universities and the Centre for Advanced Welsh and Celtic Studies (Aberystwyth), which was funded for the threeyear period 2013-2016. The researchers involved in the project have discovered a vast amount of European travel accounts of Wales; these are listed in a database which is freely accessible online. Another output of the project was a special issue on Wales of the journal Studies in Travel Writing in 2014, in which a wide variety of scholarly articles on travel writing about Wales was collected and which offered a first exploration of the topic. Moreover, a jointly-authored book concerning the discovered texts and their interpretation will be published shortly. ${ }^{23}$ The current research hand is part of this AHRC-funded project, and focuses on the representation of Wales in Continental travel guidebooks.

\footnotetext{
${ }^{20}$ For example: Pyrs Gruffudd, David T. Herbert and Angela Piccini, 'In Search of Wales: Travel Writing and Narratives of Difference, 1918-50', Journal of Historical Geography, 26 (2000), 589604; Marjorie Morgan, National Identity and Travel in Victorian Britain (Basingstoke: Palgrave, 2001); John Richard Watson, 'Wordsworth, North Wales and the Celtic Landscape', in English Romanticism and the Celtic World, ed. by Gerard Carruthers and Alan Rawes (Cambridge: Cambridge University Press, 2003), pp. 85-102; Hywel M. Davies, 'Wales in English Travel Writing 1791-8: The Welsh Critique of Theophilus Jones', The Welsh History Review, 23 (2007), 65-93. Two edited collections should also be mentioned in this respect: Travel Writing and Tourism in Britain and Ireland, ed. by Benjamin Colbert (Basingstoke: Palgrave Macmillan, 2012); Wales and the Romantic Imagination. ed. by Damian Walford Davies and Lynda Pratt (Cardiff: University of Wales Press, 2007).

${ }^{21}$ For example: Michael Maurer, Wales: Die Entdeckung einer Landschaft und eines Volkes durch deutsche Reisende (1780-1860) (Frankfurt a.M.: Peter Lang, 2014); Carol Tully, 'The Celtic Misconnection: The German Romantics and Wales', Angermion, 2 (2009), 127-41; Heather Williams, 'Cymru trwy lygaid Rousseau (ac eraill)', Y Traethodydd, 168 (2013), 241-54.

${ }^{22}$ See the website: etw.bangor.ac.uk [accessed 4 January 2017].

${ }^{23}$ See: http://etw.bangor.ac.uk/about-project [accessed 29 January 2018].
} 
This brings us to the following question: why focus on guidebooks as a topic for research? Like travel writing to Wales, guidebooks have long been ignored as a topic for academic research, although this has changed gradually during the past decades. ${ }^{24}$ As an undeniable part of tourism practices and consumerism more generally, these texts inform travellers about the country or region they are visiting whilst guiding their gazes to a specific selection of supposedly worthwhile sights. ${ }^{25}$ By providing guidance whilst claiming to be objective, they assume the role of mentor and authority. As Joanna Dybiec points out in her research on guidebook perspectives on Poland:

[T] hey shape the tourists/travelers' sensibilities and tastes by telling them what is sehenswert and sehenswürdig, worth seeing and worthy of being seen. They structure travel experience on the conceptual level, by providing hierarchies of sights and valuative comments, as well as on the pragmatic level, by drafting the tours to be taken. ${ }^{26}$

Instead of idiosyncratic post-experience interpretations of the travel destination, which can be found in travelogues, memoirs and diaries, guidebooks are written with the intention of being used during the pre-travel phase, as well as during the visit and even afterwards. They function as manuals for the traveller and have an extended period of influence. In the case of Wales, which seems to lack a strong profile amongst overseas visitors, the impact of these texts on the perception of the country could arguably be even more profound. Their examination could lead to insights concerning the changing perceptions of Wales, why Wales is seen as an interesting and worthwhile destination (or not), and how the country and its culture are evaluated.

In summary, this thesis is innovative in two ways and thus considerably furthers the academic field. Firstly, it contributes to our understanding of Continental perceptions of Wales, primarily from a tourism perspective. As has been discussed above, a serious research gap exists in this area, which needs to be scrutinised. The researchers attached to the aforementioned project 'European Travellers to Wales: $1750-2010$ ' have started to uncover a wealth of primary sources and have collected these in their database. Secondly, the thesis endeavours to contribute to this research

\footnotetext{
${ }^{24}$ Chapter 1 will deal with guidebooks as a topic for research in more detail.

${ }^{25}$ For more on the tourist gaze, see: John Urry, The Tourist Gaze, 2nd edn (London: SAGE Publications, 2002).

${ }^{26}$ Joanna Dybiec, Guidebook Gazes: Poland in American and German Travel Guides 1945-2002 (Münster: LIT, 2004), pp. 17-18. Italics in original.
} 
by examining guidebook perceptions of Wales, and therefore also adds to the growing field of guidebook studies. By using an innovative theoretical approach, which will be further detailed in Chapter 1 , the thesis furthermore attempts to expand the academic framework for travel writing concerning smaller stateless nations.

\section{Objectives of the Research}

\section{The Selection of the Primary Material}

Now that the topic of this thesis has been introduced and its relevance has been clarified, it is necessary to further define the study's objectives and identify its specific research questions. The thesis will provide a diachronic and comparative textual analysis of French-, Dutch- and German-language guidebook perspectives of Wales in the period 1850 to 2013 . The choice of these three languages was largely determined by my own linguistic abilities, but is also fruitful as these countries are geographical neighbours and are key markets for tourism in Wales. A comparative analysis of the touristic consumption of Wales by these three Continental countries could therefore reveal illuminating differences as well as similarities in perceptions and conceptualisations of the country. The timeframe of 1850 until 2013 was chosen as a result of the historical development of the guidebook genre as well as the availability of Continental guidebooks that included Wales, which only emerged during the second half of the nineteenth century. As will be discussed in Chapter 1, the modern guidebook developed during the first half of the nineteenth century and the first foreign guides to Great Britain and Wales appeared during the middle of that century. Within this rather broad timeframe, three key periods were selected that highlight crucial caesurae in Continental perceptions of Wales, and provide a chronological overview of the most important and telling comparisons between the various views of Wales in the different language guidebooks. Firstly, Chapter 3 discusses the period between 1850 and 1900. This timeframe was chosen as it was during these decades that the first Continental guidebooks to Wales were published, thereby offering an insight into the earliest European guidebook perceptions of Wales. Secondly, the period of 1955 to 1975 is examined in Chapter 4. In this period, mass tourism boomed; the guidebook gained importance as a tourism commodity and was able to reach a growing readership. The last years under examination in Chapter 
5 are the two decades between 1995 and 2013. During the turn of the twenty-first century, the geo-political face of Wales changed drastically due to the instigation of devolution. This chapter examines whether and how the guidebooks deal with this change.

The primary material was collected during a three-month archival tour through France, Germany and the Netherlands. ${ }^{27}$ In total, more than 450 German-, French- and Dutch-language guidebooks to Great Britain and Wales were discovered; 78 Dutch, 172 French and 203 German titles. As becomes clear from Figure 2, guidebooks to Great Britain and Wales proliferated during the 1980s and 1990s, and the number of German-language titles is significantly higher than those published in Dutch or French. Moreover, there are no Dutch titles before the 1940s. These figures must be read with some caution, as they include both untranslated as well as translated titles. It was ultimately decided not to include the latter for various reasons. First of all, these texts have been written in a different source language, within another socio-cultural environment and for a different target audience. The cultural parameters in which these texts were created does not necessarily reflect German, Dutch or French views of Wales, but rather that of the source culture, and were therefore considered unsuitable for the research at hand. Representations of travel destinations in translated guidebooks have undergone a double transformation: the country, its culture and history has first been interpreted by the writer of the source text, after which the translator has also (often unconsciously) altered this image through his or her own socio-cultural filter. ${ }^{28}$ Secondly, it was often impossible to determine the exact source text of the translations, making an analysis of the shifts between source and target text unfeasible. Translated guidebooks constitute a whole different area of research, which deserves separate academic attention and needs to be explored further in other studies. In the current analysis, translated titles were therefore omitted. In addition, the figures in the graph also include the various editions of the same guidebook. Many guidebook series tend to publish new editions on a regular basis without making significant changes, frequently even leaving the entire text unaltered. If multiple editions were available,

\footnotetext{
${ }^{27}$ This research trip was generously funded by the AHRC-research project 'European Travellers to Wales: 1750-2010'.

${ }^{28}$ For a more detailed discussion of the challenges posed by translated guidebooks, see: Anna-Lou Dijkstra, 'Marginalizing and Exoticizing Wales: Shifting Representations in Translated Guidebooks', Translation Studies, 9 (2016), 198-211.
} 
these were compared and alterations to the content were considered in the analysis. When no modifications were identified, one edition was used for the analysis. Specific gaps, surges and differences between the languages in the publication of titles will be discussed in the respective chapters of the periods.

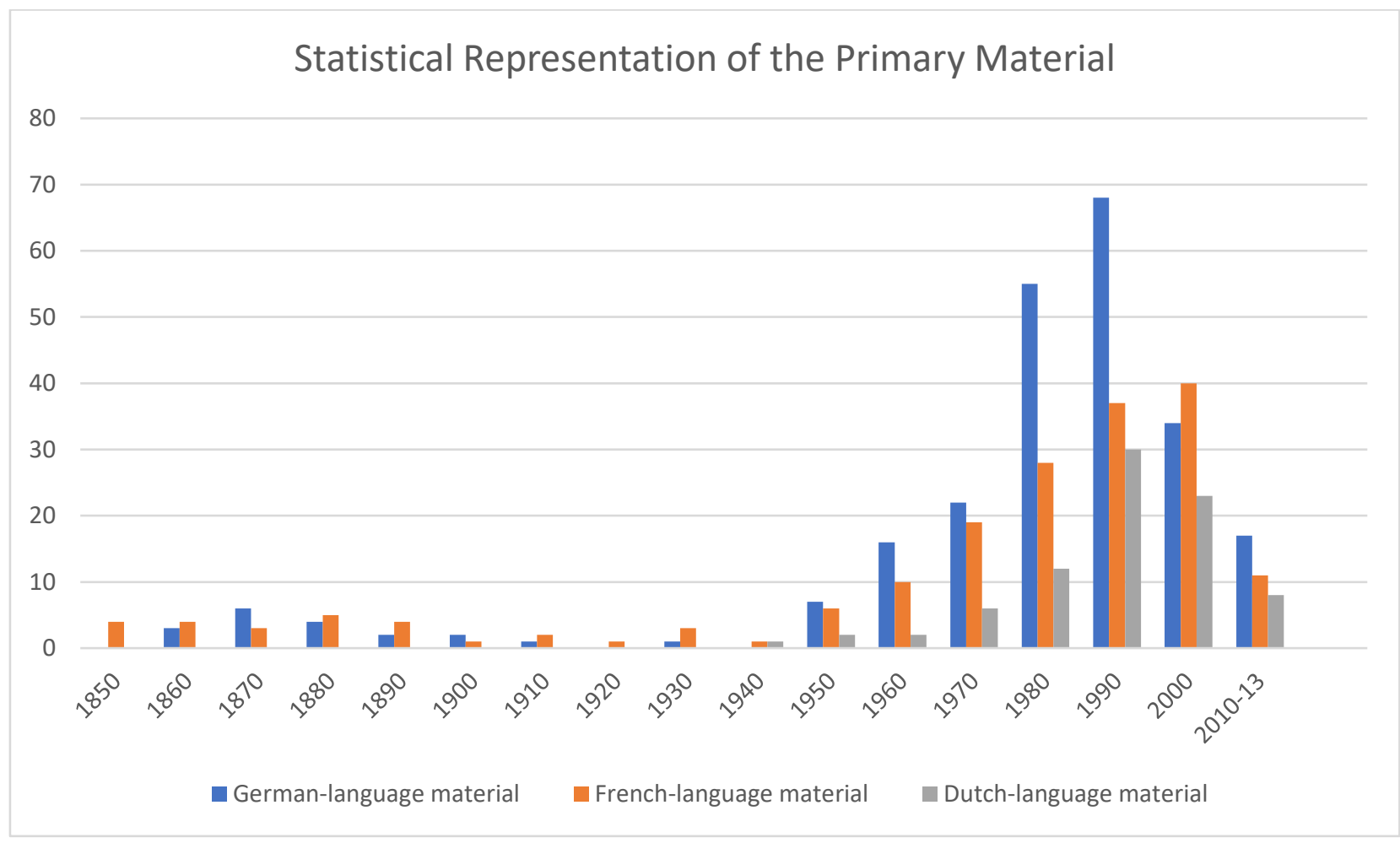

Figure 2: Overview of the primary data which was discovered during the research, including both translated and untranslated guidebooks, as well as reprints.

After the exclusion of translated titles, unaltered editions and the selection of three key periods, a corpus of fifty-four guidebooks was left. Due to the uneven amount of publications, the corpus of the chapter considering nineteenth-century guidebooks consists of ten guides; five German- and five French-language publications. The post-World War II period (1955-1975) corpus contains seventeen guidebooks, whilst the selection of contemporary guides (1995-2013) counts twentyseven titles. More detailed analyses concerning the corpora will be provided in the respective chapters.

Furthermore, it must be noted that after careful consideration it was decided not to include online materials, despite the fact that these are currently booming. Ever since the rise of mobile devices, the guidebook market has been trying to diversify in order to reach new audiences through these media. The well-known 
Lonely Planet series ${ }^{29}$ for example has an app which can be downloaded for free, and other lesser-known organisations such as Tripwolf and Pangea Guides focus solely on this new media market, offering downloadable apps free of charge. ${ }^{30} \mathrm{By}$ presenting travellers with information that can be updated instantaneously and by including interactive tools to personalise the travel experience, new media present numerous innovative ways to develop the genre. These new developments on the guidebook market have great potential for academic research, and are a promising field for future studies. However, due to their interactive and rapidly changing nature, online materials (e.g. websites and apps) will not be taken into account in this study. In my view, these new forms of the genre deserve separate academic attention. Moreover, due to the globalised character of the Internet, it is difficult to determine whether a certain app reflects German, Dutch or French perspectives on Wales, or whether these are actually texts translated from English.

\section{Methodological Approach, Theoretical Perspective and Research Questions}

This thesis will be based on a critical textual analysis of a large corpus of German-, French- and Dutch-language guidebooks. The primary material will be diachronically, synchronically and comparatively examined, and this will be conducted according to the methodology of critical discourse analysis, primarily as it was formulated by Norman Fairclough. ${ }^{31}$ Critical discourse analysis is an interdisciplinary approach which contends that language and social practices constitute one another reciprocally, and that power relations in society are constructed through language. Crucial to this approach is that texts are examined in their socio-historical and political contexts, and are used to gain insights into the way social relations are constructed. In order to achieve these insights, Fairclough developed a multi-dimensional framework, which distinguishes three parallel levels of analysis: analysis of the language (e.g. the written texts), the analysis of discourse practices (the link between language and social practice, e.g. the consumption of the

\footnotetext{
${ }^{29}$ Names of guidebook series will not be italicised in order to avoid confusion with titles of books, nor will they be put between inverted commas.

$30<$ http://www.lonelyplanet.com/apps/>; <http://www.tripwolf.com/>; $<$ https://www.pangeaguides.com/> [accessed 16 December 2015].

${ }^{31}$ Norman Fairclough, Critical Discourse Analysis: The Critical Study of Language (London: Longman, 1995).
} 
written text), and the analysis of the social practices (i.e. the socio-historical context). These three levels of the analysis are combined in order to draw conclusions about the text and its relation to wider social and cultural structures. ${ }^{32}$ Concretely, this means that the selected texts will be comparatively analysed and interpreted, after which these analyses will be contextualised by taking their socio-cultural and historical situation into account. Target audiences, infrastructural developments, changing travel cultures and wider socio-political contexts will be included to analyse and interpret the texts and their representations of Wales. The analysis will focus on a selection of themes: the initial introduction to the country; the Welsh language and culture; the inhabitants of Wales; Welsh history; and the landscape. These topics were selected since they serve as common features in the texts and are thus key comparators. By focusing on these subjects, diachronic and synchronic differences between the texts and the three languages will become apparent. Consequently, shifts can be contrasted and comparatively analysed and interpreted in order to examine the construction of Wales and Welshness in these texts.

The diachronic and comparative analysis of the primary texts will be conducted within the theoretical framework of 'imaginative peripheries'. What this framework entails will be discussed in detail in Chapter 1. In short, it is largely based on Rob Shields's Places on the Margin and Edward Said's conceptualisation of 'imagined geographies' as outlined in his seminal work Orientalism. ${ }^{33}$ Whilst researching the topic of guidebooks, I became increasingly interested in their power as cultural mediators, especially in relation to their role as place representors. As Victoria Peel and Anders Sørensen point out: 'A third feature of the guidebook is place representation. In one way or another, the coverage of a guidebook is expressed in geographical terms and, within the geographical area in question, the guidebook communicates selected aspects related to the site, region or route'. ${ }^{34}$ Especially in the case of a stateless nation such as Wales, whose geo-political, but also cultural and linguistic distinctiveness has been contested throughout much of its history, this element of the guidebook was thought to hold promising insights. Many Europeans

\footnotetext{
${ }^{32}$ See: Stefan Titscher and others, Methods of Text and Discourse Analysis (London: SAGE Publications, 2000), pp. 146-50.

${ }^{33}$ Rob Shields, Places on the Margins: Alternative Geographies of Modernity (London: Routledge, 1992); Edward Said, Orientalism (London: Routledge and Kegan Paul, 1978; repr. London: Penguin Books, 1995).

${ }^{34}$ Victoria Peel and Anders Sørensen, Exploring the Use and Impact of Travel Guidebooks, Tourism and Cultural Change, 48 (Bristol: Channel View Publications, 2016), p. 26.
} 
have no clear image of Wales, neither of its geographical location nor its cultural uniqueness. More often than not, the terms England and English are used to refer to Wales and Welsh, and there seems to be hardly any awareness of a cultural or linguistic distinction between the two countries. The guidebooks' conceptualisation and construction of geographical and socio-cultural boundaries around Wales therefore becomes highly relevant in the Continental perception of Wales. If travel guides are supposed to communicate representations of place, and their readers have little knowledge of their own to contradict them, these images become increasingly powerful in the conceptualisation of the area in question.

Wales, as a country on the periphery of Europe and Great Britain, is easily forgotten. ${ }^{35}$ Some have even claimed that its location on the periphery is to blame for the country's invisibility on the Continent. ${ }^{36}$ However, peripherality is not only a matter of geographical location but also of perception. ${ }^{37}$ It is in this realisation, which is discussed in more detail in Chapter 1, that the insights of Said, with his conceptualisation of 'imaginative geographies', and Shields, with his theories of marginality and centre-periphery construction, converge in the importance of guidebooks as cultural mediators ${ }^{38}$ and place representors along with the Continental lack of awareness of Wales and Welshness. The research interest of this thesis lies in the understanding that places and peripherality are not naturally given, but are constructed by internal and external interlocutors, and that these images can become accepted as true forms of knowledge. This has resulted in the following research questions: how is Wales spatially conceptualised in Continental guidebooks published in the period 1850 to 2013 ? Which borders, geographical, as well as cultural, historical, ethnographic and linguistic, are constructed around Wales in the guides? This thesis will scrutinise if and how Wales is textually imagined and conceptualised as being on the periphery of Great Britain, Europe and the world.

\footnotetext{
${ }^{35}$ Strikingly, this has happened several times in the recent past. Wales was for example forgotten on the map of a Eurostat report, which is responsible for the provision of statistical data to the EU (see: Hellegouarc'h-Bryce, p. 253). On 14 January 2007, the online newspaper WalesOnline reported that CNN forgot to put Wales on their map of the UK as well.

${ }^{36}$ David Botterill, Nicola Foster and others, 'Perceptions from the Periphery: The Experience of Wales', in Tourism in Peripheral Areas: Case Studies, ed. by Frances Brown and Derek Hall, Aspects of Tourism, 2 (Clevedon: Channel View Publications, 2000), pp. 7-38 (p. 19).

${ }^{37}$ Botterill, Foster and others, p. 18.

${ }^{38}$ An elaborate discussion of this term in relation to the guidebook can be found under the next heading 'Terminological Preliminaries'.
} 
In order to answer these questions, the thesis will be structured as follows. In Chapter 1, the guidebook as an object of research will be discussed in greater detail. An historical overview of the genre will be given, and the academic field regarding guidebooks will be surveyed in a literature review. Moreover, the theoretical framework for the thesis will be fully discussed, which will make clear what role guidebooks can play in the conceptualisation and peripheralisation of countries and regions. Chapter 2 will provide a socio-historical contextualisation for the rest of the thesis. The emergence of Wales as a peripheral travel destination will be examined, which will facilitate our understanding of the discourses surrounding Wales and help to frame the findings in the remainder of the thesis. Since not much research has been undertaken regarding Continental travellers to Wales, this chapter will focus on British travellers and their views of Wales. Chapters 3 to 5 will be concerned with the primary material and will each centre on one of the selected timeframes. In these chapters, the relevant touristic developments in Wales and Europe in that era will be briefly discussed, after which the primary material is analysed with respect to the research objectives. Finally, the thesis will provide a conclusion regarding the most important findings and will suggest directions for future research.

\section{Terminological Preliminaries}

Finally, there are some terminological preliminaries which need to be addressed. First of all, there is the dilemma of the demarcation of the guidebook genre. The generic definition of the guidebook has been a problematic topic for scholars, and many attempts have been made to formulate one. Following Albrecht Steinecke's earlier comments regarding the genre, Rudy Koshar aptly points out:

\footnotetext{
The problem is not only that the variability and constantly increasing number of guidebooks frustrate the researcher's attempt to grasp the genre as a conceptual whole. [...] But the guidebook's elusiveness also stems from its nature as a complex 'intertext' marked by traces of the travelogue, atlas, geographical survey, art-history guide, restaurant and hotel guide, tourist brochure, address book, and civic primer. ${ }^{39}$
}

\footnotetext{
${ }^{39}$ Rudy Koshar, German Travel Cultures (Oxford: Berg, 2000), pp. 15-16. See also: Albrecht Steinecke, Der bundesdeutsche Reiseführer-Markt: Leseranalyse - Angebotsstruktur Wachstumsperspektiven (Starnberg: Studienkreis für Tourismus, 1988), p. 13.
} 
In search of a comprehensive definition, researchers have taken various approaches. Some have attempted to define the genre primarily through what it is not. Paul Fussell, for example, considers the guidebook to be different from travel writing, as it is not autobiographical and supposedly lacks narrative qualities. ${ }^{40}$ Others have also highlighted the factuality of guidebooks and their low level of entertainment as a means to distinguish travel books from travel guides. ${ }^{41}$ However, in many studies concerning guidebooks, the term is not critically problematised at all and seems to be regarded as a universally understood and uncomplicated term. ${ }^{42}$

Peel and Sørensen criticise the lack of in-depth discussions concerning the guidebook genre and attempt to provide an inclusive definition. They base their demarcation on the theoretical framework of Jack and Phipps, who regard the guidebook as 'apodemic literature' which is defined as 'a didactic, instructional literature which exerts a significant performative role upon the reader' ${ }^{43}$ Peel and Sørensen combine this delineation with Seaton's argument that the travel guidebook is an amalgamation of a vade mecum and belles lettres: the informative inventorying element of the guidebook is always combined with elements of the belles lettres which offer 'discursive modes of apprehension' ${ }^{44}$ From this point of departure, Peel and Sørensen identify five constituents with complementary features which they regard as essential to any conceptualisation of the guidebook genre:

- Utility: The fielding of the guidebook.

- Substance: The properties of the textual substance.

- Ephemerality: The ephemeral convergence of user, description and place.

- Authority: The construction of textual authority.

- Assistance: The facilitating function of the guidebook. ${ }^{45}$

By exploring these five constituents, they finally arrive at the following definition:

\footnotetext{
${ }^{40}$ Paul Fussell, Abroad: British Literary Traveling between the Wars (Oxford: Oxford University Press, 1980), p. 203.

${ }^{41}$ See, for example: Graham Dann, 'Travelogs and the Management of Unfamiliarity', Journal of Travel Research, 30 (1992), 59-63 (p. 60); Mike Robinson, 'Narratives of Being Elsewhere: Tourism and Travel Writing', in A Companion to Tourism, ed. by Alan Lew, Colin Hall and Allan Williams (Oxford: Blackwell, 2004), pp. 305-15 (p. 305).

42 See, for example: Julie Andsager and Jolanta Drzewiecka, 'Desirability of Differences in Destinations', Annals of Tourism Research, 29 (2002), 401-21; Andrew McGregor, 'Dynamic Texts and Tourist Gaze: Death, Bones and Buffalo', Annals of Tourism Research, 27 (2000), 27-50.

${ }^{43}$ Gavin Jack and Alison Phipps, 'On the Uses of Travel Guides in the Context of German Tourism to Scotland', Tourist Studies, 3 (1996), 281-300 (p. 283).

${ }^{44}$ A.V. Seaton, 'Tourism as Metempsychosis and Metensomatosis: The Personae of Eternal Recurrence', in The Tourist as Metaphor of the Social World, ed. by Graham Dann (Wallingford: CABI, 2002), pp. 135-68.

${ }^{45}$ Peel and Sørensen, p. 26.
} 
A travel guidebook is a commercially distributed entity, made for transient non-locals to be used in the field. It contains place representations and is comprehensive as it includes practical information beyond that of a special interest subject. Yet, it is selective, and by evaluating more than just listing it facilitates a selection process. Authority is asserted through sender identity and through the potential to contend 'official' information. ${ }^{46}$

This is by far the most complete definition of the guidebook currently available, and by exploring the genre from various angles Peel and Sørensen successfully steer clear of a one-dimensional demarcation. Nevertheless, they fail to highlight one important function of the guidebook, which is crucial for the research at hand and is arguably a central aspect of the genre: the guidebook as a cultural mediator. Within academic research on guidebooks, it has been pointed out that guidebooks are important mediators between cultures. ${ }^{47}$ Travelling always constitutes a clash between cultures, between travellers and travellees, ${ }^{48}$ viewers and viewed. ${ }^{49}$ In these 'contact zones', to use Mary Louise Pratt's term, various parties who were previously separated by geographical and historical disjunctures are now able to intersect. ${ }^{50}$ Within this intersection of cultures, the guidebook must be understood as an important cultural artefact and mediator in the realm of travel.

The framework developed by anthropologist and tourism sociologist Erik Cohen can be used to better understand the guidebook's role as cultural mediator. Although Cohen originally used his model to examine the diverse roles and historical development of the human travel guide, his functional analysis has also been applied to the study of textual guidebooks. ${ }^{51}$ According to Cohen, human guides (but the same can be argued about textual guidebooks) have two principal roles to fulfil: that of leader and mediator. The leadership role is quite straightforward: directing readers

\footnotetext{
${ }^{46}$ Peel and Sørensen, p. 29.

${ }^{47}$ Koshar, German Travel Cultures, p. 7; Dybiec, p. 89; Deborah Bhattacharyya, 'Mediating India: An Analysis of a Guidebook', Annals of Tourism Research, 24 (1997), 371-89 (p. 372).

48 'Travellee' is a term first coined by Mary Louise Pratt. Derived as an analogy to the term 'addressee', it refers to people who are encountered by the traveller during his or her journey, see: Mary Louise Pratt, Imperial Eyes: Travel Writing and Transculturation, 2nd edn (London: Routledge, 2008), p. 258. The term has been criticised for implying that the travellee is passive during these encounters, remaining an object of the traveller's gaze. Nevertheless, it has been widely adopted by travel writing studies, as it encompasses everyone who comes into contact with the traveller and thus avoids assumptions about cultural, national or racial identities, see: Catharine Mee, Interpersonal Encounters in Contemporary Travel Writing: French and Italian Perspectives (London: Anthem Press, 2015), p. 4.

${ }^{49}$ Koshar, German Travel Cultures, p. 7.

${ }^{50}$ Pratt, Imperial Eyes, p. 8.

${ }^{51}$ See for example: Dybiec, pp. 83-93; Bhattacharyya, pp. 373-4.
} 
through the region, providing information about itineraries, hotels and restaurants, health regulations etc. ${ }^{52}$ However, it is the mediatory role that is the most illuminating for the current research. As a mediator, the guide places himself or herself in between the visitor and the unfamiliar environment, shielding the former from the foreign and making the experience unthreatening. ${ }^{53}$ This is also one of the primary functions of guidebooks, which 'carefully hand out doses of exoticism and then domesticate it, making the destination both attractive and innocuous'.54 The selection of sights and their interpretation is also an important aspect of this role, which strongly influences the tourist gaze. ${ }^{55}$ The guide determines what tourists see, and, even more decisively, what they do not see. As such, guides can manipulate the tourist experience. The influence of guidebooks on the perception of their readers will be discussed in more detail in Chapter 1 .

Another important element of the guidebook is that it is a typical Gebrauchstext [functional text]. ${ }^{56}$ As a result, attention is immediately drawn to its users: tourists. According to Buzard, a distinction between tourist and traveller was already noticeable in the late eighteenth century, when the first forms of early tourism and leisure travel began to emerge. ${ }^{57}$ Within this dichotomy, the term 'tourist' was and still is often used in a derogatory sense, whilst 'traveller' is the label many prefer to use when referring to themselves. As Buzard summarises:

\footnotetext{
Though it is often used in this derogatory sense without great precision, 'tourist' does rest on a rough consensus: it can conjure up in our imaginations a personality profile, a life-style, perhaps a class identification, and a host of scenarios in which 'the tourist' performs some characteristic act. The tourist is the dupe of fashion, following blindly where authentic travellers have gone with open eyes and free spirits. ${ }^{58}$
}

This popular connotation which is often implied with the term has also been adopted in early academic studies on the phenomenon of travel and consumerism. The historian Daniel Boorstin, for example, argued in 1963 that the tourist merely looks

\footnotetext{
${ }^{52}$ Erik Cohen, 'The Tourist Guide: The Origins, Structure and Dynamics of a Role', Annals of Tourism Research, 12 (1985), 5-29 (pp. 11-12).

${ }^{53}$ Cohen, p. 13.

${ }^{54}$ Dybiec, p. 339.

${ }^{55}$ Cohen, pp. 14-15.

${ }^{56}$ Sabine Gorsemann, Bildungsgut und touristische Gebrauchsanweisung: Produktion, Aufbau und Funktion von Reiseführern (Münster: Waxmann, 1995), pp. 102-9.

${ }^{57}$ See: James Buzard, The Beaten Track: European Tourism, Literature, and the Ways to 'Culture' 1800-1918 (Oxford: Clarendon Press, 1993), p. 1.

${ }^{58}$ Buzard, The Beaten Track, p. 1.
} 
for 'pseudo-events' ${ }^{59}$ The traveller, by contrast, seeks genuine experiences, thus embodying the true art of travel: 'The traveler was active; he went strenuously in search of people, of adventure, of experience. The tourist is passive; he expects interesting things to happen to him. [...] He expects everything to be done to him and for him' ${ }^{60}$ Paul Fussell, a prominent critic of tourism, regarded the interwar period as the last age of travel, after which only tourism was left. He polemically states: '[T]he resemblance between the tourist and the client of a massage parlor is closer than it would be polite to emphasize' ${ }^{61}$ However, later scholars have attempted to change this relegation of the tourist. Especially the works of Dean MacCannell and John Urry, who both consider tourism as an intrinsic part of modern life, have led to its re-evaluation as a socio-cultural phenomenon. ${ }^{62}$ Most scholars now tend to agree that the distinction between 'good' travel and 'bad' tourism has had its day and does not lead to any new conclusions. ${ }^{63}$ Following this view, this research will make no distinction between the terms tourist, traveller nor visitor, and these labels will be used interchangeably and without any evaluative connotation.

Another set of terms central to this research should be discussed as well: Wales and Welshness. Although Wales is recognised as a separate country within the United Kingdom, with its own devolved government, language, culture and sense of national identity, the homogeneity of Welsh identity and Welshness has been the subject of much academic discussion. A brief summary of this debate, which has led to a growing problematisation of these terms, will be given below. Whilst early studies tended to consider Wales as a mainly rural society which was in itself much less complex than British society, this view changed during the 1980s when a more nuanced way of looking at Wales and Welshness emerged. ${ }^{64}$ Many of these later studies concerning Welsh identity, nationalism and forms of Welshness were informed by the work of two researchers in particular, Michael Hechter and Tom

\footnotetext{
${ }^{59}$ Daniel Boorstin, The Image or What Happened to the American Dream (Harmondsworth: Penguin Books, 1963), pp. 21-23.

${ }^{60}$ Boorstin, pp. 93-94.

${ }^{61}$ Fussell, p. 42.

${ }^{62}$ Dean MacCannell, The Tourist: A New Theory of the Leisure Class (New York: Schocken Books, 1976, repr. Berkeley: University of California Press, 1999); Urry.

${ }^{63}$ See, for example: Koshar, German Travel Cultures, p. 4; Dybiec, p. 27; Graham Huggan, Extreme Pursuits: Travel/Writing in an Age of Globalization (Ann Arbor: University of Michigan Press, 2009), p. 5.

${ }^{64}$ For an overview of these earlier studies, see: Ralph Fevre and Andrew Thompson, 'Social Theory and Welsh Identities', in Nation, Identity and Social Theory: Perspectives from Wales, ed. by Ralph Fevre and Andrew Thompson (Cardiff: University of Wales Press, 1999), pp. 3-24 (pp. 5-6).
} 
Nairn, who stimulated the academic debate around Wales and Welshness significantly. In his work Internal Colonialism: The Celtic Fringe and British National Development, Hechter argues that a sense of Welsh nationalism intensified as a result of its peripheral economic relationship with the English core. According to Hechter, Wales is an 'internal colony' which has been exploited by its hegemonic neighbour. Drawing on Marxist theories, he contends that the economic inequality of the periphery stimulates the growth of nationalism and a clear sense of identity. ${ }^{65}$ The seminal study The Break Up of Britain: Crisis and Neo-Colonialism by Tom Nairn also views the rise of Welsh nationalism from a Marxist point of view, and claims that this should be seen as an attempt of the Welsh elite to counteract inequality which had resulted from uneven economic development. ${ }^{66}$ Both Hechter and Nairn's works have been highly influential, but have also been criticised over the years. One major point of criticism has been the fact that both scholars focus on the opposition between 'the Welsh' and 'the English', thus creating two homogeneous groups whilst failing to account for the internal differences that exist in both Wales and England. Neither Hechter nor Nairn highlight class divisions within Wales, and the fact that the Welsh elite was increasingly anglicised during the later nineteenth and early twentieth century is also left unnoticed. Their view of Welsh society is framed as an issue of ethnicity, a clash between Wales and England, whilst ignoring the internal social diversity within Welsh society. ${ }^{67}$

According to Fevre and Thompson, it is not the disregarding of internal differences that is the most problematic issue in Hechter and Nairn's works, but the fact that they feel the obligation to make a distinction between 'right' and 'wrong' identities:

For them identity can only be considered a problem worth studying in the British context because the wrong (British) identity has long been imposed on people for whom it is not

\footnotetext{
${ }^{65}$ Michael Hechter, Internal Colonialism: The Celtic Fringe in British National Development (London: Routledge, 1975; repr. New Brunswick: Transaction Publishers, 1999), pp. 30-43.

${ }^{66}$ Tom Nairn, The Break Up of Britain: Crisis and Neo-Colonialism (London: New Left Books, 1977). See also: Graham Day, 'Wales, the Regional Problem and Development', in Poverty and Social Inequality in Wales, ed. by Gareth Rees and Teresa L. Rees (London: Croom Helm, 1980), pp. 230-51.

${ }^{67}$ For a critique of Hechter, see for example: John Lovering, 'The Theory of the Internal Colony and the Political Economy of Wales', Review of Radical Political Economics, 10 (1978), 55-67; Graham Day, 'The Sociology of Wales: Issues and Prospects', Sociological Review, 27 (1979), 447-74; Day, 'Wales, the Regional Problem and Development'; David L. Adamson, Class, Ideology and the Nation: A Theory of Welsh Nationalism (Cardiff: University of Wales Press, 1991).
} 
appropriate and there are now compelling reasons why this mistaken identity will be cast off in favour of the proper ones: the alternative national identities of the 'Celtic Fringe'. ${ }^{68}$

Under the influence of the work of Benedict Anderson and his concept of imagined communities, ${ }^{69}$ later studies attempted to move beyond this distinction of 'good' and 'bad' identities and to provide a more complex interpretation of Wales and Welshness, which is illustrated by their titles: Wales: The Imagined Nation; When Was Wales?; Wales! Wales? ${ }^{70}$ It is in this context that Day and Suggett asked: 'How many Wales?'. ${ }^{71}$ Scholars were gradually realising that 'it was necessary to consider the diversity of Welsh experiences, the differing ways of "imagining" Wales' ${ }^{72}$ From the 1980s onwards, academics have tended to consider Wales through the framework of community and locality, rather than trying to summarise Welsh identity or Welshness as a homogeneous phenomenon.

In addition to the works already mentioned above, Denis Balsom has also contributed a seminal work which attempted to provide a more diverse, nuanced image of Wales and Welshness. In his article 'The Three Wales Model', Balsom argues that Wales is divided into three major identities which are topographically separated. Firstly, he identifies Y Fro Gymraeg, covering the west of the country (except for Pembrokeshire which has been called 'Little England beyond Wales') where most people speak Welsh and strongly identify as Welsh. The so-called Welsh Wales is the second area; it is situated in the Valleys and although mainly Englishspeaking still strongly identifies with Welsh identity. Lastly, Balsom distinguishes British Wales, which includes the eastern areas around the border with England, as well as South Glamorgan. ${ }^{73}$ The western periphery of Wales (with the exception of Pembrokeshire) is therefore identified as the most Welsh; the area in which the

\footnotetext{
${ }^{68}$ Ralph Fevre and Andrew Thompson, 'Social Theory and Welsh Identities', in Nation, Identity and Social Theory, ed. by Ralph Fevre and Andrew Thompson (Cardiff: University of Wales Press, 1999), pp. 3-24 (pp. 8-9).

${ }^{69}$ Benedict Anderson, Imagined Communities: Reflections on the Origin and Spread of Nationalism (London: Verso, 1991).

${ }^{70}$ Wales: The Imagined Nation, ed. by Tony Curtis (Bridgend: Poetry Wales Press, 1986); Gwyn A. Williams, When Was Wales?: A History of the Welsh (Harmondsworth: Penguin Books, 1985); Dai Smith, Wales! Wales? (London: Allen \& Unwin, 1984).

${ }^{71}$ Graham Day and Richard Suggett, 'Conceptions of Wales and Welshness: Aspects of Nationalism in Nineteenth-Century Wales', in Political Action and Social Identity, ed. by Gareth Rees (Basingstoke: Macmillan, 1985), pp. 91-115.

${ }^{72}$ Fevre and Thompson, p. 12. Emphasis in original.

${ }^{73}$ Denis Balsom, 'The Three Wales Model', in The National Question Again: Welsh Political Identity in the 1980s, ed. by John Osmond (Llandysul: Gomer, 1985), pp. 1-17 (pp. 5-6).
} 
language is still used by a large percentage of the inhabitants and in which an identification with Welshness as opposed to Britishness, is omnipresent.

Though also criticised as being too simplistic and failing to incorporate more diverse forms of Welsh national identity, various scholars have indicated that Balsom's division of Wales has influenced perceptions of the country nationally as well as internationally. ${ }^{74}$ In their article Mythic Geographies of Representation and Identity: Contemporary Postcards of Wales', Pritchard and Morgan for example show that postcard representations of Wales reinforce and re-map this three Wales model, thus contributing to the discursive conceptualisation and spatialisation of Welsh identity. ${ }^{75}$ More recent publications tend to examine Welshness in a certain locality, for example the South Wales Valleys. ${ }^{76}$ Further studies have focused on a specific aspect of Welsh identity, such as the language or rugby, ${ }^{77}$ whilst others use it as a means to gain insights into the political changes and differences within the country. ${ }^{78}$

For the current research, it is important to bear in mind that Wales and Welshness are recognised as problematic terms which do not reflect one single, homogeneous entity. As has been pointed out by various scholars in the field, it is impossible to provide one comprehensive definition, as nations and national identities are constantly shifting according to time and place, and multiple versions

\footnotetext{
${ }^{74}$ For some examples of studies that have critically built on Balsom's work, see: Roger Scully and Richard Wyn Jones, 'Still Three Wales? Social Location and Electoral Behaviour in Contemporary Wales', Electoral Studies, 31 (2012), 656-67; Jonathan Bradbury and Rhys Andrews, 'State Devolution and National Identity: Continuity and Change in the Politics of Welshness and Britishness in Wales', Parliamentary Affairs, 63 (2010), 229-49 (p. 232); Nikolas Coupland, Hywel Bishop and Peter Garrett, 'One Wales? Reassessing Diversity in Welsh Ethnolinguistic Identification', Contemporary Wales, 18 (2006), 1-27.

${ }^{75}$ Annette Pritchard and Nigel Morgan, 'Mythic Geographies of Representation and Identity: Contemporary Postcards of Wales', Journal of Tourism and Cultural Change, 1 (2003), 111-30.

${ }^{76}$ For example: Brian Roberts, 'Welsh Identity in a Former Mining Valley: Social Images and Imagined Communities', in Nation, Identity and Social Theory: Perspectives from Wales, ed. by Ralph Fevre and Andrew Thompson (Cardiff: University of Wales Press, 1999), pp. 111-28. See also: Rhys Jones and Carwyn Fowler, Placing the Nation: Aberystwyth and the Reproduction of Welsh Nationalism (Cardiff: University of Wales Press, 2008).

${ }^{77}$ Eddie Williams, 'Language Attitudes and Identity in a North Wales Town: "Something Different about Caernarfon"?', International Journal of the Sociology of Language, 195 (2009), 63-91; John Harris, 'Cool Cymru, Rugby Union and an Imagined Community', International Journal of Sociology and Social Policy, 27 (2007), 151-62.

${ }^{78}$ Bradbury and Andrews; Rebecca Davies, 'Banal Britishness and Reconstituted Welshness: The Politics of National Identities in Wales', Contemporary Wales, 18 (2006), 106-21; Richard Haesly, 'Identifying Scotland and Wales: Types of Scottish and Welsh National Identities', Nations and Nationalism, 11 (2005), 243-63. For a recent sociological overview of changes within Wales and Welshness, see: Graham Day, Making Sense of Wales: A Sociological Perspective (Cardiff: University of Wales Press, 2010).
} 
can exist at the same time. ${ }^{79}$ To use the term of M. Wynn Thomas, Wales may be regarded as a 'micro-cosmopolitan' entity. ${ }^{80}$ Thomas borrowed this term from Michael Cronin, who coined it in order to break up the hegemony of macroperspectives. According to Cronin, cultural diversity is often linked to larger political units, even though the same level of diversity and cultural complexity can exist in smaller entities. ${ }^{81}$ This thesis will adhere to this view of diversity and complexity in relation to Wales and Welshness, whilst simultaneously advocating a heuristic approach regarding these terms. The labels 'Wales' and 'Welshness' are understood as fluid and changeable, and all elements which the guidebooks attribute to Welshness or Welsh identity are considered as integral to it. Everything that they deem related to Wales and Welshness will be discussed and taken into account in the analysis. In this way, the thesis also contributes to the research done so far about Welshness and Wales as an imagined community. By examining the representations of Wales and the construction of its geographical identity in Continental guidebooks, the conceptualisation of these socio-geographical terms is also scrutinised from an external, Continental perspective.

\footnotetext{
${ }^{79}$ See: Bradbury and Andrews, p. 231; Day and Suggett, p. 97; Andrew Thompson and Graham Day, 'Situating Welshness: "Local" Experience and National Identity', in Nation, Identity and Social Theory: Perspectives from Wales, ed. by Ralph Fevre and Andrew Thompson (Cardiff: University of Wales Press, 1999), pp. 27-47.

${ }^{80}$ M. Wynn Thomas, 'Studying Wales Today: A Microcosmopolitan Approach', The Annual Lecture of the Learned Society of Wales and the Honourable Society of Cymmrodorion (2016), 1-13 <https://www.cymmrodorion.org/wp-content/uploads/2017/01/STUDYING-WALES-TODAY-M-WTHOMAS-6-DECEMBER-2016-compressed.pdf> [accessed 19 April 2017], p. 2.

${ }^{81}$ Michael Cronin, Translation and Identity (London: Routledge, 2006), pp. 14-16.
} 


\section{1 - The Guidebook}

The aim of this chapter is to establish the historical and theoretical frameworks for the thesis. The chronological development of the guidebook will be discussed whilst focusing on the bifurcation of the genre of travel writing into the personalised travelogue and the travel guidebook. A critical overview of the work that has already been undertaken on guidebooks will also be provided and remaining gaps in the research will be highlighted. In Sections 1.3 and 1.4 the theoretical framework will be developed, which is primarily based on Said's notion of 'imaginative geographies'. The new term 'imaginative peripheries' will be introduced which will be a guiding notion throughout the rest of the thesis.

\subsection{The Historical Development of the Genre}

The following section will discuss the historical development of the guidebook, ${ }^{82}$ although it is not the aim of this chapter to provide a comprehensive overview of the genre from its beginnings to the present day. Various studies have already been undertaken in this respect and references in the text will offer suggestions for further reading. ${ }^{83}$ Another limitation of this chapter is that it will solely discuss the development of the genre within Europe, which does not imply that similar genres did not evolve in other parts of the world ${ }^{84}$ The focus lies on the

\footnotetext{
${ }^{82}$ For a heuristic definition of the genre, see the introduction of this thesis.

${ }^{83}$ Some preliminary works that have focused on the historical development of the genre can be mentioned here. In general, Nicholas T. Parsons offers a useful starting point: Nicholas T. Parsons, Worth the Detour: A History of the Guidebook (Thrupp: Sulton Publishing, 2007). For an overview of the beginnings of the English-language guidebook, see: John Vaughan, The English Guide Book c. 1780-1870 (Newton Abbot: David \& Charles, 1974); John M. Mackenzie, 'Empires of Travel: British Guide Books and Cultural Imperialism in the 19th and 20th Centuries', in Histories of Tourism: Representation, Identity and Conflict, ed. by John K. Walton, Tourism and Cultural Change, 6 (Clevedon: Channel View Publications, 2005), pp. 19-38. For more on German-language guidebooks, see for example: Alex Hinrichsen, 'Zur Entstehung des modernen Reiseführers', in Zur Sonne, zur Freiheit! Beiträge zur Tourismusgeschichte, ed. by Hasso Spode (Berlin: Verlag für universitäre Kommunikation, 1991), pp. 21-32. A starting point for an overview of the genre's development in France is offered by: Goulven Guilcher, 'Entre continuité et innovation: les guides touristiques en langue française de 1900 à 1960', in Les Guides de voyage: au fil du Rhin et ailleurs. Actes de la journée d'études du 19 mars 2004, ed. by Martine Breuillot and Thomas Beaufils (Strasbourg: Université Marc Bloch, 2005), pp. 9-16; Goulven Guilcher, 'Les Guides européens et leurs auteurs: clef de lecture', In Situ. Revue des patrimoines, 15 (2011), 2-23 <http://insitu.revues.org/499> [accessed 23 September 2013].

${ }^{84}$ In the medieval Arab world, guidebooks were for example written for Egyptian treasure hunters: Okasha El Daly, Egyptology: The Missing Millennium. Ancient Egypt in Medieval Arabic Writings (London: ECL Press, 2005), p. 36.
} 
guidebook's separation from the travelogue and its constitution as a distinct genre in the nineteenth century. As the travel guides by John Murray and Karl Baedeker have played a crucial role in this, the chapter concentrates on the development of their series and later general tendencies of the guidebook industry. More specific contextual discussions of relevant guidebook series used in this thesis will be provided in the respective following chapters. In these, the corpus will be considered in relation to Wales as a travel destination. The aim of this section, on the other hand, is to review the genre and its historical developments in a broader sense.

If we presuppose that guidebooks are texts that direct travellers on their journey whilst providing them with spatial and cultural information, the beginnings of the genre are hard to determine. Such texts have existed for centuries, but nevertheless we would not understand them as 'guidebooks' in the modern sense of the word. Nicholas Parsons, for example, identifies the report on Palestine ordered by Joshua after the death of Moses as one of the earliest documents that has guidebook elements. ${ }^{85}$ Generally, however, the predecessors of our contemporary guidebook have been argued to be the Ancient Greek periegesis and periplous. ${ }^{86}$ These works are accounts of land and sea voyages that informed their readers (mainly merchants) about trade routes as well as other aspects of travelling. One work in particular is mentioned in this respect, and that is Pausanias's Description of Greece from around AD 170, which has even been labelled as 'the Baedeker of the ancient world" ${ }^{87}$ due to its detailed geographical descriptions, elaborate historical overview and cultural information. ${ }^{88}$

Other predecessors of the modern guidebook include itineraria and pilgrims' accounts. These texts helped Christian pilgrims find their way to religious centres and sacred places such as Jerusalem, Rome and Santiago de Compostela. After the Middle Ages, between the mid-sixteenth and late eighteenth century, travel became an important way of gathering information rather than a means of religious catharsis. Categorising and documenting the acquired information was seen as a moral obligation of the traveller, as this information could serve the wider public. Guidelines for these practices were gathered in treatises known as ars apodemica,

\footnotetext{
85 Parsons, p. 3.

${ }^{86}$ Gorsemann, pp. 45-46; Dybiec, p. 40.

${ }^{87}$ Lionel Casson, Travel in the Ancient World (London: Allen and Unwin, 1974; repr. Baltimore: The John Hopkins University Press, 1994), p. 292.

${ }^{88}$ Parsons, pp. 25-26.
} 
which literally means 'the art of being away from home' but is also frequently translated as 'the art of travel'. These writings advised travellers on the moral, religious and historical side of travel ${ }^{89}$ During the period of the Grand Tour, a custom which flourished between approximately 1660 and 1840, many works with advice for travellers were published. Grand Tours were mostly undertaken by young, upper-class European men (primarily, but not exclusively, from the UK) with the purpose of becoming familiar with valuable artistic artefacts whilst making connections with other powerful European families in order to prepare these men for public roles in their home country. Italy and France in particular were seen as important stops on the route. Although these travellers were generally accompanied by a living guide, or rather mentor, many written works were also published to aid them on their journeys, for example Thomas Nugent's Grand Tour (1749) and the Gentleman's Pocket Companion for Travelling into Foreign Parts (1722). However, these still differed in many respects from the Baedeker and Murray guidebooks which would conquer the market a century later and would revolutionise the genre. As James Buzard points out: '[T]hese early guidebooks [...] were apt to be the rather hybrid, discursive productions of an individual, rambling from accounts of the author's own travels to facts and opinions on manners and customs, to commentary on the classical texts germane to the tour' ${ }^{90}$ It is in this respect that the modern guidebook as we know it differs; instead of being a personal account of past travels, it attempts the serve the tourist on future journeys whilst providing supposedly objective information.

It is during the Romantic period that a clearer distinction between personal, subjective, sentimental travel accounts and purely informative, functional travel literature becomes apparent. Since the Age of Discovery was coming to an end, the genre of travel writing had to be 're-invented'. There were few places left that had not yet been described extensively regarding their geographical, cultural and historical features, and in response to this the subjective, personal interpretation of places became more foregrounded in travel writing. An extremely popular and influential example of such a text is Laurence Sterne's novel A Sentimental Journey

\footnotetext{
${ }^{89}$ For more on this type of travel writing, see: Juston Stagl, Apodemiken: Eine räsonnierte Bibliographie der reisetheoretischen Literatur des 16., 17. und 18. Jahrhunderts (Paderborn: Schöningh, 1983).

90 James Buzard, The Beaten Track, p. 67.
} 
(1768), whilst Goethe's Italienische Reise [Italian Journey] (1816-17) is a less sentimental yet still personalised example of this form of travel writing. Whereas such subjective travel accounts focused more on the internal experience and personal interpretation of the journey, the first 'modern' guidebooks were able to concentrate on the informative side of travel whilst supposedly fully stripping themselves of subjectivism and authorial idiosyncrasy.

The historian John Vaughan considers the period between 1780 and 1870 as the time of the formation of the guidebook genre in Great Britain. ${ }^{91}$ Although I would rather estimate the 1840 s as the closing decade of this formative period, given that John Murray had by then firmly established a good reputation for his series of travel handbooks, Vaughan is right to regard the turn of the nineteenth century as a pivotal moment in the development of the genre. During this period, several works were published which clearly mark the transition towards the genre of the 'modern' travel guidebook as a separate branch of travel writing. One of these is Heinrich August Ottokar Reichard's Guide des voyageurs en Europe [Guide for Travellers in Europe] (1793), which is identified by Goulven Guilcher as the 'premier grand guide de voyage modern' [first great guide of modern travel]. ${ }^{92}$ Reichard travelled around Europe and wrote down his observations and advice in this work with which he wanted to help other travellers who roamed the Continent. Consisting of three volumes, each one around 300 pages long, it was not yet very convenient for consultation on the road, but the fact that it went through eleven editions between 1793 and 1824 can be regarded as an indication of its popularity. A clever Frenchman, Jean-Marie-Vincent Audin, even started writing handbooks for travellers under the pseudonym of Richard, as this resembled Reichard's name. Audin published these volumes between 1824 and 1836, and eventually sold them to the French publishing house Hachette, which continued the series under the name Guides Richard until 1855. ${ }^{93}$ According to Goulven Guilcher, the Guides Richard can be considered the precursor of other major guidebook series such as those from Baedeker, Murray and their French counterpart the Guides Joanne. ${ }^{94}$

\footnotetext{
${ }^{91}$ Vaughan, p. 81.

92 Guilcher, 'Les Guides européens et leurs auteurs', p. 3.

${ }^{93}$ Goulven Guilcher, 'Les Guides Richard (1824-1836)', La Lettre du marché du livre ancien et d'occassion, 54 (1997), 4-6 (p. 4).

${ }^{94}$ Goulven Guilcher, 'Naissance et développement du guide de voyage imprimé: du guide unique à la série, une stratégie de conquête des lecteurs?', in Les Guides imprimés du XVIe au XXe siècle: villes, paysages, voyages, ed. by Gilles Chabaud and others (Paris: Belin, 2000), pp. 81-93 (p. 86).
} 
However, most scholars regard Mariana Starke as the most direct and influential predecessor of Baedeker and Murray. Her travel books, which include Letters from Italy between the Years 1792 and 1798 (1800), Travels on the Continent (1820) and Information and Directions for Travellers on the Continent (1824) changed the nature of the guidebook. Starke focused on the practical side of travelling, conscientiously noting down information about the best places to stay and eat, as well as instructions about (amongst other things) passports and foreign currencies. Apart from these travel practicalities, Starke described the various sights that she considered of interest for travellers, whilst creating a hierarchy of the best attractions by using one, two or three exclamation marks. Starke's work was extremely popular, and it has been argued that '[i]n her pioneering work to make travel easier, she became the mother of the modern guide-book and in many ways the grandmother of modern tourism'. ${ }^{95}$ Other scholars concur that it is Starke's focus on travel practicalities that made her work so popular and useful for other travellers. Instead of concentrating on personal experiences, Starke wrote her work with the future traveller in mind, whilst trying to make it as practical and well-organised as she could. In her investigation of Starke's work, Karin Baumgartner contends: '[T]he style of her travel handbook with the removal of the memoirist from the narrative, the organization of content into daytrips and walking tours, the index of sights, and the use of a rating system have served as a template for all later travel guides' ${ }^{96}$ However, even though Starke's personal interpretation of the journey is not foregrounded and her journey is not, as Baumgartner terms it, a path of 'selfdiscovery and personal transformation, ${ }^{97}$ James Buzard points out that she writes in an epistolary style and comments on recent political events, thus showing her personal opinion concerning contemporary affairs. ${ }^{98}$ He characterises Starke's Travels in Italy (1802) as follows: 'It has the appearance, when we look back at it with generic presuppositions founded on Murray and Baedeker, of an impressionistic "travel book" serving as a makeshift "handbook" in the absence of any alternative' ${ }^{99}$

\footnotetext{
${ }^{95}$ Richard Mullen and James Munson, 'The Smell of the Continent': The British Discover Europe 1814-1914 (London: Pan Macmillan, 2009), p. 113.

${ }^{96}$ Karin Baumgartner, 'Travel, Tourism, and Cultural Identity in Mariana Starke's "Letters from Italy" (1800) and Goethe's "Italienische Reise" (1816-17)', Publications of the English Goethe Society, 83 (2014), 177-95 (p. 178).

${ }^{97}$ Baumgartner, p. 178.

${ }^{98}$ Buzard, The Beaten Track, pp. 68-69.

${ }^{99}$ Buzard, The Beaten Track, p. 68.
} 
Nevertheless, Starke's work has undeniably influenced the development of the guidebook genre and Murray himself expressed his indebtedness to her, whilst simultaneously pointing out some defining differences between her work and his:

Hers was a work of true utility, because, amidst a singular medley of classical lore, borrowed from Lemprière's Dictionary, interwoven with details regulating the charges in washing-bills at Sorrento and Naples, and an elaborate theory on the origin of Devonshire Cream, in which she proves that it was brought by Phoenician colonists from Asia Minor into the West of England, it contained much practical information gathered on the spot. ${ }^{100}$

Starke's later work, such as Travels on the Continent (1820) and Information and Directions for Travellers on the Continent (1824), more closely resembled Murray and Baedeker's handbooks. The personal style was replaced by a straightforward description of sights and towns, and the book is structured according to logical geographical routes instead of Starke's own itinerary.

One of the most defining differences between Starke and the handbooks by Murray and Baedeker is, in my view, the fact that Starke did not create a distinctive trademark. Her work was well-known, but remained attached to her personally. Murray and Baedeker, on the other hand, succeeded in creating a series of travel handbooks that would carry their names, but would nevertheless not be inextricably linked to them as individuals. Instead, they invented a series that would be recognised as a brand, and their names would be used as synonyms for the whole genre. How they achieved this will be discussed below.

Their success must initially be understood within a wider socio-historical context: the Industrial Revolution. David M. Bruce points out that it was only due to innovations in the printing industry that it became possible to produce the famous small, light, hard-covered handbooks on a large scale at a relatively low cost. In addition, steam power enabled travel to become timetabled, which was important for the guidebooks as they replicated train and steamer schedules. ${ }^{101}$ Moreover, the fact that transport became more reliable, more comfortable and more affordable due to the invention of steam locomotion gave rise to a new class of travellers: the middle

\footnotetext{
${ }^{100}$ John Murray III, 'The Origin and History of Murray's Handbooks for Travellers', Murray's Magazine, 6 (1889), 623-9 (repr. in John Murray IV, John Murray III 1808-1892: A Brief Memoir (New York: Alfred A. Knopf, 1920), pp. 39-49 (p. 41)). Italics in original.

${ }^{101}$ David Bruce, 'Baedeker: The Perceived "Inventor" of the Formal Guidebook - A Bible for Travellers in the 19th Century', in Giants of Tourism, ed. by Richard Butler and Roslyn Russell (Wallingford: CABI, 2010), pp. 93-110 (p. 96).
} 
class. This new group bridged the chronological gap between the travel culture of the wealthy aristocrats of the seventeenth and eighteenth centuries on their Grand Tours, and the phenomenon of mass tourism which would conquer the world in the twentieth century. Whilst bridging this gap, the middle class was assisted by Murray and Baedeker who 'professionalized travel for the middle class, and rationalized and in this way directed - essential components of the tourist experience: the anticipation, perception, and memory of travel' ${ }^{102}$ In other words, Murray and Baedeker were in the right place, at the right time: they offered the new travelling middle class a guidebook which enabled them to educate, cultivate and orientate themselves.

John Murray is generally regarded as the most pivotal pioneer to publish a comprehensive and practical guidebook that served the needs of the middle-class traveller. The Murray publishing house had been founded by John Murray I in 1768 and had already printed several works in the genre of travel writing, amongst others Starke's acclaimed Travels on the Continent (1820). Inspired by her work, as well as by Johann Gottfried Ebel's Anleitung auf die nützlichste und genußvollste Art die Schweiz zu bereisen [How to Travel through Switzerland in the Most Useful and Enjoyable Fashion] (1793) and Edmund Boyce's The Belgian Traveller or a Complete Guide through the United Netherlands (1815), ${ }^{103}$ the founding father's son, John Murray II, decided to write a guidebook himself: A Handbook for Travellers on the Continent (1836). In the preface of this handbook, Murray outlines his objectives which shed light on some of the main characteristics of the new 'modern' guidebook and the way he wanted to reinvent and innovate the genre:

\footnotetext{
The Guide Books hitherto published are for the most part either general descriptions compiled by persons not acquainted with the spots [...], or are local histories, written by residents who do not sufficiently discriminate between what is peculiar to the place, and what is not worth seeing, or may be seen equally well or to greater advantage somewhere else. [...] They are often mere reprints of works published many years ago, by no means corrected or brought down to the present time [...]. The writer of the Handbook has endeavoured to confine himself to matter-of-fact descriptions of what ought to be seen at each place, [...] without bewildering his readers with an account of all that may be seen. ${ }^{104}$
}

\footnotetext{
102 Jan Palmowski, 'Travels with Baedeker: The Guidebook and the Middle Classes in Victorian and Edwardian Britain', in Histories of Leisure, ed. by Rudy Koshar (Oxford: Berg, 2002), pp. 105-30 (p. 106).

${ }^{103}$ Murray III, p. 41.

${ }^{104}$ John Murray, A Handbook for Travellers on the Continent: Being a Guide to Holland, Belgium, Prussia, Northern Germany, and the Rhine from Holland to Switzerland, 9th edn (London: John Murray, 1853), p. v. Emphasis in original.
} 
Familiarity of the author with the described area and regular updates were thus regarded by Murray himself as important innovations of his guidebook. In addition, the selectiveness of the guide was regarded as important; the guidebook was meant only to describe the places that were regarded as worthwhile for travellers, whilst omitting other aspects of the destination which were deemed less attractive.

Personalised observations were omitted in favour of 'matter-of-fact descriptions' written in a 'simple and condensed' style whilst avoiding 'exaggerated superlatives'. ${ }^{105}$ These books were not meant to re-tell an already finished journey, but to inform readers about their current or future travels.

During the following decades, Murray successfully established a guidebook series which significantly influenced its middle-class readership. These travellers, looking to be educated and cultivated, relied heavily on their guidebooks for advice on where to sleep and eat, as well as how to evaluate sites. The guidebook texts were widely accepted to be omniscient and trustworthy authorities, as Jan Palmowski argues in his study on the impact of the guidebook on British middle-class travel culture. ${ }^{106}$ The question remains how Murray, and later to an even greater extent Baedeker, was able to convince his readership to accept his expertise so willingly. There are arguably a few important factors that contributed to the perceived reliability of the guidebook which consequently led to their acceptance as authoritative and dependable documents whose predilections and evaluations did not need to be questioned. Esther Allen identifies several of these aspects in her early article on guidebooks “"Money and Little Red Books"”. She considers Murray’s guidebook as the most important innovative influence within the emerging genre, since '[i]t enjoyed an unprecedented success with the rapidly enlarging travelling public of its time because it was able to persuade that public to believe in its authority more forcefully than any previous guidebook had done'. ${ }^{107}$ According to Allen, it was first of all important that there was no longer a clearly recognisable, authorial presence. Instead of a travelogue or travel guide that was written by a specific author (e.g. Mariana Starke), no author is named in Murray's guidebooks.

\footnotetext{
105 Murray, A Handbook for Travellers on the Continent, p. v.

106 Palmowski, pp. 109-10.

${ }^{107}$ Esther Allen, "Money and Little Red Books": Romanticism, Tourism and the Rise of the Guidebook', LIT, 7 (1996), 213-26 (p. 215).
} 
The name 'Murray' rather refers to the publishing house and was also used when the guides were not written by one of the family members. In line with this indistinctiveness of the author, the guides no longer used the first-person singular as a narrative perspective, but instead used the first-person plural. Allen argues that this narrative point of view creates the sense of the experience of a crowd: rather than being an idiosyncratic experience of a place, the "we" which narrates the handbooks tells its readers that their experience will not be a supplement to all other experiences, separate and unique: it will be identical to all other experiences'. ${ }^{108}$ Moreover, instead of the past tense, Murray used the present tense in his guides, therefore not limiting the guide to being a re-telling of a journey already made by an existing individual, but instead leaving the descriptions open for the reader to experience on future travels. Allen subsequently concludes that by removing the author's presence from the narrative, Murray tried to enhance the perceived 'quasiscientific verifiability' of the guidebooks as he attempted to depersonalise the narrative whilst supposedly stripping it of subjectivisms.

The author's presence was removed from the narrative, but the fact that the guidebook was based on personal travels and eyewitness verification played an important role in the claim to the guidebook's trustworthiness. In the preface of Murray's Handbook to the Continent it is emphasised that:

Should the book be found to possess any superiority over others of its class, it is because it is based upon a personal knowledge of the countries described; since those routes which have not been travelled over by the author himself have, with very few exceptions, been revised by friends to whom they are actually known. Many of the descriptions have already served to guide travellers abroad, and have thus been verified on the spot. ${ }^{109}$

John Murray III proudly emphasises that his early handbooks are influenced by his private reading and that his 'tastes, studies and predilections mark the originality of [his] writing'. ${ }^{110}$ The fact that he himself had been there and had chosen the sights and the way to describe them had to reassure the reader of the reliability of Murray's handbooks. At first, it seems contradictory that the authorial presence is removed from the narrative in order to let the guidebook appear less idiosyncratic and more trustworthy, whilst its credibility also apparently depends on the fact that the guide is

\footnotetext{
108 Allen, p. 217.

${ }^{109}$ Murray, A Handbook for Travellers on the Continent, p. vi.

${ }^{110}$ Murray III, p. 48.
} 
based on personal observations. However, this connection becomes less paradoxical if it is pointed out that the aspect of eyewitness verification is detached from a clearly identifiable authorial presence. The name 'Murray' was used as a reference to the well-known and respected publishing house, instead of to the individual author. Churnjeet Mahn remarks in this respect:

\begin{abstract}
One of the primary qualifications for setting the modern guidebook apart from the literary artefact has been the lack of a single author and for [sic] the high proportion of factual material. The very idea of the author and the type of authority they may carry was steadily rewritten by the guidebook to move from the subjective to the objective, from the variable to the constant. The use of 'Murray' [...] as an anonymous institution can be seen as corresponding to the guidebook's claim to truth-values, or the accurate transcription of other places. ${ }^{111}$
\end{abstract}

That this claim can never hold true must be evident, as no description can be completely devoid of idiosyncratic evaluations. The selection of sites is determined by the author, and it is therefore his or her predilections that decide what is shown to the traveller. The opposite can be said as well: if the author chooses not to include certain aspects of the country in the guidebooks, the traveller will probably remain unaware of them.

Nevertheless, Murray succeeded in creating a clearly recognisable trademark, which is arguably one of the reasons for the enormous success of his handbooks. The fact that all the guides were collected under the same name, had uniform dimensions, a recognisable red cover with golden letters and a similar depersonalised writing style made them a familiar and seemingly trustworthy source of information. From the 1840s onwards, Murray's handbooks became an almost indispensable travelling companion. In 1850, a reviewer in The Times wrote: 'The Englishman trusts to his MURRAY as he would trust to his razor, because it is thoroughly English and reliable'. ${ }^{112}$ However, from the 1870 s onwards, the German Baedeker handbook became the undisputed leader of the market.

The Prussian-born bookseller Karl Baedeker started his guidebook empire around the same time as John Murray and his work soon became popular in Germanspeaking areas. In 1832, he had bought a publishing company in Cologne which had

\footnotetext{
${ }^{111}$ Churnjeet Mahn, 'Romantic Horizons: Fact and Fiction in the Guidebook to Scotland', in ReVisioning Scotland: New Readings of the Cultural Canon, ed. by Lyndsay Lunan, Kirsty MacDonald and Carla Sassi (Frankfurt a.M.: Peter Lang, 2008), pp. 1-12 (pp. 2-3).

${ }^{112}$ Quoted in: Parsons, p. 185.
} 
previously printed the widely-read guide Rheinreise von Mainz bis Cöln: Handbuch für Schnellreisende [Rhine Journey from Mainz to Cologne: Handbook for Swift Travellers] (1828) by Johannes August Klein. Baedeker decided to reissue this book in German and French whilst adding some of his own material, and the book became an immediate success. Owing to this business achievement and realising the demand for Murray's guidebooks which Baedeker himself sold in his bookshop, he decided to further exploit his own guidebook venture which soon flourished. He based his series on Murray's concept, and in his earlier handbooks indeed acknowledged his debt to his British colleague. ${ }^{113}$ Until 1860, the two guidebook series co-existed peacefully, Baedeker controlling the German market whilst Murray was primarily successful in English-speaking areas. However, by 1861 Fritz Baedeker had taken over his father's firm and decided to end the cooperation with Murray by boldly starting to publish guides in English, thus directly competing for the same readership. Within twenty years, Baedeker managed to dethrone Murray and by 1880 Baedeker was acclaimed as the 'prince of guide-book makers'. ${ }^{114}$

Scholars generally agree that Baedeker's success and the simultaneous downfall of Murray can be attributed to the fact that the former managed to keep pace with the changing needs of its readership, whilst the latter failed to do so. James Buzard points out that Murray continued to rely on a small number of specialists and his own travels to provide information for new guides and for the updates of older editions. He was unable to modernise his firm and wanted to remain personally in control of the content of the guidebooks. With the ever-increasing number of destinations and updates, this eventually proved to be unattainable, Buzard concludes. ${ }^{115}$ By the end of the century, the enterprise had become too costly and too difficult to maintain, and in 1901 Murray was forced to sell his guidebook series to Edward Stanford, a map publisher from London. A few years later, in 1914, the series was bought by James and Findlay Muirhead, former editors of the English Baedeker series, who renamed the Murray handbook the Blue Guides, which are still published today. Fritz Baedeker, on the other hand, did manage to modernise his family's firm. He set in place an elaborate system of editors and editors-in-chief that

\footnotetext{
${ }^{113}$ See for example: Karl Baedeker, Belgien: Handbuch für Reisende, nach eigener Anschauung und den besten Hülfsquellen bearbeitet, 5th edn (Koblenz: Karl Baedeker, 1854), p. iii.

${ }^{114}$ John Kirkpatrick, 'The Praise of Baedeker', Pall Mall Gazette, 30 August 1889, Correspondence Section, p. 2.

${ }^{115}$ Buzard, The Beaten Track, p. 73.
} 
were in charge of creating and revising the guidebooks, enabling him to maintain the growing number of editions and destinations that were covered.

Additionally, the sober language, first introduced by Murray, was further reduced to plain 'surveys of geology and religion, statistical summaries of ethnography and education, historical accounts of architecture and archaeology, plus annotated bibliographies, outlines of grammar and vocabulary [and] newly drawn and ever more detailed maps'. ${ }^{116}$ This factual, non-prescribing style is eventually what made Baedeker more successful than Murray. Even though Murray had removed the authorial presence from the guide, his guidebooks remained patronising, telling the tourist not only what to see but also how to understand it. Palmowski highlights in this respect that travelling abroad had been a new phenomenon for the British middle class, Murray's intended readership, and the reassuring and steering tone of his handbooks was valued. These readers wanted to be educated and cultivated, and looked to Murray for advice on what and how to appreciate. However, Palmowski contends that towards the end of the century the middle classes wanted to experience something different, and no longer wished to be told what they should and should not value. ${ }^{117}$ In other words, they had outgrown the advice of their Murray. Palmowski subsequently provides the telling example that whereas in the 1870s Murray still warned his readers about French food and recommended Parisian restaurants that served British cuisine, Baedeker urged its readership to explore French gastronomy. Instead of looking for the familiar, by this time middle-class travellers were ready for new experiences and Baedeker was their preferred guide for finding them. Moreover, the fact that Murray's guides were so evidently a product of their culture and time, and were so clearly written for an English audience, made them unsuitable for translation. Baedeker, on the other hand, managed to successfully publish in multiple languages. ${ }^{118}$ As a result, the German guidebook publisher was able to further expand its potential outlets and dominate the market. Overall, Baedeker's handbooks were regarded as less verbose, lighter, more accurate with better maps, cheaper and better organised than the guides published by Murray. ${ }^{119}$

\footnotetext{
${ }^{116}$ Edward Mendelson, 'Baedeker's Universe', Yale Review, 74 (1985), 386-403 (p. 396).

${ }^{117}$ Palmowski, p. 120.

118 See: Mendelson, pp. 396-7.

${ }^{119}$ See: Mullen and Munson, pp. 123-4.
} 
Both Murray's and Baedeker's authority was widely accepted and rarely questioned, and consequently had a decisive impact on travel behaviour and artistic taste, as David M. Bruce points out. ${ }^{120}$ In some instances, travellers did not even attempt to describe what they had seen in their own words, but just referred to a specific page in their guidebooks when writing to their families. ${ }^{121}$ Palmowski further investigates the effect of both series on their readers, working from the premise that ' $[\mathrm{t}] \mathrm{h}$ e spread and relative uniformity of travel guidebooks was an important precondition for the cultural impact of the Murray and the Baedeker'. ${ }^{122}$ He traces their influence in nineteenth- and early twentieth-century travel writing, quoting the famous example of E. M. Forster's A Room with a View (1908), in which the protagonist Lucy Honeychurch is unable to enjoy her trip to Florence after her cousin Charlotte has taken away her Baedeker. Without her guidebook, Lucy does not know where to go, how to look, and what to enjoy for its aesthetic value. She suddenly appears to have no artistic taste; she can only appreciate art when her guidebook tells her where to direct her gaze and how to interpret what she sees. Palmowski goes further by providing several examples of published and unpublished travel accounts which appear to be heavily influenced by their guidebooks. He identifies several texts in which the description of places seems to have been literally copied from a Murray or Baedeker guide, which leads him to the conclusion that these texts 'shape the actual impressions and assumptions, but also [that] their function as an aide-memoire [sic] served to engrave the memory and experience of their readership'. ${ }^{123}$ At the same time, guidebooks were also influenced by their readers, Palmowski argues. He shows how the guides were sometimes criticised, after which the editions were revised. Palmowski summarises: 'The guidebook was thus in intimate communion with the perceptions of its largely middle-class audience. It closely reflected middle-class views, and in turn determined them. [...] [T] he guidebooks told [tourists] what to see, and how to see it'. ${ }^{124}$

After World War I it became increasingly apparent that Baedeker's hegemony over the guidebook market had ended. Inflation, travel restrictions for Germans and international hostility towards German products have been mentioned

\footnotetext{
${ }^{120}$ Bruce, p. 93.

${ }^{121}$ See: Mullen and Mundson, p. 121.

122 Palmowski, p. 109.

${ }^{123}$ Palmowski, p. 111.

${ }^{124}$ Palmowski, p. 111.
} 
as reasons for the declining popularity of Baedeker's handbooks. ${ }^{125}$ Moreover, new travel cultures emerged that did not relate to the middle-class guidebooks published by Baedeker. In his book German Travel Cultures, Rudy Koshar identifies the rise of a 'modernist travel culture' which found the Baedeker handbooks too prudish and bourgeois. According to Koshar, these travellers were interested in the darker side of tourism which put nightlife and sexual activities at its centre. ${ }^{126}$ In addition, a working-class travel culture developed which also rejected the traditional Baedeker. Travelling was no longer the exclusive preserve of a relatively small, affluent part of the population. Due to improved holiday regulations and the growing prosperity of the working class, new types of tourists were entering the market who were looking for something other than the bourgeois Baedeker to guide and inform them. Christine Keitz argues that for these travellers Baedeker was so closely intertwined with a middle-class culture from which they felt excluded, that they regarded it as imperative to create a travel culture of their own, including their own guidebooks. ${ }^{127}$ The guidebook market thus expanded, and new guides emerged to cater to the needs of these new kinds of travellers. For the proletarian traveller, for example, there was the Dietz Arbeiter-Reise- und Wanderführer [Dietz Travelling and Walking Guide for Workers] (1932). ${ }^{128}$ There was even a series entitled Was nicht im Baedeker steht [What's Not to Be Found in Baedeker], published between 1927 and 1938, which was written in a more personalised and literary style than Baedeker. In addition, this series tried to highlight different sites that were felt to have been previously overlooked. ${ }^{129}$

Resulting from the emergence of new travel cultures, the guidebook market was able to diversify and move away from the focus on middle-class, educationally motivated tourism. New transport methods also proved an important incentive for the rise of different travel guides. The most noticeable example in this regard is the success of the Michelin guidebook which is connected to the arrival of the automobile. Whereas the nineteenth-century guidebooks had been based on railway

\footnotetext{
125 Parsons, p. 212.

${ }^{126}$ Rudy Koshar, German Travel Cultures, p. 65.

${ }^{127}$ Christine Keitz, 'Reisen zwischen Kultur und Gegenkultur: "Baedeker" und die ersten Arbeitertouristen in der Weimarer Republik', in Zur Sonne, zur Freiheit! Beiträge zur Tourismusgeschichte, ed. by Hasso Spode (Berlin: Verlag für universitäre Kommunikation, 1991), pp. 47-60 (p. 50).

128 See: Keitz, p. 47.

${ }^{129}$ See: Koshar, German Travel Cultures, p. 78.
} 
itineraries, Michelin focused on motorists as its main target audience and consequently succeeded in appealing to a new readership. ${ }^{130}$ Marc Francon provides a brief historical overview of the success of the Michelin guidebook and notices that when these guides were first published, their aim was to popularise car travel and create a market for Michelin's tyres. However, the guides soon began including information about stops on the route, hotels, and places to eat. Between the World Wars, the Michelin guide rouge developed into a gastronomical guide, whereas the Michelin guide vert became a popular tourist guidebook. ${ }^{131}$

Infrastructural improvements (first steam engines and later the rise of the automobile) influenced the development of the guidebook market. After World War II, the increase of air travel and charter flights proved to be a totally new and revolutionary stage in the tourism industry, which further reduced the perception of time and space, and marked the beginnings of international tourism. Additionally and simultaneously, new travel cultures continued to be an influential force in the diversification of the guidebook industry. An important development was the emergence of 'the backpacker' during the 1960s and 1970s. These travellers did not regard themselves as tourists and wanted to escape the increasingly commercialised tourism industry. Joanna Dybiec notes concerning these travellers: 'Their needs were catered for by the new Anglo-American guidebook series which offered not only practical directions but also an ideological orientation in terms of legitimizing and exalting budget travel'. ${ }^{132}$ Examples include the highly popular Rough Guide and Lonely Planet guidebooks, which have since broadened their readership to include more mainstream tourists as well. As with the post-Baedeker publications, these guides were written because their authors had identified a gap in the existing guidebook market. The founders of the Lonely Planet series, Tony and Maureen Wheeler, realised that travel books tended to focus on historical sites and culture whilst lacking information on beaches, night clubs and bars. ${ }^{133}$ Consequently they decided to write their own guidebook, Across Asia on the Cheap (1973), based on

\footnotetext{
${ }^{130}$ For more on Michelin, see: Marc Francon, 'L’Univers Touristique Michelin', in Les Guides imprimés du XVIe au XXe siècle: villes, paysages, voyages, ed. by Gilles Chabaud and others (Paris: Belin, 2000), pp. 113-20; Stephen L. Harp, Marketing Michelin: Advertising \& Cultural Identity in Twentieth-Century France (Baltimore: Johns Hopkins University Press, 2001).

${ }^{131}$ Francon, p. 114.

132 Dybiec, p. 61.

${ }^{133}$ See: Emily Brennan, 'A Lonely Planet Founder Looks Back', New York Times, 7 June 2013 <http://www.nytimes.com/2013/06/09/travel/a-lonely-planet-founder-looks-back.html?_r=0> [accessed 21 March 2016].
} 
their travels through Europe and Asia, which became an immediate hit and marked the beginning of a highly successful guidebook series. The Rough Guide series began in a similar way. On their website, the formation of their first guide is described as follows:

In the summer of 1981, Mark Ellingham, just graduated from Bristol University, was travelling around Greece and couldn't find a guidebook that remotely met his needs. It was here that he met Martin Dunford, who was in Greece teaching English at the time. On their return to the UK, in a bid to avoid getting 'real jobs', Mark, Martin and a small group of writers set about creating their own guidebook series; a series that aimed to combine a journalistic approach to description with a practical approach to travellers' needs. ${ }^{134}$

A new travelling culture which was searching for alternative ways of living and travelling was their intended readership, and the reason for establishing a new guidebook series is said to have derived from this perceived gap in the market. Young, adventurous and not interested in the Baedekeresque focus on history and culture, these travellers still needed to be catered for. Comparable publications in other languages also appeared, such as the French-language Guide du routard. According to André Rauch, the aim of this series was to create a guidebook for younger people, without the pedantic style of its forerunners, that made travel individualistic and personal again whilst bringing foreign cultures alive instead of confining them to museums filled with lifeless objects of the past. ${ }^{135}$

However, even though they presume to be different compared to their earlier counterparts, MacKenzie notices that there are also striking similarities between these 'backpacker' guides and their nineteenth-century forerunners. ${ }^{136} \mathrm{He}$ concludes that 'the Lonely Planet and Rough Guides represent not so much a revolution but a neo-colonial continuity', arguably maintaining a Western cultural imperialism which he identifies as being present in the nineteenth- and early twentieth-century European guidebooks. ${ }^{137}$ In some cases, the indebtedness to their precursors becomes particularly visible through direct quotes taken from these earlier texts. An example of this is the description of Heringsdorf (a seaside town in Germany) in The Rough Guide to Germany: 'Described by Baedeker as "the most fashionable of the Baltic

\footnotetext{
134 <http://www.roughguides.com/about-us/> [accessed 21 March 2016].

${ }^{135}$ André Rauch, 'Du Joanne au Routard: le style des guides touristiques', in Les Guides imprimés du XVIe au XXe siècle: villes, paysages, voyages, ed. by Gilles Chabaud and others (Paris: Belin, 2000), pp. 95-112 (pp. 103-8). Other series with similar aims and target audiences are for example the French Petit futé and the German Reihe unkonventioneller Reiseführer.

${ }^{136}$ MacKenzie, p. 21.

${ }^{137}$ MacKenzie, p. 36
} 
sea-bathing places", Heringsdorf is the oldest resort on Usedom'. ${ }^{138}$ Apart from similarities and intertextual references concerning content, the structure of these contemporary guides also closely resembles that of Baedeker and Murray. Travel practicalities, such as transport information and money matters, are followed by detailed descriptions of sites and attractions. An overview of the destination's history is likewise provided, as well as a section on culture and customs. Most importantly, similar to Murray and Baedeker, these post-World War II guidebook series managed to establish a renowned trademark. They are recognisable due to their familiar logos and cover designs instead of their authors' names.

In addition to these 'backpacker' guidebooks, there has been an increasing number of guidebooks that are characterised by an awareness of the more negative impact of the tourism industry on the environment and cultural structures of a destination, for example the Ethical Travel Guide. Moreover, it must be noted that the more cultured, middle-class travel guides aimed at a similar audience as Baedeker and Murray are also still being published. Examples of these are the Guide Bleu, Marco Polo, DuMont, as well as Baedeker itself.

In the age of globalisation, the guidebook has become an international product in many ways. Joanna Dybiec rightfully points out that Anglo-American guides such as Lonely Planet and Rough Guide are not only read by English nativespeakers, but are also consumed by millions more that are using English as a lingua franca. Moreover, Dybiec draws attention to the fact that guidebooks are translated into a growing number of languages, thus greatly expanding their readership, and that writing teams are often made up of an international selection of contributors, making the guidebook in every way an international product. ${ }^{139}$

E-guidebooks and mobile applications belong to the newest developments of the guidebook genre, which will presumably become increasingly important in our digital age. Although some of the apps produced by guidebook series are also largely based on the content and design of the printed material, they tend to offer some new and interesting added features. Through GPS, these apps can for example find the

\footnotetext{
${ }^{138}$ Gordon McLachlan, The Rough Guide to Germany, 6th edn (London: Rough Guides, 2004), p. 455. For other references to Baedeker and Murray and their descriptions of places in the Rough Guide series, see: Dan Richardson, The Rough Guide to Moscow, 5th edn (London: Rough Guides, 2009), p. 440; Dan Richardson, The Rough Guide to Egypt (London: Rough Guides, 2013), p. 332. Google ebook. ${ }^{139}$ Dybiec, p. 65.
} 
location of their users and immediately provide tips about sites and attractions in their vicinity. Information gathered through crowdsourcing, integrated in some apps such as the one produced by Frommer's (a well-known American guidebook series), enables travellers to leave reviews or other information for fellow travellers, thus circumventing the author as a producer of text and a selector of sites. This makes travel guide apps much more direct and transparent than their printed equivalents. Instead of trusting the opinion of one or a handful of authors, readers can now base their travel itineraries on a large number of reviews by peers. Some apps, like Foursquare and Gogobot, remember users' preferences and consequently become acquainted with their predilections. As a result, they are able to provide the traveller with tailored information. The most apparent advantage of apps in comparison to printed guides is that they are able to constantly remain up-to-date. Not only users can add information, but content creators are also able to adjust, delete and add data at any preferred time. Compared to this, writing, editing and updating a printed guidebook seems like a time-consuming task, which will inevitably make the guide outdated as soon as it is published.

Travel apps are one of the fastest growing products in the mobile application industry, ${ }^{140}$ and the many entries on websites and blogs about the advantages (and disadvantages) of travel apps in comparison to the traditional guidebook seem to indicate that they form a serious rival for the printed medium. ${ }^{141}$ Indeed, the guidebook market appears to be in decline; sales from Frommer's, a well-known American guidebook series, dropped from thirty-four million dollars to eighteen million dollars between 2006 and 2012, and those of Lonely Planet also fell from twenty-five to eighteen million dollars during the same period. ${ }^{142}$ In 2013 , Lonely Planet was sold for almost eighty million pounds less than it was originally bought for only seven years earlier. ${ }^{143}$ It remains unclear to what extent this decline in the

\footnotetext{
$140<$ http://www.emarketer.com/Article/Travel-Apps-Lead-Industries-Usage-Growth/1009408> [accessed 18 March 2016].

${ }^{141}$ For example: Nathalie Bonney, 'Smartphone vs. Guidebook: Which Works Better Abroad?', Good Housekeeping (2015) <http://www.goodhousekeeping.co.uk/consumer-advice/technology-madeeasy/smartphone-vs-guidebook-which-works-better-abroad> [accessed 18 March 2016]; Tamsin Bishton-Hemingray, 'Are Mobile Travel Apps a Bit Crap?', Travelblather (2011)

<http://www.travelblather.com/2011/11/mobile-travel-apps-review.html> [accessed 18 March 2016].

142 'The Guidebook Industry', The Economist, 3 April 2013, <http://www.economist.com/blogs/gulliver/2013/04/guidebook-industry> [accessed 18 March 2016].

${ }^{143}$ Mark Sweney, 'BBC WorldWide Criticised for Sale of Lonely Planet at "Significant Loss", Guardian, 19 March 2013, <http://www.theguardian.com/media/2013/mar/19/bbc-worldwidecriticised-lonely-planet-sale> [accessed 18 March 2016].
} 
printed guidebook industry can be linked to the popularity of mobile applications, but the increasing use of the Internet as well as connected programs and services undoubtedly play a crucial role. Nevertheless, research has also indicated that the guidebook remains popular as a tangible memory artefact, whilst the infinity of information available on the Internet and mobile devices overwhelms some users and is given as a reason to continue using a printed guidebook. Moreover, escaping technology has been identified as an important reason for travelling, and mobile devices are often associated with the life from which the traveller wants to get away. ${ }^{144}$ Although its future is uncertain, it remains therefore unlikely that the guidebook will completely disappear from the traveller's inventory in the near future.

\subsection{The Development of the Field: The Guidebook as an Object of Analysis}

For a long time guidebooks were ignored by critics as well as academics, and were marginalised in research on place perception. If they were mentioned as a primary source, they were often scorned for being clichéd, derivative and superficial accounts of places. In his famous 1957 essay 'Le "Guide bleu", Roland Barthes accused the guidebook of being 'un instrument d'aveuglement' [an agent of blindness] which reduces places to lifeless, fossilised monuments only to be consumed by the middle-class tourist gaze. ${ }^{145}$ In comparison to ethnographic research (academic studies concerning peoples, places and cultures) and literary travel accounts (personalised engagements with different localities), guidebooks used to be seen as products of commodified mass tourism which reduced the described areas to a list of sights and beaten tracks. ${ }^{146}$ Since Barthes, the academic opinion of guidebooks has changed dramatically. Gradually, these texts have become recognised as important and illuminating sources for various academic fields. How this change came about will be discussed in the following section.

\footnotetext{
${ }^{144}$ Peel and Sørensen, p. 201.

145 Roland Barthes, 'Le "Guide Bleu"', in Mythologies, by Roland Barthes (Paris: Éditions du Seuil, 1957), pp. 113-7 (p. 115).

${ }^{146}$ See: David Gilbert, “"London in All its Glory - or How to Enjoy London”: Guidebook Representations of Imperial London', Journal of Historical Geography, 25 (1999), 279-97 (pp. 281 2); Rudy Koshar, "What Ought to Be Seen": Tourists' Guidebooks and National Identities in Modern Germany and Europe', Journal of Contemporary History, 33 (1998), 323-40 (p. 324).
} 
An important landmark for the reappraisal of the guidebook was the growing awareness of tourism in general as a subject worthy of academic consideration which occurred during the last quarter of the twentieth century. Gradually, this practice was seen as a fruitful source for academic exploration in a variety of fields. Seminal sociological studies such as Dean MacCannell's The Tourist: A New Theory of Leisure Class and John Urry's The Tourist Gaze: Leisure and Travel in

Contemporary Societies have caused a paradigm shift in the way tourism is regarded academically. It is now widely acknowledged that tourism is an important aspect of our post-modern society and it has been argued that it must be seen as a practice which enables us to make sense of the world. ${ }^{147}$ Following this academic reevaluation of tourism as a subject of academic scholarship, research into guidebooks, as products of modern tourism, has also expanded during the last three decades.

After World War II, the first sporadic studies on guidebooks were being published. These were primarily concerned with providing a historical overview of the development of the genre. ${ }^{148}$ Scholarly attention was most noticeably concentrated on the Baedeker and Murray publishing houses and their guidebooks, which were seen as the most influential initiators of the modern guidebook and therefore pivotal to the history of the travel guide. ${ }^{149}$ French publications from this period focused on the Hachette publishing house and its nineteenth-century counterpart of the Baedeker and Murray guidebook series; the Guides Joanne. ${ }^{150}$ Subsequently, other guidebook series and their development have also occasionally received scholarly attention. ${ }^{151}$ Interest in the history and development of the genre continued, ${ }^{152}$ and in 2007 an entire book devoted to the history of the travel guide was published; Nicholas T. Parsons's Worth the Detour. During the last two decades,

\footnotetext{
${ }^{147}$ In this thesis I use the second edition of Urry's book on the Tourist Gaze. See: Urry, p. 2.

148 See: Esmond Samuel de Beer, 'The Development of the Guide Book until the Early Nineteenth Century', The Journal of the British Archaeological Association, 15 (1952), 35-46; Vaughan. ${ }^{149}$ See: William B.C. Lister and John R. Gretton, A Bibliography of Murray's Handbooks for Travellers and Biographies of Authors, Editors, Revisers and Principal Contributors (Dereham: Dereham Books, 1993); Alex Hinrichsen, Baedeker-Katalog: Verzeichnis aller Baedeker-Reiseführer von 1832-1987 mit einem Abriß der Verlagsgeschichte (Holzminden: Ursula Hinrichsen Verlag, 1988); Mendelson; Hinrichsen, 'Zur Entstehung des modernen Reiseführers'.

${ }^{150}$ See: Nordman, Daniel, 'Les Guides-Joanne: ancêtres des guides bleus', in Les Lieux de mémoire II: la nation, ed. by Pierre Nora, 3 vols (Paris: Gallimard, 1986), I, pp. 529-67.

${ }^{151}$ See: Goulven Guilcher, 'Les Guides Michelin 1900-1914', La Lettre du marché du livre ancien et d'occasion, 38 (1994), 6-7; Werner Hauenstein, Wegweiser durch Meyers Reisebücher: 1862 - 1936 (Stadtoldendorf: Verlag Ursula Hinrichsen, 1993).

${ }^{152}$ For one of the most recent articles on this subject, see: Guilcher, 'Les Guides européens et leurs auteurs'.
} 
research into guidebooks proliferated and these texts became appreciated as fruitful academic sources, outgrowing the rather limited historical angle on the genre's development. The various approaches to guidebooks coming from a range of academic fields will be discussed in more detail below.

One book deserves separate attention here, and that is Rudy Koshar's German Travel Cultures. Koshar was one of the first to solely use guidebooks as a primary source in a book-length study which surpassed being a history of the genre. In this work, Koshar examines the relationship between society and leisure, and shows that guidebooks have played an active role within this relationship. He uses a selection of guidebooks to illuminate the development of various German travel cultures, which have arguably played an important role in the construction of a national German identity. ${ }^{153}$ The premise underlying his research is that cultural artefacts 'do not just reflect larger political or social contexts. They also actively shape and re-shape such contexts, creating important webs of significance between the "reader" and the text, and between the text and the larger community of readers'. ${ }^{154}$ Reading is therefore not seen as a mere individual act, but as something that is connected to a whole range of life practices, set within a larger socio-historical context. Koshar follows the work of the French philosopher Michel de Certeau, who has argued that readers 'inhabit' texts and spaces, influencing their meanings and conveying these to other people and cultural productions. ${ }^{155}$ As such, meanings are not fixed, but are created through dialogues between individual readers, texts, contexts and larger communities. In his study, Koshar investigates how guidebooks may have worked for individual readers as well as larger, collective communities and how these coincided with and influenced various German travel cultures. ${ }^{156}$ His main argument is that travel guides should be seen as the motor and product of travel cultures and collective identities. ${ }^{157}$ Although he bases his arguments on a sometimes rather meagre selection of primary sources, Koshar compellingly shows how Baedeker created a middle-class German travel class, which was eager to cultivate itself and was proud of the post-unification achievements of its nation. $\mathrm{He}$

\footnotetext{
${ }^{153}$ For more of Koshar's work on this subject, see: Rudy Koshar, "What Ought to Be Seen"”.

${ }^{154}$ Koshar, German Travel Cultures, p. 5. My emphasis.

${ }^{155}$ Michel de Certeau, The Practice of Everyday Life (Berkeley: University of California Press, 1984), p. xxi.

${ }^{156}$ Koshar, German Travel Cultures, p. 6.

${ }^{157}$ Koshar, German Travel Cultures, p. 15.
} 
subsequently demonstrates the diversification of German travel culture during the Weimar Republic, in which new travel cultures, such as sex tourism and workingclass tourism, rapidly developed. Additionally, he investigates the role guidebooks played in the strengthening, with all the disastrous consequences this entailed, of German national identity during the Nazi regime, and how American guidebooks, as influential 'outsiders', were used to construct a post-war German identity. Koshar's study must be seen as an important step in the advancement of guidebook research, as it convincingly demonstrated that guidebooks are not only passive, clichéd reflections of tourism practices, but should instead be considered active creators of an 'optics of tourism'. ${ }^{158}$

Another important example of a book-length study investigating the relationship between guidebooks and different travel cultures is Joanna Dybiec's substantial work Guidebook Gazes: Poland in American and German Travel Guides 1945-2002. She considers guidebooks as significant mediators between cultures and uses American and German guidebooks published after World War II until the start of the new millennium to investigate the attitudes of these travel cultures towards Poland. Dybiec examines the genre as 'an intersection of travel cultures, ideologies and collective beliefs'. ${ }^{159}$ In her analysis she identifies notable differences between the way Poland is portrayed in American and German guidebooks, especially before the fall of Communism in 1989. In the pre-1989 American travel guides, Poland is often described as offering the tourist a rare glimpse behind the Iron Curtain, a 'curious playground of communism'. ${ }^{160}$ These guides use a rather colloquial narrative voice, which, according to Dybiec, reflects the attitude of American travel culture towards Poland. Whereas Europe was strictly divided between East and West, Americans could travel relatively freely in their role as victors and presumed liberators. For them, the tensions in Europe were of no immediate concern, and could

\footnotetext{
${ }^{158}$ Koshar, “What Ought to Be Seen"”, pp. 325-6. In recent years, the connection between guidebooks and collective identities has also been extended to gender research in which travel guides are often seen as emancipatory tools for the empowerment of female travellers, primarily during the nineteenth century. The general argument is that by enabling women to travel without a living companion but instead with a guidebook, the genre contributed to the emancipation of women whilst strengthening their gendered identity. See: Anja Peters, "Mein beschränkter Raum zwingt mich, auf das Selbstschauen zu verweisen." Adele Schopenhauers Florenz-Reiseführer', German Studies Review, 37 (2014), 487-506; Betty Hagglund, 'Gendering the Scottish Guidebook: Sarah Murray's “Companion and Useful Guide"', Women's Writing, 17 (2010), 129-46; Palmowski, pp. 116-7. ${ }^{159}$ Dybiec, p. 20.

${ }^{160}$ Dybiec, p. 341.
} 
even add to the touristic appeal of Poland, Dybiec concludes. ${ }^{161}$ The German guidebooks, on the other hand, hardly comment on Poland's Communist status and primarily regard travelling there as a form of Heimat tourism; Germans from areas which used to be part of Prussia travelled to Poland to visit their hometown. The tone of these guidebooks is much less verbose than that used in their American counterparts, which, according to Dybiec, reflects the conflicting emotions of German travellers to Poland, who are burdened with guilt, sadness and even anger over losing their Heimat. ${ }^{162}$ After 1989, the differences between the American and German perceptions of Poland in guidebooks seem to diminish, which Dybiec interprets as a reflection of the globalising tendencies of the tourism industry and a weakening of the national perspective. ${ }^{163}$ Similarly to Koshar, she contextualises her guidebook analysis within a broader framework of socio-historical developments, thus transcending the limits of a textual analysis. As a result, she shows how guidebooks can provide insights into a wide variety of aspects relating to international tourism practices. Her work not only provides illuminating insights into perceptions of Poland in German and American guidebooks, but also contributes to our understanding of German and American travel cultures in general.

Gradually, guidebooks and their potential as sources for research have come to the attention of other academic fields as well. Tourism studies, for example, are now acknowledging the crucial role and potential of guidebooks in the tourism process. Since the start of the twenty-first century, the various usages and functions of guidebooks as information sources have been increasingly examined from a tourism research perspective. ${ }^{164}$ Studies in this area have confirmed that guidebooks are consulted before, after and during travelling, and radically affect the perception of places. ${ }^{165}$ As such, guidebooks are not unproblematic and superficial reflections of

\footnotetext{
${ }^{161}$ Dybiec, pp. 342-3.

162 Dybiec, p. 343.

${ }^{163}$ Dybiec, p. 340.

${ }^{164}$ See: Peel and Sørensen; Chak Keung Simon Wong and Fung Ching Gladys Liu, 'A Study of PreTrip Use of Travel Guidebooks by Leisure Travelers', Tourism Management, 32 (2011), 616-28; Sachiko Nishimura, Robert Waryszak and Brian King, 'The Use of Guidebooks by Japanese Overseas Tourists: A Quantitative Approach', Journal of Travel Research, 45 (2007), 275-84.

${ }^{165}$ McGregor, p. 38. See also: Malin Zillinger, 'The Importance of Guidebooks for the Choice of Tourist Sites: A Study of German Tourists in Sweden', Scandinavian Journal of Hospitality and Tourism, 6 (2006), 229-46; A. Lew, 'Place Representation in Tourist Guidebooks: An Example from Singapore', Singapore Journal of Tropical Geography, 12 (1991), 124-37.
} 
an area, but have the power to influence the touristic image of a destination. ${ }^{166}$ In his research on guidebook usage, Andrew McGregor observes that only eight per cent of tourists had not consulted a guidebook before the journey and that this small group had already visited the destination, a region of Indonesia, before. Moreover, he notices that tourists only tend to visit those sites that are mentioned in their guidebooks, and rarely contradict the evaluations and interpretations made in these texts. ${ }^{167}$ Other research into guidebook usage corroborates these findings. Malin Zillinger's study for example points out that sixty-seven per cent of German tourists to Sweden declared that they used and were influenced by guidebooks. She argues that there is a direct connection between the amount of attention given to a certain site in a guidebook and the number of visitors. ${ }^{168}$ These texts thus have the power to identify and popularise certain sites, whilst simultaneously making other places invisible.

These findings correspond to MacCannell's theory about tourist attractions. According to him, tourist attractions consist of three elements which are closely linked: tourists, sights and markers. The idea behind this is that virtually every object or place can become of interest to the tourist, as long as it is marked and visited. MacCannell states: 'Note that markers may take many different forms: guidebooks, informational tablets, slide shows, travelogues, souvenir matchbooks, etc' ${ }^{169}$ This also works the other way around: 'If a sight is not mentioned in any guides, it is unmarked, it is not an attraction from the standpoint of institutionalized tourism, and it is not likely to be visited much by tourists'. ${ }^{170}$ This arguably not only holds true in regard to tourist attractions and sights, but also for whole regions and even countries. Zillinger's research indicates that if certain regions are not elaborately discussed in guidebooks, they are far less likely to be visited by tourists, especially when they are further removed from the tourist's home country and have limited accessibility. ${ }^{171}$ The question thus arises how much emphasis is placed on Wales as a distinctive travel destination in Continental guidebooks. The guides published in the nineteenth

\footnotetext{
${ }^{166}$ McGregor, p. 46. See also: Tamara Young, 'Framing Experiences of Aboriginal Australia: Guidebooks as Mediators in Backpacker Travel', Tourism Analysis, 14 (2009), 155-64; Jens Kristian Steen Jacobson and M.S. Graham Dann, 'Images of the Lofoten Islands', Scandinavian Journal of Hospitality and Tourism, 3 (2003), 24-47.

${ }^{167}$ McGregor, pp. 34-38.

168 Zillinger, pp. 232, 244-5.

${ }^{169}$ MacCannell, p. 41.

${ }^{170}$ MacCannell, p. 61.

171 Zillinger, p. 245.
} 
century could be especially revealing in this respect, as Wales was not easily accessible to travellers from the Continent during this period.

Although Zillinger's work offers illuminating insights into the influence of guidebooks on the number of visitors to a certain region, it disregards the actual content of the guidebooks and their evaluation of sites and attractions. Not only do guidebooks inform tourists which sights to see, which establishments to visit and which cultural events to experience, more importantly they also form a framework through which the entire visit is perceived. ${ }^{172}$ Since guidebooks are, as researchers Suzuki and Wakabayashi have pointed out, 'one of the most widely used media for travelling anywhere outside one's familiar place, containing multiple representational styles such as maps, photos and linguistic descriptions', ${ }^{173}$ they influence the tourist gaze and touristic experience to a great extent. In his study on guidebooks, McGregor convincingly shows that these texts considerably affect tourists' perceptions of a destination, functioning as dynamic agents 'which have a massive amount of power over how an individual, or a whole culture, comes to see the world'. ${ }^{174}$ In this role as dynamic agents, guidebooks are notable distributors of cultural information whilst mediating national identities and destination images. As such, the influence of guidebooks does not remain restricted to the individual reader, but has wider cultural significance.

The creation of oversimplified descriptions of the destination, its culture and inhabitants, largely based on stereotypes, is pivotal in this respect as they play an important role in the perception of destinations. Manfred Beller, a scholar working in the field of imagology, argues that our mental perception of cultures is not based on objective experience, but rather on exposure to and interpretation of images (both visual and textual). ${ }^{175}$ These images, Beller subsequently contends, influence our opinion of others and our behaviour towards them, but they are always selective. It is impossible to perceive all aspects of a certain country and its culture, and resulting from this a selection of images comes to represent a whole. ${ }^{176}$ Travel writing, and

\footnotetext{
172 See: Lew, pp. 125-6; Bhattacharyya, p. 381.

${ }^{173}$ Koshiro Suzuki and Yoshiki Wakabayashi, 'Cultural Differences of Spatial Descriptions in Tourist Guidebooks', in Spatial Cognition IV: Reasoning, Action, Interaction, ed. by Christian Freska and others (Berlin: Springer Verlag, 2004), pp. 147-64 (p. 149).

${ }^{174}$ McGregor, p. 46.

175 Manfred Beller, 'Perception, Image, Imagology', in Imagology: The Cultural Construction and Literary Representation of National Characters - a Critical Survey, ed. by Manfred Beller and Joseph Leerssen (Amsterdam: Rodopi, 2007), pp. 3-16 (p. 4).

${ }^{176}$ Beller, p. 5.
} 
guidebooks in particular, also suffer from this inevitable selectivity as these texts are forced to represent a destination through the use of a limited amount of textual and visual images. As a result, the world becomes a simplified amalgamation of straightforward characteristics, which can lead to the stereotyping of entire cultures and peoples. To use the words of Ken Teague, who examines the depiction of cultures in museums: 'The representation of any culture is necessarily selective. The process involves the appropriation, analysis and re-presentation of that culture, and runs the inherent risk of creating cultural stereotypes'. ${ }^{177}$ In their work on national stereotypes and guidebooks, Jennifer Bender, Bob Gidlow and David Fischer note that guidebooks play an important role in the 'formation, maintenance and use of stereotypical images'. ${ }^{178}$ The researchers subsequently contend that guidebooks do this by categorising and condensing complex cultural information in order to make it manageable for the reader. Their analysis of English, German, Spanish and French guidebooks to Switzerland convincingly shows how the cultural diversity of a multilingual country like Switzerland is reduced to a limited number of generalising characteristics which are used to describe the country as a monocultural unity. ${ }^{179}$ Guidebooks can thus condense complex cultures and national or regional identities to a handful of uncomplicated features, providing the reader with an unequivocal image of the destination.

The question remains what role the guidebook reader plays in this. As was argued above, it is generally acknowledged that guidebooks influence touristic perception and behaviour. More extreme views even regard tourists as controlled by guidebooks which are said to function as 'bibles' and 'scripts' for the tourist experience. ${ }^{180}$ As a result, tourists have allegedly become 'chasers of images'; ${ }^{181}$ they are only looking for those sites and sights that they have been told are worthwhile. From these points of view, the tourist is a rather passive, uncritical consumer of the

\footnotetext{
${ }^{177}$ Ken Teague, 'Representations of Nepal', in Tourists and Tourism: Identifying with People and Places, ed. by Simone Abram, Jacqueline D. Waldren and Donald V.L. Macleod (Oxford: Berg, 1997), pp. 173-95 (p. 173).

178 Jennifer Bender, Bob Gidlow and David Fischer, 'National Stereotypes in Tourist Guidebooks: An Analysis of Auto- and Hetero-Stereotypes in Different Language Guidebooks about Switzerland', Annals of Tourism Research, 40 (2013), 331-51 (p. 335).

${ }^{179}$ Bender, Gidlow and Fischer, p. 344.

180 Paul Scott, 'Guidebooks: Prewar to Postwar Imaging', Journal of Intercultural Studies, 25 (1998), 89-106 (p. 89).

${ }^{181}$ Graham Dann, The Language of Tourism: A Sociolinguistic Perspective (Wallingford: CABI, 1996), p. 83. This is not only limited to visual images, but also includes textual images created in written sources.
} 
guidebook text. It is not taken into account that tourists might read and use guidebooks differently depending on their interests (what they like to see), the amount they read (all chapters, or just a section on a specific museum) and their involvement with the guidebooks (critical or uncritical). ${ }^{182}$ A study recently undertaken by Victoria Peel and Anders Sørensen attempts to fill this gap in the research and provides insights from readers' perspectives. The scholars argue that the influence of guidebooks on tourist behaviour has not yet been subjected to critical academic interrogation. Their aim is therefore to investigate how guidebooks affect tourists and tourism, and how they might have manipulated the creation of tourist places in different contexts. ${ }^{183}$ By examining travel blogs and the way the usage of guidebooks is described in them, the researchers try to provide a more balanced perspective on the influence of these texts on their users. In the surveyed blogs, numerous different usages were discussed by travellers. ${ }^{184}$ From this material, the researchers conclude that it is difficult to provide broad generalisations about the use of guidebooks, as these are too idiosyncratic. Moreover, Peel and Sørensen problematise the general view that guidebook readers are 'slavish and linear':

The guidebook is [...] carried, consulted, left behind, argued over, skimmed, shared, adapted, ignored and destroyed. Guidebooks are downloaded, have pages torn out which are then carried and discarded, are used as a means to navigate the plethora of internet resources or are left at home and not used at all. ${ }^{185}$

Peel and Sørensen's study shows that the reader should not be overlooked in the process of perception and interpretation, and that these users of texts cannot be reduced to passive consumers. The textual and visual images they are furnished with by their guidebooks may be contested or discarded.

However, it must be noted that the material on which they base their conclusions is taken from travel blogs, written by people who identify themselves as 'travellers' rather than 'tourists'. As was explained in the introduction of this thesis, the term 'tourist' is often associated with a range of negative connotations, whereas

\footnotetext{
182 See: Anette Therkelsen and Anders Sørensen, 'Reading the Tourist Guidebook: Tourists' Ways of Reading and Relating to Guidebooks', Journal of Tourism Studies, 16 (2005), 48-60. For different uses of guidebooks, see: Nishimura, Waryszak and King.

${ }^{183}$ Peel and Sørensen, pp. 1-2.

${ }^{184}$ For an overview of the various usages, see the table in: Peel and Sørensen, p. 116.

185 Peel and Sørensen, p. 129.
} 
the term 'traveller' is frequently perceived to refer to the true adventurous discoverers of new places. ${ }^{186}$ According to Peel and Sørensen, the latter associate guidebooks with the practice of mass-tourism and are ashamed of being seen with them, ${ }^{187}$ and basing an itinerary on the information provided by a guidebook was often considered as cheating, since guidebooks allegedly deprive the traveller of having a truly original experience. ${ }^{188}$ The authors of these blogs can therefore be regarded as people who do not want to be perceived as tourists; they aspire to be 'true travellers'. Consequently, they are particularly critical about and dismissive of guidebooks in general. It might even be assumed that people who write travel blogs inevitably use guidebooks differently compared to more 'conventional' tourists who do not feel the need to publicly disseminate their supposedly original travel experiences. The question thus remains how representative Peel and Sørensen's material is. Naturally they are right to point out that guidebook readers should not be dismissed as passive consumers, but this does not make textual analyses of guidebooks redundant as they presume. ${ }^{189}$ Textual analysis has its shortcomings, but by examining large corpora, as is intended in this thesis, such studies can provide illuminating insights into the depiction of a certain destination and the creation of, to use Koshar's term, 'webs of significance' between readers, texts and wider communities. ${ }^{190}$ Although some of the information provided by guidebooks might be refuted by individual readers, it remains the premise of this research that these texts create a framework for perceiving a destination, as they are important providers of spatial and cultural information. Moreover, influenced by guidebooks (to various degrees), tourist perceptions and expectations actively shape and conceptualise destinations, thus contributing to the socio-spatial construction of the world. This assertion, vital for the rest of this study, will be examined further in the following section.

\footnotetext{
${ }^{186}$ Although this thesis does not make a distinction between the two terms, it does acknowledge that the two are still often used in different ways in public discourse.

${ }^{187}$ Peel and Sørensen, p. 104.

${ }^{188}$ Peel and Sørensen, p. 125.

${ }^{189}$ Peel and Sørensen, p. 60.

${ }^{190}$ Koshar, German Travel Cultures, p. 5.
} 


\subsection{Guidebooks and the Socio-Spatial Construction of Destinations}

It is widely acknowledged that destinations are not fixed constructions, but are actively conceptualised by both insiders and outsiders. Theories developed in the field of human geography can provide some valuable insights in this respect, and the following section will partly draw on ideas from this discipline. In human geography, destinations are seen as a "negotiated reality, a social construction by a powerful set of actors' ${ }^{191}$ Following this argument, Greg Ringer has contended that tourism has the power to create and reconstruct 'geographic landscapes as distinctive tourist destinations through manipulations of history and culture'. ${ }^{192}$ He does not use the word 'manipulation' in a negative sense here, but rather refers to the transformation (both through active production, as well as more passive consumption) of historic or cultural artefacts and practices, as well as landscapes, in order to make a certain place visible as a destination. In other words, tourist destinations are constantly changing socio-spatial constructions, their identities being perpetually reproduced and questioned. ${ }^{193}$ Internally, new identities are being created and old ones adjusted, but external sources play a crucial role in this process as well. ${ }^{194}$ This thesis will examine the socio-spatial construction of Wales as a distinct entity in Continental guidebooks by building on two central concepts which are closely related: discourses and imaginative geographies. These theoretical frameworks and their significance for tourism, guidebooks and Wales will be discussed below.

\footnotetext{
${ }^{191}$ David Ley, 'Behavioral Geography and the Philosophies of Meaning', in Behavioral Problems in Geography Revisited, ed. by Kevin R. Cox and Reginald G. Golledge (New York: Methuen, 1981), pp. 209-30 (p. 219).

${ }^{192}$ Greg Ringer, 'Introduction', in Destinations: Cultural Landscapes of Tourism, ed. by Greg Ringer (London: Routledge, 1998), pp. 1-13 (p. 7).

${ }^{193}$ See: Velvet Nelson, 'The Construction of Slovenia as a European Tourism Destination in Guidebooks', Geoforum, 43 (2012), 1099-110 (p. 1099). See also: Anssi Paasi, 'Region and Place: Regional Identity in Question', Progress in Human Geography, 27 (2003), 475-85; Jarkko Saarinen, "'Destinations in Change": The Transformation Process of Tourist Destinations', Tourist Studies, 4 (2004), 161-79.

${ }^{194}$ Nelson, p. 1100.
} 


\title{
1.3.1 Guidebooks and Discourses
}

Discourses, being socially and historically constructed systems of meaning, play a crucial role in shaping these shifting destination identities. They reflect, as well as construct, our knowledge of a certain topic and the way we talk about it, and also form the basis of social practices which influence our actions and policies. Therefore, discourses about place can be argued to be performative; they contribute to the creation of the matters of which they speak. As Jaworski and Pritchard aptly point out in their work on the relationship between tourism, communication and discourse:

\begin{abstract}
Discourse, including language, defines experience and performance, and by empowering action or inaction, naturalises social relations. But discourse and communication are also products of social relations and we need to explore and understand how their meanings have been constructed and used across the totality of human experience - and that includes tourism experience. ${ }^{195}$
\end{abstract}

Guidebooks, as important influencers of tourists, their experiences and expectations, must therefore be regarded as significant constructors of meaning. A comparative diachronic analysis of Continental guidebooks will therefore shed light on the construction of Wales as a tourist destination and Welshness as a tourist commodity through these texts. As discourses are not fixed, but change over time whilst continuously shaping our ways of seeing the world and influencing our practices, ${ }^{196}$ following the changing representations of Wales through various historical stages will elucidate the Continental construction of a touristic Wales. As Jarkko Saarinen, who specialises in tourism geography, rightly asserts: '[D]iscourses map, construct and distinct [sic] a world meaningful to us, including the world of tourism'. ${ }^{197}$ In his article "Destinations in Change", Saarinen examines the role of discourses in the changing construction of tourist destinations, and argues that tourism discourses have a dual nature. On the one hand, they shape our (immaterial) knowledge and understanding of a tourist destination, but on the other hand they influence tourism practices and policies, thus shaping the actual (material) tourism landscape. It is in

\footnotetext{
195 Annette Pritchard and Adam Jaworski, 'Introduction: Discourse, Communication and Tourism Dialogues', in Discourse, Communication and Tourism, ed. by Adam Jaworski and Annette Pritchard, Tourism and Cultural Change, 5 (Clevedon: Channel View Publications, 2005), pp. 1-16 (p. 2).

${ }^{196}$ See: Michel Foucault, Power/Knowledge: Selected Interviews and Other Writings, 1972-1977, ed. by Colin Gordon (Harlow: Prentice Hall, 1980).

${ }^{197}$ Saarinen, p. 167.
} 
the immaterial aspect of the discursive formation that tourism literature, including travel guidebooks, plays an important role. Saarinen states: 'The main factors comprising the discourse of region that produces the (immaterial) idea of a tourist destination include travel, tourism and regional literature, tourist maps, guide books, tourist advertisements, the Internet, movies, TV shows and the media in general' ${ }^{198}$ Guidebooks thus play a role in the reproduction of the discourse that determines the socio-spatial identity of a destination. ${ }^{199}$ However, at the same time travel guides are reflections of external constructions, negotiations and contestations produced by other agents, and in other texts and media. It can therefore be argued that they are manifestations of wider issues of power, but simultaneously also powerful constructors of meanings and place perceptions.

Such manifestations of power in guidebooks have been examined in various studies by using discourse analysis. In her analysis of the Lonely Planet guidebook to India, Deborah Bhattacharyya for example concludes that this guide reinforces an Orientalist view of India which is based on the remnants of a colonial discourse of the country's past glory and present exoticism. ${ }^{200}$ She reveals that the guidebook does not provide any moral guidelines for the Western traveller, but does scrutinise Indian culture and customs. These, Bhattacharyya shows, have to be in the service of the traveller; if they are not, they are criticised. Moreover, British colonial rule is depicted relatively positively, whereas Indian uprisings during this period are condemned. As a result, age-old uneven colonial power relations between 'superior' Westerners and 'inferior' Indians are maintained.

Although Velvet Nelson's study deals with a different country, Slovenia, her findings can be compared to those of Bhattacharyya. Her analysis also reveals that guidebooks uphold old power relations, in her case the dichotomy dividing East (Communist) and West (Capitalist) Europe. Within this division, the idea of Eastern Europe as the unstable and backward side of the Continent is perpetuated, whilst it is implied that the West is superior. ${ }^{201}$ As a result, Nelson asserts that 'Slovenia will continue to be associated with the negative external perceptions based on the persistent Eastern European discourse' ${ }^{202}$ Another study undertaken by Scott

\footnotetext{
${ }^{198}$ Saarinen, p. 167.

${ }^{199}$ See also: Pritchard and Morgan, p. 111.

${ }^{200}$ Bhattacharyya, p. 383.

${ }^{201}$ Nelson, pp. 1104-5.

202 Nelson, p. 1106.
} 
Laderman has also contended that guidebooks maintain the old division of 'bad', 'inferior' Communists and 'good', 'superior' Capitalists. In his examination of guidebooks to Vietnam, Laderman argues that guidebooks affect the construction of historical memory, and in his analysis he convincingly shows that guidebooks still depict the American intervention in Vietnam as a heroic and altruistic deed.

According to Laderman: 'The discourses identified in the guidebooks reveal that the U.S. role in Indochina has been viewed largely through a Cold War lens of antiCommunism that assumes American benevolence'. ${ }^{203}$ As a result, old and superseded notions about the war and the role of the West are preserved through these texts and eventually shape contemporary interpretations of the historical events.

Whilst the discourses examined in these examples are based on actual historical events, guidebooks have also been shown to be based on fictional discourses. In her article 'Romantic Horizons: Fact and Fiction in the Guidebook to Scotland', Churnjeet Mahn explores the role of guidebooks in the construction of a Scottish Romantic ideal in the nineteenth century. According to Mahn, it was due to the claim of being based on eyewitness accounts that the guidebooks managed to convince their readers of their factuality, even though their portrayal of the country was based on romanticised fictional accounts. Mahn contends that by referring to famous Romantic writers and by using their vocabulary to describe certain places whilst simultaneously posing as factual accounts of a certain area, the guidebooks eroded the space between romance and reality. ${ }^{204}$ Consequently, Scotland became conceptualised in the tourist imagination as a highly romanticised fictional place. Mahn contends that these nineteenth-century portrayals of the country have influenced the tourist industry of Scotland up to the present day, and have even affected the construction of a Scottish national identity:

[Nineteenth-century guidebooks] illustrate how the images and stereotypes which essentialise Scottish identity, an identity consistently irreducible to those elements, came into being. The guidebook offered a discursive formation with a new power to authorise fiction as fact, to be more 'real' than the real. ${ }^{205}$

\footnotetext{
${ }^{203}$ Scott Laderman, 'Shaping Memory of the Past: Discourse in Travel Guidebooks for Vietnam', Mass Communication and Society, 5 (2002), 87-110 (p. 95).

${ }^{204}$ Mahn, p. 9.

205 Mahn, p. 11.
} 
For the research at hand, Mahn's study offers a rare example of an examination of the portrayal of a Celtic country found in guidebooks. Discourses concerning colonial rule or the dichotomy dividing the Communist East and Capitalist West will most likely not play a major role in the material used in this research, whereas Romantic fictions about the country and their (re)production in guidebooks may be expected to form part of the discourses used in the Continental guidebooks about Wales. Further examination of the primary material is needed for this, which will be undertaken in Chapters 3 to 5. Chapter 2 will focus on the romantic conceptualisation of Wales by British travellers.

To summarise, destinations are socio-spatial constructions which are shaped, transformed and endowed with meaning by external as well as internal actors. Discourses play a crucial part in this, as they affect our understanding of the world and the way we justify, devise and carry out our actions. As tourism plays an important role in the construction of destinations, guidebooks must also be regarded as having a considerable influence in perpetuating, preserving and changing destination discourses. These texts can arguably strengthen discourses which divide the world according to a dichotomy from a bygone age (the colonial period, the Cold War), but they can also help shape new discourses that influence the destination's identity and its image as a tourist area. Examining this process of the discursive formation is vital since, to use Bhattacharyya's words: 'The guidebook is a crucial part of the touristic process, because it mediates the relationship between tourist and destination, as well as the relationship between host and guest. [...] The guidebook provides a cognitive framework for perceiving India and for interpreting what one perceives'. ${ }^{206}$ Drawing from Bhattacharyya's conclusions and the previously discussed studies, it can be contended that guidebooks, in their role as spatial and cultural mediators, have the ability to perpetuate and shape discourses which divide the world in a discursive dichotomy of 'us' and 'them', 'domestic' and 'exotic', and 'self' and 'other'. These antitheses inevitably imply the existence of borders between them, which will be further explored in the following section.

${ }^{206}$ Bhattacharyya, p. 372. 


\subsubsection{The Imaginative Conceptualisation of Places}

Within the general theoretical framework of discourses and the socio-spatial construction of destinations, the concept of 'imaginative geographies' might prove to be illuminating in the analysis of Continental guidebooks on Wales. The concept was first introduced by Edward Said and has been further developed in a range of academic fields, such as cultural theory, gender studies and human geography. ${ }^{207}$

Said is primarily known as one of the most influential founders of postcolonial studies, for which his seminal work Orientalism ([1978] 1995), based on Foucault's epistemological conceptualisation of discourse, has played a crucial role. In this work, Said explores Western cultural representations of the Orient which have affected and constructed the notion of 'the East' in the Western world. Taking the notions of 'the Occident' and 'the Orient' as his geographical focal points, Said claims that geographical and cultural entities are man-made; they are not naturally occurring phenomena, but are rather constructed through popular discourses which create relations of power between self and other. ${ }^{208}$ This argument is based on Foucault's principle that knowledge constitutes power: to have knowledge about something means to have the ability to dominate it and to have authority over it. As Said argues throughout Orientalism, the West has constructed the idea of the Orient whilst removing the latter's own voice and always speaking on its behalf.

Many studies on travel writing have used Said's theories and concepts in order to reveal uneven power relations between travellers and hosts. A prime example of such a study is Mary Louise Pratt's Imperial Eyes: Travel Writing and Transculturation in which the way travel writing has constructed images of the world outside Europe for European readers is critically investigated and unequal power relations are exposed. ${ }^{209}$ Although postcolonial studies on travel writing have changed the way we read these accounts and have indelibly altered the academic

\footnotetext{
${ }^{207}$ For example: Writing Women and Space: Colonial and Postcolonial Geographies, ed. by Alison Blunt and Gillian Rose (New York: Guilford Press, 1994); Joanne P. Sharp, Geographies of Postcolonialism: Spaces of Power and Representation (London: SAGE Publications, 2009). ${ }^{208}$ Said, Orientalism, p. 5.

${ }^{209}$ Many later studies have built on Pratt's work, for example: Leonard Guelke and Jeanne Kay Guelke, 'Imperial Eyes on South Africa: Reassassing Travel Narratives', Journal of Historical Geography, 30 (2004), 11-31. Postcolonial studies on travel writing from a gender perspective have also abounded, for example: Alison Blunt, Travel, Gender and Imperialism: Mary Kingsley and West Africa (New York: Guilford Press, 1995); Cheryl McEwan, Gender, Geography and Empire: Victorian Women Travellers in West Africa (Aldershot: Ashgate, 2000); Sara Mills, Discourses of Difference: An Analysis of Women's Travel Writing and Colonialism (London: Routledge, 1991).
} 
field of travel writing, it is not this aspect of Said's work that has most relevance for the study at hand. A direct colonial relationship has never existed between Wales and the Continent, and to examine Continental guidebooks to Wales through a postcolonial framework would be unfitting. Nevertheless, it must be kept in mind that Continental views of Wales could possibly be altered and influenced by English perceptions of the country expressed in English-language guidebooks, other forms of travel writing or via general public discourse. Moreover, by using Said's conceptualisation of imaginative geographies, issues of hegemony and marginalisation can still be explored without being bound to a strictly postcolonial point of view.

Said's concept of 'imaginative geographies', expounded in Orientalism, provides a more valuable theoretical angle for my guidebook analysis. In the chapter 'Imaginative Geography and its Representations: Orientalizing the Oriental', ${ }^{210}$ Said develops this concept, arguing that the Orient never actually existed as a geographical entity, but was created by the West through depictions in literature, anthropology, geography, sociology and other forms of representation. Resulting from these depictions, the geographical entity known as 'the Orient' became accepted as an objective truth, argues Said. Drawing on Gaston Bachelard's concept of the 'poetics of space', Said illustrates how boundaries are created and endowed with meaning in our minds, and how these facilitate a division between 'us' and 'them'. Therefore, geographical notions such as 'our land' and 'their land' are manmade. ${ }^{211}$ Said explores how the dissemination and the representation of borders through language, culture and institutions endorse them and furnish them with the appearance of given realities rather than invented constructions. In other words, the imaginary becomes accepted as a form of truth. This corresponds to what was stated earlier about destinations being social constructions, rather than fixed entities. It is here that guidebooks play an essential role; they help distribute imaginative geographies by representing the world as an orderly divided place. Moreover, due to their claim of authority and truthfulness, and the willingness of their readers to accept the information that is provided by them and to follow their advice, these works shape the construction of imaginative geographies; their authority legitimises

${ }^{210}$ Said, Orientalism, pp. 49-73.

${ }^{211}$ Said, Orientalism, p. 54. 
their world view. It can thus be claimed that the dissemination of imaginative geographies through guidebooks affects the socio-spatial construction of destinations whilst endowing them with meaning. However, it must be noted that guidebooks alone would not be able to conjure up these boundaries and cause them to become generally accepted truths. Imaginative geographies, as part of wider discourses, draw their robustness from the fact that they are widely and extensively circulated, making other truths difficult to perceive. Nevertheless, by examining the imaginative geographies constructed in guidebooks, a fragment of the discourse can be revealed.

The concept of imaginative geographies has been explored before in relation to travel writing. In Pleasure and Guilt on the Grand Tour: Travel Writing and Imaginative Geography, 1600-1830, Chloe Chard for example investigates the construction of Italy as an imaginative geography in British and French travel writing during the period of the Grand Tour. By examining the language used in travel writing, especially tropes and other stylistic devices, as well as the themes deployed, Chard scrutinises the construction of Italy as a topography of pleasure. Although she does not closely follow Said's definition of imaginative geographies, they both concur that the concept is pivotal for the experience of the traveller and the shaping of a destination, forming a network through which the foreign is defined and understood. $^{212}$

Like Chard, most studies that have been published on the creation of imaginative geographies in travel writing focus on the seventeenth until the early nineteenth century, a period in which the world was explored and divided by powerful, primarily Western nations. In this period, divisions between 'us' and 'them' through the creation of imaginative geographies became crucial to justify the politics of imperialism and colonialism. ${ }^{213}$ Due to this focus on the colonial period, however, the relationship between contemporary travel writing and imaginative geographies has generally remained neglected as a subject of academic research. One

\footnotetext{
212 Chloe Chard, Pleasure and Guilt on the Grand Tour: Travel Writing and Imaginative Geography 1660-1830 (Manchester: Manchester University Press, 1999), pp. 9-14.

${ }^{213}$ See for example: Michael T. Bravo, 'Precision and Curiosity in Scientific Travel: James Rennell and the Orientalist Geography of the New Imperial Age (1760-1830)', in Voyages and Visions: Towards a Cultural History of Travel, ed. by Jas Elsner and Joan-Pau Rubiés (London: Reaktion, 1999), pp. 162-83; Mary B. Campbell, Wonder \& Science: Imagining Worlds in Early Modern Europe (Ithaca: Cornell University Press, 1999); Emma Jinhua Teng, Taiwan's Imagined Geography: Chinese Colonial Travel Writing and Pictures, 1683-1895 (Cambridge, MA: Harvard University Press, 2004); Gayle R. Nunley, Scripted Geographies: Travel Writings by Nineteenth-Century Spanish Authors (Lewisburg: Bucknell University Press, 2007).
} 
quite recent exception is the article 'The Representation of Mongolia in Contemporary Travel Writing: Imaginative Geographies of a Travellers' Frontier' by David Tavares and Marc Brosseau. The researchers intentionally move away from a (post)colonial focus on imaginative geographies, and argue that contemporary travel writing is 'one of today's producers of tomorrow's imaginative geographies', ${ }^{214}$ thus detaching the term from its theoretical background in postcolonialism. Contrary to the view that contemporary travel writing is more or less a continuation of the discourse found in colonial travel writing, ${ }^{215}$ Tavares and Brosseau demonstrate the relevance of contemporary travel writing for the construction of socio-geographical assumptions. They show how Mongolia is imagined as a 'frontier', both physically as well as conceptually, in an age of globalisation and mass-tourism. Mongolia is not only constructed as geographically far away, but also as a land that is immersed in an aura of myth and magic which becomes an important place for the performance of the author's identity as an 'explorer'. 216

There are, to my knowledge, no studies on the construction of imaginative geographies in guidebooks. However, there are a few guidebook analyses that touch upon the concept, even though they do not mention Said nor the term 'imaginative geographies' directly. These examinations are worth scrutinising in more detail, as they have, to some extent, an approach to the material which resembles my own in the analysis of the Continental guidebooks to Wales. In a recent article, Bosse Bergman explores how guidebooks contribute to the articulation of an 'imagined' tourist geography. As a theoretical point of departure, Bergman does not use Said's terminology of 'imaginative geographies' but rather Rob Shields's conceptualisation of social spatialisation, which does draw heavily on the work of both Foucault and Said. According to Shields, the spatial is an ongoing social construction on which hegemonic systems of ideology and practice are grounded: 'Spatial suppositions will be argued to ground a cultural edifice of perceptions and prejudices, images of places and regions, and to establish performative codes, which relate practices and modes of social interaction to appropriate settings' ${ }^{217}$ In his article, Bergman focuses on

\footnotetext{
${ }^{214}$ David Tavares and Marc Brosseau, 'The Representation of Mongolia in Contemporary Travel Writing: Imaginative Geographies of a Travellers' Frontier', Social \& Cultural Geography, 7 (2006), 299-317 (p. 302).

${ }^{215}$ Steve Clark, 'Introduction', in Travel Writing and Empire: Postcolonial Theory in Transit, ed. by Steve Clark (London: Zed Books, 1999), pp. 1-28.

${ }^{216}$ Tavares and Brosseau, p. 312.

${ }^{217}$ Shields, p. 46.
} 
guidebooks published before World War II, justifying his approach of leaving out material published after the 1930s by stating: 'Surely their contribution to geographical imaginations is less important in the massively mediated world and "googled" earth of today than during earlier periods of modernity, mainly even before visual media included photography and the mass production of postcards'. ${ }^{218}$ Although it is doubtlessly true that in the modern world travellers are influenced by many new and different forms of information, it has already been asserted that guidebooks still have a strong influence on tourist perceptions. To so readily discard the possible effect of contemporary guidebooks on the touristic experience seems to be somewhat hasty and simplistic. Bergman subsequently asserts that guidebooks have contributed to the tourist-driven spatialisation of the world by describing different places, nation-states, cities and other localities. He refutes Rudy Koshar's viewpoint that guidebooks have a nationalising effect, ${ }^{219}$ and instead argues that these texts have strengthened the internationalisation of tourism. By assembling geographical areas which did not correspond to officially recognised national borders, guidebooks created an international map of tourist places, Bergman claims. ${ }^{220}$ Examples include guides to transnational places such as the Alps, the Riviera and the Balkans. Bergman claims that through the guidebooks these geographies were consolidated in the touristic consciousness, even though they did not exist as bordered entities, thus contributing to the internationalisation of tourism. This thesis contends that the spatialising role of guidebooks is neither restricted to reinforcing a national travel culture, as is argued by Koshar, nor to the creation of an international one, as Bergman suggests. It is plausible that both processes can simultaneously take place; mass-tourism, and guidebooks as an inherent part of this practice, have evidently contributed to the internationalisation of tourism, but in certain cases have also strengthened national travel cultures. The main point is that guidebooks are able to create and consolidate certain imaginative geographies in the touristic consciousness. They can either highlight national identities and borders or construct new, transnational geographies whilst endowing them with meaning.

\footnotetext{
${ }^{218}$ Bosse Bergman, 'Guides to a Geography of Tourism', Belgeo, 3 (2012), 1-12 <http://belgeo.revues.org/7176> [accessed 3 July 2015].

${ }^{219}$ Koshar, German Travel Cultures, p. 15.

${ }^{220}$ Bergman, p. 6.
} 
Another recent study that investigates the imaginative spatial construction of a destination in guidebooks is the aforementioned article by Velvet Nelson 'The Construction of Slovenia as a European Tourism Destination in Guidebooks'. Nelson examines the socio-spatial formation of the former Communist country Slovenia as a tourist destination in guidebooks. She does not directly use Said's conceptualisation of 'imaginative geographies' as a framework for her research either, but the underlying notion of her research corresponds to his ideas. Coming from a background in human geography, Nelson uses discourse analysis as the basis for her research. As a starting point she states: 'Geographic research in tourism recognizes destinations to be socio-spatial constructions. Discourses about regions and places influence this construction in terms of how destinations are seen and represented, particularly through textual sources such as tourism guidebooks'. ${ }^{221}$ By analysing the collective and conflicting discourses concerning Eastern and Central Europe used in major English-language guidebook series such as Lonely Planet and Rough Guides, Nelson examines the textual construction of Slovenia as a European tourist destination for external audiences. She asserts that although Slovenia, as part of Yugoslavia, was never officially aligned to the Soviet Union, guidebooks continue to define and situate the country in reference to the Iron Curtain and often create an Eastern European identity for the country. Owing to this, the old East-West divide remains a determining factor in the spatialisation of Slovenia, thus perpetuating the country's supposedly non-Western identity even for travellers who were born after the fall of Communism and for whom the East-West division would not be an entrenched frame of mind. ${ }^{222}$ It thus becomes clear, in line with Said's arguments, that tourist destinations and geographies in general are not naturally given, static entities, but are rather socio-spatial constructions. In the same way as Said exposes the imaginative distinction between Orient and Occident, how this eventually became accepted as true and was used to explain our world and its socio-political dynamics, Nelson demonstrates how the dichotomy between Communist East and Capitalist West still determines how we define and divide Europe even a quarter of a century after the fall of Communism.

${ }^{221}$ Nelson, p. 1099. See also p. 59 of this thesis.

${ }^{222}$ Nelson, pp. 1104-5. 
In her research on guidebooks to Poland which was already discussed previously in this thesis, Dybiec also notices the apparent difficulty these texts have in situating Poland within Europe, both geographically as well as ideologically, after the fall of Communism. Having lost its appeal as a country that can offer the tourist a peek behind the Iron Curtain, the American guides seem at a loss regarding how to position Poland as a European tourist destination. Communism had been the main identifying feature of Poland as a tourist destination for the American market, and after its dissolution new ways of interpreting and situating the country had to be found. In the German guidebooks published after 1989, Poland's place within Europe and the division of Europe into a Western and Eastern part is also a central issue. To quote Dybiec: '[T]he guidebooks from the 1990s repeatedly raised the question of Poland's place on the cultural map of Europe, in this way participating in the discourse on the identity of Europe and the relation between its "west" and "east", 223 Dybiec shows that the German guides represented Poland as excluded from Western Europe and that a return to the West would be a demanding task, which would only require sacrifices from the East: 'It was the eastern "periphery", assumed to be less European, of which flexibility and adjustments were required in order to return to the core, whereas the "western" part could remain unchanged'. ${ }^{224}$ Although not explored further in Dybiec's work, the division between 'periphery' and 'core', which she describes here, seems to provide another useful model which could frame the analysis of Continental guidebooks to Wales. As Wales is situated on the periphery of Europe, as well as of Great Britain, and has been dominated by the English hegemonic centre for centuries, looking into this relationship appears instructive for the analysis of guidebooks to Wales, and will therefore be discussed in more detail in the section below. In the exploration of Wales within the dialectics of centre and periphery, the concept of imaginative geographies will be a useful framework. The construction of borders and boundaries between perceived peripheries and centres will be examined, whilst focusing on the conceptualisation of Wales as a tourist destination within the wider geographical context of Great Britain and Europe.

${ }^{223}$ Dybiec, p. 185.

${ }^{224}$ Dybiec, p. 190. 


\subsection{The Correlation between Tourism, Peripherality and Guidebooks}

Tourism is a paradoxical force when it comes to the creation of easily recognisable destinations. On the one hand, it has been argued that international mass tourism 'touristifies' the entire world by making virtually every place accessible to be scrutinised by the tourist gaze. ${ }^{225}$ Tourism, being both a product and producer of globalisation, has progressively connected areas with each other and has enabled a growing number of people (primarily from the Western world but increasingly also from other regions) to explore areas outside of their locality. As a result, boundaries have become blurred and places submerged into global sameness. ${ }^{226}$ On the other hand, however, it has been asserted that the dynamics of tourism are largely based on a quest for difference. ${ }^{27}$ This is all the more pertinent in a globalising world in which places look more and more the same and 'the rhetoric of tourism has been stretched in its attempts to contrive geographical distinctiveness'. ${ }^{228}$ One way of strengthening the uniqueness of an area is to emphasise its regional or national spatial identity, which plays an increasingly important role in tourism marketing and its endeavours to enhance the attractiveness of a specific area. In a globalising world in which differences are waning, cultural identities portrayed through (amongst others) heritage, symbols and customs which are closely linked to a certain place, 'provide an almost inexhaustible supply of material which can be appropriated and adapted for the purpose of creating a distinctive sense of nationhood for tourists' ${ }^{229}$ Identities are thus increasingly used in tourism as commodities to distinguish an area from the rest of the world.

\footnotetext{
${ }^{225}$ Andreea Antonescu and Mathis Stock, 'Reconstructing the Globalisation of Tourism: A GeoHistorical Perspective', Annals of Tourism Research, 45 (2014), 77-88 (p. 77).

${ }^{226}$ Marie-Françoise Lanfant, 'Introduction', in International Tourism: Identity and Change, ed. by Marie-Françoise Lanfant, John B. Allcock and Edward M. Bruner (London: SAGE Publications, 1995), pp. 1-23 (p. 8).

${ }^{227}$ See: Urry, p. 12. The underlying structure and dynamics of tourism have been the object of much academic debate, and the viewpoint that tourism is largely based on a quest for difference is not universally accepted within academia. Adrian Franklin, for example, sees tourism as a method to deal with modernity. In his view, tourism forms an inherent part of our daily lives that enables us to take a stand in the globalising world; see: Adrian Franklin, Tourism: An Introduction (London: SAGE Publications, 2003), pp. 2-5.

${ }^{228}$ George Hughes, 'Tourism and the Semiological Realization of Space', in Destinations: Cultural Landscapes of Tourism, ed. by Greg Ringer (London: Routledge, 1998), pp. 17-32 (p. 18).

${ }^{229}$ Catherine Palmer, 'Tourism and the Symbols of Identity', Tourism Management, 20 (1999), 313 21 (p. 316).
} 
Owing to this, it has been asserted that international tourism can actually help marginalised and 'minoritised' stateless areas to gain recognition on a global level. In the early, yet still important and influential work on identity tourism International Tourism: Identity and Change, Marie-Françoise Lanfant remarks in this respect:

Tourism is a double-edged sword. In certain cases it contributes towards repressing, marginalizing and neutralizing autonomous or resistance movements. In other cases it allows ethnic minorities that have been cut off from international decision-making to claim and assert their identities. ${ }^{230}$

Susan Pitchford's Wales-focused research argues in favour of the latter possibility. In her study Identity Tourism: Imaging and Imagining the Nation, she investigates tourism's potential for (re)shaping images and identities. She contends that tourism, especially identity tourism, can help protect marginalised cultures as it depends on the notion of difference: cultural idiosyncrasies become tourist commodities and therefore valuable and worth preserving. Instead of pursuing a policy of cultural and linguistic standardisation, which is often to the state's advantage, tourism serves in these cases as an incentive to preserve the distinctiveness of lesser-known cultures. ${ }^{231}$ Indeed, the Welsh tourist board has tried to use Wales's language and cultural uniqueness as marketing tools in order to attract overseas visitors. Morgan and Pritchard have observed that whereas distinctive features of Welshness are generally evaluated negatively within the UK, overseas they are regarded as positive additions to the tourist experience. ${ }^{232}$ In other words, overseas tourism marketing has attempted to raise Wales's profile as a distinctive country, different from the rest of the UK. Intranational British borders and differences are therefore highlighted in order to increase Wales's attractiveness as a tourist destination. ${ }^{233}$ Nevertheless, as

\footnotetext{
${ }^{230}$ Lanfant, 'Introduction', p. 6.

${ }^{231}$ Susan Pitchford, Identity Tourism: Imaging and Imagining the Nation, Tourism Social Science Series, 10 (Bingley: Emerald, 2008), pp. 80-81.

${ }^{232}$ Nigel Morgan and Annette Pritchard, 'Culture, Identity and Tourism Representation: Marketing Cymru or Wales?', Tourism Management, 22 (2001), 167-79 (p. 174).

233 The 2016 Visit Wales marketing campaign seemed to have renounced this strategy and focused on the natural features of Wales as well as outdoor activities. In this campaign, Wales was not branded as a culturally or linguistically unique country. The images of the TV advert could have been taken almost anywhere in the world and did not create a sense of distinctiveness for Wales. The campaign was not altered for foreign markets, and could also be found on the German website of Visit Wales under the name 'Das ist Wales' [That is Wales]. See: <http://www.visitwales.com/adventure/tvadvert-2016> [accessed 16 March 2016]; 〈http://www.visitwales.com/de/abenteuer/tv-advert-2016> [accessed 16 March 2016]. However, the 2017 campaign (both for the domestic as well as the German market) again represents Wales as the Land of Legends, highlighting its cultural distinctiveness, see:
} 
has already been noted in the introductory chapter, Wales is still a largely unknown tourist destination. The regional awareness of Wales amongst non-UK respondents is still much lower compared to the other parts of the UK. ${ }^{234}$ The success of these international marketing campaigns therefore remains doubtful. In 2015, Visit Wales invested one and a half million pounds in a campaign to promote Wales in Germany, as this country was identified as one of three most promising target markets for the Welsh tourism sector (together with Ireland and the USA). The aim was to 'raise Wales' profile and inspire consumers to visit Wales'. ${ }^{235}$ Further research and tourism surveys are needed to examine whether Wales's profile has indeed been raised due to these efforts.

The question remains why Wales has hitherto remained such an unfamiliar destination for many Europeans. As was already discussed in the introductory chapter of this thesis, several scholars have attempted to identify a guilty party, but these explanations have remained rather one-sided. A study that provides a more multifaceted approach to the connection between Wales, its invisibility and tourism, and which reaches more nuanced conclusions, is 'Perceptions from the Periphery: The Experience of Wales' (2000), by David Botterill, Nicola Foster and others. This research connects Wales's peripheral location on the western edge of Great Britain and Europe with its perceived indistinctiveness in the eyes of many Continental tourists. The researchers argue that Wales is a typically peripheral area, which implies more than merely the geographical location of the country on the European fringes next to its hegemonic neighbour England. Additional factors that are also said to count towards the country's peripheral status are: an urbanisation that is centred around moderate-sized towns, relatively poor (albeit improving) transportation links, and the country's comparatively weak economy that is largely based on traditional industries and tourism. ${ }^{236}$ It must be noted that this analysis of Wales's economy is somewhat dated, as traditional industries in Wales, such as the iron and steel industry, have decreased sharply during the past twenty years and are no longer the main trades of the country. Whereas in 1995 there were still 15,420 people employed

<http://www.visitwales.com/legends/tv-advert-2017> [accessed 4 May 2017];

$<$ http://www.visitwales.com/de> [accessed 4 May 2017].

${ }^{234}$ Visit Britain, Overseas Visitors to Britain, p. 46.

${ }^{235}$ Welsh Government, 'News and Alerts: Visit Wales Germany Marketing Campaign',

<http://content.govdelivery.com/accounts/UKWALES/bulletins/e80dd2> [accessed 16 March 2016].

${ }^{236}$ Botterill, Foster and others, pp. 11-12. 
in this sector, this number had dropped to 6,630 in 2015; a decline of almost sixty per cent. ${ }^{237}$ The service sector, on the other hand, is growing rapidly in Wales; faster than anywhere else in the UK. ${ }^{238}$ Nevertheless, it can still be contended that Wales is a peripheral area due to the presence of the other characteristics mentioned above. Moreover, the service industry is primarily centred in Cardiff and its direct surroundings, and is therefore not evenly represented throughout the country.

Subsequently, Botterill's team discusses five case studies which explore the relationship between Wales, its peripheral status and tourism. In one of these, Nicola Foster investigates Wales's peripherality and its connection to the country's low profile amongst overseas tourists. She sees a direct correlation between these two, since a peripheral status has significant implications for 'destination information flows' ${ }^{239}$ According to her research, which confirms what has been already been noted about the international perception of the country, Wales is not perceived negatively abroad, but there appears to be a gap in the awareness of Wales, and she consequently contends that ' $[\mathrm{b}] \mathrm{y}$ nature, awareness must precede image' ${ }^{240}$ Foster attributes this lack of awareness and resulting perception gap to weak 'destination information flows'; in her view, Wales is not sufficiently marketed abroad and does not have a strong commercial supply of products overseas (for example comparable to Scottish whisky). ${ }^{241}$ It cannot be denied that these factors play an important role in the lack of awareness concerning Wales, but Foster's explanation does seem quite one-sided as it does not incorporate information flows that originate from the tourists' country.

Although Foster does not directly point this out, destination information flows are not one-way monologues, but should rather be understood as dialogues. On the one hand, tourism marketing, international promotion of Welsh products and

\footnotetext{
${ }^{237}$ Welsh Government: Stats Wales, 'Iron and Steel Production by Year, Measure and Area' $<$ https://statswales.wales.gov.uk/Catalogue/Business-Economy-and-Labour-Market/EconomicIndices/Indices-of-Production-and-Construction/ironandsteelproduction-by-year-measure-area> [accessed 16 March 2016].

${ }^{238}$ Sion Barry, 'Wales' Financial Services Sector is the Fastest Growing in the UK', WalesOnline, 29 January 2016 <http://www.walesonline.co.uk/business/business-news/wales-financial-services-sectorfastest-10808675> [accessed 16 March 2016].

${ }^{239}$ Botterill, Foster and others, p. 19. This terminology refers to the information about a certain destination that is available for (overseas) tourists. It is not solely limited to tourism marketing, but also includes products that are associated with the country (e.g. Scottish whisky) and other forms of knowledge that are disseminated about the area in question.

${ }^{240}$ Botterill, Foster and others, p. 20.

${ }^{241}$ Botterill, Foster and others, p. 21.
} 
other forms of destination information disseminated from Wales influence the image of the country abroad. At the moment, these flows are weak, but they could play a more important role in the foreign perception of Wales if they were stronger and projected a clearer image. On the other hand, however, it has already been contended that destinations are shaped and constructed by outsiders as well and this process should therefore be seen as a two-way interchange. It is here that guidebooks come into play, influencing tourist expectations whilst providing the tourist with information about the country in question. Guidebooks have an important role in the articulation of a tourist geography and the socio-spatial construction of a travel destination. At this stage, it is still unclear how these information flows interact with each other and whether their influence on destination perception is equal or not. However, as the information flows disseminated from Wales are generally weak, the role of the guidebooks therefore increases. Since tourists are not being furnished with strong images and knowledge originating from Wales, it can be argued that the textual and visual images presented to them in the guidebooks play a progressively important role. In other words, tourists lack countering information that could incite them to evaluate the guidebooks' information more critically. These assumptions are still conjectural and more reader-response research needs to be done in this area. However, as it was already established that guidebooks influence tourist perceptions to a great degree, it can be contended that this influence is all the more extensive when the information flows deriving from the destination itself are lacking.

In his work Places on the Margins, Rob Shields also investigates the social construction of marginal areas. He asserts that the cultural periphery is constructed in relation to a core, which together form a hierarchical system of centres and peripheries. ${ }^{242}$ Peripherality is therefore more than a checklist of geographical and economic characteristics, or a lack of information flows, but is rather actively created. This concurs with the notion that peripherality is mainly a matter of perception. ${ }^{243}$ Even though economic, geographical and sociological factors might contribute to the classification of an area as peripheral, as long as this is not perceived it cannot be designated as such. As Brown and Hall state in their work on

\footnotetext{
${ }^{242}$ Shields, p. 3.

${ }^{243}$ Frances Brown and Derek Hall, 'The Paradox of Peripherality', in Tourism in Peripheral Areas: Case Studies, ed. by Frances Brown and Derek Hall, Aspects of Tourism, 2 (Clevedon: Channel View Publications, 2000), pp. 1-6 (p. 3).
} 
tourism in peripheral areas: 'The peripheral destination may possess symptoms of peripherality, but relies on the subjective interpretation of these symptoms by the tourist, while simultaneously the tourist will not perceive an area as peripheral without certain symbols of peripherality being present' ${ }^{244}$ Drawing on this idea, whilst connecting it to Said's concept of imaginative geographies, the term 'imaginative peripheries' might be suggested. This adds a new dimension to Said's theory, which primarily focuses on the creation of geographies within a framework of uneven power relations in which the hegemonic party determines the geography of the other within a colonialist setting. By incorporating the concepts of peripherality and peripheralisation, Said's terminology could also be used to understand the conceptualisation of peripheral areas and their construction as places outside of time and reality. By examining how borders and boundaries (both geographically as well as historically and culturally) are constructed, the creation of imaginative peripheries can be revealed. As peripheries are normally constructed in relation to a core, it is especially important to examine the borders that are created between them.

Guidebooks influence tourist expectations and perceptions of destinations, and thus play a crucial role in the, for lack of a better term, 'peripheralisation' of an area. By for example describing a stateless, marginal nation such as Wales in a single volume, a guidebook can heighten the tourist's awareness of geographical and cultural boundaries surrounding the area, thus creating an understanding of the country as a distinct cultural and historical entity, instead of merely being a periphery of a core area. As such, stateless, peripheral nations could be given a place on the tourist map, which could eventually lead to an increase in the nation's visibility on the socio-cultural and political map. Conversely, guidebooks also have the power to increase the peripherality of an area. By, for example, emphasising the physical remoteness of the area, which can add to its attractiveness as a tourist destination, or by underlining other aspects of peripherality, such as underdeveloped transportation links, it can be turned into a defining feature of the area. This does not imply that guidebooks cannot fulfil both functions; they can heighten the profile of a stateless nation as a distinctive entity whilst simultaneously stressing its peripherality as the foremost aspect of the country's attractiveness as a destination.

${ }^{244}$ Brown and Hall, p. 3. 
It is this tension between Wales's perceived status as a separate entity within the UK and its position on the fringe of Europe and Great Britain that will be a guiding theme throughout this thesis. The differences between the guides in the various languages and the chronological changes within this depiction will be scrutinised. How is Wales put on the touristic map of Great Britain and Europe, particularly within the historical context of Wales's growing autonomy on a political, as well as cultural level as a country in the process of devolution? Based on the notion that peripherality is always constructed in relation to a core ${ }^{245}$ the relationship between Wales, England and Great Britain, and the position of Wales regarding these areas, will be underlying themes in the research. However, since cores and peripheral areas can also exist within peripheries (as so-called satellites), such internal distinctions will be scrutinised as well. Are certain parts within Wales for example seen as less or more peripheral, and what are the consequences of this in regard to their touristic attractiveness? In other words, this thesis will examine the sociospatial construction of Wales as an imaginative periphery within Europe and Great Britain and especially in relation to England. The creation of the country's imaginative geographical, linguistic and cultural borders will be scrutinised, and how their content is endowed with meaning.

245 Brown and Hall, p. 2. 


\section{2 - Wales as a Travel Destination on the Imaginative Periphery}

\subsection{Introduction}

The aim of the following chapter is to provide a historical and conceptual contextualisation for the analysis of the primary material, which will be undertaken in Chapter 3, 4 and 5. It examines the emergence of Wales as a travel destination and the concepts that played a key role in this. It will be argued that the country was imagined as a peripheral place by visitors from the beginning of its touristic discovery. The development of this discourse of peripherality will be traced, which will lay the foundations for the rest of the thesis. In order to achieve this, the chapter intends to bring together existing studies on the emergence of Wales as a peripheral travel destination and thus partly functions as a literature review.

Two central topics in the following analyses of the guidebooks will be Wales's landscape and the country's supposedly Celtic roots. These have arguably contributed significantly to the peripheralisation of Wales as a travel destination and it therefore seems fruitful to examine these topics and their origins in greater detail, as well as to clarify their importance for the spatial and temporal conceptualisation of Wales. Due to the prominence of these themes in the Continental guidebooks from the nineteenth to the twenty-first century, the question arises from where these images originated and whether they could be part of a larger transnational discourse about Wales.

In order to gain insight into the discursive formation of Wales as a peripheral travel destination, it is necessary to shift the scope of this chapter with respect to place and time. Firstly, due to the relative lack of academic studies on overseas touristic views of Wales, ${ }^{246}$ the focus will lie on British (primarily English) touristic

\footnotetext{
${ }^{246}$ Noticeable exceptions in this respect are: Maurer; Tully, 'The Celtic Misconnection'; Alison Martin, 'Celtic Censure: Representing Wales in Eighteenth-Century Germany', Studies in Travel Writing, 18 (2014), 122-33; Kathryn N. Jones, 'Locating "Pays de Galles" in the Twenty-First Century: Dynamic Model or Forgotten World?', Studies in Travel Writing, 18 (2014), 187-98. The latter two articles have been published in a special issue of the academic journal Studies in Travel Writing, which was edited by Kathryn N. Jones, Carol Tully and Heather Williams, the researchers from the AHRC-funded research project 'European Travellers to Wales: 1750-2010'. As was already mentioned in the introduction of the thesis, this project investigates European perceptions of Wales.
} 
perceptions of Wales. This emphasis on domestic travel can furthermore be justified by the fact that, as Carol Tully has pointed out, early German travellers (the same can be asserted for other Continental travellers) perceived Wales through an English lens: they often stayed with English or anglicised gentry, read informative sources from the English press and only had access to Welsh cultural artefacts through English translations. ${ }^{247}$ English and British travel accounts will therefore provide a contextualising framework for the discourse analysis in the following chapters of the thesis. ${ }^{248}$ At the end of the chapter, this material will be supplemented with academic investigations concerning Continental conceptualisations of Wales as an imagined travel destination. In this section, similarities to and differences from the British views of Wales will be highlighted.

Secondly, in order to scrutinise the emergence of Wales as a (peripheral) travel destination it is necessary to focus on the period of British (and finally German and French) Romanticism, which precedes the thesis's timeframe. During this period Wales was being re-evaluated in respect to its natural landscape, and became geographically imagined as a rural idyll and utopian refuge. Moreover, it was also in this era that a touristic interest in the country's Celtic roots developed, which has remained an important touristic asset for Wales until the present day.

\footnotetext{
For an overview of the project, see: Rita Singer, 'Project Report: Teithwyr Ewropeaidd i Gymru, 1750-2010/European Travellers to Wales, 1750-2010', Journal of Tourism History, 8 (2016), 85-91.

247 Tully, 'The Celtic Misconnection', p. 128. Similar to Tully, Stefan Zimmer contends that Julius Rodenberg's views of Wales, one of the first German Romantics to discover Wales, were also heavily influenced by English perspectives: Stefan Zimmer, 'Julius Rodenberg and Ferdinand Walter: Deutsche Annäherungen an Wales im 19. Jahrhundert', in 150 Jahre 'Mabinogion': Deutschwalisische Kulturbeziehungen, ed. by Bernhard Maier and Stefan Zimmer (Tübingen: Max Niemeyer, 2001), pp. 253-64 (p. 256).

${ }^{248}$ Due to this importance of the English lens and the fact that academic attention seems to concentrate on English conceptualisations of Wales, this chapter will primarily be based on perceptions from this part of Britain. The works of English Romantic writers, such as Samuel Taylor Coleridge and Percy Bysshe Shelley, were highly popular on the Continent and may have influenced Continental perceptions of Wales. However, Scottish writers such as James Macpherson and Walter Scott contributed to the general popularisation of the Celt during the same period, as will be discussed later in this chapter, which may have affected the touristic discovery of Wales on the Continent as well.
} 


\subsection{The Romantic Imaginations of Wales: A Discursive Prelude}

\subsubsection{The Welsh Landscape: From a Country of 'Horrid Rocks' to a Utopian Refuge}

The description of Wales as a peripheral area, both spatially as well as culturally, has been a continuous theme in travel writing for centuries. Prys Morgan for example observes that Giraldus Cambrensis, a travelling twelfth-century royal clerk who accompanied the Archbishop of Canterbury, noted that the Welsh lived secluded in the woods and had their own peculiar customs and laws. ${ }^{249}$ In the centuries that followed, this image does not seem to change dramatically and Wales is repeatedly described as a periphery; an area spatially and culturally removed from the centre. In contrast to later periods, however, this peripherality was regarded as a negative trait; Wales was perceived to be inaccessible, uncivilised and barren. Before the Romantic reappraisal of the country and its inhabitants, there was a persistent stereotype that the Welsh were barelegged and barefooted, poor and generally uncouth. ${ }^{250}$ Despite attempts by the English to 'civilise' (i.e. anglicise) the Welsh after the Acts of Union (1535/1542), the image of the inhabitants of Wales as crude and even bestial persisted well into the eighteenth century. ${ }^{251}$ This impression of the Welsh as a wild and hardened people was directly connected to the landscape of the country which was regarded as harsh and desolate. Daniel Defoe's A Tour through the Whole Island of Great Britain (1991 [1724/27]) is often mentioned by academics in order to illustrate the prevalent negative attitudes towards Wales as a travel destination in the early eighteenth century. ${ }^{252}$ Defoe for example describes Wales as

\footnotetext{
${ }^{249}$ Prys Morgan, 'Wild Wales: Civilizing the Welsh from the Sixteenth to the Nineteenth Centuries', in Civil Histories: Essays Presented to Sir Keith Thomas, ed. by Peter Burke, Brian Harrison and Paul Slack (Oxford: Oxford University Press, 2000), pp. 265-84 (p. 266).

${ }^{250}$ For a concise and illuminating overview of the English perception of its westerly neighbour, see: Morgan, 'Wild Wales'.

${ }^{251}$ See also: Sarah Prescott, Eighteenth-Century Writing from Wales: Bards and Britons (Cardiff: University of Wales Press, 2008), pp. 86-88.

${ }^{252}$ See, for example: Martin, p. 122; Shawna Lichtenwalner, Claiming Cambria: Invoking the Welsh in the Romantic Era (Newark: University of Delaware Press, 2008), pp. 94-95; Jane Zaring, 'The Romantic Face of Wales', Annals of the Association of American Geographers, 67 (1977), 397-418 (p. 401).
} 
a country of 'horrid rocks' and 'full of horror'. ${ }^{253}$ Nevertheless, this negative evaluation of Wales does not extend to the whole country; man-made, cultivated places, such as the industrial area surrounding Milford Haven, are extolled. ${ }^{254}$ This preference for, as John Towner aptly defines them, 'humanised scene[s] of cultivation' was not limited to Wales or Great Britain, but was an aesthetic tendency that could be found all over Europe before the second half of the eighteenth century. ${ }^{255}$

This predilection changed towards the end of that century, and 'a taste for wilder scenes developed - mountains, gorges, waterfalls, forests - and this was to draw visitors into the peripheral regions of Britain, Europe and later North America'. ${ }^{256}$ Therefore, for the first time, peripheral areas became the objects of travellers' desires. This change in taste is generally regarded as a reaction against urbanisation and industrialisation, which led to a re-evaluation of more uncultivated places. ${ }^{257}$ Moreover, infrastructural developments also played an important role, as the increased accessibility of peripheral areas made their discovery physically possible. ${ }^{258}$ One of these places was Wales, which was opened up for tourism due to the completion of turnpike roads and the increasing number of hotels. ${ }^{259}$ In addition to these developments, the possibilities of travelling to the Continent on a traditional Grand Tour had been severely limited between the early 1790s and 1815 as a result of the Napoleonic Wars, which gave a great impetus to the British exploration of their own country. ${ }^{260}$

Peripheral landscapes became therefore consumable and attractive for the increasingly urbanised British traveller. In the case of Wales, two books should be mentioned here that are generally regarded as having significantly influenced the

\footnotetext{
${ }^{253}$ Daniel Defoe, A Tour through the Whole Island of Great Britain, ed. by Philip Furbank, Bob Owens and Anthony Coulson (Yale: Yale University Press, 1991), p. 191.

${ }^{254}$ Defoe, p. 192.

${ }^{255}$ John Towner, An Historical Geography of Recreation and Tourism in the Western World 15401940 (Chichester: John Wiley \& Sons, 1996), p. 139.

256 Towner, p. 140.

${ }^{257}$ See also: Orvar Löfgren, On Holiday: A History of Vacationing (Berkeley: University of California Press, 2002), pp. 19-34; John K. Walton, 'British Tourism between Industrialization and Globalization: An Overview', in The Making of Modern Tourism: The Cultural History of the British Experience, 1600-2000, ed. by Hartmut Berghoff and others (Basingstoke: Palgrave, 2002), pp. 10931.

258 Towner, p. 141.

${ }^{259}$ John Davies, A History of Wales, 2nd edn (London: Penguin Books, 2007), p. 337.

${ }^{260}$ See: James Buzard, 'The Grand Tour and After (1660-1840)', in The Cambridge Companion to Travel Writing, ed. by Peter Hulme and Tim Youngs (Cambridge: Cambridge University Press, 2002), pp. 37-52 (pp. 42-47).
} 
initial popularisation of Wales as a travel destination. Firstly, Thomas Pennant's $A$ Tour in Wales (1778-1783), of whom it has been said that his influence on Welsh tourism can hardly be overstated and who has even been called 'Father of Cambrian Tourists'. ${ }^{261}$ According to Shawna Lichtenwalner, who discusses the Welsh travel writer at length, Pennant managed to reimagine Wales in ways that appealed to the changing preferences of the era: 'In Tour the peasantry was transformed from "uncouth" to "unspoiled" and the landscape becomes "romantic" and "picturesque" rather than horrid. By appealing to contemporary tastes, Pennant was able to change public perceptions of Wales'. ${ }^{262}$ She furthermore contends that Pennant wrote for an English audience and thus appealed to their predilections in particular. Although he praised Wales and the Welsh, their cultural and historical successes were kept in the past, thus eliminating every form of threat that might have emanated from them. Lichtenwalner argues that by repeatedly emphasising Welsh historical insurrections and their defeats, Pennant reinforced the idea of English superiority. ${ }^{263}$ In this respect, Pennant further strengthened the unequal relationship between the English and Welsh, and consolidated the centre-periphery dynamics between the two countries.

Overall, it can doubtlessly be stated that Pennant's work did herald the beginning of a greater touristic interest in Wales in the subsequent decades. Nevertheless, by solely focusing on Pennant, Lichtenwalner fails to notice the importance of a second work which greatly contributed to the discovery of Wales as a travel destination; William Gilpin's Observations on the River Wye, and Several Parts of South Wales, etc. Relative Chiefly to Picturesque Beauty; made in the Summer of the Year 1770 (1782). This work popularised Wales as a Picturesque travel destination. The Picturesque was an aesthetic ideal that developed during the later decades of the eighteenth century, and in which Wales and Gilpin played a central role.

The Picturesque must be seen in relation to two other eighteenth-century aesthetic concepts: the Beautiful and the Sublime. These two notions were elaborated

\footnotetext{
${ }^{261}$ See: Lichtenwalner, p. 98. For a detailed discussion of Pennant's work and its influence on tourism in Wales, see: Lichtenwalner, pp. 98-109. See also: William John Hughes, Wales and the Welsh in English Literature: From Shakespeare to Scott (Wrexham: Hughes and Son, 1924), p. 99; Malcolm Andrews, The Search for the Picturesque: Landscape Aesthetics and Tourism in Britain, 1760-1800 (Aldershot: Scolar Press, 1989), p. 112.

262 Lichtenwalner, p. 98.

${ }^{263}$ Lichtenwalner, p. 102.
} 
in Edmund Burke's Philosophical Enquiry into the Origin of our Ideas of the Sublime and Beautiful (1757), and significantly contributed to the new appraisal of the natural landscape. Whereas man-made forms had been the aesthetic ideal during the previous centuries, natural forms, including mountainous landscapes, became increasingly appreciated. According to Burke, the Sublime triggered a reaction of dread and intimidation, associated with masculinity, whereas the Beautiful caused reassurance and was linked to femininity. Mountainous North Wales became the epitome of Sublimity, furthermore adorned by the chaotic forms of the numerous ruins of castles and abbeys that could be found there. ${ }^{264}$ Snowdonia in particular became a place of 'Sublime negligence', which visitors now began to appreciate. ${ }^{265}$ Mountainous areas were consequently subjected to a radical change in perception. Rather than being 'horrid' and 'full of terror' as they had been for Defoe and his contemporaries, new ways of seeing these landscapes emerged.

However, it was not only mountainous landscapes that were part of the Sublime, as Peter Lord convincingly points out. According to him, industrial landscapes were also integrated in the Sublime aesthetics, since man-made furnaces and mills, which used to be dependent on water power, were often situated next to streams or waterfalls. ${ }^{266}$ William Gilpin himself notes in this respect:

One circumstance, attending this alternacy, is pleasing. Many of the furnaces, on the banks of the river, consume charcoal, which is manufactured on the spot; and the smoke, which is frequently seen issuing from the sides of the hills; and spreading its thin veil over a part of them, beautifully breaks their lines, and unites them with the sky. ${ }^{267}$

The Sublimity of the factories was preferably seen at night, when the lights would make the scenes even more gloomy. It therefore appears as if industry could be incorporated into the Sublime, but the later development of the Picturesque taste, which will be discussed in more detail below, focused on negligence and decay, thus excluding industrial progress again.

\footnotetext{
${ }^{264}$ Andrews, pp. 42-45. Chloe Chard, on the contrary, argues that ruins were seen as feminine during the long eighteenth century: Chard, pp. 133-5.

265 Andrews, pp. 110-1.

${ }^{266}$ Peter Lord, The Visual Culture of Wales: Industrial Society (Cardiff: University of Wales Press, 1998), pp. 20-21.

${ }^{267}$ William Gilpin, Observations on the River Wye, and Several Parts of South Wales, Etc. Relative Chiefly to Picturesque Beauty; Made in the Summer of the Year 1770 (London: R. Blamire, 1782), p. 12 <http://archive.org/details/cu31924104096304> [accessed 15 April 2014].
} 
William Gilpin brought the aesthetic ideals of the Sublime and the Beautiful together in his theoretical discussion 'On Picturesque Beauty' in Three Essays (1792). Whereas harmonious forms were the high point of the aesthetic ideal of the Beautiful, and terrifying and magnificent forms were extolled in the Sublime, the Picturesque combined the two. ${ }^{268}$ Gilpin especially sought scenes worthy of painting (i.e. literally 'picture-esque'), which brought together the harsh forms of the Sublime with the softer lines of the Beautiful. As the title of his earlier mentioned work already indicates, Gilpin considered the Wye Valley as a place of considerable Picturesque potential as it could be converted to a painting straightaway. ${ }^{269}$

In her monograph Grand Tours and Cook's Tours, Lynne Withey describes Gilpin's work as 'enormously influential in shaping English tastes in landscape and art and in popularizing travel to the regions he had visited'. ${ }^{270}$ She subsequently adds that Gilpin's work on the Wye Valley 'unleashed a horde of tourists' in the area. ${ }^{271}$ Although Andrews emphasises that there were already tourists in the Wye area before the publication of Gilpin's tour, he also contends that towards the end of the century it had truly become a touristic area, where boats filled with drawing tables for eager amateur painters were sailing up and down the river. ${ }^{272}$

According to Andrews, Sir Uvedale Price played a pivotal role in further developing the Picturesque taste, since he made a clearer distinction between the Picturesque and the earlier terms Sublime and Beauty in his An Essay on the Picturesque (1794), which was followed by the additional publication under the title 'Volume II' in that same year. ${ }^{273}$ Instead of focusing on grotesque ruins and natural landscapes, like Gilpin had done earlier, Price included more everyday objects in his description of the Picturesque taste. However, they had to be neglected:

\begin{abstract}
Instead of smooth parkland the Picturesque artist will prefer rough pasture; instead of wellshorn sheep, the shaggy goat; and instead of the commissioned Stubbsian portrait of the 'sleek, pampered steed', grooms and jockeys, he will prefer the 'wild forester, and the wornout cart-horse'. The list of new preferences could extend indefinitely. The Picturesque eye is habitually drawn to the humble, uncultivated parts of nature and human society; and that becomes the tourist's goal. ${ }^{274}$
\end{abstract}

\footnotetext{
268 See: Buzard, 'The Grand Tour and After (1660-1840)', pp. 45-47.

${ }^{269}$ See: Andrews, p. 56.

${ }^{270}$ Lynne Withey, Grand Tours and Cook's Tours: A History of Leisure Travel, 1750 to 1915

(London: Aurum Press, 1997), p. 37.

${ }^{271}$ Withey, p. 37.

272 Andrews, p. 89.

${ }^{273}$ Andrews, p. 58.

${ }^{274}$ Andrews, p. 64.
} 
Objects like cottages, old mills, but also people became central to the Picturesque gaze. However, the latter needed to be gypsies or beggars in order to be included; they had to be 'ruined humans'. ${ }^{275}$ Andrews subsequently adds that Picturesque painters and tourists were looking for humbler, more rural ways of life.

Aesthetic movements such as the Sublime and the Picturesque stimulated the popularisation of certain areas in Wales significantly (most noticeably the Wye Valley, but also Snowdonia). However, these changing predilections must be seen within the context of a broader Romantic sensibility which emerged in Great Britain and other European regions during the end of the eighteenth and the first half of the nineteenth century. This era must be regarded as a turning point in the perception of Wales, which gradually became imagined as the epitome of natural beauty, a spiritual sanctuary and a source of moral superiority. Although Mary-Ann Constantine argues that Wales has been severely neglected in studies on the Romantic period and is correct in pointing out this gap, there are a few seminal studies on the subject which will be discussed here. ${ }^{276}$ To begin with, both Jane Zaring's article 'The Romantic Face of Wales' and Prys Morgan's book chapter 'Wild Wales: Civilizing the Welsh from the Sixteenth to the Nineteenth Century' provide useful overviews of the changing evaluation of Wales and the Welsh by outsiders.

Although published some forty years ago, Zaring's study is still relevant for the research at hand, as she also employs a socio-geographical framework for her analysis. In her article, Zaring follows the changing perceptions of Wales, its landscape and its inhabitants, and compares the image projected by outsiders with the actual agricultural, industrial and demographic changes that took place in the country during this time. She also contends that until the end of the eighteenth century, Wales was seen as a desolate place, and refers to Defoe to illustrate her argument. She rightly identifies the Romantic period as an era of remarkable change in the perception of Wales, and illustrates this by referring to portrayals of the country by various authors, some of which will be discussed in more detail later in this chapter. Zaring then moves on to show that according to agricultural surveys taken at the

\footnotetext{
${ }^{275}$ Andrews, p. 59.

276 Mary-Ann Constantine, 'Beauty Spot, Blind Spot: Romantic Wales', Literary Compass Online, 5 (2008), 577-90 <DOI: 577-9010.1111/j.1741-4113.2008.00546.x> (p. 577).
} 
time, Wales was not at all the Romantic, natural, solitary refuge these visitors claimed it to be. Instead, the country was rapidly industrialising and urbanising. These developments were drastically changing the landscape as well as the demographics of the country: '[A]t the time when the Romantics discovered Wales, seeing it as a wilderness where simple Celtic peasants pursued an age-old, pastoral calling, Welshmen revolutionized their agriculture'. ${ }^{277}$ According to her, visitors often simply ignored these modernisations and instead focused on what they wanted to see. ${ }^{278}$ What Zaring attempts to prove in this article is that perceptions of the landscape are often not in agreement with the geographical reality: '[E]ighteenth and early nineteenth century views of Wales illustrate vividly the powerful way in which the eye of the beholder sees through the lens of the contemporary weltanschauuung, ${ }^{279}$ As an early study in the field, Zaring shows that Wales and its landscape were being imagined differently in various decades, and that this had more to do with changing cultural currents than with the socio-graphical reality of the country.

As does Zaring, Prys Morgan traces the changes in the perceptions of Wales, primarily amongst English visitors, and argues that before the Romantic period, the Welsh were seen as 'strange poverty-stricken neighbours with odd customs and manners, who lived in a repellent landscape of hills and mountains', but that this image radically changed towards the end of the eighteenth century when Wales became perceived as the pinnacle of the Picturesque. ${ }^{280}$ Unlike Zaring, however, who maintains that travellers simply ignored the modernising changes in Wales, Morgan contends that travellers were well-aware of the country's transformation. According to him: "Wales was divided into two ill-defined zones, an "outer Wales", which was in a state of rapid industrialization and modernization, and an "inner Wales" - the real object of Romantic expeditions'. ${ }^{281}$ Morgan subsequently asserts that 'the object of English Romantic travel, was, at least after 1800, being gradually confined to certain regions, while other parts of Wales were being developed, modernized, and, in a material sense, civilized' ${ }^{282}$ Although both Zaring and Morgan contend that the

\footnotetext{
277 Zaring, p. 414.

${ }^{278}$ Zaring, p. 409.

279 Zaring, p. 398.

${ }^{280}$ Morgan, 'Wild Wales', p. 270.

${ }^{281}$ Morgan, 'Wild Wales', p. 276.

${ }^{282}$ Morgan, 'Wild Wales', p. 277.
} 
industrialising areas of Wales were not of interest to the Romantic traveller, their explanations of the way visitors dealt with the inherent differences of the country vary. Whilst Zaring argues that travellers simply did not perceive Wales's industrialisation because they were only able to view the country through the prism of Romanticism, Morgan claims that travellers consciously chose to direct their gaze towards those parts of the country that corresponded to their preconceived notions of the destination. Both articles, however, show that Wales was not perceived as a clear socio-cultural entity, but was rather conceptualised as a patchwork of different spaces which could be endowed with a range of identities and connotations.

Another important academic contribution to the study of perceptions of Wales during the Romantic period is Damian Walford Davies and Lynda Pratt's edited volume Wales and the Romantic Imagination. The aim of this collection is to bring together essays on the figuring of Wales by natives and visitors and to 'reconfigure our notions of centre-margin relations'. ${ }^{283}$ According to the two editors, the volume contests the notion that Wales was seen as remote, peripheral and backward, and instead argues that it was often situated in an international context, creating transcultural interconnectedness: 'Wales was viewed by Romantic authors through the lens of a cosmopolitan imagination, and Wales and the Romantic Imagination seeks to bring that sense of transcontinental interrelation back into focus' ${ }^{284}$ However, when the individual contributions are scrutinised, it can be contended that imaginative peripherality, both geographically as well as culturally, was the primary reason for the popularity of Wales as a Romantic travel destination.

For example, Samuel Taylor Coleridge and Robert Southey, two prolific Romantic writers and political radicals, wanted to establish a Pantisocratic commune, a utopian cooperative based on equality. Instead of the initial plan to found this commune in America, which turned out to be unfeasible due to a lack of funds, Southey suggested Wales, which was apparently imagined to be fit for such an idealistic undertaking. For Southey, Wales was 'full of imaginative potential. It was a place in which longings could be realized and social and literary experiments put into

\footnotetext{
${ }^{283}$ Damian Walford Davies and Lynda Pratt, 'Introduction: Devolving Romanticism', in Wales and the Romantic Imagination, ed. by Damian Walford Davies and Lynda Pratt (Cardiff: University of Wales Press, 2007), pp. 1-12 (p. 5).

${ }^{284}$ Walford Davies and Pratt, 'Introduction', p. 5.
} 
practice', as Lynda Pratt asserts. ${ }^{285}$ The fact that Southey chose Wales for his political utopia suggests that he perceived Wales as a place where everything was possible, untouched by the strictness and formalities of London etiquette and political life. Even though the establishment of the commune never went ahead, Southey kept visiting the country, considered settling there and greatly invested in Welsh history and culture (as is reflected in his poem 'Madoc'), which shows that Wales greatly appealed to him as an imaginative place and source of inspiration.

Similar to Southey, other Romantic writers also saw Wales as a political alternative to England. As David Chandler argues in his article 'Walter Savage Landor and Wales in the 1790s', the young Landor fled from his parental home and English politics to Wales. Like Southey, he also did not settle in Wales, but returned to the country on multiple occasions and spent some years in South Wales to find peace and solitude. ${ }^{286}$ Initially, he had imagined the Welsh to be a defiant people, who would be willing to fight for their freedom. This image matched his own desires to get away from London and English political life. However, as Chandler points out, Landor eventually realised that this idea of Wales and the Welsh was merely his own invention, which led to his disappointment in the country and its inhabitants. ${ }^{287}$ Percy Bysshe Shelley can also be rated amongst such Romantics who viewed Wales as a space suitable for social reform. In his contribution “"One Draught from Snowdon's Ever-Sacred Spring”: Shelley's Welsh Sublime', Cian Duffy examines the relation between Wales's landscape and Shelley's perception of the country as a place for individual revitalisation as well as political changes. Like the Romantic writers discussed previously, Shelley also regarded Wales as a political space that could oppose the London regime. ${ }^{288}$ Duffy convincingly illustrates how Shelley used Wales's sublime landscape to artistically express his own inner turmoil, whilst also using it as a political allegory against the "corrupt establishment based in and

\footnotetext{
${ }^{285}$ Lynda Pratt, 'Southey in Wales: Inscriptions, Monuments and Romantic Posterity', in Wales and the Romantic Imagination, ed. by Damian Walford Davies and Lynda Pratt (Cardiff: Cardiff University Press, 2007), pp. 86-103 (p. 87).

${ }^{286}$ David Chandler, 'Walter Savage Landor and Wales in the 1790s', in Wales and the Romantic Imagination, ed. by Damian Walford Davies and Lynda Pratt (Cardiff: Cardiff University Press, 2007), pp. 141-60 (p. 146).

${ }^{287}$ Chandler, pp. 145-9.

${ }^{288}$ Cian Duffy, “'One Draught from Snowdon's Ever-Sacred Spring”: Shelley's Welsh Sublime', in Wales and the Romantic Imagination, ed. by Damian Walford Davies and Lynda Pratt (Cardiff: Cardiff University Press, 2007), pp. 180-98 (p. 182).
} 
represented by London'. ${ }^{289}$ Although Lichtenwalner does not highlight Shelley's political imaginations of Wales, she too asserts that the poet projected his own wishfulfilments onto Wales which had nothing to do with reality, but merely reflected the changes of his own state of mind. ${ }^{290}$

From these studies, it appears that several Romantic travel writers imagined Wales as a utopia, a space where revolutionary dreams could come true and where one could change the existing order of things. At first, this seems to be in stark contrast with the perceptions discussed earlier of Wales as an idyllic Picturesque space far removed from industrialisation and urbanisation. However, it can be argued that these imagined versions of Wales ultimately all amount to the peripheralisation of the country. By imagining the country as a political opposite to England, a remote place where one can get away from the social and dogmatic restraints of centralistic London society, Wales is yet again conceptualised as a secluded dream-world, an other to the centre and a tabula rasa which can perform any role the traveller desires. ${ }^{291}$ Instead of perceiving the country for what it really is, wish-fulfilments continue to govern its perceptions.

\subsubsection{Celtic Tourism in Wales during the Romantic Period}

In addition to fringe topographies, a growing interest in more peripheral cultures and people also developed during the second half of the eighteenth century. These were often regarded as exotic and quaint; remnants of older, purer ways of life that had not yet been contaminated by modern society. As a result, the culture and inhabitants of Wales attracted the curiosity and attention of visitors, and the Welsh themselves also began to appreciate and research their literature and language. Prys Morgan remarks that in the eighteenth and early nineteenth century there was an 'outburst of interest in things Welsh and [a] highly self-conscious activity to preserve or develop them'. ${ }^{292}$ New societies were established that devoted themselves to the

\footnotetext{
${ }^{289}$ Duffy, pp. 188-91.

${ }^{290}$ Lichtenwalner, p. 112. See also: Zaring, p. 404.

${ }^{291}$ For more on Wales as a tabula rasa, see: Caroline Franklin, 'Wales as Nowhere: The Tabula Rasa of the "Jacobin" Imagination', in 'Footsteps of Liberty and Revolt': Essays on Wales and the French Revolution, ed. by Mary-Ann Constantine and Dafydd Johnston (Cardiff: University of Wales Press, 2013), pp. 11-33.

292 Prys Morgan, 'From a Death to a View: The Hunt for the Welsh Past in the Romantic Period', in The Invention of Tradition, ed. by Eric Hobsbawm and Terence Ranger (Cambridge: Cambridge University Press, 1992), pp. 43-100 (p. 43).
} 
preservation of ancient Welsh texts and the language, which until then had gradually been confined to oblivion due to centuries of anglicisation. The first official one was the Cymmrodorion, which was founded as early as 1751 and operated from London. Its successor, the Gwyneddigion, was more successful and re-established Welsh traditions such as the Eisteddfod. ${ }^{293}$ Consequently, an antiquarian movement developed, which led to a Welsh eighteenth-century Renaissance. ${ }^{294}$ According to Andrew Davies, English Romantic poets and travel writers were heavily influenced by these antiquarians and used their research as a source of inspiration. ${ }^{295}$

This interest in the past not only led to an academic interest in Welsh traditions within Wales, but also attracted the attention of romantically primed outsiders. This fascination has been referred to as the phenomenon of Primitivism, which Pittock describes as follows:

Primitivism was a high cultural codification of orally based folk culture, which was beginning to suffer large-scale attrition through improved communications, migration to cities, enclosure, clearances and war. Primitivism provided a cultural counterweight to the modernization and rationalization of society encompassed by the Enlightenment through its displays of commitment to the preservation and transmission of the past, particularly the past of Scotland, Wales, Ireland and the outlying regions of England. ${ }^{296}$

Primitivism and peripherality are thus closely linked, as fringe areas were imagined to be strongholds of older and purer societies, and as a result Celticism became one of the main strands of Primitivism, as Pittock subsequently points out. The Celts, long regarded as unwanted aliens with a barbaric language and backward culture, were now 'permitted to be the picturesque representations of both the heroic bedrock and finer feelings of [British] society'. ${ }^{297}$ Primitivism could be incorporated seamlessly into the Romantic conceptualisation of Wales as an unspoilt natural space where modernisation had not yet penetrated, and the image of the Celt was designed to fit into this image of idealised backwardness:

\footnotetext{
${ }^{293}$ Lichtenwalner, p. 17.

${ }^{294}$ See, for example: Prys Morgan, The Eighteenth Century Renaissance (Swansea: Christopher Davies, 1981); Morgan, 'From a Death to a View'.

${ }^{295}$ Andrew Davies, "Redirecting the Attention of History": Antiquarian and Historical Fictions of Wales from the Romantic Period', in Wales and the Romantic Imagination, ed. by Damian Walford Davies and Lynda Pratt (Cardiff: University of Wales Press, 2007), pp. 104-21 (pp. 104-5).

${ }^{296}$ Murray Pittock, Celtic Identity and the British Image (Manchester: Manchester University Press, 1999), p. 36.

${ }^{297}$ Pittock, p. 37.
} 
The construction of the Celt takes place, then, roughly from 1650 to 1850 . That means that it coincides with developments such as the invention of the Sublime, the cult of Nature and the idea of the Noble Savage. All these aspects have been written to the profile of what it meant to be Celtic. The construction of the Celt in itself documents the revolt against rationalism and against the Enlightenment, and the attributes stereotypically ascribed to 'the Celt' have a profile to match. ${ }^{298}$

Literary conceptualisations of the Celt played a crucial role in its popularisation and dissemination. Thomas Gray's poem ‘The Bard' (1757) and Robert Southey's 'Madoc' (1805) are often mentioned in this respect, ${ }^{299}$ and it has been argued that these were influential sources of inspiration for many later poets. ${ }^{300}$ The former in particular is said to have contributed considerably to the discovery of Wales as a Celtic tourist destination. What Macpherson's Ossian did for Scottish tourism and the popularisation of Celtic Scotland, 'The Bard' arguably did for Wales. ${ }^{301}$ Gray dramatises the story of the asserted genocide of the bards by Edward I. The narrative is situated in North Wales, and Andrews claims that ' $[\mathrm{h}]$ ardly any of the later Picturesque tourists to these regions would have been ignorant of it; for it evoked in impassioned lyrical verse the spirit of North Wales, a landscape and culture romantically remote from lowland, sophisticated southern England'. ${ }^{302}$ Prys Morgan even contends that tourists went looking for the place on the banks of the River Conwy where the events of the poem had supposedly taken place. ${ }^{303}$ The wild sublime nature of North Wales was thus further romanticised and popularised as tourists conceived this imagined space as inhabited by ancient, mystical people. They were therefore not only imagining Wales as a remote periphery, but also as inherently spiritual and antiquated.

The thematisation of bards, druids and Celts in (amongst others) Gray's and Macpherson's writing led to an increasing interest in these topics. Whilst these

\footnotetext{
${ }^{298}$ Joep Leerssen, 'Celticism', in Celticism, ed. by Terence Brown (Amsterdam: Rodopi, 1996), pp. 120 (p. 5).

${ }^{299}$ See, for example: Mary-Ann Constantine, “"Viewing Most Things thro’ False Mediums”: Iolo Morganwg (1747-1826) and English Perceptions of Wales', in Romanticism's Debatable Lands, ed. by Claire Lamont and Michael Rossington (Basingstoke: Palgrave Macmillan, 2007), pp. $27-38$ (p. 34); Lichtenwalner, p. 67-92.

${ }^{300}$ Constantine, 'Beauty Spot, Blind Spot', pp. 577-8.

${ }^{301}$ For more on Ossianic influences on Scottish tourism, see: Nigel Leask, 'Fingalian Topographies: Ossian and the Highland Tour, 1760-1805', Journal for Eighteenth-Century Studies, 39 (2016), 18396; Cara Aitchison, Nicola E. Macleod and Stephen J. Shaw, Leisure and Tourism Landscapes: Social and Cultural Geographies (London: Routledge, 2000), pp. 81-83; Katherine Grenier, Tourism and Identity in Scotland, 1770-1914: Creating Caledonia (Aldershot: Ashgate, 2005).

302 Andrews, p. 127.

${ }^{303}$ Morgan, The Eighteenth Century Renaissance, p. 121.
} 
characters had been regarded as barbarians and had not received much attention in previous periods, they now fitted into the Rousseauesque image of Wales and Scotland as places where modernisation and rationalisation were still averted, and where the past appeared to linger. During the end of the eighteenth century, literary images of primitive Celtic bards primed the expectations of travellers, who were delighted to encounter the former during their travels through the country. ${ }^{304}$ However, as Sarah Prescott discusses in her article 'Women Travellers in Wales: Hester Lynch Thrale Piozzi, Mary Morgan and Elizabeth Spence' (2014), the disappointment could be great when these bards did not correspond to their representation by Gray as old men with long grey locks and loose robes. ${ }^{305}$ Prescott convincingly illustrates how the travel accounts of these women were influenced and framed through literary representations of bardic and Celtic culture at the turn of the eighteenth century. By quoting and referencing literary images, they interpreted and gave meaning to what they saw themselves. Although Prescott emphasises that industrialisation and the changing demographic landscape of Wales were not ignored by these women, the idea of Celtic Wales remained a strong framework for perceiving the country.

Overall, it can be contended that the search for ancient cultures, supposedly untouched by modern society, as well as Celticism thus became compelling reasons for travelling to Wales; they became objects of the Romantic tourist gaze. It must be emphasised, however, that most studies on early Celtic tourism have focused on Scotland and Ossian, whilst Wales has remained largely overlooked. More research is certainly needed in this area as further insights into the development of Wales as a Celtic tourist destination could also shed more light on the current touristic views of Wales. Additional studies would for example be desirable to examine the claim that the image of the primitive, colourful Celt is still one of the main reasons for travelling to Wales, ${ }^{306}$ and this thesis aims to contribute to this objective. In the analysis of the primary material which will be undertaken in the following chapters, it will be shown that the Romantic conceptualisation of Wales as a peripheral, natural area, where a Celtic people hold on to their old traditions, resurfaces time and again

\footnotetext{
${ }^{304}$ Andrews, pp. 128-9.

${ }^{305}$ Sarah Prescott, 'Women Travellers in Wales: Hester Lynch Thrale Piozzi, Mary Morgan and Elizabeth Spence', Studies in Travel Writing, 18 (2014), 107-21 (p. 113).

306 Pittock, p. 39.
} 
in Continental guidebooks. Although this image evidently evolves during the course of the twentieth century, and there are clear differences between the Dutch, German and French guidebooks, the Romantic face of Wales has left an undeniable stamp on the representation of the country, its culture and inhabitants.

\subsection{Celticity and Peripherality}

For the current research, this celticisation of Wales is exceedingly important as it contributed considerably to the conceptualisation of the country as an imagined peripheral travel destination. For this reason, the connection between Celticity and imaginative peripherality needs to be scrutinised in more detail at this stage, as this will be a central line of enquiry in the analyses of the primary material in the following chapters.

What most people nowadays understand under the term 'Celtic' is still based on the creative conceptualisation of this term during the Romantic period. That this image is not based on any factuality has become clear from the previous sections, which exposed the Romantic perception of the Celt as resulting from literary invention and the search for older and more simple societies. The Celt as an imaginative concept is most elaborately discussed in Malcolm Chapman's The Celts: The Construction of a Myth. In this work, Chapman more or less follows a chronological approach during which he traces the conceptualisation of the Celtic tradition, culturally, ethnographically and linguistically, through the ages. Overall, he argues that it is a purely imaginary concept, although its interpretation has shifted over time. One aspect has remained constant, though; the Celt has consistently been categorised and identified as an other, thus remaining the creation of an opposite by the centre. Chapman traces the first usage of the term to the ancient Greeks, who used it to refer to non-Greek people living north-west of their borders. ${ }^{307}$ The Romans also identified the people outside of their borders, primarily those east and west of the Rhine, as Keltoi, Galli, Gauls. Until the seventeenth century, Chapman asserts, the connection between the term and the areas now understood to be Celtic had not been established. ${ }^{308}$ With the publication of Edward Lhuyd's Archaeologica

\footnotetext{
${ }^{307}$ Malcolm Chapman, The Celts: The Construction of a Myth (Basingstoke: Macmillan, 1992), pp. 30-32.

${ }^{308}$ Chapman, The Celts, pp. 203-5.
} 
Britannica in 1707, a linguistic connection was made between Welsh, Breton, Cornish and Scottish and Irish Gaelic, and by labelling these languages as 'Celtic' Lhuyd ultimately linked the term to the languages and geographic locations for which it is still used today. He could also have used another label, for example 'Gaulish' or 'British', as Chapman points out, but these already had different meanings and connotations. To some extent, the term Celtic for this language group was therefore arbitrary. ${ }^{309}$

Whether or not the designation of Wales, its language and culture as Celtic is historically correct or not is not the main question here, although Chapman goes to great lengths to deny the term's credibility. More important, and more illuminating, is the way in which this term has been interpreted differently over time and has become inextricably connected with peripherality. ${ }^{310}$ As Chapman emphasises throughout his work, the Celt has consistently been defined by the centre as inhabiting fringe regions, an other lurking behind an imagined border:

[T]he Celts (in their Greek, Roman and English guises) have been on the edge of a more dominant world; indeed, this formulation is close to being a tautology: the Celts have not found themselves by chance on the edges of someone else's world, but have been historically constituted as peripheral, and this condition is a fundamental feature of their definition. ${ }^{311}$

In relation to the centre, the Celts have always been conceptualised as peripheral, marginal and backward, and this relation between self and other has been one of the defining elements of Celticity. Chapman explains the dynamics between centre and periphery by visualising this as a ripple movement; the centre is innovative and modernising, and these advances flow towards the periphery in a ripple-like movement. The periphery, always looking towards the centre for innovations, finally adopts these but by then they have already become old-fashioned. This (albeit relatively simplistic) model explains why the periphery is perpetually perceived as backward. Chapman adds one chapter on Romanticism in particular, which fits in with what has been said about the discovery of Wales as a travel destination during this period. He describes Romanticism as an example of an 'apparent countercurrent' from this ripple. ${ }^{312}$ As has been already argued, towards the end of the

\footnotetext{
${ }^{309}$ Chapman, The Celts, p. 207.

${ }^{310}$ See also: Leerssen, pp. 7-8.

${ }^{311}$ See, for example: Chapman, The Celts, p. 95.

${ }^{312}$ Chapman, The Celts, p. 120.
} 
eighteenth century people started to appreciate the wild nature and primitive culture supposedly still present in Wales. The centre was thus looking at and longing for the periphery instead of the other way around, as Chapman visualises it. However, he emphasises that this re-appreciation takes place in and is thus determined by the centre. Therefore, it is an apparent counter-current, as the periphery remains defined and consumed by others. ${ }^{313}$

Important in the conceptualisation of the Celt is the fact that it has historically been based on opposites: self/other, rule/unrule, controlled/uncontrolled, clean/dirty, modern/backward etc, in which the Celt has traditionally occupied the second half of these dichotomies. ${ }^{314}$ Whilst these characteristics used to be perceived negatively, they became positive attributes during the Romantic period, and this interpretation has defined the Celt up to now. 'Disorder' became 'freedom', 'dirty' and 'backward' transformed into 'natural' and so on. New opposites such as religion/magic and rational/irrational were also added, which contributed to the image of the Celt as a colourful alternative to the rationality of the Enlightenment. ${ }^{315}$ As Chapman points out, these Romantic dichotomies were, and are still, embedded in the opposition Anglo-Saxon/Celt. Consequently, the Celtic fringe areas, including Wales, became idealised as places of wish-fulfilment, opposites to industrialising and urbanising England. ${ }^{316}$ Chapman finally asserts that these imagined contrasts continue to influence modern writers, tourists and urban escapees, ${ }^{317}$ and the following chapters will indeed contend that the conceptualisation of Wales as Romantic other in contrast to Anglo-Saxon England is a central trope in the imaginative peripheralisation of Wales as a tourist destination.

Chapman's exposure of the Celt as an imagined construct has been highly influential in Celtic studies and has affected the way in which concepts such as Celtic, the Celt and Celticity are approached. ${ }^{318}$ Within this debate, there are those who have adopted Chapman's view, for example Simon James who examines the

\footnotetext{
${ }^{313}$ Chapman, The Celts, p. 138.

${ }^{314}$ Chapman, The Celts, pp. 210-1.

${ }^{315}$ Chapman, The Celts, pp. 212-3.

${ }^{316}$ Chapman, The Celts, p. 214.

317 Chapman, The Celts, p. 217.

${ }^{318}$ For some examples of studies building on Chapman's work, see: Moya Kneafsey, 'Tourism Images and the Construction of Celticity in Ireland and Brittany', in Celtic Geographies: Old Culture, New Times, ed. by David C. Harvey and others (London: Routledge, 2002), pp. 123-38; Celticism, ed. by Terence Brown (Amsterdam: Rodopi, 1996); John Lowerson, 'Celtic Tourism: Some Recent Magnets', Cornish Studies, 2 (1994), 128-37.
} 
Iron Age people in Britain and questions their categorisation as Celtic. ${ }^{319}$ But there are also those who have downright contradicted Chapman's claim that the Celts are merely a construct, such as Barry Cunliffe who draws on archaeological, classical and linguistic evidence in an attempt to refute the former's theories. ${ }^{320}$ Most scholars, however, have engaged with Chapman's insights and have acknowledged them to be useful, whilst at the same time expressing points of critique. One example of this is Amy Hale and Philip Payton's edited volume New Directions in Celtic Studies, which explores ways in which this academic field can move forward in innovative and fruitful ways whilst recognising Chapman's exposure of the Celt's constructed nature. ${ }^{321}$ I concur here with Hale and Payton's argument that although the Celt might be a relatively modern construct, this does not necessarily mean that the entire academic field around it is bogus. ${ }^{322}$ Chapman openly denigrates people who are interested in the phenomenon and study it from a dilettante or scholarly point of view. ${ }^{323}$ In doing so, he ignores the fact that the insights of people interested in and studying aspects of Celtic culture or languages are genuinely contributing to academic scholarship, as well as to our understanding of the languages and the areas nowadays associated with this term. That the term itself was rather arbitrarily assigned to the field does not diminish the value and academic quality of the work that has been and is being done in its name. Moreover, as Murray Pittock also indicates, Chapman neglects the idea of the Celts as an imagined community by merely considering them in ethnic rather than in socio-political terms. ${ }^{324}$ Although Pittock is right in pointing out that Chapman largely ignores the socio-political side of the Celt, it remains doubtful whether the Welsh, Irish, Scottish and Bretons can indeed be described as one common socio-political Celtic community and whether they experience themselves in this way. The most conciliatory and reflective article in this debate is perhaps Patrick Sims-Williams's 'Celtomania and Celtoscepticism'. The author admits that the terms Celt and Celtic are vague and have been used differently in a range of academic fields. However, as Sims-Williams rightfully

\footnotetext{
${ }^{319}$ Simon James, The Atlantic Celts: Ancient People or Modern Invention? (Wisconsin: University of Wisconsin Press, 1999).

${ }^{320}$ Barry W. Cunliffe, The Ancient Celts (London: Penguin, 1999).

${ }^{321}$ New Directions in Celtic Studies, ed. by Amy Hale and Philip Payton (Exeter: University of Exeter Press, 2000).

${ }^{322}$ Hale and Payton, p. 7.

${ }^{323}$ Chapman, The Celts, pp. 229-36.

324 Pittock, p. 6.
} 
underlines, this does not mean that the terms are useless and superfluous. It merely necessitates that scholars do not attempt to provide an overarching definition of a supposedly Celtic socio-cultural, linguistic and political unity and continuity, but that the different fields of Celtic studies need to be aware of their definition of the concept. $^{325}$

Chapman's proposition of the externally constructed identity of the Celt calls to mind Edward Said's work on the Orient, which was discussed in the previous chapter. Both Orient and Celt are imagined as others; how this otherness is interpreted (positively or negatively) can vary. The first one, to my knowledge, to notice the similarity between Orient and Celt was McCormack, who immediately highlighted that more research needed to be done concerning their relation. ${ }^{326}$ Said himself has also shown an interest in one Celtic country in particular: Ireland. However, his interests do not lie in the country's designation as 'Celtic' and all this might entail, but rather in the socio-political context of Ireland in terms of its history of colonial oppression. ${ }^{327}$ In his contribution 'Celticism', Joep Leerssen also notices the apparent similarities between Orient and Celt. He generally agrees with Chapman that the Celt is a construct, an other which has been created by outsiders and which can be made to fit any role. ${ }^{328}$ Like Chapman, he also concurs that peripherality is a central characteristic of the Celt, which it shares with the Orient:

From Brittany to the Hebrides the 'Celtic' parts of modern Europe form part of a distant and far-flung periphery (viewed from the metropolitan centres, that is), and as such they came to be dominated by, while remaining marginal to, the metropolitan polity and its cultural values. [...] The connotation of peripherality has been all-pervasive in the notion of Celticism. ${ }^{329}$

Although the Orient and the Celt share many characteristics, amongst others peripherality and being identified as an other opposed to a centre, Leerssen also warns scholars not to blindly regard the two terms as referring to the same phenomenon. Taking Ireland as an example, Leerssen rightly points out that this

\footnotetext{
${ }^{325}$ Patrick Sims-Williams, 'Celtomania and Celtoscepticism', Cambrian Medieval Celtic Studies, 36 (1998), 1-35 (pp. 33-34).

${ }^{326}$ W.J. McCormack, From Burke to Beckett: Ascendency, Tradition and Betrayal in Literary History, 2nd edn (Cork: Cork University Press, 1994), p. 225.

${ }^{327}$ Edward Said, Culture and Imperialism (London: Chatto and Windus, 1993; repr. London: Vintage Books, 1994). In particular the chapter 'Yeats and Decolonization' (pp. 265-87) is illuminating in this respect.

${ }^{328}$ Leerssen, pp. 3-4.

${ }^{329}$ Leerssen, p. 7.
} 
country has not been a colony in the literal sense of the word, although many scholars have tried to demonstrate the colonial relationship between England and the Celtic countries. ${ }^{330}$ However, as has already been noted in the previous chapter, it is not the (post)colonial argument of Said's theoretical framework that is at the core of the research at hand, but rather his notion of imagined geographies and its relevance for the conceptualisation of peripherality.

Just as the Orient was, as Said puts it, 'orientalised', it can be asserted that the Celt has been 'celticised'. In the following, the process of celticisation and what this entails will be scrutinised in more depth, and its consequences for a travel destination, in this case Wales, will be evaluated. Three closely intertwined aspects are central in this process of celticisation: race, time and space. Whereas the term Celtic had been used to denote a linguistic categorisation since Edward Lhuyd's Archaeologica Britannica (1707), the Celt as a racial or ethnographical term only developed during the nineteenth century, primarily under the influence of Ernest Renan and Matthew Arnold. In his essay 'La Poésie des races celtiques', Renan describes the Celts as a race, which he identifies and characterises by opposing it to other races, primarily the Anglo-Saxons and Teutons. In his work The Gaelic Vision in Scottish Literature, Malcolm Chapman provides a useful assessment of the role Renan and Arnold played in the development of the Celt as an ethnographic category. ${ }^{331}$ He points out that for Renan the Celt symbolised an opposite to the modern, civilised world. Renan popularised the image that had emerged during the Romantic period of the Celt as a spiritual, emotional and natural race. As McCormack aptly summarises, he imagined the Celtic race as 'living virtually outside of history, materially disadvantaged, but wonderfully spiritual and poetical'. ${ }^{332}$ Matthew Arnold, arguably responsible for the celticization of Wales, ${ }^{333}$ based his ideas of the Celtic race on those of Renan and describes the Celt according to a list of characteristics such as: spirituality, sensitivity, femininity, hospitality,

\footnotetext{
${ }^{330}$ Apart from Said himself (see note 324), other examples of such studies are: Hechter; Jane Aaron and Chris Williams, Postcolonial Wales (Cardiff: University of Wales, 2005); Kirsti Bohata, Postcolonialism Revisited (Cardiff: University of Wales Press, 2004); Ireland and Postcolonial Theory, ed. by Clare Carroll and Patricia King (Notre Dame: University of Notre Dame Press, 2003). ${ }^{331}$ Malcolm Chapman, The Gaelic Vision in Scottish Literature (London: Croom Helm, 1978), pp. 81112.

332 McCormack, p. 227.

${ }^{333}$ Pitchford, p. 19.
} 
anarchy and extravagance, which were contrasted to Anglo-Saxon qualities. ${ }^{334} \mathrm{By}$ juxtaposing the Celt with modernising trends occurring in other parts of Western Europe at the time, the Celtic race was perceived to be living in the past. Its language and culture were regarded as poetic and artistic, but at the same time as having no role to play in modern, practical, political society. Temporality, already noticeable in the conceptualisation of Primitivism described above, therefore became even more closely connected to the idea of a Celtic race; its language and culture were seen as relics from the past which could be observed and consumed, but did not belong in modern society. 335

Consequently, travelling westwards to the Celtic periphery was being imagined as travelling back to the past, to a place where time had stood still and older (and supposedly better) civilisations still existed. In 1711, this connection between moving towards the Celtic fringe and temporality had already been noted by Leibniz, who found that the further one travelled to the periphery of Europe, the older the languages became. ${ }^{336}$ In the introduction of his essay 'La Poésie des races celtiques', Renan also describes this in a lively fashion. According to him, the 'real' Brittany can be found on the most western periphery of the peninsula, where the landscape and its inhabitants are strikingly different from those in the more central regions of France. ${ }^{337}$ Renan adds that the same can be said of Wales, Scotland and to a certain extent Ireland: the further one travels towards the periphery, the more likely it is that one encounters a genuine Celtic culture. ${ }^{338}$

This westerliness has become another defining feature of Celticity, but has also been used more widely as a trope to evoke images of peripherality and otherness in general:

[T] he invocation of the west as a source of heroism, mystery and romance goes back at least to antiquity, and is found in many different cultures under such varied names as Atlantis, Elysium, El Dorado or the English land of Cockaigne. In modern times, however, Ireland and the United States would seem to be outstanding examples of countries in which the myth of the west has been elevated to the level of a national ideal. ${ }^{339}$

\footnotetext{
${ }^{334}$ Matthew Arnold, On the Study of Celtic Literature (London: Smith, Elder and Company, 1867), pp. 105-10.

335 See: Chapman, The Gaelic Vision in Scottish Culture, pp. 90-91.

${ }^{336}$ See: Leerssen, p. 7.

${ }^{337}$ Ernest Renan, 'La Poésie des races celtiques', Revue des deux mondes, 5 (1854), 473-506 (p. 473 ).

338 Renan, pp. 473-4.

${ }^{339}$ Luke Gibbons, Transformations in Irish Culture (Cork: Cork University Press, 1996), p. 23.
} 
Although Gibbons primarily focuses on Ireland here, the same has been argued for Wales, where the western periphery is often regarded as the pinnacle of Welsh distinctiveness and a storehouse of cultural and linguistic continuity. In particular the work of Pyrs Gruffudd should be mentioned here, who has published widely on the relationship between western geographical locatedness, landscape and perceptions of Welshness. ${ }^{340}$ Gruffudd maintains that the Welsh landscape has been moralised by the Romantics during the nineteenth and the Neo-Romantics during the twentieth century. They regarded rural landscapes as reflecting the true essence of the nation, and the people inhabiting these areas were seen as purer and morally superior. According to Gruffudd, these idealised landscapes and peoples were primarily situated on the western fringes of Britain (i.e. also Wales), where they were imagined to be sources of spirituality, untouched by the depravity of modern society. ${ }^{341} \mathrm{He}$ adds that: 'Much of the construction of Wales as a spiritual zone was based around its consumption through travel [...]. Texts added to the notion of the Celtic Fringe as the spiritual reservoir or conscience of Britain'. ${ }^{342}$ Resulting from its reputation, Wales attracted many writers and poets in search of inspiration and 'moments of enlightenment', ${ }^{343}$ and their works often further reinforced the image of Wales as a place outside of time and reality.

In another article, 'In Search of Wales: Travel Writing and Narratives of Difference, 1918-1950', Gruffudd, together with David T. Herbert and Angela Piccini, examines this construction of Wales by travel writers in greater detail. ${ }^{344}$ According to these scholars, travel writing played an important role in the creation of an imaginative geography of Wales, in which a sense of difference, Celticity and temporality were significantly foregrounded. Their study is primarily concerned with H.V. Morton's travel narrative In Search of Wales (1932), but their contextualisation of his narrative within a broader interwar discourse surrounding Wales is of interest to the current study. Although they acknowledge that the representation of Wales in the examined narratives reflects the Romantic discourses of the country as aesthetic

\footnotetext{
${ }^{340}$ See for example: Pyrs Gruffudd, 'Tradition, Modernity and the Countryside: The Imaginary Geography of Rural Wales', Contemporary Wales, 6 (1994), 33-47; Pyrs Gruffudd, 'Prospects of Wales: Contested Geographical Imaginations', in Nation, Identity and Social Theory: Perspectives from Wales, ed. by Ralph Fevre and Andrew Thompson (Cardiff: University of Wales Press, 1999), pp. 149-67.

${ }^{341}$ Gruffudd, 'Prospects of Wales', p. 151.

${ }^{342}$ Gruffudd, 'Prospects of Wales', p. 153.

${ }^{343}$ Gruffudd, 'Prospects of Wales', p. 158.

${ }^{344}$ Gruffudd, Herbert and Piccini, 'In Search of Wales'.
} 
and unspoilt by modern society, the scholars argue that influences from early twentieth-century academics must also be taken into account. They focus on H.J. Fleure, Professor of Geography and Anthropology in Aberystwyth from 1917 to 1930, who theorised the connection between a Celtic race and the Welsh landscape. According to Fleure, remote upland Wales in particular was 'a refuge of old ways and old types'; 345 a space of cultural continuity. He termed this area the 'Celtic West', which was 'a refuge of civilizing influences protected by its remoteness from the rapid cultural changes of lowland and central Europe'. ${ }^{346}$ As Gruffudd, Herbert and Piccini point out, Fleure influenced many contemporary scholars, such as Cyril Fox, director of the National Museum of Wales, and Iorwerth Peate, founder of St Fagans National History Museum. More important, however, is his asserted influence on travellers and travel writers to Wales. Telling in this respect is the fact that Fleure contributed a chapter entitled 'The Land of Wales' to the Blue Guide to Wales, in which he describes Wales as 'a refuge, a treasure house of Britain's past' ${ }^{347}$ Here we thus see how academic discourses can permeate tourism discourses. Moreover, it is not unlikely that Continental guidebook writers consulted the English-language Blue Guide when they were reading up on Wales and its cultural and historical background, and were influenced by its descriptions.

According to Herbert, Gruffudd and Piccini, Fleure's conceptualisation of Celtic Wales permeated interwar travel writing to a significant extent, and influenced travel writers such as Eiluned and Peter Lewis, Edmund Vale and A.G. Bradley. ${ }^{348}$ Although their argument is credible, it is difficult to prove that these writers have actually been influenced by the work of Fleure and his colleagues, or that they were merely reflecting omnipresent discourses regarding Celtic Wales which had been circulating since the Romantic period. Albeit perhaps slightly premature regarding the origins of these representations, Herbert, Gruffudd and Piccini do convincingly show that the image of Wales as a unity of geographical elements and supposedly Celtic characteristics is prevalent in the conceptualisation of Wales as a travel destination in the interwar period. One frequently used trope in interwar travel writing about Wales that they identify, is the Renanian idea of the Welsh as a Celtic

\footnotetext{
${ }^{345}$ Fleure, quoted in: Gruffudd, Herbert and Piccini, 'In Search of Wales', p. 591.

${ }^{346}$ Gruffudd, Herbert and Piccini, 'In Search of Wales', p. 592.

${ }^{347}$ Fleure, quoted in: Gruffudd, Herbert and Piccini, 'In Search of Wales', p. 593.

${ }^{348}$ Gruffudd, Herbert and Piccini, 'In Search of Wales', p. 593.
} 
race. By imagining this race as changeless, consisting of the last survivors of an ancient and pure British race, the Welsh are cast as timeless. This perceived cultural continuity and and ancientness was mapped onto the landscape of Wales, which was seen as wild and dotted with age-old monuments. ${ }^{349}$ This image of ethnic Wales, grounded onto the natural and built landscape, becomes something consumable in the travel narratives discussed in the article: 'The reader of such travel writing learns to articulate Wales through concepts which are activated via the act of travelling through Wales, a journey punctuated with visits to sites and monuments already deemed as central to "understanding" the Welsh psyche'. 350

The popularisation and commodification of Celticity continued and intensified during the decades following World War II. The concept became increasingly associated with a strong aversion to modern society, including its materialism, rationalism and globalism. Marion Bowman, who examines contemporary Celtic spirituality, summarises: 'Celts [...] have increasingly become regarded as Noble Savages, less tainted by the ills of modern life, repositories of a spirituality, a sense of tradition, a oneness with nature that has elsewhere been lost. The Celtic period (however it is dated) has become a Golden Age, the Celtic areas looked to as havens of spirituality'. ${ }^{351}$ The Romantic concept of the Celt has thus survived and re-appeared time and again as the image of an idealised society which could be juxtaposed with the real world and all its ills. Especially during the 1960s and 1970s, decades characterised by a widespread aversion to the establishment, the admiration for Celtic culture was given new impetus which led to an increasing touristic commodification and consumption of Celtic culture. ${ }^{352}$ The counter-cultural movements of this period, which opposed the materialism of the post-war generation, were searching for different approaches to life. Unsurprisingly, the Celts, a traditionally peripheralised people localised on the fringe of the Western world, appealed to the imagination of such movements, as has been argued by various scholars. ${ }^{353}$ As Alan M. Kent asserts, there was a strong semantic connection

\footnotetext{
${ }^{349}$ Gruffudd, Herbert and Piccini, 'In Search of Wales', pp. 595-6.

${ }^{350}$ Gruffudd, Herbert and Piccini, 'In Search of Wales', p. 600.

${ }^{351}$ Marion Bowman, 'Contemporary Celtic Spirituality', in New Directions in Celtic Studies, ed. by Amy Hale and Philip Payton (Exeter: University of Exeter Press, 2000), pp. 69-91 (p. 74).

352 See: Chapman, The Celts, p. 224.

${ }^{353}$ Alan M. Kent, 'Celtic Nirvanas: Constructions of Celtic in Contemporary British Youth Culture', in Celtic Geographies: Old Culture, New Times, ed. by David C. Harvey and others (London: Routledge, 2002), pp. 208-26 (p. 212); Marion Bowman, 'The Commodification of the Celt: New Age/Neo-Pagan Consumerism', in The Marketing of Tradition: Perspectives on Folklore, Tourism
} 
between Celticity, spirituality and counter-cultural sentiment. ${ }^{354}$ By now, the interest in Wales's supposedly Celtic origins has become mainstream and is a concept which is used by various tourist attractions to draw in visitors. Examples of such attractions are St Fagans National Museum of History, Castell Henllys, an open-air museum which shows visitors an 'authentic' Celtic Iron Age village, as well as Celtica, an interpretation centre for Celtic history and culture which closed in $2006 .{ }^{355}$ As tourism has been argued to be 'one of the engines which manufacture and structure relationships between centres and peripheries', ${ }^{356}$ such attractions could play a role in the conceptualisation of peripheral travel destinations, in this case Celtic Wales.

In her article 'Tourism Images and the Construction of Celticity in Ireland and Brittany', which is based on the social construction of the Celt within a centreperiphery framework, Moya Kneafsey 'examines the extent to which tourism images either reinforce or disrupt these centre-periphery relations' ${ }^{357}$ Although her research focuses on Ireland and Brittany, her arguments can also be applied to Wales. Kneafsey's results show that the images produced by a variety of tourism agencies present both countries as places of refuge from modernity, sources of spirituality where one can reconnect with nature: 'The distinctiveness of representations of the Celtic regions lies in the suggestions of spatial, temporal and cultural peripherality which are made through reference to the mystical, otherwordly and elemental characteristics of the people and places being promoted' ${ }^{358}$ However, Kneafsey concludes that these peripheral images are the key to touristic success in the examined countries, and that by appropriating these images traditionally peripheral areas can achieve a 'centre' status. ${ }^{359}$ Through the commodification of Celticity, this identity, and its association with peripherality and a (positive) sense of backwardness, becomes a profitable product. Although it is doubtlessly true that

and the Heritage Industry, ed. by Teri Brewer, Folklore in Use: Applications in the Real World, 2 (Enfield: Hisarlik, 1994), pp. 143-52; Lowerson, p. 131.

${ }^{354}$ Kent, p. 211.

${ }^{355}$ For St Fagans and its relation to Celtic tourism, see: Rhiannon Mason, 'Nation Building at the Museum of Welsh Life', Museum and Society, 2 (2004), 18-34. For more on the latter two tourist sites specifically, see: Pitchford, pp. 155-72; Pyrs Gruffudd, David T. Herbert and Angela Piccini, "“Good to Think": Social Constructions of Celtic Heritage in Wales', Environment and Planning D, 17 (1999), 705-21.

${ }^{356}$ The Tourist Image: Myth and Myth Making in Tourism, ed. by Tom Selwyn (Chichester: Wiley, 1996), p. 9.

${ }^{357}$ Kneafsey, p. 126.

${ }^{358}$ Kneafsey, p. 132.

${ }^{359}$ Kneafsey, p. 137. 
Celticity is a valuable tourist commodity, Kneafsey's final argument remains problematic. The commodification of Celticity, especially when represented as having a continuous relationship with modern Welsh identity, runs the risk of establishing and reinforcing the connotations related to Celticity and perpetuating the image of the country as unable to modernise and occupy a role in the globalising world.

In their article "“Good to Think": Social Constructions of Celtic Heritage in in Wales', Gruffudd, Herbert and Piccini examine tourist responses to constructions of Welshness at heritage sites. They take Castell Henllys and Celtica as case studies, and notice that at both attractions the terms Celtic and Welsh are used as synonyms without problematising them. After having interviewed visitors of both sites, they draw the conclusion that many tourists regard the Welsh as direct descendants of the Celts, including in their descriptions all the connotations this entails. They regarded the Welsh as a purer race than the English, immediately reinforcing the dichotomy between 'us' and 'them' that has constituted the definition of the Celt since Renan and Arnold. ${ }^{360}$ The researchers conclude that these attractions emphasise the image of the Welsh as unchangeable, stuck in the past and incapable of coping with modern social developments. ${ }^{361}$ Even if Celticity might be a profitable tourism product (although Celtica closed down after only eleven years as a result of disappointing visitor numbers), it remains questionable whether it can play a constructive role in the conceptualisation of centre-periphery relations. Whilst it can make the periphery appealing to the centre and can be appropriated by the periphery in order to further its economic progress, as Kneafsey argues, it also seems to strengthen centreperiphery dynamics by upholding traditional dichotomies. This issue of the role of tourism images in the creation, transformation and popularisation of centre-periphery dynamics will be the focus of the research at hand.

\subsection{Continental Constructions of Wales}

Hitherto, this chapter has focused on the conceptualisation of Wales as a peripheral travel destination by British writers and the aspects that contributed to the

\footnotetext{
${ }^{360}$ Gruffudd, Herbert and Piccini, "“Good to Think", p. 717.

${ }^{361}$ Gruffudd, Herbert and Piccini, "“Good to Think", p. 719.
} 
country's peripheralisation. This focus was justifiable, as the secondary material available which is specifically concerned with Continental travellers to Wales is very limited. As will become clear in the following chapters, the contextualisation which has so far been given will be useful in order to frame the perceptions of Wales in Continental guidebooks and to understand the development of a transnational discourse regarding Wales as a peripheral travel destination. However, there is a small number of scholarly articles that deal with Continental perceptions of Wales which need to be scrutinised here. As with the British-focused studies, they tend to direct their attention to the Romantic appraisal of Wales, although recent studies have attempted to break with this tradition. ${ }^{362}$

An examination of the secondary literature concerned with perceptions of Wales in German travelogues makes it clear that there are both strong similarities as well as evident differences compared to contemporaneous British views of Wales. A central work in this respect is Michael Maurer's edited collection Wales: Die Entdeckung einer Landschaft und eines Volkes durch deutsche Reisende (17801860), in which Maurer collected essays from early German travellers to Wales and added an informative (albeit somewhat repetitive) introduction. ${ }^{363}$ According to Maurer, Germans started to explore Wales from the end of the eighteenth century onwards. They were primarily in search of aesthetic landscapes, which they indeed found. Overall, they were not interested in the culture or inhabitants of Wales: 'Es war also zunächst die Landschaft, welche die Deutschen nach Wales zog, die Suche nach ästhetischen Eindrücken, nach dem Romantischen, nicht etwa die Menschen, ihre Lebensformen und ihre Kultur' [It was first of all the landscape which drew Germans to Wales, the pursuit of aesthetic impressions and Romanticism, not the people, their way of life and their culture]. ${ }^{364}$ It is only relatively late, towards the mid-nineteenth century, that Germans seem to become aware of a distinctive sense of Welshness which is immediately closely linked to Celticity. Maurer identifies Jacob and Wilhelm Grimm's Irische Elfenmärchen (1826) as the beginning of this awareness, which ultimately finds its expression in the publication of Julius

\footnotetext{
${ }^{362}$ For example: Jones, 'Locating "Pays de Galles" in the Twenty-First Century'; Carol Tully, 'Out of Europe: Travel and Exile in Mid-Twentieth-Century Wales', Studies in Travel Writing, 18 (2014), 174-86.

363 Maurer, pp. 7-22.

${ }^{364}$ Maurer, p. 11. Italics of original.
} 
Rodenberg's Ein Herbst in Wales (1858). ${ }^{365}$ Wrongly identified by Maurer as having described the Welsh as a Celtic 'nature race' before Renan, ${ }^{366}$ it is highly likely that Rodenberg was influenced by the latter's conceptualisation of the Celt. Rodenberg describes Wales and the Welsh as a typically peripheral area; a Celtic land where a poetic people lives in harmony with its natural surroundings and has protected its cultural continuity from external influences. ${ }^{367}$ Maurer concludes:

\begin{abstract}
Die Entdeckung eines Volkes an der europäischen Peripherie durch die Deutschen aus dem Zentrum verfolgt durchaus ein gewisses Interesse. [...] Die romantische Sensibilität drückt nun gerade die Waliser als 'sinnliche Kelten' ans Herz - Menschen, die noch in ihrer traditionellen Lebenswelt ruhen und noch nicht verdorben sind durch den protestantischen Arbeitsgeist der Moderne. ${ }^{368}$
\end{abstract}

[The discovery of a people on the European periphery by the Germans from the centre is certainly of some interest. [...] The Romantic sensibility embraces the Welsh as 'sensual Celts' - a people that has persisted in their traditional way of life and has not yet been ruined by the modern Protestant industrious attitude.]

According to Maurer, it is thus Wales's peripherality that attracted the Germans to Wales in the nineteenth century; in terms of its remote and unspoilt nature, as well as its supposedly spiritual and backward people. Surprisingly, he also contends that Wales was imagined by German travellers as an escape from a 'Protestant industrious attitude'. It remains unclear on what Maurer bases this assumption, especially since Wales was a hotbed for Methodism, a related denomination of Protestantism.

Like Maurer, Carol Tully argues that before Rodenberg, the Germans seemed generally uninterested in Wales as a cultural entity. Whilst they travelled to Ireland and Scotland to discover the distinctive cultures of these countries, Wales was primarily seen as a 'scene of social, religious and technological change'. ${ }^{369}$ Despite the fact that the Brothers Grimm did mention the Welsh oral tradition in the 1822 Anmerkungen to their Kinder- und Hausmärchen and that Charlotte Guest's translation of the Mabinogion (1838-1849) was almost instantly translated into German in 1842, the German interest in and awareness of Welsh culture remained insignificant, according to Tully. ${ }^{370}$ In contrast to Maurer, who asserts that early

\footnotetext{
365 Maurer, p. 19.

${ }^{366}$ Maurer, p. 20.

${ }^{367}$ Maurer, p. 20.

${ }^{368}$ Maurer, p. 22.

${ }^{369}$ Tully, 'The Celtic Misconnection', p. 129.

370 Tully, 'The Celtic Misconnection', p. 131.
} 
German visitors solely came to Wales for the natural landscape, Tully convincingly argues that, although the landscape of Wales was romanticised, many were also interested in the social and industrial advances which were rapidly changing the country. ${ }^{371}$ A sentimental Romantic search for aesthetic landscapes was therefore not the only appeal of Wales as a travel destination for the Germans. ${ }^{372}$ A recurrent theme in the travel accounts discussed by Tully is the perception of Wales as part of England, a region which was regarded as having great economic potential and whose mineral resources could be exploited: 'Wales becomes, then, a different "site of renewal", one centred not on the revival of modern culture through the ideals and paradigms of the past, but aimed instead at a future for the nation based on industrial expansion and effective colonisation'. ${ }^{373}$ According to Tully, Wales was not primarily discovered by the Germans due to its peripherality, but due to its closeness to the centre. The fact that Wales was thought to be approaching the centre as a result of its industrialisation and urbanisation was of interest to these visitors, and it was therefore not solely the Romantic landscape, as Maurer claims, that appealed to them, although this doubtlessly also played a role for some. On the one hand, it can therefore be stated that Wales was discovered as a peripheral area, but on the other there were those who appreciated the country for its closeness to the centre.

It is important in this respect that these earliest German travellers all visited Wales as part of a larger tour through Great Britain, and often merely traversed Wales en route. Rodenberg's Ein Herbst in Wales was the first widely-read text to deal solely with Wales which perceives Wales from a Celticised, Renanian point of view. As his book was published in 1858, it has been rightly contended that the German Romantic appraisal of Wales's culture and people was relatively late. ${ }^{374}$ However, as Rodenberg's text was the first that focused solely on Wales and described the country in great detail, it could be argued that it functioned as an important informative source for German readers. Although, as Stefan Zimmer underlines, Rodenberg's views are doubtlessly influenced by English discourses of

\footnotetext{
371 Tully, 'The Celtic Misconnection', p. 135.

372 This view is shared by Alison E. Martin, who convincingly shows that the German translation of Samuel Jackson Pratt's Gleanings through Wales, Holland and Westphalia (1795) has removed many overtly sentimental sections in order to create a text that is instead focused on the provision of basic information about the country. This implies that the translator thought the German readership would not be interested in Romantic ponderings.

373 Tully, 'The Celtic Misconnection', p. 141.

${ }^{374}$ Zimmer, p. 254; Tully, 'The Celtic Misconnection', p. 140; Maurer, pp. 19-20.
} 
the time, his work offers an insight into the German Romantic evaluation of Wales at the time. ${ }^{375}$ Not long after the publication of Rodenberg's travel narrative, Baedeker published his first guide to the whole of Great Britain, perhaps aware of the growing touristic interest in the British Isles which was now also directed to areas outside of London and its direct surroundings. However, as will be discussed in Chapter 3, Baedeker's interpretation of the country is far from Rodenbergesque.

In France, the prism of Celticity became noticeable in the perception of travellers at an earlier stage. In an illuminating talk, Heather Williams has given a concise overview of some early nineteenth-century French travel writers to Wales and their ways of perceiving the country. ${ }^{376}$ According to Williams, postrevolutionary France not only had to rethink its present and future, but also its past. The Franks, seen as the ancestors of the unpopular elite, were replaced by the Gauls to fulfil this function in France's origin myth. As the Gauls were considered to be a Celtic race, this led to the popularisation of Celticity which is generally called 'Celtomania'. ${ }^{377}$ John Watkins provides an apt précis of this phenomenon:

Celtomania as a doctrine can be summed up in the following terms: the Celts are the oldest
people on earth; their language, the mother of all other languages, has been preserved almost
intact in Breton and Welsh; they were profound philosophers whose revelations were handed
down to the bardic schools of Wales; dolmens, laid out so as to form astronomical
observatories, were the altars upon which their priests, the Druids, made human sacrifices. ${ }^{378}$

Central to this Celtomania, therefore, is the temporalisation of the Celt as oldfashioned, unchangeable and traditional. The fact that, as Williams points out, many nineteenth-century French travel writers identified Wales as Celtic would thus imply that they regarded the country as a storehouse of the past, a place where old languages and cultures could be found. ${ }^{379}$ It was indeed with the exact intention of finding history that some French travellers came to Wales. The idea that the Celts were the ancestors of the French was taken very seriously, as is proven by the

\footnotetext{
${ }^{375}$ Zimmer, p. 256.

${ }^{376}$ Heather Williams, 'Views and Visions of Wales in French Nineteenth-Century Travel Writing', Swansea University seminar, Swansea, 16 November 2015 <https://www.academia.edu/27794506/Views_and_visions_of_Wales_in_nineteenthcentury_French_travel_writing_talk_> [accessed 14 December 2016].

${ }^{377}$ Heather Williams, Postcolonial Brittany: Literature between Languages, Cultural Identity Studies, 2 (Bern: Peter Lang, 2007), pp. 35-38.

${ }^{378}$ John Watkins, 'Wales and France', The Transactions of the Honourable Society of Cymmrodorion, 2 (1967), 179-202 (p. 181).

${ }^{379}$ Williams, 'Views and Visions of Wales in French Nineteenth-Century Travel Writing', p. 7.
} 
foundation of the Académie celtique in 1805 which was dedicated to research in this field. The focus was in first instance directed to Brittany, the Celtic area of France, and subsequently also to Wales.

A textbook example of a French Celtophile traveller was Hersart de la Villemarqué (1815-1895), a Breton philologist who went to Wales in the winter of 1838-1839. ${ }^{380}$ In her article “"Impertinent Structures": A Breton's Adventure in NeoGothic Wales', Mary-Ann Constantine discusses La Villemarqué's perception of Wales through the prism of medievalism. She argues that he saw Wales 'as the source of a Celticity which could be drawn upon in various ways to revive the fortunes of the Breton language' and that he came to Wales 'to look for manuscripts which might shed further light on Brittany's medieval past' ${ }^{381}$ Although this was his 'official' mission, La Villemarqué appears to have been more preoccupied with fauxantiques and neo-Gothicism than with actual remnants of Wales's past, as Constantine notes. ${ }^{382}$ Nonetheless, La Villemarqué has been identified by John Watkins as having played a crucial role in the popularisation and dissemination of Welsh literature and culture in France. ${ }^{383}$ Watkins subsequently asserts that he had a major impact on many later writers, critics and academics, and it could thus be argued that his influence on French discourse concerning Wales has been significant. According to Watkins, Ernest Renan was amongst those inspired by La Villemarqué's work. ${ }^{384}$ As was noted earlier in this chapter, Renan in turn significantly affected the conceptualisation of the Celt and inspired British critics and writers, such as Arnold and Yeats. This is a clear example of how discourses are created transnationally, transcending borders and languages.

Overall, Watkins's observation that 'from the Renaissance onwards, French interest in Wales and Welsh culture has been primarily an interest in things past ${ }^{\prime 385}$ is relevant for the research at hand, although he also concedes that in modern times this

\footnotetext{
${ }^{380}$ It is a widely-held belief that La Villemarque also went to Wales in 1855, but this has been disputed by Mary-Ann Constantine in a recent publication. See: Mary-Ann Constantine, 'La "Sainte Terre de Cambrie": La Villemarqué et le romantisme gallois', in Au-delà du 'Barzaz Breiz': Théodore Hersart de la Villemarqué, ed. by Nelly Blanchard and Fañch Postic (Brest: Centre de recherche bretonne et celtique, 2016), pp. 209-28.

${ }^{381}$ Mary-Ann Constantine, “'Impertinent Structures”: A Breton's Adventures in Neo-Gothic Wales', Studies in Travel Writing, 18 (2014), pp. 134-47 (p. 135).

382 Constantine, "“Impertinent Structures"”, p. 136.

${ }^{383}$ Watkins, p. 191.

${ }^{384}$ Watkins, p. 194.

${ }^{385}$ Watkins, p. 198.
} 
French image of Wales might have become more diverse. ${ }^{386}$ Other scholars have indeed found more diverse reactions to Wales. Kathryn N. Jones, for example, has argued that some Breton travellers perceive Wales as a dynamic model for the future of the stateless nation. ${ }^{387}$ Heather Williams similarly problematises the notion of a one-sided French view of Wales as stuck in the past, and contends that early nineteenth-century travellers were also interested in the industrial side of Wales, similar to the German travellers from this period. ${ }^{388}$ She contends that from the 1830s onwards Celticity was brought into the mix, and Wales was being perceived through the prism of Brittany. However, as Williams convincingly shows, Celticity and industrialisation are not regarded as mutually exclusive. She goes even further by asserting that notions of Celticity and industrialisation are inseparable in many French travel accounts: 'These two factors are inseparable: Celticism or Celtomania, on the one hand, and industrial anxieties on the other; these break down into two: France's fear of being left behind, but also fear of the social problems that industry may bring' ${ }^{389}$ In her analysis, Williams illustrates that many French travel writers regarded Wales as an example of a harmonious co-existence of industry and rural idyll. She refers to the travel account of La Villemarqué and that of another French Celtophile, Henri Martin, who both make great efforts to portray Wales as a perfect balance of rurality, Celticity and industrialisation. ${ }^{390}$

This seems to contradict the argument of this chapter, namely that Celticity was linked to temporalisation and peripherality, whereas industrialisation and urbanisation came from the innovative centre. However, rather than invalidating these insights, Williams's claims could enrich our line of thought. Rather than examining perceptions of Wales as referring to a closed entity, it might be more fruitful to regard Wales as a collection of various spaces, which can all have a different relation to the centre. Within Wales, the awareness that there are various forms and expressions of Welshness has by now become mainstream in academia, and it is from this perspective that the perceptions of Wales in Continental guidebooks should also be examined. In particular the various perceptions of rural North Wales and industrialised South Wales will be central in this respect, as these

\footnotetext{
${ }^{386}$ Watkins, p. 200.

387 Jones, 'Locating "Pays de Galles” in the Twenty-First Century', pp. 192-5.

${ }^{388}$ Williams, 'Views and Visions of Wales in French Nineteenth-Century Travel Writing', p. 10.

${ }^{389}$ Williams, 'Views and Visions of Wales in French Nineteenth-Century Travel Writing', p. 8.

${ }^{390}$ Williams, 'Views and Visions of Wales in French Nineteenth-Century Travel Writing', pp. 14-15.
} 
spaces both embody various conceptualisations of Welshness. The perceived tension between and co-existence of these different spaces in the guidebooks will be a key point of investigation in the following chapters.

\subsection{Concluding Remarks}

The aim of this chapter was to provide a historical and conceptual contextualisation for the coming chapters which will examine the primary material. It intended to explore the development of Wales as an imagined peripheral travel destination. As a result of the available secondary material, the chapter considered British travellers during the Romantic period, even though this focus lay outside of the scope of this research in terms of nationality and timeframe. Nonetheless, it has offered crucial insights into the emergence of Wales as a tourist space, as well as the discourses used to interpret and frame the country, its culture and inhabitants.

Overall, it can be summarised that Wales has continuously been constructed as a peripheral area in various ways. During the Romantic period, many travellers imagined the country's topography as an opposite to industrialisation and urbanisation, an area outside of the centre which was still unaffected by modern society. Especially the Wye Valley and Snowdonia became popular areas, as they corresponded to the aesthetic ideals of the time; the Picturesque and the Sublime. Nature in its most untouched form became desirable for the increasing number of people who lived in crowded and polluted cities. Some, like Southey and Shelley, even went further and endowed this landscape with political meaning, conceiving it as a place where everything was possible; a place of wish-fulfilment.

These visions primarily regarded Wales as an empty land, a tabula rasa consisting of mountains and picturesque streams. However, the aversion to modernisation and industrialisation went hand in hand with a growing interest in socalled primitive cultures. The idea that in Wales one could find an ancient Celtic culture took hold of the imagination of many and was reinforced by images in literature, for example Gray's 'The Bard'. From the start, this idea of Celtic Wales was strongly related to the country's perceived peripherality. According to popular conceptions, the Celts were the original inhabitants of the British Isles, who had been driven to the outskirts by invaders. Here, they had preserved their culture and 
language. Like its landscape, its supposedly Celtic culture was therefore employed to reinforce the image of Wales as a peripheral destination. Its Celtic roots were used to construct Wales as a source of spirituality, untouched by modernity. The Romantic conceptualisation of the Celt has influenced the popular understanding of the term up to the present day, and has remained a noteworthy part of Wales's conceptualisation as a travel destination. Although it has successfully been re-appropriated by the country itself, and has become a profitable tourist commodity, it remains questionable what the long-term consequences of these images are for Wales outside of the tourist domain.

Finally, some French and German views of Wales were taken into account. Overall, the themes which were discussed in the preceding sections also played an important role in the emergence of Wales as a travel destination for German and French visitors. Many Germans were attracted to Wales due to its natural landscape. It was only later that an interest in the country's inhabitants and culture developed, mainly out of fascination with the past. For nineteenth-century French travel writers, Wales's Celtic roots were one of the country's most appealing aspects, although it must be conceded that travellers with industrial interests were also numerous. ${ }^{391}$ In search of the past of their own country, they were interested in Wales and its cultural traditions. Nevertheless, both German and French travellers were also attentive to Wales's industrialised side. In light of the industrial rivalry between the three countries at that time, it is hardly surprising that a glimpse at the achievements and progress of the competitor would appeal to these tourists. In these views, Wales was therefore clearly perceived to be part of the industrialising and innovating centre. Finally, it can be argued that multiple visions of Wales co-existed for these Continental travellers. Wales was not seen as a coherent cultural whole, but was instead divided into various spaces which all had different relations with the centre. This is a crucial insight for the following chapters, which will examine the spatialisation of Wales and the division of different spaces in Continental guidebooks. The tension and concomitance of natural and industrial landscapes will be particularly illuminating in this respect.

\footnotetext{
${ }^{391}$ Many examples of travel writers with an inclination towards the industrial side of Wales can be found in the database of the AHRC-funded project 'European Travellers to Europe: 1750-2010' <http://etw.bangor.ac.uk/accounts-of-travel> [accessed 19 April 2017].
} 


\section{3 - 1850-1900: Wales - Picturesque and Futuristic, With a Touch of Otherness}

\subsection{Introduction}

This chapter discusses perceptions of Wales in German- and French-language guidebooks in the period from 1850 to 1900 . As was established in Chapter 1, it was during this timeframe that the first modern guidebook series (both in English, German and French) were established, which, amongst other countries and areas, published guides to Great Britain. The primary material will consist of some of the most well-known nineteenth-century guidebook series, such as Baedeker and Guides Joanne, although lesser-known series will also be included in the analysis.

Due to its immense popularity and hegemony on the market, the Germanlanguage analysis will be primarily based on the Baedeker guidebooks. Karl Baedeker published his first handbook to Britain in 1862, but this edition solely included London and its direct surroundings. ${ }^{392}$ For a more complete description of Great Britain the traveller had to wait until the 1866 edition, which again focused on London, but also described trips to South England, Wales and Scotland. ${ }^{393}$ By examining multiple editions of the Baedeker series, changes in the discourse in these canonical guidebooks can be detected. Another German-language series that will be scrutinised is the Meyers Reisebücher collection, of which it has been argued that it was the second most widespread guidebook in the German-speaking world after the Baedeker guides. ${ }^{394}$ The French material shows a greater variety and includes multiple different series. The first French guidebook to Wales to be included here originates from the Guides Richard collection. ${ }^{395}$ After the Guides Richard handbooks were taken over by the Hachette publishing house in 1855, they were integrated into their Guides Joanne series, of which the editions from 1865 and 1886 will be considered in the analysis. ${ }^{396}$ Other French material that will be included

\footnotetext{
${ }^{392}$ Karl Baedeker, London und seine Umgebung nebst Reiserouten vom Continent nach England und zurück, Baedeker Handbuch für Reisende (Koblenz: Karl Baedeker, 1862).

393 Baedeker, London nebst Ausflügen (1866).

${ }^{394}$ Hauenstein, p. 7.

395 J. B. Richard and Adolphe Joanne, Itinéraire descriptif et historique de la Grande-Bretagne, Guides Richard (Paris: Éditeur des Guides-Richard, 1853).

${ }^{396}$ For more on the origins and development of the Guides Joanne series, see: Hélène Morlier, 'Les Guides Joanne: invention d'une collection', In Situ. Revue des patrimoines, 15 (2011), 2-23.
} 
consists of a guide from the Bibliothèque du voyageur series, which was eventually eclipsed by Hachette, ${ }^{397}$ as well as one of the Guides Garnier frères series.

The timeframe (1850-1900) is slightly broader than in the next two chapters. This can be attributed to the fact that there is simply less material available for this period, which justifies this extension in order to encompass enough data for a comprehensive comparison. Moreover, no Dutch material was found for this period. Research on Dutch travel writing is lacking and reasons for the nonexistence of Dutch guidebooks to Great Britain in the nineteenth century remain uncertain. A plausible explanation could be that the market for Dutch travel guides was simply too small during this stage, considering the fact that travelling was still the privilege of more affluent households. Hendrik Schott, who wrote his dissertation on Dutch travel writing in the nineteenth century, remarks that there were no Dutch Baedeker or Murray equivalents during this period. Therefore, German and English guides were often used by Dutch travellers. ${ }^{398}$ Since French was the language of the elite in Europe, it is also likely that Dutch travellers used guidebooks in that language.

Most sections of this chapter will discuss the French and German material simultaneously in order to avoid repetition, as their representations of Wales show many similarities. Any identified differences between the languages will be highlighted.

\subsection{Reaching Wales in the Nineteenth Century: Steamers and Railways}

Unsurprisingly perhaps, the emergence of German- and French-language guidebooks to Great Britain coincides with the increase of cross-Channel travellers. These travellers were in need of practical and cultural information during their visit, and were aided by newly produced guidebooks. The following section will scrutinise this expanding movement between the Continent and the British Isles, thus

\footnotetext{
${ }^{397}$ See: Goulven Guilcher, 'La Rivalité Chaix-Hachette pour la conquête du marché de la lecture ferroviaire en France 1846-1865', Revue d'histoire des chemins de fer, 3 (1992), 279-305.

${ }^{398}$ Hendrik Schott, 'Niederländische Reiseliteratur des 19. Jahrhunderts: Geschichte, Umfeld und Vielfalt einer Literaturgattung' (unpublished doctoral thesis, Philologische Fakultät der Universität Köln, 1990), p. 162; See, for example, Smits's travel advice in: De oude Heer Smits, 'Brief over het reizen. Van den ouden Heer Smits, aan zijn kleinzoon', De Nederlandsche Spectator, 2 (1861), 190-1 (p. 190). In this letter the author advises his (fictitious) Dutch grandson to take a Baedeker or Murray guide with him when travelling, and does not mention any Dutch equivalents.
} 
contextualising the rise of Continental guidebooks to Great Britain as well as their growing target audience.

A crucial prerequisite for an increase in Continental travel to Wales and Great Britain in general was the improvement of infrastructure, especially that connecting the Continent to the Isles. During the eighteenth century, crossing the Channel had been a lengthy and hazardous task. There were no regular services, and passengers had to use unstable packet boats or make private arrangements with captains. No bookings could be made in advance, and sailing ships had to rely on tides and the direction of the wind, which could lead to delays in embarkation. ${ }^{399}$

This all changed due to the arrival of the steamship. In his work The Beaten Track, James Buzard provides a succinct overview of the development of European infrastructure during the first half of the nineteenth century. He states that by 1816 the first cross-Channel passenger service between Brighton and Le Havre was operational, and that by 1821 regular steamboats were carrying passengers from Dover to Calais. ${ }^{400}$ Connections between other French and English ports were also established. ${ }^{401}$ Steamships no longer depended on wind directions, and services were therefore faster and more reliable. By 1840 , nearly 100,000 people were crossing ' $\mathrm{La}$ Manche' annually. ${ }^{402}$ Whereas it could take five hours to sail from Dover to Calais in 1789 on a good day, ${ }^{403}$ the same journey only required three hours by $1843,{ }^{404}$ which was further reduced to one and a half in $1899 .{ }^{405}$ In addition to these improvements, the journey also became less costly, making it possible for more people to travel. ${ }^{406}$

Furthermore, European railroads developed rapidly, albeit unequally, in the first half of the nineteenth century. However, even in unified countries such as Great Britain and France, railways were not run by one central company and travelling across larger distances was therefore still problematic and slow. It was only in 1875

\footnotetext{
${ }^{399}$ See: Jeremy Black, The British Abroad: The Grand Tour in the Eighteenth Century (Bridgend: Sutton Publishing, 2003), pp. 12-14; Gregor Dallas, 1815: The Roads to Waterloo (London: Pimlico, 2001), p. 90.

400 Buzard, The Beaten Track, p. 41.

${ }^{401}$ Paul Gerbod, Les Voyageurs français à la découverte des îles Britanniques du XVIIIème siècle à nos jours (Paris: L'Harmattan, 1995), p. 27.

${ }^{402}$ Buzard, The Beaten Track, p. 41.

403 Black, p. 15.

${ }^{404}$ John Murray, Hand-book for Travellers in France: Being a Guide to Normandy, Brittany; the River Loire, Seine, Rhône, and Garonne; the French Alps, Dauphiné, Provence, and the Pyrenees (London: Murray, 1843), p. xix.

${ }^{405}$ Baedeker, Grossbritannien, p. xviii.

406 Gerbod, p. 27.
} 
that passengers from France to Great Britain no longer had to reclaim their luggage at each regional stop. ${ }^{407}$ In 1843, Murray estimated a total of thirty to thirty-two hours for a trip from London to Paris, during which the last part of the journey from Calais to Paris was by far the longest. ${ }^{408}$ In the eighth edition (1861), Murray remarks: 'France, although tardy in commencing the construction of railways, [...] has yet made good progress since 1851 . At present railways connect all the chief towns, and a network of lines finished or in progress connects the remotest corners of the empire'. ${ }^{409}$ Between 1852 and 1869, the railway network in France expanded from $3500 \mathrm{~km}$ to more than $17,000 \mathrm{~km}$ in total. ${ }^{410}$ A journey from London to Paris in 1861 was reduced to twelve hours, when taking the route through Folkestone and Boulogne. ${ }^{411}$ Rail connections from London and Paris to their respective coasts are said to have contributed considerably to the increase in cross-Channel travellers. ${ }^{412}$

Reasons for crossing the Channel may have varied, with some travelling for work, whilst others were visiting relatives. It is difficult to say how many people actually visited Britain for pleasure, and would thus be considered to belong to the principal target audience for guidebooks. Claire Hancock estimates that only fifteen per cent of French tourists went to Great Britain between 1846 and 1860. ${ }^{413}$ However, their absolute number grew explosively between 1855 and 1904, from 7259 to approximately 30,000 , constituting a quarter of all foreign travellers to Great Britain. Although the British Isles had to compete with traditional travel destinations such as Switzerland and Italy, almost a quarter of all French tourists chose to visit their overseas neighbour. ${ }^{414}$ The French guidebooks to Great Britain also note this growth in cross-Channel travel and emphasise that the relations between the countries improved due to infrastructural advancements and tourism:

En ouvrant des relations nouvelles, en créants des intérêts communs, la vapeur a rapproché les deux nations que séparaient naguère encore de vieilles rivalités et des antipathies

\footnotetext{
${ }^{407}$ Buzard, The Beaten Track, p. 41.

${ }^{408}$ Murray, Hand-Book for Travellers in France, p. xix.

409 John Murray, A Handbook for Travellers in France: Being a Guide to Normandy, Brittany; the River Loire, Seine, Rhône, and Garonne; the French Alps, Dauphiné, Provence, and the Pyrenees; the Island of Corsica, \&c., \&c., \&c.; their Railways and Roads, 8th edn (London: Murray, 1861), p. xvii. ${ }^{410}$ Nordman, p. 544.

${ }^{411}$ Murray, A Handbook for Travellers in France, p. xvi.

412 Palmowski, p. 107.

${ }^{413}$ Claire Hancock, Paris et Londres aux XIXe siècle: représentations dans les guides et récits de voyage (Paris: CNRS Éditions, 2003), p. 24.

${ }^{414}$ See: Gerbod, p. 72.
} 
réciproques, en apparances insurmontables; et à l'heure qu'il est, les voyages d'outreManche sont aussi fréquents qu'ils étaient rares. ${ }^{415}$

[By opening new relations and by creating common interests, the steamer has brought the two nations closer together. These were until recently still separated by old rivalries and mutual antipathy which seemed insurmountable; but by now, cross-Channel travels are as frequent as they were once rare.]

Apart from regular steamer connections, the 1851 and 1862 world exhibitions in London were mentioned by the guidebooks as important reasons for the improved relations between France and Great Britain, as well as the increase of travellers in both directions: 'Le détroit de la Manche n'est plus une barrière; c'est un trait d'union' [The English Channel is not a barrier anymore; it is a hyphen]. ${ }^{416}$ In comparison to France, travelling from Germany ${ }^{417}$ took considerably longer, ${ }^{418}$ when coming from Berlin, travellers were advised to take the train to Hamburg and travel from there to London by steamer. The journey from Berlin to Hamburg took eight to nine hours, to which the traveller could add a further fortyeight to sixty hours for the journey from Hamburg to London. ${ }^{419}$ Needless to say, travellers also departed from more western parts of Germany, which allowed them to save a substantial amount of time. In the 1870s, the shortest journey possible from Germany to Great Britain, according to Meyer's handbook, was from Cologne to London, via Antwerp, which would take approximately twenty-six hours. ${ }^{420}$

Not only did travelling across the Channel and on the Continent improve, become quicker and increasingly comfortable during the course of the nineteenth century, but the infrastructure in Great Britain also developed rapidly. According to Philip Bagwell, the travelling time between major British cities was halved between 1770 and $1830 .{ }^{421}$ Owing to rapid industrialisation, rich landowners started building

\footnotetext{
415 Richard and Joanne, p. v.

${ }^{416}$ Alphonse Esquiros, Itinéraire descriptif et historique de la Grande-Bretagne et de l'Irlande, Collection des Guides-Joanne (Paris: Hachette, 1865), p. xi.

${ }^{417}$ In this thesis I use the term 'Germany' to refer to those areas which are currently part of the Federal Republic of Germany. Technically we cannot speak of 'Germany' in this era as the country only became unified in 1871, and this united German Empire also comprised different areas than what we would currently understand under the designation 'Germany'. Nevertheless, the term will be used from a pragmatic point of view. All the German-language guidebooks used in this chapter were published in cities that are now part of the Federal Republic of Germany.

${ }^{418}$ Unfortunately, no comparable data on German visitor numbers was found for these decades. This might be due to the fact that Germany was not united at this stage, and consistent data collection was not yet organised on a federal level.

${ }^{419}$ Ernst Georg Ravenstein, Reisehandbuch für London, England und Schottland, Meyers Reisebücher (Hildeburghausen: Bibliographisches Institut, 1870), p. 6.

${ }^{420}$ Ravenstein, Reisehandbuch für London, England und Schottland, p. 3

${ }^{421}$ Philip S. Bagwell, The Transport Revolution from 1770 (London: Batsford, 1974), p. 41.
} 
railways in the $1850 \mathrm{~s}$ in order to transport coal, iron and other materials from the mines to ports, as a result of which the railway network in Wales expanded too. ${ }^{422}$ It was soon discovered that the railways could be used for other purposes as well, in particular to serve the tourist industry. Over 1,400 miles of railways were constructed in Wales in the period between 1840 and 1870, linking together industrial areas, market towns and tourist resorts. ${ }^{423}$ Throughout the second half of the nineteenth century, a railway network was constructed that connected many Welsh seaside resorts to England in order to promote tourism in these areas (see Maps 1 and 2). In his seminal work A History of Wales, John Davies provides a succinct overview of the various railways and their construction dates, and subsequently remarks: 'Although tourism first came to Wales in the wake of tastes and interests which became fashionable in the period 1775-1800, it was the railways, in the period 185075 , which gave rise to tourism as an industry'. ${ }^{424}$ The completion of the railway to Holyhead in 1848 was of great importance for the development of towns such as Rhyl. Resorts like Barry and Tenby also profited from the expansion of the railway network, as did seaside towns such as Aberystwyth and Tywyn. ${ }^{425}$ It is therefore not surprising that during this period guidebooks to Great Britain began to include Wales, since the country was in the process of being opened up for travellers from the Continent. In this period, guidebooks are largely constructed around railway itineraries, and it can be argued that the existence of these was a prerequisite for the inclusion of Wales as a travel destination in these texts.

\footnotetext{
${ }^{422}$ See: The Oxford Companion to British Railway History: From 1603 to the 1990s, ed. by Jack Simmons and Gordon Biddle (Oxford: Oxford University Press, 1999), pp. 554-5; Jack Simmons, The Railway in England and Wales, 1830-1914 (Leicester: Leicester University Press, 1978).

${ }^{423}$ See: Davies, A History of Wales, p. 396; Geraint H. Jenkins, A Concise History of Wales (Cambridge: Cambridge University Press, 2007), pp. 176-7.

${ }^{424}$ Davies, A History of Wales, p. 396.

${ }^{425}$ See: Peter E. Baughan, North and Mid Wales, ed. by David St John Thomas and J. Allan Patmore, A Regional History of the Railways of Great Britain, 11 (Newton Abbot: David \& Charles, 1980), pp. 25-27, 155-61; Derek S. M. Barrie, South Wales, ed. by David St John Thomas and J. Allan Patmore, A Regional History of the Railways of Great Britain, 12 (Newton Abbot: David \& Charles, 1980), pp. $131-3$.
} 


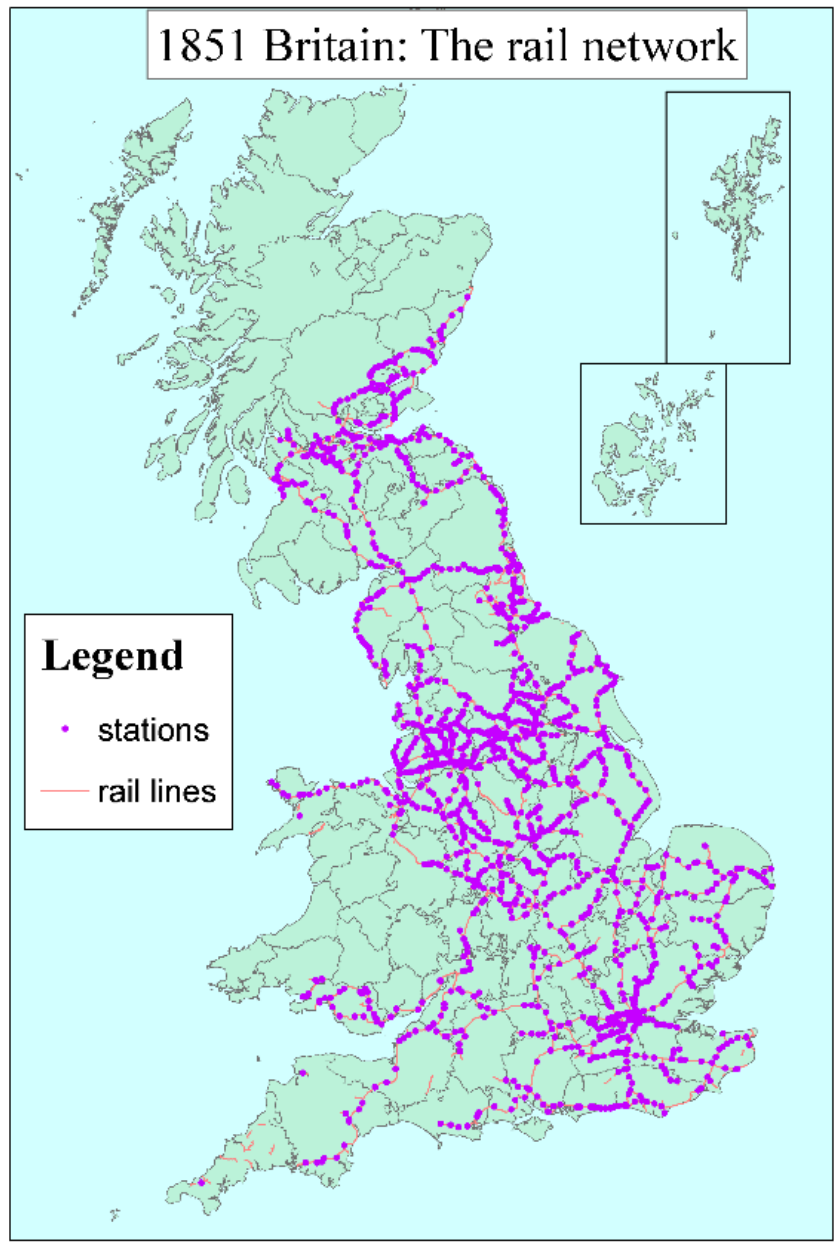

Map 1: In 1851, the rail network in Wales was primarily limited to the transportation of industrial materials to the South Wales ports, as well as of travellers heading for Ireland and beyond. ${ }^{426}$

${ }^{426}$ Leigh Shaw-Taylor and others, '1851 Britain: The Rail Network', Mapping the Rail Network, The Cambridge Group for the History of Population and Social Structure: Department of Geography and Faculty of History, <http://www.geog.cam.ac.uk/research/projects/occupations/britain19c/railways/> [accessed 8 December 2014]. 


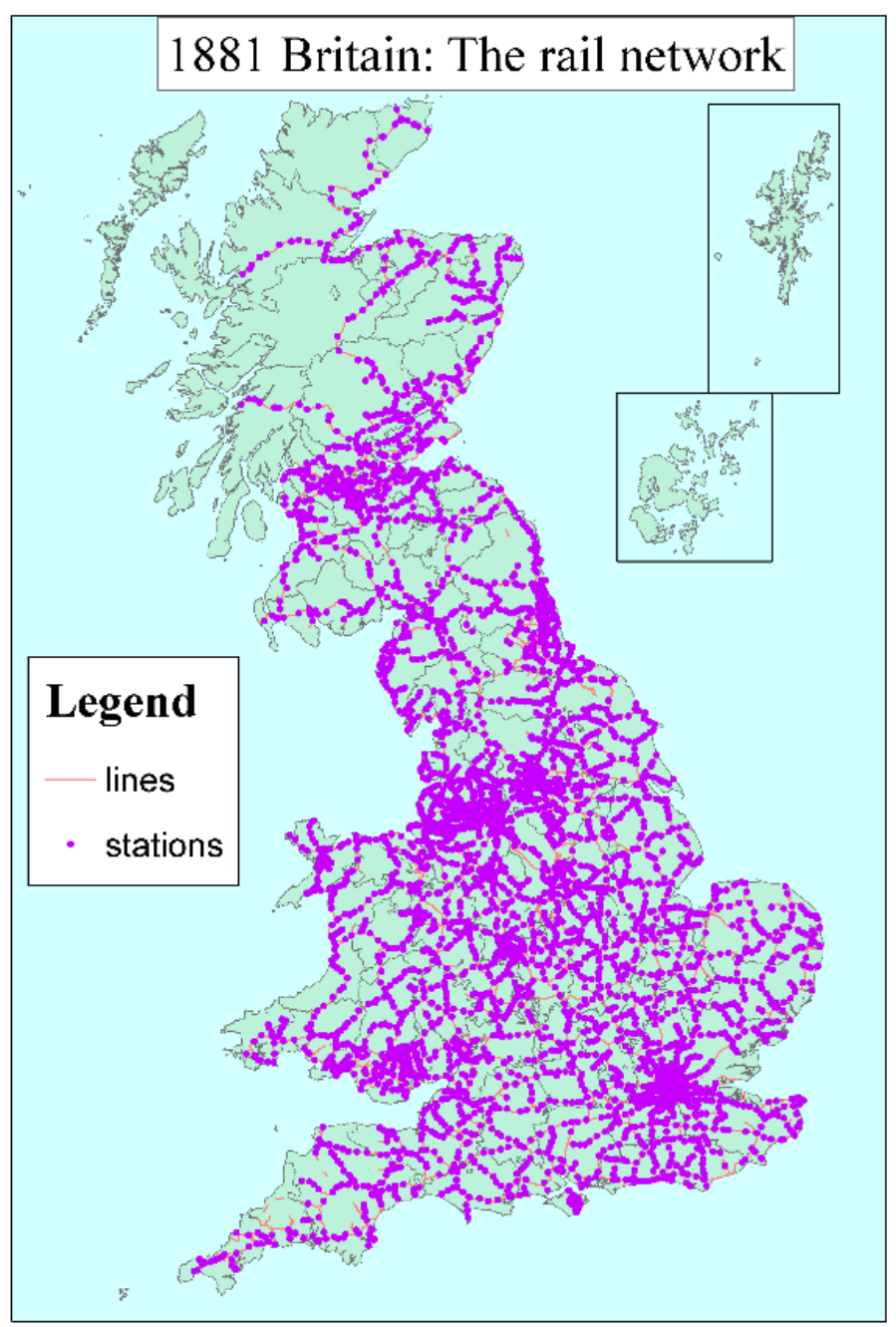

Map 2: During the next three decades, Wales was made accessible due to the expansion of the railway network. ${ }^{427}$

The development of the railway network not only changed the way people travelled, but also how they observed and consumed the landscape. Due to the "[a]nnihilation of time and space', ${ }^{428}$ landscapes could henceforth be consumed from within the train, and the Baedeker and Murray guides, based on railway routes and itineraries, even gave tips on the best sceneries during the journey. ${ }^{429}$ In John Murray's A

\footnotetext{
${ }^{427}$ Leigh Shaw-Taylor and others, ' 1881 Britain: The Rail Network', Mapping the Rail Network, The Cambridge Group for the History of Population and Social Structure: Department of Geography and Faculty of History, <http://www.geog.cam.ac.uk/research/projects/occupations/britain19c/railways/> [accessed 8 December 2014].

${ }^{428}$ Wolfgang Schivelbusch, The Railway Journey: The Industrialization of Time and Space in the 19th Century (Berkeley: University of California Press, 1986), p. 33.

${ }^{429}$ Koshar, German Travel Cultures, p. 34.
} 
Handbook for Travellers in North Wales, for example, the views from within the train are elaborately described and the traveller is informed about the various outlooks. ${ }^{430}$ According to the Guides Joanne guidebook, few scenes are as admirable as the panorama from the train when departing from Caernarfon. ${ }^{431}$ The train was thus more than a travelling method, it was also a way to touristically consume the landscape of the travel destination.

\subsection{Obscuring Wales as a Travel Destination and Topographical Entity}

During the second half of the nineteenth century, Wales was gradually becoming more accessible for travellers and was starting to emerge as a travel destination. However, the main attraction for Continental visitors when travelling to Great Britain was and continued to be London. ${ }^{432}$ This is clearly reflected in the guidebooks, which devote most, if not all, of their attention to the capital city. In general, the rest of Great Britain is discussed in far less detail, and is primarily seen as an extension of London only of interest to those tourists who can spare the money and time. The Meyers Reisebücher guide, first published in 1870, places its focus on London, which covers the first 400 pages of the book, in perspective as follows: 'Die Excursionen ausserhalb Londons beschränken sich auf die wichtigsten Reiserouten durch England, Wales und Schottland [...] - immerhin eine willkommene Zugabe für Jene, deren Interesse und Zeit nicht auf einen Besuch Londons allein angewiesen ist' [The excursions outside of London are restricted to the most important travel routes through England, Wales and Scotland [...] - in any case a welcome addition for those whose interest and time are not limited to a visit to London alone]. ${ }^{433}$ Wales is thus seen as a possible trip from London, but is not presented as a destination in its own right. Similarly, Baedeker informs its readers that London is the pinnacle of a visit to

\footnotetext{
${ }^{430}$ John Murray, A Handbook for Travellers in North Wales, 2nd edn (London: Murray, 1864), p. 11.

${ }^{431}$ Esquiros, p. 264.

${ }^{432}$ See: Gerbod, p. 76; Ingrid Kuszynski, 'Ins gelobte Land der Freiheit und des Wohlstands: Reisen nach England', in Reisekultur: Von der Pilgerfahrt zum modernen Tourismus, ed. by Hermann Bausinger, Klaus Beyrer and Gottfried Korff (Munich: C.H. Beck, 1991), pp. 237-43 (p. 242).

${ }^{433}$ Ravenstein, Reisehandbuch für London, England und Schottland, p. vi.
} 
the British Isles, yet admits that the other parts of Great Britain all have unique qualities too. ${ }^{434}$

After London, it is primarily Scotland, and to a certain extent Ireland, that is seen as a worthwhile travel destination. The Guides Richard series published a guide to London in 1851, which was extended only two years later to include the whole of the United Kingdom of Great Britain and Ireland. In the preface, the author comments on this by stating that the descriptions of Scotland and Ireland, 'ces deux parties si intéressantes du Royaume-Uni' [those two very interesting parts of the United Kingdom] were still missing from its collection, thus ignoring the touristic value of Wales. ${ }^{435}$ Compared to Wales, the chapters concerning Scotland and Ireland are more extensive and, unlike the former, often include introductory sections. This difference between the various parts of the British Isles is especially significant in the French-language guidebooks. The Guides Joanne, for example, dedicates more than 200 pages to the description of Scotland (including an elaborate introduction) and eighty pages to Ireland, whereas Wales gets a mere thirty-two pages, without any introductory statement. ${ }^{436}$ The Guides Garnier frères shows a similar division. This guidebook summarises Wales in only ten pages, whilst Scotland is covered in almost eighty and Ireland in 130 pages. $^{437}$

Wales's relative obscurity compared to the other parts of the British Isles is further strengthened by the titles of the guidebooks. The only series that specifically mentions Wales in its titles is Baedeker, whilst the other guidebooks, both Frenchand German-language, solely include the terms Angleterre, Écosse, Irlande and England, Schottland, Irland [England, Scotland, Ireland] respectively. In these cases, it must be concluded that Wales was incorporated into the term for England. In this respect, it is worth noticing that the French-language Guides Garnier frères is the only nineteenth-century guidebook that explains the difference between the terms England, England and Wales, United Kingdom and Great Britain, whilst nonetheless using the term Angleterre [England] to describe the location of Snowdon. ${ }^{438}$

\footnotetext{
${ }^{434}$ Baedeker, London nebst Ausflügen (1866), p. viii.

435 Richard and Joanne, p. v.

${ }^{436}$ Esquiros.

${ }^{437}$ William Darcy, Nouveau guide général du voyageur: en Angleterre, en Écosse et en Irlande, Guides Garnier frères (Paris: Garnier frères, 1864).

${ }^{438}$ Darcy, pp. 15, 25. For other examples of such instances, see: Baedeker, Grossbritannien, pp. 162, 174.
} 
These preliminary observations seem to indicate that Wales is not a prominent entity in nineteenth-century Continental guidebooks. The descriptions of Wales will be scrutinised in more detail below, and it will become apparent that this marginalisation of Wales takes place on multiple levels, exceeding titles and numbers of pages, whilst manifesting itself topographically, historically and culturally. This section investigates the portrayal of Wales topographically, primarily focusing on the creation of borders and boundaries. This is an important initial step in the analysis, as it is virtually impossible to endow any space with meaning without first defining it. When no boundaries and borders are established, they cannot be imbued with cultural and socio-historical content that can be evaluated. In the following, it will be contended that nineteenth-century Continental guidebooks generally fail to create an image of Wales as a distinct and separate space, which complicates the subsequent endowing of the country with any sort of substantial and distinctive meaning.

To start with, the topographical location of Wales is often left undetermined. The 1866 Baedeker edition, for example, does not include a map of Great Britain but only one of London. The traveller is therefore left to his/her own devices to discover the exact location of Wales. In the 1875 edition, a map has been added, albeit without any clear demarcation marks between England and Wales. It therefore remains problematic for the reader to determine where the border between England and Wales lies. In the French guidebook from the Bibliothèque du voyageur series, the boundaries between England and Wales are described in a very imprecise manner. Whilst the western border of England is identified as the Irish Sea (thus, without any distinction, including the whole of Wales), Wales is localised 'entre l'embouchure de la Severne au sud, celle de la Dee au nord' [between the estuary of the Severn in the South and that of the Dee in the North], ${ }^{439}$ which is a rather vague demarcation and neglects to determine the largest part of the border between England and Wales.

This indefinability of Wales becomes even more apparent when the itineraries through the country are scrutinised. Unlike the Scottish and (if included) Irish routes, the Welsh itineraries are not grouped together in one, separate chapter

\footnotetext{
${ }^{439}$ Nouveau guide à Londres, dans ses environs, en Angleterre, en Écosse, en Irlande, Bibliothèque du voyageur (Paris: Napoléon Chaix, 1862), pp. 65, 259.
} 
introduced by a preface, but are instead dispersed amongst the routes through England. ${ }^{440}$ Owing to this, the task of finding the routes through Wales is complicated considerably. This difficulty is increased even further by the fact that some of the routes through Wales are not clearly defined as such. In the 1866 Baedeker guide, for example, the route through North Wales is called 'Von Shrewsbury nach Chester. North Wales' [From Shrewsbury to Chester. North Wales] and the one running through Mid-Wales is entitled 'Von Birmingham nach Shrewsbury. Central Wales' [From Birmingham to Shrewsbury. Central Wales]. ${ }^{441}$ Although the subtitles indicate that this itinerary traverses Wales, England is both point of departure and arrival. It is also noticeable in this respect that the three routes through Wales that are described in this guide run from east to west and back again; from England to Wales to England. This furthermore endorses the assertion that Wales was seen as an area that could be explored from England or London, but not as an individual destination.

Owing to the fact that the routes through Wales are frequently not clearly grouped together in a separate chapter and occasionally have indistinguishable titles, it can be contended that Wales is not represented as a separate entity. Another good example of this fragmentation of Wales is route 62 of the Guides Richard handbook: 'Tour dans la principauté de Galles' [Tour through the Principality of Wales]. Even though the title implies that the route describes the whole country, it merely includes South and Mid-Wales, up to Aberystwyth. ${ }^{442}$ The rest of Wales is described in different routes, which are named according to the places they connect, for example 'Route 80 - de Londres à Holyhead' [Route 80 - from London to Holyhead]. ${ }^{443}$ Although half of this route runs through Wales, this is not directly recognisable from the title of the itinerary, especially since it is a singular route through Wales in between purely English itineraries. In some cases, the guides not only fail to regard Wales as a topographical entity, but even exclude whole parts of the country. The Meyers Reisebücher series, for example, omits South Wales altogether; Aberystwyth is the most southern part of Wales that is described. This area is thus not regarded as a worthwhile region that should be part of the traveller's experience. By omitting this

\footnotetext{
${ }^{440}$ See, for example: Richard and Joanne; Esquiros; Baedeker, London nebst Ausflügen (1866).

${ }^{441}$ Baedeker, London nebst Ausflügen (1866), pp. 266-70, 264-6.

${ }^{442}$ Richard and Joanne, pp. 63-68.

${ }^{443}$ Richard and Joanne, pp. 98-102.
} 
part of the country, the integrity of Wales is once again compromised. Wales is not a distinct topographical unity, but is rather reduced to the rural northern parts of the country, thus omitting the South with its thriving industrial economy as a part of Wales. ${ }^{444}$

Even though Wales remains a largely unrecognised entity within Great Britain in most nineteenth-century Continental guidebooks, interest in the country slowly increases towards the end of the century. In particular the German-language guidebooks gradually recognise Wales's potential as a tourist destination. First of all, this development is noticeable in the proposed length of stay in Wales. The early 1866 Baedeker guide does not especially recommend Wales as a travel destination and remarks: 'Für den gewöhnlichen Reisenden wird es genügen, wenn einige der Haupt-Eisenbahnrouten nebst angrenzenden Sehenswürdigkeiten beschrieben werden' [For the ordinary traveller it will be sufficient to describe some of the main railway itineraries and their adjacent attractions $].{ }^{445}$ Consequently, the guide reduces the country to a handful of sites that can be quickly visited. A later edition from 1881 recommends a slightly more elaborate trip to North Wales of two days, during which the traveller is hurried from sight to sight:

\begin{abstract}
Am 1ten mit dem ersten Zuge von Chester nach Bangor, zu den Brücken, weiter Eisenbahn oder Dampfboot nach Carnarvon [sic], Schloss besehen, Abends Eisenbahn nach Llanberis; 2. auf den Snowdon bei klarem Wetter um 5 Uhr Morgens oder womöglich noch früher; Post um $2 \frac{1}{2}$ u. 5 3/4 U. Nm. nach Bettws-y-Coed [sic], Eisenbahn nach Conway [sic] und zurück nach Chester. ${ }^{446}$

[On the $1^{\text {st }}$ day, take the first train from Chester to Bangor, to the bridges, further to Carnarvon [sic] by train or steamer, visit castle, in the evening train to Llanberis; $2^{\text {nd }}$ day, weather permitting, climb Snowdon at 5 o'clock in the morning or, if possible, even earlier; post coach at 2:30 and 5:45 o'clock to Bettws-y-Coed [sic], train to Conway [sic] and back to Chester.]
\end{abstract}

Other German-language guidebooks suggest a more generous time schedule than Baedeker. The 1870 edition of Meyers Reisebücher recommends a nine-day visit to Wales, during which a circular tour around North Wales is made and a handful of locations in the interior of Snowdonia are visited in addition. ${ }^{447}$ The Wales-route of

\footnotetext{
444 This focus on North Wales is a recurring theme throughout this chapter and will be discussed in more detail in Section 3.4.2.

${ }^{445}$ Baedeker, London nebst Ausflügen (1866), p. 258.

${ }^{446}$ Karl Baedeker, London nebst Ausflügen nach Süd-England, Wales und Schottland sowie Reiserouten vom Continent nach England, Baedeker Handbuch für Reisende, 7th edn (Leipzig: Karl Baedeker, 1881), pp. 323-4.

${ }^{447}$ Ravenstein, Reisehandbuch für London, England und Schottland, pp. 528-9.
} 
the series's 1876 edition has scarcely changed, but a suggestion is added for travellers with limited time; they should either visit the Wye Valley or Snowdon. ${ }^{448}$ The influence of the Picturesque aesthetics are clearly noticeable here.

However, it is a later handbook in the Baedeker series, Grossbritannien: England (ausser London), Wales, Schottland und Irland [Great Britain: England (except London), Wales, Scotland and Ireland], which demonstrates the most significant shift in the guidebooks' awareness of Wales. This guide was added to the series in 1889 and went through various editions during the following years. ${ }^{449}$ It is the only nineteenth-century guidebook that describes the British Isles whilst excluding its capital, which was henceforth discussed in a separate handbook. Due to this omission, the rest of the Isles, including Wales, could be taken into more detailed consideration. As such, this guidebook has a unique position amongst the nineteenthcentury primary material, and it is therefore permissible to scrutinise this guide in greater depth. In this Baedeker handbook, Wales is given its own introductory subchapter in the general section on British culture, ${ }^{450}$ and the number of routes traversing the country has increased significantly: instead of three, Wales has now been allocated eight routes with a total of seventy-one pages. Whereas the 1881 edition had still recommended two days for the exploration of North Wales, the 1899 Baedeker advises a tour of three weeks, although it was considered possible to see the most beautiful places in Wales within a few days. ${ }^{451}$ Wales is no longer the region of which only the main railway routes and their adjacent attractions are described, but is instead starting to be a valued as a worthwhile touristic area.

This Baedeker guidebook describes Wales in more detail, but it does not imply that it is consequently identified as a distinctive country. On the contrary, Wales's status as an integrated part of Great Britain is highlighted:

Das Fürstentum Wales (wälsch Cymru) [...] wurde in seinem südl. Teil bereits von den Normannen unter Wilhelm II. (1087-1100) und Heinrich I. (1100-1135), im nördl. Teil von Eduard I. (1276-84) unterworfen und bildet seit 1535 einen integrierenden Bestandteil des britischen Reichs. ${ }^{452}$

\footnotetext{
${ }^{448}$ Ravenstein, London, England, Schottland und Irland, p. 701. It is noteworthy in this respect that the French-language guidebooks refrain from giving any time indication for a trip through Wales. ${ }^{449}$ Due to restricted availability, the 1899 edition of this title will be used for the following analysis. In respect to the content of the chapter about Wales, both editions are essentially identical. However, page numbers may differ.

${ }^{450}$ Baedeker, Grossbritannien, p. xxix.

${ }^{451}$ Baedeker, London nebst Ausflügen (1881), p. 323; Baedeker, Grossbritannien, p. 232.

452 Baedeker, Grossbritannien, p. xxix. Emphasis in original.
} 
[The Principality of Wales (in Welsh Cymru), [...] of which the southern part was already subjugated by the Normans under William II (1087-1100) and Henry I (1100-1135), and the northern part by Edward I (1276-1284), has formed an integral part of the British Empire since 1535.]

Through this statement, it is immediately made clear to the reader that Wales is part of the British Empire, and has not been autonomous for a long time. The early conquest of Wales by the English is highlighted, which is not evaluated negatively. Instead, it can be argued that this subjugation of Wales is seen as an important step towards the eminence of the British Empire. The guidebook discusses Wales more elaborately, yet the country is still not clearly set apart as a distinct topographical and cultural entity. The fact that the routes through the country continue to be dispersed amongst those in England further corroborates this assertion. There is a relatively elaborate route through North Wales, as well as a succinct one through Mid-Wales, but the routes through the southern parts of the country are not assembled into one itinerary and are instead listed separately. Even though Wales features more prominently, it is therefore still not seen as a cohesive entity, as are Ireland and Scotland.

It is nevertheless noticeable that towards the end of the nineteenth century, Baedeker is expanding its scope and is starting to explore more peripheral areas of Great Britain outside of the country's capital city. This probably reflects the growth of tourism coming from the Continent as well as the increasing convenience and speed of public transport which made out-of-the-way destinations more accessible. Despite the fact that Wales is still not identified as a distinct destination and separate part of Great Britain, the country is starting to gain recognition as a tourist destination. It is noteworthy in this respect that the most influential French counterpart of Baedeker, Guides Joanne, appears to develop in completely the opposite direction. Between 1865 and 1908, this French-language series did not issue a new edition of its guidebook to Great Britain. During this period, Joanne was instead preoccupied with publishing various new sub-series, amongst others the Guide-Diamant. This series was meant to be smaller and lighter than the comprehensive older editions in order to help reduce the weight of the travellers' luggage. Resulting from the decreased volume of these guides, it was necessary to 
focus on topographically smaller areas. ${ }^{453}$ The series consequently focused on London whilst greatly restricting the sections concerning other British regions. ${ }^{454}$ In these publications, Wales is accordingly diminished to an appendix and is covered in far fewer pages. Instead of expanding its scope like Baedeker, it seems that Joanne priviliged the need to focus on more limited areas in order to meet the wishes of its readership.

Overall, the analysis thus far has revealed that in the nineteenth-century French- and German-language guidebooks, Wales was not a topographically distinct and foregrounded travel destination. Throughout this period, the touristic focus lies on London, followed by Scotland in particular. Although most guides include various routes through Wales, the country is not represented as an entity. Topographical and geographical boundaries, separating Wales from England, are not or merely vaguely described. Instead, Wales is generally condensed to a handful of routes that are dispersed amongst those running through England. As a result, Wales is not a bordered two-dimensional space, but is reduced to a one-dimensional string of selected sights and villages, connected by railroads.

\subsection{Welsh Landscapes: Nature and Industry as Travel Incentives}

Overall, nineteenth-century Continental guidebooks did not regard Wales as one of the primary interests when visiting Great Britain. Most importantly, however, they did not seem to perceive Wales as one coherent space, a geographical entity. The following section examines what motivations the guides did give their readers for travelling to Wales. In other words, it scrutinises in more detail the touristic value that was attributed to the country. It will be argued that it was the landscape that was seen as particularly worthwhile, being a prime example of the Picturesque and Sublime aesthetic values, which had been formulated in the eighteenth century (see Chapter 2.2).

\footnotetext{
${ }^{453}$ Hélène Morlier, Les Guides-Joanne: genèse des guides-bleus. Itinéraire bibliographique, historique et descriptif de la collection de guides de voyage, 1840-1920 (Paris: Les Sentiers débattus, 2007), p. 614.

${ }^{454}$ For an overview of Guides Joanne editions dedicated to London and Great Britain, see: Morlier, Les Guides-Joanne, pp. 282-5.
} 


\subsubsection{The Aesthetic Ideals of the Picturesque and the Sublime}

The nineteenth-century guidebooks, both French- and German-language publications, regarded the picturesque landscape as the main reason for travelling to Wales. In the itineraries through Wales, most descriptions are devoted to mountains, valleys and other natural features, as well as ruinous abbeys and castles. This emphasis is exemplified by the fact that there are only two Welsh sights with a double asterisk in the 1899 Baedeker edition: the Aberglaslyn Pass and the view from Snowdon, which can both be counted as natural sights. ${ }^{455}$ This might not be surprising, as Wales was first discovered as a tourist destination in the eighteenth century due to these features, which corresponded to the aesthetic ideals of the Picturesque and the Sublime. It has been argued by James Buzard that these preferences continued to govern touristic discourses throughout the nineteenth century. ${ }^{456}$ This assertion is further corroborated by Rudy Koshar who, in his study of the Baedeker series, explains its focus on nature as resulting from the positive reevaluation of the countryside during the eighteenth century. ${ }^{457}$ On the question of why German travellers began to explore Wales, Michael Maurer asserts: 'Die entscheidende Antwort wird lauten, daß in Wales eine Landschaft zu erleben war, welche in besonderer Weise der Sensibilität jener Epoche [der Romantik] entsprach, die im späten 18. Jahrhundert begann und im mittleren 19. Jahrhundert noch nicht zu Ende war' [The ultimate answer is that travellers were able to experience a landscape in Wales that especially corresponded to the sensibility of that Romantic era, which had started in the eighteenth century and had not yet ended in the mid-nineteenth century]. ${ }^{458}$ This 'sensibility' was not specifically German, but occurred all over Europe, albeit in different national forms. ${ }^{459}$ It is therefore not surprising that these aesthetic ideals are present in both German as well as French nineteenth-century guidebooks.

Some of these, especially the German-language handbooks, regard the wild, sublime nature of Wales as one of the most important reasons for visiting the country. Meyer's guide for example remarks: 'Von allen Gegenden steht in

\footnotetext{
${ }^{455}$ Baedeker, Grossbritannien, pp. 270, 272.

${ }^{456}$ Buzard, 'The Grand Tour and after (1660-1840)', p. 47.

${ }^{457}$ Koshar, German Travel Cultures, p. 57.

${ }^{458}$ Maurer, p. 7. Emphasis in original.

${ }^{459}$ Löfgren, p. 20.
} 
landschaftlicher Beziehung Wales nur gegen Schottland in zweiter Linie. [...] Die Berge sind von malerischen Formen, meist schroff, felsig, kahl oder mit Heide bedeckt' [With respect to its landscape, Wales is only inferior to Scotland. [...] The mountains have scenic forms, mostly precipitous, rocky, barren or covered with moorland]. ${ }^{460}$ The 1866 Baedeker edition directly links Wales's unsuitability for agricultural cultivation to its natural beauty: 'Es ist das weitaus gebirgigste Teil von England, da über ein Viertel des Bodens der Kultur unzugänglich ist, und umschließt namentlich in seiner nördlichen Hälfte eine Fülle landschaftlicher Schönheiten' [It is by far the most mountainous part of England, since more than a quarter of the land is unsuitable for cultivation, and includes especially in its northern half an abundance of natural beauty]. ${ }^{461}$ First of all it must be noted that this quotation underlines what has been argued above, namely that Wales was regarded as an undistinguishable part of England. Secondly, it is clear that the aesthetic values of the Sublime determine the way in which Wales is perceived and evaluated.

However, the gentler and more tamed aesthetics of the Picturesque are even more abundant in the guidebooks, published both in French and in German. The admiration of the delicate balance between 'untouched' nature and man-made landscapes is concisely illustrated by the following description of the Elan Valley in the 1865 Guides Joanne edition, which 'n'était au commencement de ce siècle qu'un lieu sauvage et inculte; il abonde aujourd'hui en beautés naturelles et artificielles' [was at the beginning of this century nothing more than a wild and uncultivated place; nowadays it abounds with natural and artificial beauty]. ${ }^{462}$ Human intervention could thus have positive effects on the landscape. In addition, the recurring use of the words malerisch and pittoresque [picturesque] should be noted, which are used to describe the extensive number of ruinous castles and abbeys, as well as natural features. 463

Certain guidebooks take this picturesque quality of Wales very literally; the Guides Richard for example describes the area surrounding Laugharne as follows: 'Les hauteurs qui avoisinnent cette ville offrent de vastes et riches panoramas, et tout

\footnotetext{
${ }^{460}$ Ravenstein, Reisehandbuch für London, England und Schottland, p. 532.

${ }^{461}$ Baedeker, London nebst Ausflügen (1866), p. xxix.

462 Esquiros, p. 238.

${ }^{463}$ For some examples, see: Baedeker, Grossbritannien, pp. 163, 248; Baedeker, London nebst Ausflügen (1866), pp. 259, 265; Ravenstein, London, England, Schottland und Irland, pp. 705, 707; Richard and Joanne, p. 65; Darcy, p. 247; Esquiros, p. 263.
} 
le district des scènes dignes du crayon de l'artiste' [The heights surrounding this town offer vast and splendid panoramas, and the whole district presents scenes worthy of the artist's pencil]. ${ }^{464}$ The Guides Garnier frères makes a very similar remark concerning the same area, recommending the region around Carmarthen and especially Laugharne as worthwhile for artistic reproduction. ${ }^{465}$

This literal connection between the picturesque landscape and artistic endeavours also manifests itself in the intertextual relationship between the paintings by landscape artist Richard Wilson (1714-1782) and the steel engravings used in the Meyers Reisebücher guide to Great Britain. Wilson, one of the first painters to discover Wales's landscape, was widely influential and inspired Romantic painters such as John Constable and William Turner. ${ }^{466}$ In Meyer's guidebook, four steel engravings are included in the section about Wales, depicting the Vale of Llangollen, Conwy Castle (Figure 3), Llanberis and Caernarfon Castle. The resemblance between Meyer's steel engraving of Conwy Castle and Wilson's painting (Figure 4) is difficult to deny. The viewing point of both illustrations is similar. Both Wilson and Plato Ahrens (the illustrator for Meyers Reisebücher) depict the castle from the same distance and angle, and include the lake and its natural surroundings. Ahrens's image conveys a picturesque image of Wales to the guidebook-reader: the idyll of rural life, mountains and ruins were all themes exploited by picturesque painters. ${ }^{467}$ Nevertheless, the guidebook's representation of Conwy Castle is more modern than that of Wilson, and also reflects the actual state of the castle in the second half of the nineteenth century whilst taking heed of the guidebook's raison d'être: providing upto-date information. ${ }^{468}$

\footnotetext{
${ }^{464}$ Richard and Joanne, p. 66.

465 Darcy, p. 246.

${ }^{466}$ John E.H. Steegman and Iorwerth C. Peate, 'Richard Wilson', Dictionary of Welsh Biography <http://wbo.llgc.org.uk/en/s-WILS-RIC-1713.html> [accessed 12 December 2014].

${ }^{467}$ See: Andrews, p. 64.

${ }^{468}$ Conwy Castle had been renovated from 1865 onwards, when the castle became civic instead of private property, which could explain why Ahrens's representation of the castle is less ruinous. The Conwy Suspension Bridge, which is only observable in Ahrens's version, was built in 1826 and could therefore not have been included in Wilson's painting (1714-1782). It remains unclear why the Conwy Railway Bridge, which was completed in 1848, was not added to the drawing. This bridge was possibly regarded less appropriate for the picturesque depiction of the castle and was therefore excluded, or Ahrens based his drawing on earlier descriptions and images of the castle. See: Jeremy A. Ashbee, Conwy Castle and Town Walls (Cardiff: Cadw Welsh Assembly Government, 2007), p. 18
} 


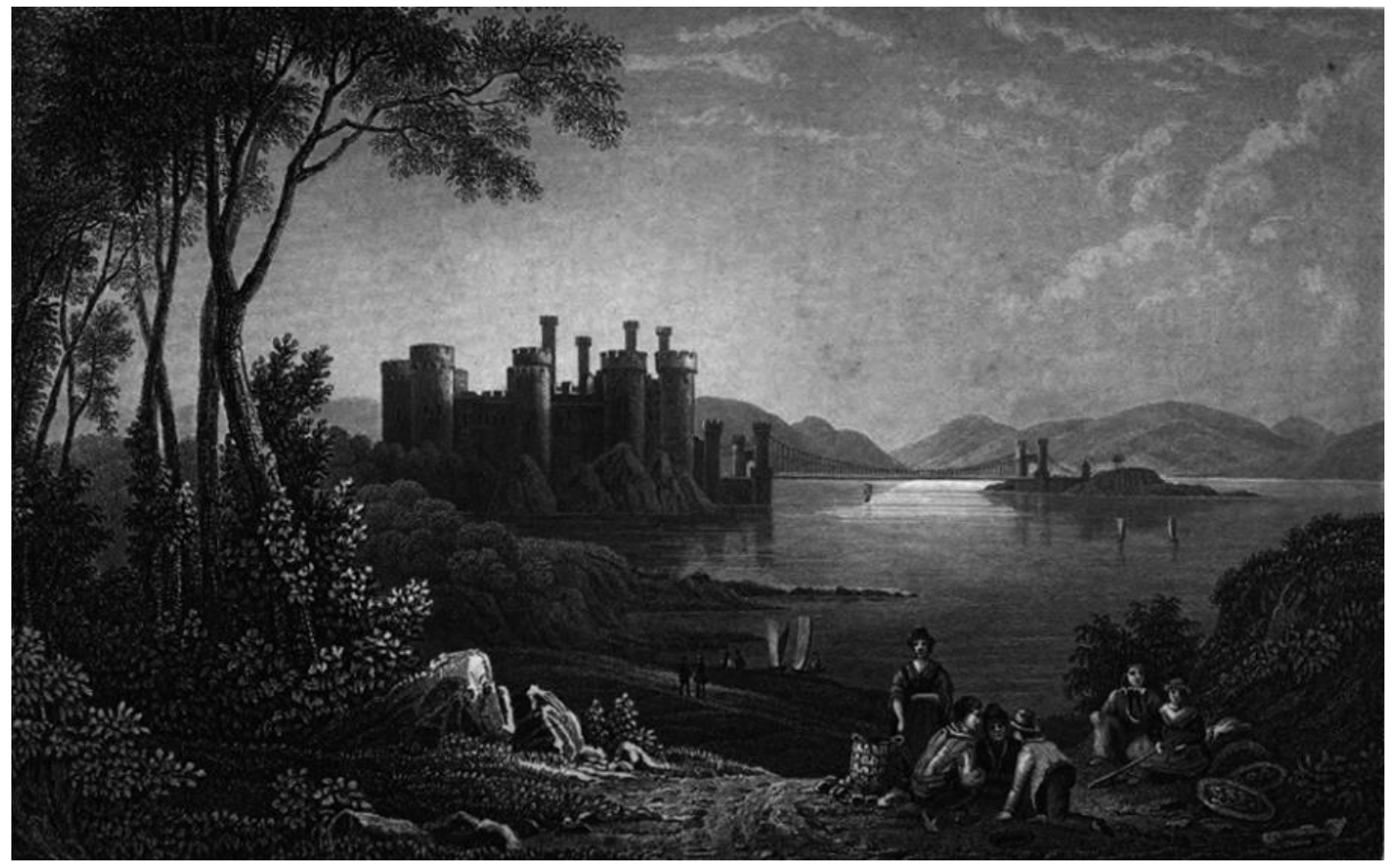

Figure 3: Depiction of Conwy Castle in Meyers Reisebücher. ${ }^{469}$

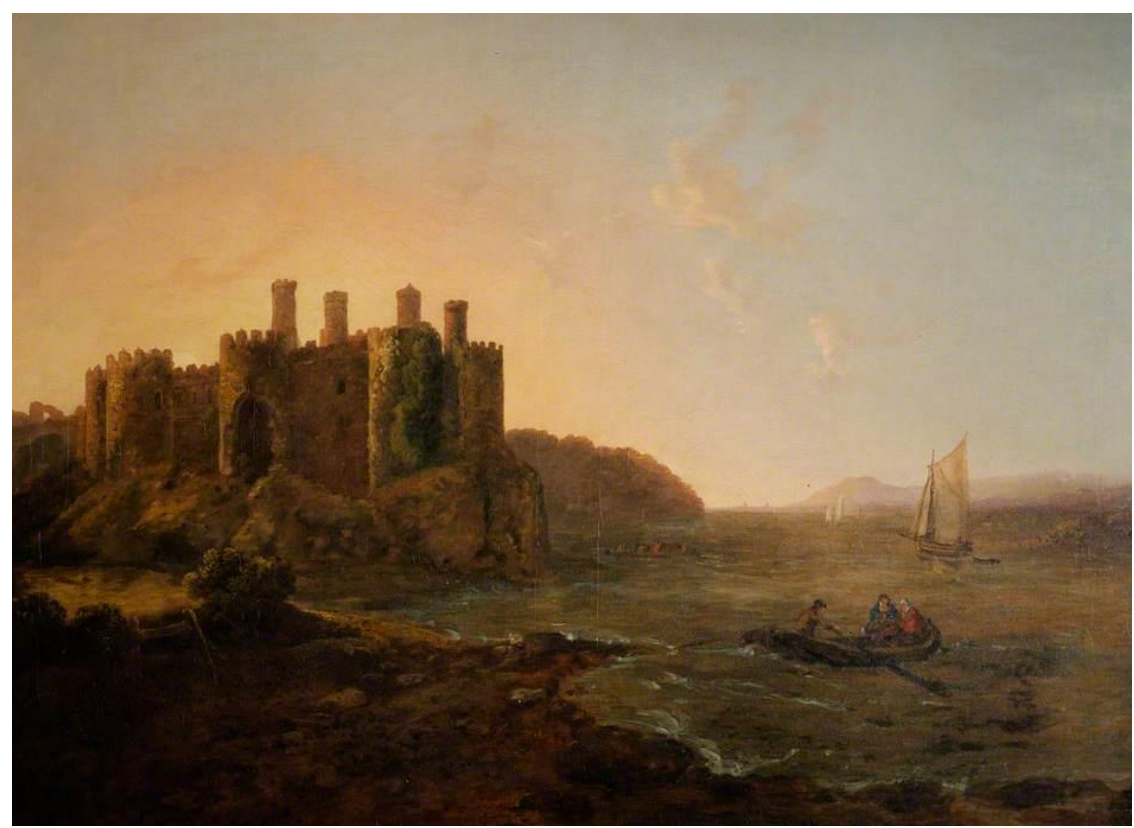

Figure 4: Richard Wilson's depiction of Conwy Castle. ${ }^{470}$

${ }^{469}$ Ravenstein, Reisehandbuch für London, England und Schottland, p. 541.

${ }^{470}$ Richard Wilson, Conwy Castle (Conwy: Guildhall, 1714-1782). 
It can be contended that as a result of this close connection between the landscape and certain aesthetic doctrines which are clearly part of the guidebooks' representations of Wales, tourists literally become 'chasers of images', ${ }^{471}$ in search of landscapes and scenes which resemble works of art, or that could be turned into artistic images. However, this occurrence is not unique to Wales; other parts of Great Britain are also described as malerisch or pittoresque. ${ }^{472}$ In this regard, there is hardly anything particularly Welsh about this emphasis on aesthetic landscapes. It was argued in Section 3.3 that Wales was regarded as an indistinguishable part of England, lacking clear borders or boundaries that enclosed a definable Welsh space. The aesthetic value that is bestowed upon the country is also not unique; again the guidebooks fail to create a distinctive Wales.

In addition to these picturesque, natural landscapes which were strewn with ruinous monuments, the industrial landscape is also valued for its artistic and aesthetic value. Both Baedeker and Guides Joanne do not dismiss the possibility of the traveller personally visiting furnaces and slate quarries because of their presumed aesthetic qualities. Regarding the valley of Merthyr Tydfil, Baedeker states: 'Der Anblick des Thales bei Nacht, wenn zahllose Hohöfen mit düsterem Schein aus dem Dunkel hervorleuchten, ist imposant. Von den zahlreichen Eisenwerken sind am leichtesten zugänglich die Cyfarthfa Iron Works' [The sight of the valley by night is imposing, as the countless furnaces light up from the darkness with a gloomy brightness. Of the numerous ironworks, the Cyfarthfa Iron Works are the most easily accessible]. ${ }^{473}$ This response is reminiscent of the aesthetic principle called the 'Industrial Sublime', which influenced many travellers and artists during the end of the eighteenth and the beginning of the nineteenth century (see Section 2.2). This approach appreciated the drama of the industrial world, and especially the view of the furnaces by night. ${ }^{474}$ Not only does Baedeker's description aestheticise the industrial landscape, but it also recommends the furnaces as worthwhile sights for the

\footnotetext{
${ }^{471}$ Dann, The Language of Tourism, p. 83.

472 Some examples can be found here, though this list is not at all exhaustive: Ravenstein, Reisehandbuch für London, England und Schottland, pp. 111, 388, 460; Nouveau Guide à Londres, pp. 161, 286, 326; Darcy, pp. 329, 439, 581.

${ }^{473}$ Baedeker, Grossbritannien, p. 161. Emphasis of orginal.

${ }^{474}$ Lord, pp. 29-31.
} 
tourist. ${ }^{475}$ The Guides Joanne has a similar point of view and describes the Swansea Valley as follows: 'La vue de vallée, qu'ils parcourent pour se rendre dans cette dernière ville, est extraordinaire. Durant la nuit, une clarté flamboyante s'échappe d'une multitude de fours à coke; le jour, d'épais nuages de fumée s'élèvent des mille cheminées des usines' [The view of the valley which is crossed when travelling to that city is extraordinary. At night, a blazing light comes from the multitude of coal furnaces; during the day, thick clouds of smoke rise from the thousands of factorychimneys]. ${ }^{476}$ Apart from these two series, the industrial sublime does not seem to be part of the general discourse used for Wales. However, there was a strong socioeconomic interest in the industrialised areas of Wales, which will be discussed in Section 3.4.3.

\subsubsection{Snowdonia: Viewing Wales Through a Swiss Lens}

One geographical area in particular should be highlighted here, and that is Snowdonia. As was shown earlier in this chapter, the northern part of Wales was usually described most elaborately. Compared to other regions within Wales, it was often depicted more as an entity by describing North Wales in a distinct chapter and by grouping itineraries together. Touristically, the guidebooks frequently regard the North as the most worthwhile area of Wales, which is for example introduced by Baedeker as follows: 'Er umfaßt eine Anzahl der schönsten Gebirgs-, Küsten- und Thallandschaften der britischen Inseln, und wenige Gebiete gleichen Umfangs dürften sich mit "Snowdonia" an Mannigfaltigkeit der Naturschönheiten messen können' [It includes a number of the most beautiful mountains, coastlines and valleys of the British Isles, and few areas of equal size can compete with 'Snowdonia' regarding its variety of natural beauties]. ${ }^{477}$

Climbing Snowdon was one the main attractions for visitors to Wales, and the mountain generally receives a significant amount of attention in the guidebooks. ${ }^{478}$ As a tourist site, it is not so much the activity of climbing the mountain that is

\footnotetext{
${ }^{475}$ For more on the aestheticisation of industrial landscapes, see: Tilman Fischer, Reiseziel England: Ein Beitrag zur Poetik der Reisebeschreibung und zur Topik der Moderne (1830-1870) (Berlin: Erich Schmidt Verlag, 2004), pp. 515-7.

${ }^{476}$ Esquiros, p. 188.

477 Baedeker, Grossbritannien, p. 232.

${ }^{478}$ See, for example: Ravenstein, Reisehandbuch für London, England und Schottland, pp. 538-9; Baedeker, London nebst Ausflügen (1866), p. 268; Richard and Joanne, p. 70; Esquiros, p. 272.
} 
regarded as the reason for its popularity. Instead, it is primarily the panorama at the top that the guides praise. It is from the summit that the tourist would be able to have an extensive view over various parts of Great Britain. The 1899 Baedeker guide describes Snowdon in most detail, devoting no less than four pages to the climb and view from the top, which is given a double asterisk. ${ }^{479}$ The panorama is described extensively:

Die **AUSSICHT vom Gipfel des Snowdon, obschon kaum so malerisch und großartig wie einige der schottischen Bergpanoramen, ist sehr ausgedehnt und mannigfach und umfaßt den größern Teil von Nord-Wales, eine weite Meeresfläche und über 20 Bergseen. Am schönsten ist die Aussicht bei Sonnenaufgang oder -Untergang [...]: doch ist der Gipfel oft ganze Tage lang in Nebel gehüllt und der Reisende möge daher auf eine Enttäuschung gefaßt sein. Der Nebel ist andrerseits kein unbedingtes Übel, da einige der schönsten Beleuchtungs-Effekte durch sein Steigen oder Zerteilen erst möglich werden. ${ }^{480}$

[The **VIEW from the summit of Snowdon, although hardly as picturesque and magnificent as some of the Scottish panoramas, is very extensive and manifold. It covers the largest part of North Wales, a considerable expanse of the sea and more than twenty mountain lakes. The view is most beautiful at sunrise or sunset [...]: however, mist often enshrouds the summit for days in a row and travellers may thus prepare themselves for a disappointment. Conversely, the mist is not necessarily a misfortune, since some of the most striking light effects are caused by its rising or disappearance.]

The traveller is thus instructed how, when and in what circumstances to appreciate the view from the summit. Subsequently, a detailed description is provided of what can be seen there in every direction. A panorama map of the view from Snowdon is also included (Map 3).

${ }^{479}$ Baedeker, Grossbritannien, pp. 271-5.

${ }^{480}$ Baedeker, Grossbritannien, p. 272. 


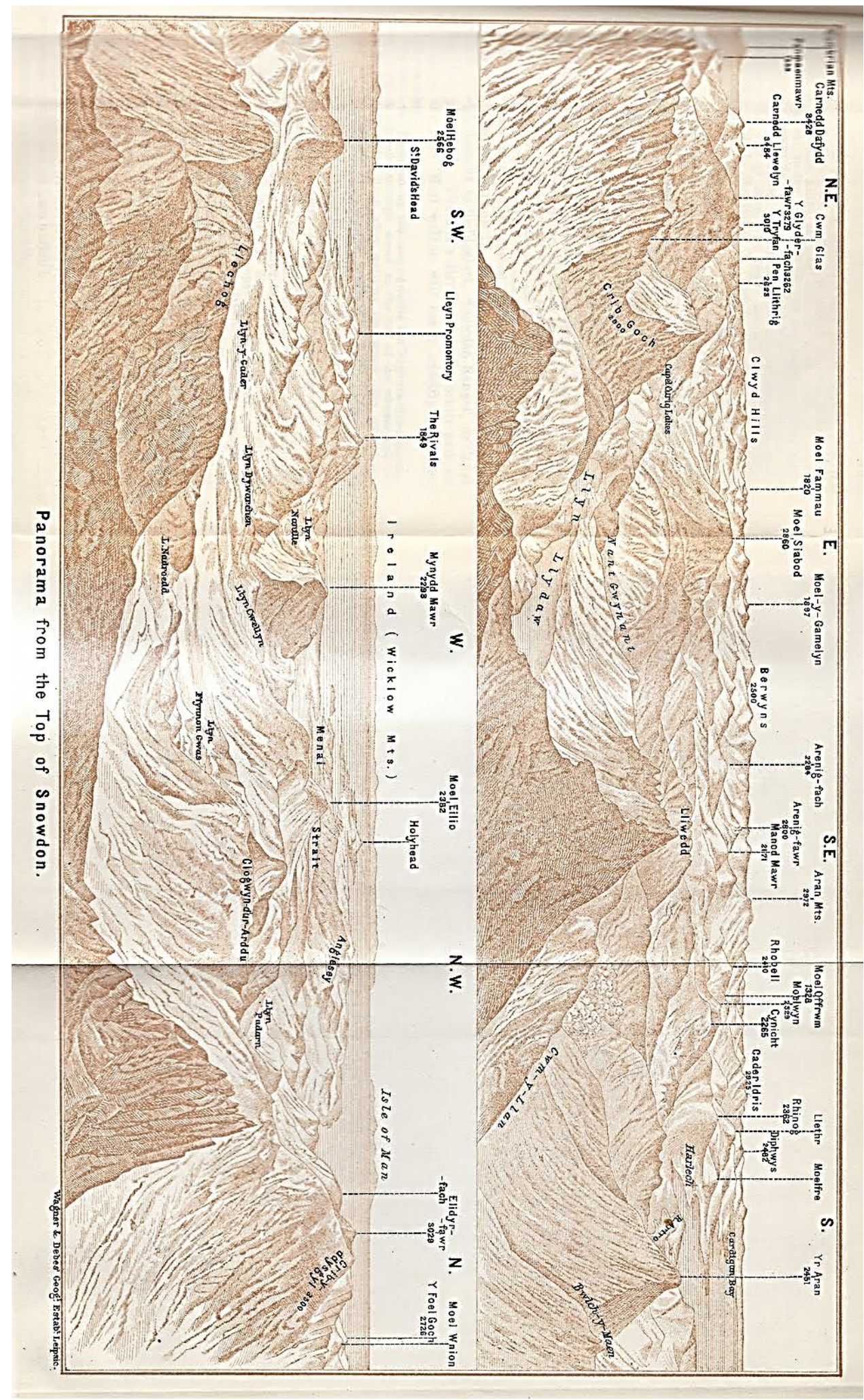

Map 3: Thanks to Baedeker's guide, travellers were able to discern everything they saw from the top of Snowdon. ${ }^{481}$

${ }^{481}$ Baedeker, Grossbritannien, p. 272. 
It can be argued that the panoramic overview and Baedeker's cartographical representation of it serve as a 'pattern for organizing visual experience'. ${ }^{482}$ As Stephan Oettermann asserts, climbing mountains became increasingly popular in the nineteenth century due to their purpose as viewing points. ${ }^{483}$ The panorama offered the tourist a means to grasp the landscape, to understand it, and therefore ultimately control it. Consequently, Wales, whilst described by eighteenth-century travellers as a 'barren' place, was now appropriated by guidebooks by turning the landscape into an easily understandable, and therefore no longer threatening, consumable commodity. In this respect, the Guides Joanne adds a noteworthy anecdote about Snowdon: 'On a dit que César était sans doute assis sur les hauteurs du Snowdon quand il forma le projet ambitieux de gouverner le monde' [They say that Caesar probably sat on the heights of Snowdon when he made his ambitious plans to rule the world]. ${ }^{484}$ Climbing Snowdon and viewing the world at its feet thus becomes a way of subjugating and controlling nature, or, as is implied by the Guides Joanne, even the globe.

The satisfaction of 'conquering nature' was vital in the emergence and spread of mountaineering during the eighteenth and nineteenth century, and contributed significantly to the popularisation of the Alps in this period. ${ }^{485}$ However, more mainstream and less adventurous travellers were also attracted to the Alps. Arising from the Romantic ideals of a return to nature, in combination with increasing urbanisation, many nineteenth-century tourists were seeking the qualities of fresh country air and an opportunity to get away from it all, which led to the growing popularity of the Alps as a destination for early modern tourism. ${ }^{486}$ From the $1830 \mathrm{~s}$ onwards, alpine mountain ranges were explored by organised groups, as well as individuals guided by handbooks. ${ }^{487}$ This development was an important contributing factor to the increasing interest in Wales, as is argued by Maurer:

\footnotetext{
482 Stephan Oettermann, The Panorama: History of a Mass Medium, trans. by Deborah L. Schneider (New York: Zone Books, 1997), p. 7.

483 Oettermann, p. 11.

${ }^{484}$ Esquiros, p. 272.

485 See: Alan Ewert and Stacy Taniguchi, 'The Motivations and Satisfactions Attendant to Mountaineering', in Mountaineering Tourism, ed. by Ghazali Musa, James Higham and Anna Thompson-Carr (Abingdon: Routledge, 2015), pp. 156-80.

${ }^{486}$ See: Nordman, p. 530; Koshar, German Travel Cultures, pp. 58-60; Walton, p. 119.

${ }^{487}$ See: Koshar, German Travel Cultures, pp. 57-58; Löfgren, p. 34.
} 
Die Blicklenkung deutscher Reisender auf Wales ging von dieser Voraussetzung aus: Sie wähnten, in Wales Schweizer Alpenlandschaften zu finden. Das bedeutet gleichzeitig, daß nicht das ganze Land für sie gleichermaßen interessant war, sondern sich ihr Augenmerk auf 'Snowdonia' richtete, die Gegend um den höchsten Berg herum. ${ }^{488}$

[The gaze of German travellers was steered towards Wales because they imagined themselves surrounded by Swiss alpine landscapes. This simultaneously implies that they were not interested in the whole country, but primarily in 'Snowdonia', the area around the highest mountain.]

This asserted resemblance between Wales and Switzerland is also emphasised by the guidebooks, most likely in order to increase the touristic appeal of the country to its readers. The Welsh mountain Cnicht, for example, is called the 'Matterhorn von Wales', ${ }^{489}$ and Llanberis is described as the 'Chamonix von Wales' ${ }^{490}$ This comparison of Wales to the Alps is by no means restricted to the German guidebooks. The French guides also frequently designate the Welsh mountains as 'alpine landscapes'. ${ }^{491}$ It can be argued that due to these comparisons between Wales and Switzerland, the latter is used as a lens through which to view the former. Expectations of Wales are consequently influenced and shaped, using Switzerland as a prism through which to perceive Wales. As a result, the guidebook user is even less likely to identify Wales as a culturally distinctive and unique part of Great Britain, but instead focuses on viewing Wales as an alpine substitute.

\subsubsection{The Industrial Landscape: A Journey into the Future}

This emphasis on Wales's natural beauty does not imply that the industrial landscape was ignored. As was asserted in Section 3.4.1, some guides recommended industrial sights from an aesthetic point of view. Furthermore, these sights were also deemed worthwhile due to their innovative and modernising value. The guides present industrial developments and architectural achievements as important incentives for travelling. For German travellers, France and Great Britain were generally noticeable destinations in this respect, since industrialisation had occurred here earlier than in Germany, which was slowly advancing and only started to

\footnotetext{
${ }^{488}$ Maurer, p. 14.

${ }^{489}$ Baedeker, Grossbritannien, p. 271.

${ }^{490}$ Baedeker, Grossbritannien, p. 267.

${ }^{491}$ See, for example: Darcy, p. 248; Richard and Joanne, p. 70. Another noteworthy example in this respect is the comparison between Swansea's beach and Naples: Esquiros, p. 189.
} 
develop its industry by the middle of the nineteenth century. ${ }^{492}$ According to Wolfgang Kaschuba, Germans were still travelling out of Natursehnsucht [longing for nature] during this period, but an interest in new societies and modern worlds developed simultaneously. He subsequently argues that travelling became a journey through time:

Je nach Land und Gesellschaft zeigt sich hier Vergangenes und dort Zukünftiges. [...] Wer die Natur sucht, [...] der reist quasi zurück in der Zeit. Wer umgekehrt die 'Moderne' aufsucht in Paris oder London, reist nach vorn, betrachtet dort die Zukunft der eigenen Gegenwart. ${ }^{493}$

[Depending on country and society, the traveller can experience history here or future there. [...] People who are looking for nature [...] are more or less travelling back in time. People who, on the contrary, visit 'modernity' in Paris or London travel forwards, observing the future of their own present.]

Kaschuba asserts that seeing technological and innovative sites and sights was the main activity during such travels into 'the future':

\begin{abstract}
Unterwegs und am Ziel wird dann oft ein regelrechtes Technik-Besichtigungsprogramm absolviert: neue Fabriken und Brücken, Maschinenanlagen und Kriegsschiffe. [...] Kaum eine Reise besonders nach Frankreich oder England wird mehr unternommen, ohne solche Technik-Impressionen einzuplanen. ${ }^{494}$

[During the journey and at the destination, travellers often completed an actual technologysightseeing tour: new factories and bridges, mechanical constructions and warships. [...] Hardly any journey to France or England was undertaken without planning visits to such technological sights.]
\end{abstract}

Although it has been asserted that Wales was primarily visited because of its natural features (which Kaschuba calls a journey into the past), the next section will show that industrial progress was also an important feature of Wales as a travel destination in the nineteenth century.

Kaschuba implies that travellers either went 'into the future' (inspecting industrial and architectural sites) or 'into the past' (searching for unspoilt nature), but the guidebooks do not regard industry and nature as mutually exclusive and portray Wales as offering both to the traveller. The Baedeker series in particular is illuminating in this respect, and the development of this guidebook series and its

\footnotetext{
${ }^{492}$ Tom Kemp, Industrialization in Nineteenth-Century Europe, 2nd edn (London: Longman, 1985), p. 93.

${ }^{493}$ Wolfgang Kaschuba, 'Erkundung der Moderne: Bürgerliches Reisen nach 1800', Zeitschrift für Volkskunde, 87 (1991), 29-52 (pp. 35-36).

${ }^{494}$ Kaschuba, pp. 45-46.
} 
focus on industry and modern advancements will be discussed in some detail. Regarding the Baedeker guidebooks, it has been claimed that these travel texts especially appreciated modernity. ${ }^{495}$ According to Rudy Koshar, this is because of its intended readership, the so-called 'cultured Bürger', who had a 'love of technology, consumption, and material advance' ${ }^{496}$ He remarks that for Baedeker, combining cultural, natural and industrial sites in the guides was not regarded as contradictory.

The guidebooks to Great Britain from this series illustrate this point perfectly. In the preface to its 1899 Grossbritannien edition, Baedeker highlights the versatile nature of Britain as a tourist destination, being an exemplary combination of different kinds of touristic aspects: 'Die britischen Inseln bieten sowohl dem Natur- und Kunstfreunde wie dem Techniker und Industriellen soviel des Interessanten, daß ihr Besuch auch von Deutschland aus unzweifelhaft mehr und mehr zunehmen wird' [The British Isles offer people who are interested in nature and art, as well as in technology and industry, so many interesting sights that the number of visitors from Germany will also doubtlessly increase $].{ }^{497}$ As will be shown below, this evaluation was also considered to hold true for Wales. Even though the picturesque landscape was arguably seen as the most important reason for travelling to Wales, the country's industrialisation was not considered incompatible with this. Sites that display Wales's modernisation are frequently recommended, and it can therefore be contended that to make a journey to Wales was also to make a journey into the 'future'.

The 1866 Baedeker guide, for example, awards two double asterisks to sites in Wales; the first one to the 'romantische **Cwm Elan' [romantic **Cwm Elan], ${ }^{498}$ a typically picturesque site, but the second one is awarded to the Britannia Bridge. 499 This bridge, which had been completed in 1850, was regarded as a state-of-the-art design and a significant engineering accomplishment. The final stages of the building process attracted the attention of engineers and sightseers alike. ${ }^{500}$ Modern achievements are thus recommended, and detailed information is provided about the

\footnotetext{
${ }^{495}$ Burkhart Lauterbach, 'Baedeker und andere Reiseführer: Eine Problemskizze', Zeitschrift für Volkskunde, 85 (1989), 206-34 (p. 219); Koshar, "WWhat Ought to Be Seen”, p. 333; Koshar, German Travel Cultures, pp. 48-50.

${ }^{496}$ Koshar, German Travel Cultures, p. 48.

${ }^{497}$ Baedeker, Grossbritannien, p. v.

${ }^{498}$ Baedeker, London nebst Ausflügen (1866), p. 265. Emphasis in original.

${ }^{499}$ Baedeker, London nebst Ausflügen (1866), p. 269.

${ }^{500}$ John Rapley, The Britannia \& Other Tubular Bridges: And the Men Who Built Them (Charleston: Tempus Publishing, 2003), pp. 10, 105-7.
} 
construction process, the length, height and weight of the bridge. The apparent contradiction between the two main features of Wales (picturesque landscape and modern constructions) is noted by Baedeker, but is not seen as irreconcilable: 'Malerisch ist die Brücke natürlich nicht; für den Laien sieht sie sogar beim ersten Anblick ziemlich unscheinbar und ganz einfach aus. Bei näherer Betrachtung, namentlich von unten, gewinnt man erst einen Begriff der wirklichen Verhältnisse' [The bridge is of course not picturesque; in the eyes of a layman it even looks quite unprepossessing and very simple. Only on closer examination, especially from below, one can comprehend its true proportions]. ${ }^{501}$ A clear admiration for the scale of the construction becomes apparent from this remark and the detailed description of the bridge.

Not only architectural phenomena are described admiringly; industrial sites are also considered worthwhile for the tourist, for example the Merthyr Tydfil Ironworks and Pembroke Dockyards. ${ }^{502}$ The 1899 Baedeker guide to Great Britain even expanded its descriptions of Wales's industry, and this contradicts Burkhart Lauterbach's assertion that only the Baedeker handbooks from the first half of the nineteenth century include industrial sites whilst they are almost completely omitted in later editions. ${ }^{503}$ Despite the fact that during the 1870 s and 1880 s Germany's industrialisation was catching up with its French and British rivals, ${ }^{504}$ the descriptions of sites such as Merthyr Tydfil and Cardiff's industrial centres still testify to an evident admiration for Britain's manufacturing works and industrial development. The guide informs its reader regarding the Cardiff Docks: 'Die prächtigen Docks [...] wurden von dem verst. Marquis of Bute, dem Besitzer des Bodens, erbaut, dessen Unternehmungsgeist und Thatkraft die Stadt einen großen Theil ihrer jetzigen Blüte verdankt' [The magnificent Docks [...] were built by the late Marquess of Bute, the owner of the land. The town owes a large part of its current growth to his initiative and energy]. ${ }^{505}$ Merthyr Tydfil, in the nineteenth century one of the most important centres for the iron industry in Wales and

\footnotetext{
${ }^{501}$ Baedeker, London nebst Ausflügen (1866), pp. 269-70.

502 Baedeker, London nebst Ausflügen (1866), pp. 259, 261.

${ }^{503}$ Lauterbach, p. 219.

${ }^{504}$ Kemp, pp. 100-1.

${ }^{505}$ Baedeker, Grossbritannien, p. 160. Emphasis in original.
} 
Europe, ${ }^{506}$ is described as a gewerbthätige [industrious] town, ${ }^{507}$ which had only begun to flourish during the preceding fifty years. Merthyr Tydfil's and Cardiff's development and growth are thus seen as results of industrialisation, which is positively evaluated in the guide, and it can therefore be argued that Baedeker directly connects industrialisation to progress and socio-economic advancement.

A first indication of the museumification of Wales's industry can also be discerned: the traveller is advised which furnaces to visit, and at what time the blasting in the slate quarries takes place. Especially the slate industry, at that time already in decline despite some short-lived upturns, ${ }^{508}$ is apparently starting to recognise the possibilities of the tourist industry which was, on the contrary, rapidly growing towards the end of the nineteenth century. According to the guide, the tourist can for example try to split slate at the Penrhyn Slate Quarry (presumably in exchange for a small payment) as a form of entertainment, and it was apparently also possible to buy slate souvenirs at the entrance. Moreover, the narrow-gauge Ffestiniog railway, originally built for the transport of slate from Blaenau Ffestiniog to Porthmadog's harbour, was opened for passengers in 1865 and is suggested by the guide as a touristic attraction. ${ }^{509}$

Negative consequences of industrialisation, for example on the environment, are marginalised by Baedeker: 'Bei bestimmten Windrichtungen ist Swansea ganz in den Rauch der Kupferwerke gehüllt, der indeß für die Gesundheit weniger nachteilig ist als man annehmen sollte' [With certain wind directions, Swansea is completely enshrouded in the smoke from the copperworks which is, however, less detrimental to public health than one would assume]. ${ }^{510}$ The fact that there were frequent protests over the filth produced by the factories shows that in reality pollution was a highly controversial point of debate. ${ }^{511}$ Although Baedeker does not consider environmental issues any further, this does not imply that the evaluation of industry is unambiguously positive. On the one hand, the slate quarries are described as

\footnotetext{
${ }^{506}$ See: Davies, A History of Wales, p. 372. The Cyfarthfa Ironworks in Merthyr Tydfil traded with America, and delivered rails to Russia as well as Austria.

${ }^{507}$ Baedeker, Grossbritannien, p. 161.

${ }^{508}$ See: Merfyn Jones, The North Wales Quarrymen, 1874-1922 (Cardiff: University of Wales Press, 1981).

${ }^{509}$ Baedeker, Grossbritannien, p. 266.

${ }^{510}$ Baedeker, Grossbritannien, p. 164.

${ }^{511}$ Davies, A History of Wales, p. 393.
} 
impressive spectacles, but on the other hand they are also said to disfigure the natural surroundings. ${ }^{512}$

Compared to the Baedeker series, the other major German-language series from this period, Meyers Reisebücher, focuses less clearly on Wales's modernising aspects. Although the Britannia Bridge is described in detail, thus showing a clear interest in modern architecture, ${ }^{513}$ other industrial sites are not particularly highlighted as touristically worthwhile. Two explanations for this difference between these series can be suggested. Firstly, as was mentioned earlier in this chapter, Meyers Reisebücher did not describe Wales further south than Aberystwyth. Major industrial centres such as Merthyr Tydfil are therefore not included. Secondly, Meyer's intended readership differed from Baedeker's. Instead of the cultured middle-class Baedeker readership which was interested in these topics, Meyer aimed his guidebooks especially at hikers. ${ }^{514}$ This could further explain the series's focus on North Wales, which was primarily an area for mountaineering activities due to its landscape.

In comparison to the German-language nineteenth-century guidebooks, the French guides show less interest in Wales's industrial landscape. The Guides Garnier frères guide to Britain does not mention Welsh industry at all, apart from some references to harbours and commerce. Even the Menai bridges are not mentioned, which were generally considered architectural spectacles. ${ }^{515}$ Several other French guidebooks do praise the bridges as engineering miracles, describing the Britannia Bridge as the 'huitième merveille du monde' [Eighth Wonder of the World] ${ }^{516}$ and the Tubular Bridge as the work of a genius and 'orgueil des temps modernes' [pride of modern times]. ${ }^{517}$ Industrial sights are also favourably described in the French guidebooks. They are recommended as worthwhile for the tourist, but are less wholeheartedly admired as signs of progress. The Guides Richard handbook, for example, recommends the Cyfarthfa ironworks as 'chose à voir' [something to see]. ${ }^{518}$ The 1865 Guides Joanne guidebook suggests visiting the furnaces in the

\footnotetext{
512 Baedeker, Grossbritannien, pp. 242, 267.

${ }^{513}$ Ravenstein, Reisehandbuch für London, England und Schottland, p. 542.

${ }^{514}$ Hinrichsen, 'Zur Entstehung des modernen Reiseführers', p. 28.

515 Noteworthy in this respect is that the only pen-and-ink drawing of a Welsh sight that is included in this guide is from the Penrhyn Slate Quarry: Darcy, p. 251.

${ }^{516}$ Richard and Joanne, p. 148.

${ }^{517}$ Esquiros, p. 268.

${ }^{518}$ Richard and Joanne, p. 92.
} 
Swansea Valley in order for the tourist to get an idea of 'la grandeur et de la puissance des fournaises' [the grandeur and power of the furnaces]. ${ }^{519}$ Ore-smelting methods are considered to be of interest for the tourist, thus turning industrial processes into tourist sights. Moreover, the industrial and picturesque sides of the Welsh landscape are not regarded as incompatible, and are even mentioned in the same breath in the desciption of Aberafon: 'Petite localité situeé à l'embouchure de l'Avon, où l'on trouve des fonderies de cuivre considérables. Toute cette partie du pays de Galles est très-pittoresque [sic], couverte de monuments des anciens temps, et jouit de l'avantage d'un climat très-doux [sic]' [Small village situated along the estuary of the Avon, where one can find extensive ironworks. This whole part of Wales, which is strewn with ancient monuments, is very picturesque, and enjoys the advantages of a very mild climate]. ${ }^{520}$ The 'extensive ironworks' in the area are thus not seen as detrimental to its picturesque character.

Nevertheless, it is clear that the French guidebooks take a much more critical standpoint towards industrialisation than the German guides. Negative effects of the growing industry are mentioned, for example in the guide from the Bibliothèque du voyageur series:

\footnotetext{
Les richesses minérales ont donné une grande importance au comté de Glamorgan; d'immenses établissements ont été créés dans les parties les plus sauvages de ce comté, où la pierre à chaux, le charbon, le fer etc., abondent; les canaux, les routes, toutes les voies de communication ont été pratiqués, ouverts au prix des plus grands sacrifices pour faciliter les transports de tous les points du Glamorgan aux ports de la côte. ${ }^{521}$

[Mineral wealth has given great importance to the county of Glamorgan; huge enterprises have been established in the wildest parts of the county, where limestone, coal, iron etc. are abundant: canals, roads and all kinds of communication channels have been constructed, opened at the cost of great sacrifices to facilitate transport from every part of Glamorgan to the harbours on the coast.]
}

Although industrialisation is said to have contributed to the rising significance of Wales and has brought commercial activities to the country, the guide also remarks that Wales has paid a price for this. What these 'great sacrifices' entail is not further explained, but it may be assumed that the guide is referring to the destruction of the natural landscape. The same guide describes Merthyr Tydfil, admired by Baedeker because of its industry and Gewerbthätigkeit [commercial activities], as: 'une ville

\footnotetext{
${ }^{519}$ Esquiros, p. 188.

${ }^{520}$ Richard and Joanne, p. 65.

${ }^{521}$ Nouveau guide à Londres, p. 260.
} 
mal bâtie, triste, sale, située au milieu de collines nues et désolées; pas de monuments, pas de rues dignes de ce nom, pas même de sentiers practicables' [a badly built city, cheerless, dirty, situated in the middle of barren and desolate hills; no monuments, no streets worthy of such name, not even passable trails]. ${ }^{522}$ Unlike the Baedeker guides, which depicted industrialisation as a sign of progress and socioeconomic opportunity, this French-language guide emphasises the negative consequences industrialisation can have on the country.

The 1865 Guides Joanne expresses clear admiration for the industrialisation around Merthyr Tydfil, and meticulously describes the number of furnaces, workers and coal that is being mined there. However, the guide also states that despite this industrial prosperity, the town is 'sale, triste, malsaine, à cause de l'accumulation des habitants dans les rues étroites et fangeuses' [dirty, miserable, unsanitary due to the accumulation of people in the narrow and muddy streets]. ${ }^{523}$ Again, the negative consequences of industrialisation are mentioned, thus taking a more negative stance towards these developments than the Baedeker guides.

This difference between the French-language guides compared to their German-language counterparts becomes even clearer when the portrayals of the workers are scrutinised. Overall, guidebooks have been criticised for portraying countries devoid of humans. The most famous critique is probably by Roland Barthes, who asserted that humans are only used as 'un gracieux décor romanesque, destiné à circonvenir l'essentiel du pays: sa collection de monuments' [a graceful romantic background, destined to surround the essential parts of the country: its monuments]. ${ }^{524}$ Rudy Koshar describes this asserted de-humanisation very vividly, arguing that if we were to imagine places as they are described by Baedeker 'then the image of a society depopulated by the neutron bomb comes to mind. The monuments, churches and great factories still stood, but most inhabitants had made a mysterious exit, leaving an eerie "post-human" world behind'. ${ }^{525}$ Although people are indeed generally ignored and omitted from the landscapes described, in a few instances they are introduced. It is noteworthy that this primarily happens in the descriptions of the industrial sites, which is probably due to the fact that in these

\footnotetext{
522 Nouveau guide à Londres, pp. 260-1.

${ }^{523}$ Esquiros, p. 201

${ }^{524}$ Barthes, p. 114.

${ }^{525}$ Koshar, German Travel Cultures, p. 50.
} 
instances people were omnipresent and heavily involved in the various processes that were described. Moreover, as will be argued below, they were used to enhance the grandeur of these sites.

Baedeker for example mentions the workers at the Penrhyn Slate Quarry: 'Die Arbeiter, die günstigenfalls 25-30s. wöchentlich verdienen, arbeiten in Rotten zu viert; zwei brechen die Schieferblöcke los, während die beiden andern sie spalten und zurechtmachen' [The workers, who earn 25-30s per week at most, work in groups of four; two break off the blocks, whilst the other two split and dress the slate]. ${ }^{526}$ Although their salary is mentioned, which can be understood as criticising the low wages of the quarrymen, the workers remain voiceless objects of the tourist gaze. They function within the organisation of the quarry and are in that sense only cogs in a big machine. ${ }^{527}$ This can further be illustrated by the following quotation, still describing the Penrhyn Quarry:

Die Schieferbrüche von Penrhyn, angeblich die größten der Welt, beschäftigen über 3000 Arbeiter und liefern täglich c. 360 Tonnen Schiefer. Der Totaleindruck des Steinbruchs ist der eines gewaltigen Amphitheaters, dessen Stufen oder Terrassen je 15m hoch sind; doch gewinnt man keine genügende Vorstellung der ungeheuren Größe, bis man die pygmäenhaften Gestalten der Arbeiter in den untern Stockwerken erkannt hat. ${ }^{528}$

[The Penrhyn Slate Quarries, allegedly the largest in the world, employ more than 3000 workers and supply ca. 360 tons of slate per day. Overall, the quarry resembles an enormous amphitheatre, whose steps or terraces are $15 \mathrm{~m}$ high; however, one cannot comprehend its magnificent size until one has seen the pygmy-like figures of the workers on the lowest levels.]

Instead of understanding the workers' situation in a meaningful way, they are rather portrayed as part of a larger mechanism. They are used to amplify the vastness of the slate quarries by highlighting how insignificant and small these people are in comparison to their surroundings. As a result, the workmen are not described as individuals, but rather as, to use Esther Allen's words, 'a faceless collectivity' ${ }^{529}$

\footnotetext{
${ }^{526}$ Baedeker, Grossbritannien, p. 242.

${ }^{527}$ There is one noticeable exception to this 'objectification' of local inhabitants. In the 1866 Baedeker guide, a certain Robert Pugh is recommended as personal guide for climbing Cadair Idris (p. 265). For the same purpose, the 1889 edition refers to the 'weisen, alten "Cymru"' [wise, old 'Cymru'] (p. 257, in the 1899 edition this is omitted). It could be asserted, albeit not confirmed, that this 'wise, old' man is the same Robert Pugh. Baedeker could have preferred to omit his name in order to make the guide less personal (no other people are mentioned by name). It remains questionable, however, why Baedeker used the name Cymru [Wales]; he may have meant the word Cymro [Welshman]. This single mention of a specific person strikes the reader as unusual, since the guide normally refrains from giving such information.

${ }_{528}$ Baedeker, Grossbritannien, p. 242. Emphasis in original.

${ }^{529}$ Allen, p. 223.
} 
This seems to support Barthes's views that people were merely used as a decoration of the landscape. A social understanding of Wales is not achieved in this guide, as this aspect is not considered to be part of the tourist experience. As Burkhart Lauterbach conveys concisely: 'Ziel der Präsentation im Reiseführer ist nicht etwa Hinterfragung oder Kritik, sondern naturalistische Betrachtung, möglicherweise gar Bewunderung, in der sich eine affirmative Haltung gegenüber dem Geschehen und als sehenswürdig Empfohlenen ausdrückt' [The aim of the presentation in the guidebook is not to question or criticise, but rather to give a naturalistic impression, perhaps even admiration, whilst expressing an affirmative attitude towards the events which are described as worth seeing]. ${ }^{530}$

This idea of the unreflective, uncritical guidebook seems to apply to a lesser degree to the French-language guidebooks from this period. It has already been argued that these guides take a more critical stance towards industrialisation, and this is also noticeable in their depiction of humans, particularly the living conditions of the workmen. It must be stressed that overall the French-language guides do not take more notice of the workers than their German-language counterparts, and this subject is again largely absent from the descriptions. Normally, information is limited to the number of workers at a certain site, and occasionally they are used to enhance their surroundings in the same way as in the German guides. In the description of the Llanberis Slate Quarry, for example, the 1865 Guides Joanne remarks: 'Ces carrières donnent du travail à 2000 personnes, hommes et garçons. Les bruits et les mouvements de l'industrie humaine, encadrés dans la paisible et sauvage vallée de Llanberis, présentent un contraste frappant, bien digne d'intéresser le voyageur' [These quarries provide work for 2000 people, men and boys. The sounds and movements of human diligence, enclosed by the tranquil and wild valley of Llanberis, present a striking contrast, worthy of interest to the traveller]. ${ }^{531}$ In this example, the work of the quarrymen adds to the grandeur of the quarries themselves. Human activity is used to create a contrast to the otherwise quiet natural landscape of the valley.

However, in some instances the French-language guides do show a deeper consideration for the workers, and a critical attitude towards British society can be

\footnotetext{
${ }^{530}$ Lauterbach, p. 231.

${ }^{531}$ Esquiros, p. 272.
} 
discerned. After describing Merthyr Tydfil as a sad and dirty town with no decent streets and drainage, the Nouveau guide à Londres [New Guide to London] adds that all the inhabitants are employed in the mines, the ironworks and the furnaces. ${ }^{532}$ Due to this overall negative depiction of the town, the work of the inhabitants seems even less enviable, and these remarks suggest an implicit disapproval of the miners' living conditions. Unequivocal criticism is expressed in the 1865 Guides Joanne handbook, which takes an uncharacteristically engaged stand in favour of the workers in Merthyr Tydfil:

\begin{abstract}
La population des ouvriers elle-même est pauvre et ignorant. En 1845, sur 695 couples mariés, 1016 personnes étaient incapable de signer leur nom. Il serait temps que ceux qui profitent de ces travaux, sources de si grandes richesses, songeassent à améliorer l'état du peuple. ${ }^{533}$
\end{abstract}

[The working population itself is poor and ignorant. In 1845, 1016 people out of 695 married couples were unable to write their own name. It is time that those who benefit from these works, sources of such great richness, consider improving the condition of the people.]

Although the workers are called 'poor and ignorant', these traits are not considered to be inherent to these people and their class, but instead the factory owners are held responsible for their deprived state.

The more critical stance towards industrialisation and socio-economic problems in the French-language guides compared to the German-language material must be seen in a wider context of criticism by the French of the social situation in Great Britain towards the end of the nineteenth century. Great Britain had been an example of progress for many French people after 1815, and was often regarded as an enlightened country due to its freedom of the press and rapid industrialisation. ${ }^{534}$ However, during the second half of the nineteenth century, the working and living conditions of the lower classes in London and other industrial cities were openly criticised by French travellers. ${ }^{535}$ This socially critical discourse is also used in the guidebooks from this period. Moreover, as has been pointed out by Heather Williams, many French visitors viewed Wales's industry through the eyes of the competitor. ${ }^{536}$ Whereas German tourists could be overawed by the industrial

\footnotetext{
532 Nouveau guide à Londres, pp. 260-1.

${ }^{533}$ Esquiros, p. 201. The statistics presumably derive from the infamous Blue Book reports, published in 1847 , although the author could have quoted them from a different source as well.

534 Gerbod, p. 26.

535 Gerbod, pp. 109-10.

${ }^{536}$ Heather Williams kindly sent me her chapter draft for the jointly-authored book written by the researchers of the AHRC-funded research-project 'European Travellers to Wales: 1750-2010', which
} 
development of the economically superior British Empire, the French were primarily 'weary and humiliated' by the progress made by Britain in the post-Napoleonic period. ${ }^{537}$ The less enthusiastic and at times critical discussion of Wales's industry should therefore be read as revealing resentment of British progress. As Williams aptly states in respect to French travelogues and their discussion of industrial sites: 'The texts show that praising the technological advances of a clear rival goes against the grain for the French observers'. ${ }^{538}$ This is not to say that German travellers did not condemn the downside of industrialisation: the poverty and deprivation of the working class is also described by them. ${ }^{539}$ It was therefore certainly not the case that German visitors ignored these aspects, but it can be argued that the German-language guidebooks did not want to contradict the ideal of Great Britain as embodying the prime example of progress and modernity. ${ }^{540}$

Despite these differences between the French- and German-language guidebooks from this period, it can be concluded that these depictions of Wales significantly contributed to the spatialisation of the country. As was contended in Section 3.3, Wales was not clearly separated from England by imagined geographical borders or boundaries. Generally, the former was regarded as an indistinguishable part of the latter. The guidebooks' proposed main reasons for travelling to Wales, the picturesque and industrial landscape, can also be asserted to be not intrinsically linked to the country and its culture in any specific way. Picturesque landscapes could also be found elsewhere, in the UK but also in places like Switzerland, and industrial sites were abundant in different parts of Great Britain too.

Moreover, by depicting Wales as innovative and industrialised, the country becomes part of the centre. In Chapter 1 and 2, it was outlined how dichotomies between centre and periphery are established, and how the centre is usually perceived as the source of innovation and progress. By depicting Wales as being a prime example of innovative architecture and an industrialised world-leading area, it is thus presented as part of this centre. There is no perceived difference between Wales and England in this respect, which therefore merge together to form the modernising

is forthcoming. In this chapter, she discusses various French travel writers and their views of Wales during the long nineteenth century.

${ }_{537}$ Margaret Bradley and Fernand Perrin, 'Charles Dupin's Study Visits to the British Isles, 1816 1824', Technology and Culture, 32 (1991), 47-68 (47).

${ }^{538}$ See Williams's chapter in the forthcoming book mentioned above.

${ }^{539}$ See: Fischer, pp. 562-98.

${ }^{540}$ See: Fischer, p. 408. 
core. How this centre is subsequently evaluated (praised as progressive, or criticised as detrimental), differed slightly in the French- and German-language guides.

\subsection{Aspects of Welshness}

So far, the analyses of the nineteenth-century French- and German-language guidebook series have shown that Wales was primarily seen as a place of picturesque and sublime beauty, whilst industrialisation and modernisation were also given a fair share of consideration. However, these characteristics are not exclusively Welsh, and could also be found in other areas in Britain and Europe. As such, Wales was arguably not valued for its Welshness, its own particular identity. This coincides with what was asserted earlier in this chapter, namely that Wales was not considered to be a clearly defined and bordered entity. On the whole, the country was primarily seen as an indistinguishable part of England, integrated into the industrialising and modernising centre.

This section scrutinises to what extent and how the guides do thematise Welshness and create a specifically Welsh space. Even though Wales is generally considered to be an integral part of England and Great Britain, the existence of a distinct sense of Welshness is at times also acknowledged. By examining certain aspects of Welshness, such as culture, language and history, the conceptualisation of a distinct Welsh space in these texts will be explored. For reasons of coherence, the two languages will be discussed separately here. This will enable the analysis to highlight chronological changes in the guidebooks' representations, as well as underline differences between the languages.

\subsubsection{German Views: Adding a Dash of Otherness}

It has already been pointed out that in the German-language travel handbooks, Wales was not discussed in a separate chapter, and was usually not given a clear introductory section. Nevertheless, before the description of the first itinerary that runs through Wales, some of the guidebooks provide a few preliminary remarks. The following passage originates from the 1866 Baedeker guidebook:

Wales ist ein 50 Stund. langes, 15-30 Stund. breites Gebirgsland mit 1,112,000 Einw. Von den niedern Classen wird überall die alte britische ('Welsh') Sprache gebraucht; in den 
besuchtern Gegenden jedoch versteht man English. Der Name 'Wales' ist angelsächs. Ursprungs und heisst 'Land der Fremden': das Adjektiv ‘Welsh' entspricht dem deutschen 'wälsch'. Die Bewohner zeigen sich durch kräftigen Wuchs aus und zeigen gewöhnlich eine grosse Anhänglichkeit für ihre wilden Thäler und Berge. ${ }^{541}$

[Wales is a 50hr-long, 15-30hr-wide mountainous country with 1,112,000 inhab. The old British ('Welsh') language is used everywhere by the lower classes; in the more visited areas English is however understood. The name 'Wales' has an Anglo-Saxon origin and means 'Land of Strangers': the adjective 'Welsh' corresponds to the German 'wälsch'. The inhabitants are sturdily built and usually show a great affection for their wild valleys and mountains.]

The Meyers Reisebücher guidebook, published only shortly after this Baedeker edition, provides a very similar first impression of Wales, its inhabitants and language:

Von den 1,111,780 Bewohnern (im Jahre 1861) redet ein grosser Theil noch seine alte kymrische Sprache. In den Städten und Gasthöfen spricht man natürlich auch englisch. 'Welsh' oder 'Welch' entspricht dem deutschen 'Wälsch', und Wales ist 'Wälschland', das Land der Fremden. Eigenthümliche Trachten und Sitten haben sich in einigen Theilen des Landes erhalten. ${ }^{542}$

[A large part of the 1,111,780 inhabitants (1861) still speaks its old Cymric language. In the towns and inns of course they also speak English. 'Welsh' or 'Welch' corresponds to the German 'Wälsch', and Wales is 'Wälschland', the Land of Strangers. Characteristic costumes and customs have been preserved in some parts of the country.]

These two quotations differ significantly from what has hitherto been said about the portrayal of Wales. In these instances, Wales is not regarded as an indistinguishable part of England, but its apparent otherness is instead emphasised. Particularly the fact that only the anglophone name of Wales is provided, translated as Land der Fremden contributes to this othering. By using the English name, Wales is not only seen through German eyes, but also through English eyes, thus transforming the country through multiple lenses. Moreover, the connection is drawn between the English Welsh and the German wälsch. According to Grimm's German Dictionary, which allows insights into the historical usage of German words, this term generally referred to nations other than German. It was used to denote various peoples, and to underline the difference between these groups and the Germans (i.e. a sign of dissimilarity, 'they are not one of us'). Furthermore, it was often loaded with negative connotations. ${ }^{543}$ In these instances, a boundary between 'us' and 'them',

${ }^{541}$ Baedeker, London nebst Ausflügen (1866), p. 258.

${ }^{542}$ Ravenstein, London, England, Schottland und Irland, p. 701.

543 'Wälsch', in Das Deutsche Wörterbuch von Jacob und Wilhelm Grimm auf CD-ROM und im Internet, <http://germazope.uni-trier.de/Projekte/DWB/> [accessed 20 November 2014]. 
'self' and 'other', 'familiar' and 'foreign' is created and within this dichotomy Wales is clearly portrayed as the other. The characterisation of the language as old and the inhabitants as sturdily-built people wearing characteristic costumes further adds to the othering of Wales and Welshness. This depiction of Wales seems to correspond to Michael Maurer's observations that German travellers were looking for the 'unfamiliar', which had to be more exotic than England, since the latter was seen as akin to Germany. This unfamiliarity was thought to be found in Wales, ${ }^{544}$ which thus functioned as the opposite to England.

However, the assertion that tourists were drawn to Wales because of its otherness must immediately be called into question in the case of the guidebooks. Even though the quoted passages clearly contrast with what has been argued in the previous sections of this chapter, namely that Wales was an indistinguishable part of England, it can be contended that they do not negate this argument. The paragraphs are very brief and only form a small fraction of the whole representation of Wales and Welshness. It could therefore rather be asserted that they form an anomaly, albeit a remarkable one. Particularly when seen in context, it becomes clear that the othering of Wales should be interpreted as a noteworthy exception rather than a central theme in the conceptualisation of Wales in nineteenth-century Germanlanguage guidebooks. The Baedeker quotation is for example immediately followed by the sentence: 'Für den gewöhnlichen Reisenden wird es genügen, wenn einige der Haupt-Eisenbahnrouten nebst angrenzenden Sehenswürdigkeiten beschrieben werden' [For the ordinary traveller it will be sufficient to describe some of the main railway itineraries and their adjacent attractions], ${ }^{545}$ thus instantly downplaying any sincere curiosoity and interest in Welshness that the guide might have instigated amongst its readers. In the Meyers Reisebücher, Wales is described as '[d]as wellige Hügelland Englands' [the undulating uplands of England], shortly before commenting on the country's language and customs, thus once more conceptualising Wales as being part of England. ${ }^{546}$ It could therefore be argued that the quoted sections on Welshness might just have given Wales that pinch of otherness which could attract the attention of the guidebook reader, but they do not leave an evident mark on the general representation of Wales and Welshness.

\footnotetext{
${ }^{544}$ Maurer, p. 22.

${ }^{545}$ Baedeker, London nebst Ausflügen (1866), p. 258.

${ }^{546}$ Ravenstein, London, England, Schottland und Irland, p. 701.
} 
In the later editions of the Baedeker and Meyers Reisebücher guides, the awareness of and interest in Welshness seems to gradually increase. In the 1899 Baedeker edition, a brief paragraph about Wales has been added to the general preface about Great Britain which replaces the passage quoted above. Wales is no longer designated as Land der Fremden, but instead the Welsh name Cymru (albeit unexplained) is used in addition to '[d]as Fürstentum Wales' [the Principality Wales $].{ }^{547}$ Regarding the language and the costume, the guide informs its readers: 'Außer in ganz abgelegenen Bezirken wird English überall verstanden [...]. Die wälsche Nationaltracht wird der Reisende kaum mehr zu sehen bekommen' [English is understood everywhere, except in very remote areas [...]. Travellers will probably not get to see the Welsh national costume]. ${ }^{548}$ The spread of the English language in Wales can thus be traced throughout the guidebooks in this period. Whereas earlier guidebooks informed their readers that English is only understood in the most frequented regions, the 1899 Baedeker edition already asserts that English can be used almost everywhere in Wales. As such, the nineteenth-century German-language guides attest to the anglicisation of Wales during the late nineteenth century. It is also noticeable that the later Baedeker identifies the existence of a Welsh national dress, although it is immediately stated that this is also vanishing. Whilst the Meyers Reisebücher guidebook still in general refers to 'characteristic costumes', by the end of the century the concept of a Welsh national costume has become widely recognised in and outside Wales, and is being marketed as a tourist commodity. ${ }^{549}$

Noteworthy in this respect is the fact that the awareness of the Welsh language seems to increasingly permeate the German-language guidebooks towards the end of the nineteenth century. Whereas Welsh place names scarcely appear in the earlier Baedeker editions, they feature more abundantly, albeit unsystematically, in the Meyers Reisebücher from the 1870s; names such as $Y r$ Wyddfa [Snowdon] and Eryri [Snowdonia] are for example used and accompanied by explanatory translations. ${ }^{550}$ In the later 1899 Baedeker edition, Welsh place names feature to an

\footnotetext{
${ }^{547}$ Baedeker, Grossbritannien, p. xxix. Italics in original.

${ }^{548}$ Baedeker, Grossbritannien, p. xxix.

${ }^{549}$ See: Christine Stevens, 'Welsh Costume: The Survival of Tradition or National Icon?', Folk Life, 43 (2004), 56-70 (pp. 64-65).

${ }^{550}$ Ravenstein, Reisehandbuch für London, England und Schottland, p. 538. Language confusion concerning Welsh place names also occurs for example in the description on the same page of one of the paths leading up to Snowdon's summit: 'Capel Curig, die längste und schwierigste, aber auch die lohnendste Route. Von Gorphwysfa, am Fusse des Berges, 9 Meil. bis auf den Gipfel' [Capel Curig, the longest and hardest, but also the most rewarding route. From Gorphwysfa, at the bottom of the
} 
even greater degree, although still not systematically. Occasionally, German translations are provided: 'Carnarvon oder Caernarvon (Caer-yn-ar-Fon, die "Veste gegenüber Mona")' [Carnarvon or Caernarvon (Caer-yn-ar-Fon, the 'fortress opposite Mona')]. ${ }^{551}$ In some cases a transcription of the pronunciation is given: 'Pwllheli (spr. Puhltheli)' [Pwllheli (pron. Puhltheli)]. ${ }^{552}$ Although the existence of the Welsh language is thus slowly being recognised in the German-language guidebooks towards the end of the nineteenth century, it would be exaggerating to conclude that the guides celebrate it as an expression of distinct Welshness. The guides rather view it from a practical side; by adding pronunciation guidelines, a glossary of Welsh words often used in place names and by stating that 'eine oberflächliche Kenntnis der Aussprache der wälschen Namen ist wünschenswert' [a superficial knowledge of the pronunciation of Welsh names is desirable], ${ }^{553}$ the guidebooks appear to touch upon the theme of language primarily in order to provide the reader with informative facts rather than treating the language as a touristic curiosity. A possible reason for this increasing consciousness of the existence of the Welsh language can perhaps be attributed and paralleled to the emerging German academic appreciation of the Welsh language during the second half of the nineteenth century. In 1851, the German philologist Johann Kaspar Zeuß published the first volume of his seminal work Grammatica Celtica, which marks the beginning of Celtic studies in Germany. During the following decades, there were several Germanic scholars who contributed significantly to the field internationally, such as Ernst Windisch (1844-1918), Heinrich Zimmer (1851-1910) and Kuno Meyer (1858-1919). During the 1870s, Celtic studies were firmly established as an academic subject at various German universities, albeit often only as part of a wider Indo-European department. ${ }^{554}$

Although the language is perhaps not yet valued for its possible touristic appeal, it is noticeable that particularly the 1899 Baedeker guidebook seems to be

mountain, 9 miles to the summit]. The Welsh word gorphwysfa seems to refer here to a place name, but does in fact mean 'resting place'. The author of the guide was perhaps given directions by a local, and misunderstood his/her Welsh or Welshified English.

${ }^{551}$ Baedeker, Grossbritannien, p. 245. Emphasis in original.

552 Baedeker, Grossbritannien, p. 247. Emphasis in original.

${ }_{553}$ Baedeker, Grossbritannien, pp. xxix, 233.

554 See: Hildegard L.C. Tristram, 'Einleitung: 150 Jahre deutsche Hibernistik', in Deutsche, Kelten und Iren: 150 Jahre deutsche Keltologie - Gearóid Mac Eoin zum 60. Geburtstag gewidmet, ed. by Hildegard L.C. Tristram (Hamburg: Buske Verlag, 1990), pp. 11-53 (p. 20). 
increasingly aware of Wales as a space with unique cultural elements. This gradually growing responsiveness towards aspects of Welshness during the end of the nineteenth century also becomes apparent in the descriptions of Welsh mythology and history. Whereas there are no references to Welsh mythology in the Meyers Reisebücher and the earlier Baedeker guides, the 1899 Baedeker edition does refer to certain mythological tales that are directly connected to place names. ${ }^{555}$ However, these remain isolated cases and their impact on the overall conceptualisation of Wales as an integral part of the English centre is negligible.

In the case of the description of Welsh history, there appears to be a slight paradigm shift towards the end of the century. The earlier German-language guidebooks describe many castles, old abbeys and other ancient buildings, but omit their historical background. The description of such picturesque landscape features can be characterised by what James Buzard calls the 'aestheticised approach', which was initially formulated by Uvedale Price (see Chapter 2.2.1). This point of view divests landscapes, ruins and even people of every form of political, historical and moral connotation, and instead observes them from a distance, purely as objects. ${ }^{556}$ Baedeker mentions, for example, that Edward I built Conwy and Caernarfon castles, but describes them primarily as aesthetic edifices, encapsulating Conwy as 'malerisch' [picturesque] and Caernarfon as 'eine stattliche Ruine' [a magnificent ruin]. ${ }^{557}$ Their historical importance for Wales is thus ignored. Occasional references to historical events are described from an Anglo-Saxon perspective; the Welsh are for instance only mentioned in the general historical overview when they are subjugated by the Anglo-Saxons. ${ }^{558}$ Again, Wales is viewed through an English lens. Although Meyer denotes Llewelyn the Last as the 'letzte unabhängige Fürst von Wales' [last independent Prince of Wales] and refers to a number of historical events in Wales, these all focus on the subjugation and defeat of the Welsh, instead of their heydays or victories. ${ }^{559}$ The righteousness of Edward I's actions is not questioned and this partial view is strengthened by the fact that Welsh leaders and national

\footnotetext{
${ }^{555}$ For example the myth of Beddgelert and Llyn Idwal, see: Baedeker, Grossbritannien, pp. 270, 263.

${ }^{556}$ Buzard, 'The Grand Tour and after (1660-1840)', p. 46.

${ }^{557}$ Baedeker, London nebst Ausflügen (1866), pp. 267, 270.

${ }^{558}$ Baedeker, London nebst Ausflügen (1866), p. xxvi. Emphasis in original.

${ }^{559}$ Ravenstein, Reisehandbuch für London, England und Schottland, p. 544.
} 
heroes such as Owain Glyndŵr are called Häuptlinge and Rebellen [chieftains; rebels]. ${ }^{560}$

As was the case with the language and mythology, the 1899 Baedeker edition shows a growing understanding of Welsh history. Although the Edwardian castles are still primarily seen as aesthetic edifices, their original purpose as military strongholds used to prevent a Welsh resurgence is discussed more explicitly: ‘*CONWAY CASTLE, auf einem vom Fluß aufsteigenden Felsen prächtig gelegen, ist von O. (der Hängebrücke) aus gesehen, wohl die schönste Ruine in Wales. Es wurde von Eduard I. 1284 erbaut, um die Wälschen im Schach zu halten' [*CONWAY CASTLE, stunningly situated on a rock that rises from the river, is arguably the most beautiful ruin in Wales, especially as seen from the east (the suspension bridge). It was built by Edward I in 1284 to keep the Welsh in check]. ${ }^{561}$ Nevertheless, it remains doubtful whether this growing awareness of the historical participation of the Welsh is a positive change for their overall portrayal. Although Conwy Castle is no longer only seen as a sublime ruin without any military history, the Welsh are now portrayed as rebels. This image is further strengthened by the selection and description of other historical events. The Rebecca Riots, for example, are mentioned, as is Owain Glyndŵr's revolt, which both highlight the rebelliousness of the Welsh. ${ }^{562}$ It is noticeable that Glyndwor, who was called a freedom fighter in the 1866 edition, is now labelled Häuptling [chieftain].

Overall, it can be argued that the earlier nineteenth-century editions of the Baedeker and Meyer guidebooks largely ignore aspects of Welshness. Although brief paragraphs are inserted that appear to conceptualise Wales as a culturally distinct space, it must be emphasised that these sections are brief and should be read within their textual context in which Wales is generally downplayed as a touristic destination and described as part of England. However, towards the end of the century the guides, in particular Baedeker, start to pay more attention to these aspects. The language is gradually permeating the texts, and the 1899 Baedeker guidebooks is starting to intersperse its representation of the country with references to Welsh mythology and history. This is an important shift in the conceptualisation of Wales as a distinctive cultural space but should at the same time not be

\footnotetext{
${ }^{560}$ Ravenstein, Reisehandbuch für London, England und Schottland, pp. 536, 544.

${ }^{561}$ Baedeker, Grossbritannien, p. 239.

${ }^{562}$ Baedeker, Grossbritannien, pp. 168, 257 respectively.
} 
exaggerated. These instances remain isolated cases and do not significantly alter the representation of Wales as part of the innovative centre as was discussed earlier in this chapter.

\subsubsection{French Views: Celtomanic Wales}

Whilst short introductory paragraphs were added to the German-language guidebooks of this period which provided the reader with some general background information concerning the country's geography, culture and language, hardly any French-language guidebook does this. Usually, references to Welshness are scarce and itineraries through Wales are added without any form of preface in these texts. The following section highlights the references to Welshness that are made in these guidebooks, but it should be stressed that these remain isolated cases and that the overall attention given to a distinct sense of Welsh culture and identity is minimal.

There is one nineteenth-century French-language guidebook that includes an introductory section about Wales; the Nouveau Guide à Londres [New Guide to London] from the Bibliothèque du voyageur series. For this reason, this text deserves to be scrutinised in more depth at this stage. In the guide, the section about Wales is introduced by the following passage:

[Le pays de Galles] est peuplé des descendants des Gals ou Gaëls, qui s'établirent en Angleterre environ quatre-vingts ans avant Jules César. On y parle la vieille langue kymrique ou gaëlique. [...] Après que les Romains eurent soumis les Gaules, l'île de Bretagne reçut les druides et un grand nombre de fugitifs. Aujourd'hui, on rencontre encore dans quelques contrées de l'Angleterre et de l'Écosse, et à l'extrémité de notre Bretagne, ces débris de Celtes qui s'y maintiennent toujours purs de tout mélange étranger. ${ }^{563}$

[Wales is populated by the descendants of the Gals or the Gaels, who settled in England about eighty years before Julius Caesar. They speak the old Cymric or Gaelic language. [...] After the Romans had defeated the Gauls, the British Isles welcomed the druids and a large number of refugees. Nowadays, one still encounters remaining Celts in some parts of England and Scotland, as well as on the outskirts of our Brittany, who remain pure and immune to every foreign mixture.]

Although Wales is not explicitly mentioned as a geographical location in this passage, it can be assumed that the guide includes the country in the words 'some parts of England', as this section is used as an introduction to Wales specifically. It is especially noticeable that for the first time, the term 'Celtic' is being used in relation to Wales, its language and its inhabitants; a designation that was not at all apparent in

${ }^{563}$ Nouveau Guide à Londres, pp. 259-60. 
the nineteenth-century German guidebooks. In the quoted passage, a genetic connection is made between the French Gauls and the Celts, and the peripheral location they supposedly inhabit. A link is thus created between these various ethnic groups, whilst a distinction is simultaneously made between the Celts and the other people on the British Isles, presumably those of Anglo-Saxon descent. The country's Celtic identity starts to emerge as a topic of touristic interest, and racial origins begin to play a role in the guidebooks. ${ }^{564}$ The Celts (and therefore also the Welsh) are described as a 'pure' race, speaking an 'old' language and living on the periphery. As a result, the guide creates an image of the Welsh as a rare and nearly extinct species, a 'Celtic other' living on the outskirts of society. In this example, the guide therefore establishes a distinct, yet marginal, Celtic space in which Wales is situated.

Although it would be exaggerating to state that Celticity is a major theme in the nineteenth-century French-language guidebooks, it is noticeable that it is emerging as a guidebook topic in relation to Wales. The 1865 edition of the Guides Joanne series also refers to Wales's Celticity, specifically regarding its language, which it describes as: 'un des dialects bien tranchés de l'ancienne race celtique' [one of the very distinct dialects of the old Celtic race]. ${ }^{565}$ Both guidebooks discussed above link the Welsh language to the past, and highlight its Celtic origins, therefore identifying it as a relic from ancient times. Apart from these remarks, the French guidebooks do not mention the Welsh language at all. No pronunciation aids are provided, Welsh place names hardly permeate the texts, and the Guides Richard even describes these as obsolete. ${ }^{566}$ The language is thus fully ignored as a means of communication. It can be argued that in those instances that it is mentioned, it merely serves to add a touch of exotic, Celtic flavour to the country.

This growing interest in Celticism also becomes apparent from the references to Arthurian legends in relation to Wales, which is a key difference between the French and German texts from this period. In comparison to the German-language guidebooks, the French texts show a much greater interest in Welsh mythology, especially those stories that are connected to the Arthurian tradition. Associations between several geographical locations in Wales and specific Arthurian tales are

\footnotetext{
${ }^{564}$ This theme will be clearly present in the guidebooks published after World War II, discussed in Chapter 4.

565 Esquiros, p. Xxv.

${ }^{566}$ Richard and Joanne, p. 65.
} 
made; Caerleon is for example indicated as the possible location of Arthur's Round Table ${ }^{567}$ and Carmarthen is highlighted as the birthplace of the fameux enchanteur [famous sorcerer] Merlin. ${ }^{568}$ The Arthurian tradition is certainly regarded as a feature that can enhance the attractiveness of Wales to tourists. ${ }^{569}$ The Guides Joanne 1865 edition, for example, identifies Carmarthen as the hometown of Merlin and subsequently adds: 'A 3 mil. vers l'E., on montre, dans le rocher, une caverne où, selon la tradition, la belle Fée, ou la Dame du Lac, ensevelit tout vivant le malheureux magicien' [ $3 \mathrm{mi}$ to the east, one can see a cave in a rock where, according to the legend, the beautiful enchantress, or the Lady of the Lake, buried the poor wizard alive]. ${ }^{570}$ Sites connected to the legends were apparently considered appealing to the nineteenth-century French traveller, and were therefore identified by the guides as places of interest. The Welsh landscape was thus not only regarded as an aesthetic place, as was argued in Section 3.4.1, but also as a scene of magic: a scenery for wizards and enchantresses. By projecting these magical Arthurian tales onto the Welsh landscape, Wales is being imagined in a mythological setting. This interest in Arthurian myths will become a more prevalent theme in the Frenchlanguage guidebooks throughout the following centuries, as will be shown in the following chapters.

A tendency towards mythologising Wales is also apparent in the depiction of the country's history in the Guides Joanne. This text praises Shakespeare's depiction of 'Owain Glendower' as magnifique [magnificent]. ${ }^{571}$ The fact that Glyndŵr was depicted by the playwright as a wild and exotic man, governed by emotions and magic, does not seem problematic to the guide which subsequently adds: 'Le glorieux fantôme de ce chef gallois plane ainsi, dans les imaginations, sur toute la contrée environnante' [In people's imagination, the glorious ghost of this Welsh

\footnotetext{
${ }^{567}$ Esquiros, p. 188; Darcy, p. 244; Richard and Joanne, p. 63.

${ }^{568}$ Esquiros, p. 190. See also: Darcy, p. 246. The popularity and recognisability of this figure could arguably be linked to La Villemarqué's (whose influence on French discourse on Wales was already discussed) version of this legend, entitled Myrddin ou l'enchanteur Merlin (1862).

569 This interest in Arthurian legend is also found in many other French travelogues from this period, and seems to greatly contribute to the touristic appeal of Wales for French travellers during the nineteenth century. See for example: Alfred Erny, 'Voyage dans le pays de Galles', Le Tour de Monde, 15 (1867), 257-88; Jules Gourdault, L'Europe pittoresque: Pays du nord (Paris: Hachette, 1892); Charles Le Goffic, 'Chez Taffy: quinze jours dans la Galles du sud', La Revue hebdomadaire, 5 (1901), 448-68, 22-50, 229-50, 369-95, 520-47; A. Mahé de la Bourdonnais, 'Le pays de Galles et Monmouth', in Voyage dans l'Île de Man et le pays de Galles en 1890 avec des réflexions sur l'histoire des habitants: notes des voyages (Paris: Jeande, 1894), pp. 187-203.

${ }^{570}$ Esquiros, p. 190. Emphasis in original.

${ }^{571}$ Esquiros, pp. 260-1.
} 
chieftain still floats over the surrounding area]. ${ }^{572}$ Real historical events are therefore viewed through the prism of the supernatural, fitting the image of Wales as a land of sorcerers and enchantresses.

Apart from this mythologising view of Wales's past, the French guidebooks tend to ignore the country's history in a similar way to the German-language guidebooks from this period. The country is for example generally ignored in the historical overview of Great Britain. The Nouveau guide à Londres [New Guide to London] even designates the Romans as the first occupiers of the island, and does not start its detailed overview until after the Norman invasion of 1066. The guide disregards everything that happened before this date, whilst putting a very French focus on Britain's history. Furthermore, Wales and the Welsh are fully absent in the following overview. ${ }^{573}$ However, when historical episodes are described in the sections about Wales, the French guides tend to be more favourable towards the Welsh, as they do not describe the events solely from an English point of view. This seems to correspond to their more critical stance towards the British industrialised state, in which a stronger sense of sympathy for the Welsh travellee became apparent. For example, both the Guides Richard and the Guides Garnier frères mention in relation to the town of Cardigan that the Welsh defeated the English there in $1136 .{ }^{574}$ The Guides Joanne series shows the most interest in Welsh history in general; these guides frequently mention historical figures such as Owain Glyndŵr, Rhys ap Gruffydd and Llewelyn the Great, as well as the hostilities between the Welsh and the English, albeit succinctly. ${ }^{575}$ As a result, the Welsh people are portrayed more assertively, highlighting their agency as historical actors.

The historically tense relationship between France and Britain might have influenced this favourable view of the Welsh as oppressed by the English, but the fad of Celtomania which was especially influential in France during this period (see Chapter 2.4) is also doubtlessly connected to the celticisation of Wales in the Frenchlanguage guidebooks. The works of La Villemarqué, which were published in the 1840 s and 1850s, and the translation of poems from Charlotte Guest's Mabinogion into French during the 1840s, had already familiarised the public with Welsh

\footnotetext{
572 Esquiros, p. 261.

${ }^{573}$ Nouveau guide à Londres, p. 68.

${ }^{574}$ Richard and Joanne, p. 68; Darcy, p. 248.

${ }^{575}$ For example: Richard and Joanne, pp. 100-1; Esquiros, pp. 203, 243, 271.
} 
mythology. ${ }^{576}$ This contextualisation could explain the growing interest in Welsh literary traditions and the Celtic background of the country in the nineteenth-century French-language guidebooks. This is also reflected by the fact that the Eisteddfod is mentioned; a 'fête galloise à laquelle assistaient beaucoup de Bretons français' [a Welsh festival which was attended by many French Bretons]. ${ }^{577}$ It can be argued that this interest in the guides is an indication of a clearer awareness of Welsh distinctiveness. Although still a marginal topic in the texts, Welshness is being noted and readers of these guidebooks are allowed to distinguish a greater sense of Welsh identity which is different from England and Englishness.

\subsection{Concluding Remarks}

In this chapter, the perception of Wales in nineteenth-century French and German guidebooks has been scrutinised. For socio-historical contextualisation, some preliminary remarks were made on the infrastructural developments in Europe and Wales specifically. Owing to the increasing accessibility of Wales and the growing speed and comfort of travelling, Continental travellers were coming to Great Britain in ever greater numbers. The first modern guidebooks to Great Britain that were published in France and Germany focused mainly on London and its direct surroundings. Although Wales was included in later editions, it still received less attention than the capital, as well as its Celtic siblings Scotland and Ireland. More importantly, Wales was not regarded as a distinct geographical entity; borders were not clearly demarcated and itineraries through the country were not grouped together but rather disseminated in between itineraries through England. As a result, the guides do not create a distinct geographical space for Wales, and it is consequently difficult to endow it with socio-cultural meaning.

Overall, Wales was primarily seen as an undistinguishable part of England and Great Britain. This becomes clear from the proposed reasons for travelling there, which generally have little to do with any specific sense of Welshness. The most apparent reason was the picturesque and sublime character of the country's landscape. However, these landscapes are not exclusive to Wales, and can also be

\footnotetext{
${ }^{576}$ Michael Glencross, Reconstructing Camelot: French Romantic Medievalism and the Arthurian Tradition (Cambridge: Brewer, 1995), pp. 106-11, 134-6.

${ }^{577}$ Richard and Joanne, p. 69.
} 
found in other parts of Great Britain and Europe, for example Switzerland, a country with which Wales was frequently compared in the guides. Moreover, Wales's industrialisation and architectural advancements were praised and highlighted as interesting for the tourist. As was argued in Chapter 2, centres are often perceived as innovative and industrialised, and as a result it can be contended that Wales is frequently viewed as part of the centre in these guidebooks. Instead of being given its own space, Wales is considered to be an integral, indistinguishable part of Great Britain or England. It is incorporated within this nation-state without granting the country any distinct space. A crucial difference between the German and French guidebooks in respect to Wales's industrialisation was that some French-language texts took a more critical stance towards the effect of industrialisation on the environment and the workers. A possible reason for this could be that France had been one of the industrialising frontrunners itself, and had therefore less reason to be overawed by British competence than Germany.

It must be emphasised that there were some indications that the guides perceived Wales as distinctive. The earlier German guidebooks frequently added a brief paragraph, in which Wales was depicted as Land der Fremden, where people with peculiar costumes and customs resided. However, this interest in Wales's distinctiveness remained very limited, and arguably merely added a dash of otherness to the country. Towards the end of the century, the guidebooks seemed to develop a heightened awareness of Welshness, albeit still marginal. It could be stated that this is the seed of an interest in Welshness and Celticity which will thrive in the twentieth century guidebooks. The French guidebooks from this period were interested in Welshness from another perspective, and were primarily concerned with the country's Celtic background and its Arthurian tradition. However, like their Germanlanguage counterparts, this interest was also rather a marginal phenomenon. This interest was contextualised within the phenomenon of Celtomania, which spread across Europe from the late eighteenth century onwards. 


\section{4 - 1955-1975: The Emergence of Celtic Wales}

\subsection{Introduction}

\subsubsection{The Gap: 1906-1955}

This chapter covers the period from 1955 until 1975, during which the genre of the guidebook diversified and evolved rapidly. Owing to this, the selected timeframe offers illuminating insights into the perceptions of Wales, which are becoming increasingly varied. However, many similar themes and depictions are also apparent in the guidebooks and the three languages throughout this period, revealing general tendencies in the Continental discourses used for Wales. This timeframe was not only chosen because of its striking developments; between 1900 and 1950, a significant gap in the German material has been identified which made a comparative analysis of Continental guidebooks from this earlier period impossible. In the following, this gap will be addressed first.

After the turn of the twentieth century, the production of German guidebooks to Great Britain virtually ceased. The last German-language Baedeker guide to the country was published in 1906, and it was not until 1986 that a new edition on this area was issued. The only other German-language guides to Britain that were published in the first half of the century were produced by British railway companies, which primarily functioned as advertisements for their respective itineraries. ${ }^{578}$ In this period, the first Dutch-language guide appeared as well, which was also published by British railway companies. ${ }^{579}$ The publications show that these concerns were trying to attract German and Dutch travellers in order for them to use their facilities. However, original German-language material is absent from this period, and it would take until 1955 for the first German post-War travel guide to Great Britain to be published again.

\footnotetext{
${ }^{578}$ In 1907 and 1911, the Great Eastern Railway published the guide Touren in England, Schottland, Wales und Irland via Hoek van Holland-Harwich [Touring in England, Scotland, Wales and Ireland via Hook of Holland-Harwich], and the London Midland and Scottish Railway followed in ca. 1930 with the guide Reisen in Gross-britannien und Irland [Travelling in Great Britain and Ireland]. In 1932, the London and North Eastern Railway published Nach England und Schottland über Harwich [To England and Scotland via Harwich], written by Dell Leigh.

579 A joint publication by the London and North Eastern Railway and the London Midland and Scottish Railway entitled Engeland en Schotland [England and Scotland] (ca. 1936).
} 
The question now remains regarding what possible explanations could be proposed for this gap in the publication of German-language guidebooks to Great Britain between 1906 and 1955. In the following section, it is argued that these must be sought in various factors which influenced German tourism in this period. To start with, historical events played a crucial role. Since the Baedeker handbook to Great Britain was updated every seven to eight years, it could be assumed that a new edition would have been in the planning for the year 1913 or 1914, which understandably did not happen due to the outbreak of World War I. In the period following this global conflict, German travellers were faced with strict passport and visa regulations which limited their freedom of movement considerably. ${ }^{580}$ When they did travel, it was mainly within their own country, and this development is reflected in the vast number of regional guides published by Baedeker in the 1920s. ${ }^{581}$ It was only in 1928 that travel restrictions were lifted and that it became possible again for Germans to visit Great Britain without a visa.

Despite these restrictions, there were still Germans who continued to travel abroad and to Great Britain in the 1920s. According to the statistics of Frederick Wolff Ogilvie, the number of German travellers to the British Isles increased significantly from almost eight thousand in 1921 to nearly fifty thousand in $1929 .{ }^{582}$ However, Ogilvie's figures show that once the Great Depression hit Europe, the number of German overseas travellers declined drastically. Travelling abroad became increasingly expensive for Germans due to the depreciation of the Reichsmark during the crisis. Touring Great Britain was especially problematic in this respect because of the strong position of the pound sterling in comparison. ${ }^{583}$ As a result, travel became a luxury that only few could afford, and foreign tourism declined more steeply in Germany than anywhere else in Europe. ${ }^{584}$

It can be argued that another contributing factor to the low level of German tourists abroad was the fact that domestic tourism was actively promoted. Representatives of the industry saw tourism as one of the key sectors that could help

\footnotetext{
${ }^{580}$ Christine Keitz, Reisen als Leitbild: die Entstehung des modernen Massentourismus in Deutschland (Munich: Deutscher Taschenbuch Verlag, 1997), p. 44.

${ }^{581}$ For a list of all the works published by Baedeker, see:

<http://karlbaedeker.com/VD\%20Biblio\%20\%20\%28Bae-D\%29.htm> [accessed 7 May 2015].

${ }^{582}$ Frederick Wolff Ogilvie, The Tourist Movement: An Economic Study (London: P.S. King \& Son, 1933), pp. 81-82. Unfortunately, no comparable statistical data from before World War I was found. ${ }^{583}$ Victor T. C. Middleton, British Tourism: The Remarkable Story of Growth (Oxford: ButterworthHeinemann, 2007), p. 8.

${ }^{584}$ Keitz, Reisen als Leitbild, pp. 45-46.
} 
Germany's economic recovery after the Great Depression and subsequently encouraged Germans to take their holidays in the homeland. ${ }^{585}$ In addition to this positive reinforcement of domestic tourism, the government also attempted to introduce Auslandsgebühren [fees for travelling abroad] in 1924 as well as in 1931 in order to further ensure that Germans took their holidays within their own country. However, this failed due to fierce protests against the idea. ${ }^{586}$ After its rise to power in 1933, the Nazi regime largely controlled tourism and restricted German tourism abroad. Although the Nazi leisure organisation Kraft durch Freude [Strength through Joy] did organise international tours, the regime mainly redirected travel towards the homeland, making the less frequented parts of Germany as attractive as possible for the tourist. By limiting the amount of Reichsmarks citizens could take out of the country, travelling abroad was further restricted. ${ }^{587}$ After World War II, German tourism only recovered slowly, and it was not until 1958 that the number of international West German tourists exceeded the number of incoming foreigners. ${ }^{588}$

Due to these various reasons, the number of German overseas tourists declined, and the market for guidebooks to these countries consequently disappeared with it. The Baedeker firm, the most important publisher of travel guidebooks up to this point, was directly affected by this and sales dropped; in 1929 only half as many guidebooks were sold as in $1913 .{ }^{589}$ In addition to the possible reasons for this enumerated above, the nature of the travel guidebook audience also changed during this period, which furthermore contributed to Baedeker's downfall. After World War I, the old structures of society were not re-established, and the working class and lower middle class became the new travellers. ${ }^{590}$ Due to the fact that they had less time and money to spare than their nineteenth-century more affluent counterparts, they often travelled in organised groups which resulted in an upsurge in social and socialist travel organisations in post-World War I Europe. ${ }^{591}$ This might have undermined the raison d'etre of the guidebook, which was created to liberate tourists from personal guides so that they could roam about independently. Moreover, many

\footnotetext{
${ }^{585}$ Koshar, German Travel Cultures, p. 74.

${ }^{586}$ Keitz, Reisen als Leitbild, pp. 54-55, 67.

${ }^{587}$ Koshar, German Travel Cultures, p. 126.

${ }^{588}$ Koshar, German Travel Cultures, p. 172.

${ }^{589}$ Koshar, German Travel Cultures, p. 81.

${ }^{590}$ Keitz, Reisen als Leitbild, p. 53.

${ }^{591}$ Middleton, p. 5. For a more detailed account of socialist travel organisations in Germany, see: Christine Keitz, 'Die Anfänge des modernen Massentourismus in der Weimarer Republik', Archiv für Sozialgeschichte, 33 (1993), 179-209.
} 
organisations focused on home tours, since these were most popular due to their relatively low prices. ${ }^{592}$

Not only can it be asserted that such travellers were in less need of a guidebook, indeed these new working travelling classes also actively opposed the traditional Baedeker guides, as was already discussed in Chapter 1.1. Many emerging contemporary target audiences found the classical Baedeker too prudish, or too bourgeois, and were unable to identify themselves with these texts. ${ }^{593}$ A telling example of this anti-Baedeker sentiment is the following statement which was published in the travel magazine of the Leipzig Labour movement:

\begin{abstract}
Überhaupt der Bädecker! Er ist nur ein großes Kirchenverzeichnis. Über das Herz Englands, über Lancashire, von wo jede soziale Bewegung Englands kam, erfährt man durch den Bädecker so gut wie nichts. Aber jede Kathedrale ist im Querschnitt gezeichnet, die Geschichte jedes Steins wird erzählt. Doch über die Geschichte der Menschen lesen wir wenig - abgesehen von der Geschichte der Könige, aber dieser Teil ist ja auch schon fast Geschichte der Götter. ${ }^{594}$

[Above all the Baedeker! It is merely a large church directory. The Baedeker tells you as good as nothing about the heart of England, about Lancashire, where every social movement of England originated. Instead it gives a cross-section of every cathedral, and tells the history of every stone. However, we read little about the history of the people - apart from the history of kings, but this part is almost a history of the gods.]
\end{abstract}

It can therefore be contended that the gap in German-language guidebook publications to Great Britain was the result of economic difficulties and governmental interventions, as well as the changing nature of German travel culture. These various reasons for the decline in German travel guides to overseas countries are not mutually exclusive and could all have played a role. Moreover, what has been said about the Baedeker concern also applies to other nineteenth-century series, such as the Meyers Reisebücher, the production of which was officially stopped in 1936.595

In comparison, the situation concerning French guidebooks seems to be strikingly different. In contrast to their German-language counterparts, the French series continued to publish guidebooks to Great Britain during the first decades of the twentieth century. The Guides bleus, the successor of the Guides Joanne ${ }^{596}$ which

\footnotetext{
592 See: Keitz, 'Die Anfänge des modernen Massentourismus in der Weimarer Republik', p. 189.

${ }^{593}$ For a more elaborate discussion of these changing travel cultures, see Chapter 1.1 of this thesis.

${ }^{594}$ Quoted in: Keitz, 'Reisen zwischen Kultur und Gegenkultur', p. 52.

595 Hauenstein, p. 7.

${ }^{596}$ Hélène Morlier, 'Les Guides Joanne', p. 21.
} 
had focused on London towards the end of the nineteenth century, started reprinting their guides to the British Isles regularly after the turn of the century. ${ }^{597}$ It can be argued that in contrast to Baedeker, who seems to have been unable to appeal to new target audiences, French guidebooks were more successful in this respect. The Guides bleus series managed to create new guides that were directed towards different groups of travellers, thus securing its position on the market. For example, illustrated monographs were introduced as well as shorter volumes that were less expensive. ${ }^{598}$ Moreover, as was discussed in Chapter 1.1, the emerging Michelin series was able to fill the niche of attracting the new readership consisting of motorist travellers. In addition, the circumstances for travelling abroad were more favourable in France than in Germany. After World War I, the free movement of French citizens was not as restricted due to passport and visa regulations as in Germany, and the Great Depression was relatively mild in France. ${ }^{599}$ Furthermore, paid holidays were introduced in 1936, due to which 'French tourism was legally transformed from a regime of privilege to a regime of access' ${ }^{600}$ Even though it must be noted that the French were not travelling abroad en masse during this period, ${ }^{601}$ these differences with Germany and the German guidebook market could account for the continuing publication of French guidebooks to Great Britain.

\subsubsection{The Post-World War II Decades: The Rapid Growth of $\underline{\text { Tourism }}$}

During the decades following World War II, international tourism grew to an unprecedented degree, and between 1950 and 1975 overseas tourism to the UK expanded significantly. According to Paul Gerbod's statistics, the number of overseas visitors had been between 450,000 and 720,000 during the last years of the 1940 s, which increased rapidly to $1,400,000$ by the end of the 1950 s. Visitors from the USA comprised the majority, but travellers from West Germany, ${ }^{602}$ France and

\footnotetext{
${ }^{597}$ Reprints of the 1914 edition appeared in 1921 and 1934.

598 Guilcher, 'Entre continuité et innovation', pp. 10-11.

${ }^{599}$ See for more details: Paul Beaudry and Franck Portier, 'The French Depression in the 1930s', Review of Economic Dynamics, 5 (2002), 73-99.

${ }^{600}$ Ellen Furlough, 'Making Mass Vacations: Tourism and Consumer Cultures in France, 1930s to 1970s', Comparative Studies in Society and History, 40 (1998), 247-86 (p. 252).

${ }^{601}$ Furlough, pp. 258-64.

602 This chapter will focus on tourism from West Germany, since leisure travel to the West was virtually impossible for the inhabitants of East Germany. For them, travelling abroad was limited to other socialist countries, such as Bulgaria, Hungary and Czechoslovakia (see: Dybiec, p. 125). When
} 
the Netherlands were also numerous. ${ }^{603}$ The report Tourism in the UK: The Broad Perspective discusses travel trends in the UK during the mid-1960s until the early 1980s, and notes that Britain saw a massive increase in overseas tourism during the 1970s. ${ }^{604}$ The majority of overseas tourists tended to concentrate on London, which attracted 8.4 million foreign visitors in $1978,{ }^{605}$ whilst Scotland was the second favourite destination with 1.2 million visitors. The report shows that Wales was certainly not the least popular place to visit (which was Cumbria with 0.2 million visitors) and attracted 0.7 million tourists in $1978 .{ }^{606}$ The statistics also disclose that France, the Federal Republic of Germany (FRG) and the Netherlands were important overseas markets for the UK; whereas West German and French tourists each constituted around twelve per cent of overseas tourists during the period 1973 until 1980, tourists from the Netherlands comprised seven per cent on average. The FRG, France and the Netherlands were thus, after the USA, three of the major overseas tourist markets of the UK, together making up over a quarter of all foreign visitors. ${ }^{607}$

It can undoubtedly be stated that infrastructural improvements played an important role in the increase in travellers between the British Isles and the Continent. Ferry crossings became more regular, and the introduction of the hovercraft service between Calais and Dover in 1966 also contributed to the growth of Channel crossings. ${ }^{608}$ In addition, a growing number of people had a car at their disposal, whilst air travel became an increasingly popular method of transportation as well. Regular charter flights between the Continent and Britain made the journey faster than ever before. ${ }^{609}$ With the conversion of Cardiff airport from a military to a

the term Germany is used, this therefore only refers to West Germany and the inhabitants of this country.

${ }^{603}$ Gerbod, pp. 167-70.

${ }^{604}$ British Tourist Authority, Tourism in the UK: The Broad Perspective (London: The British Tourist Authority, 1981), p. 4.

${ }^{605}$ Although these numbers originate from 1978, they do indicate that overseas tourism increased during the decades after World War II. Due to the lack of statistical research during this era, this study was taken into account. Paul Gerbod also contends that London remained the primary destination of foreign visitors during these decades and adds that only fifteen out of 1000 tourists visited Wales (Gerbod, p. 171). These figures are not implausable, but it is not clear from which sources Gerbod took them and they should therefore be treated with caution.

${ }^{606}$ British Tourist Authority, p. 20.

${ }^{607}$ British Tourist Authority, p. 6.

${ }^{608}$ Axel Schildt, “'Die kostbarsten Wochen des Jahres”: Urlaubstourismus der Westdeutschen (19451970)', in Goldstrand und Teutonengrill: Kultur- und Sozialgeschichte des Tourismus in Deutschland 1945 bis 1989, ed. by Hasso Spode (Berlin: Verlag für universitäre Kommunikation, 1996), pp. 69-85 (p. 80).

${ }^{609}$ Schildt, pp. 79-80; Isabelle Vandewalle and Manouk Borzakian, 'Le Tourisme durable à l'étranger ou la possibilité d'un autre voyage', Centre de recherche pour l'étude et l'observation des conditions 
civilian airport after World War II, it even became possible to fly directly to Wales. Moreover, the ongoing construction of the M4, which was started in 1956 and was intended as one of the first major post-war road improvements, was the beginning of a better connection between London and South Wales. The road was not completed until 1996, but the erection of the Severn Bridge in 1966 significantly facilitated entering Wales from London. ${ }^{610}$

These infrastructural developments also make their way into the guidebooks. The Guides bleus guide to Great Britain from 1958 informs its readers:

Un voyage de France en Angleterre ou en Irlande n'offre aujourd'hui pas plus de difficultés qu'un déplacement de Paris à Chartres. En une heure, l'homme pressé est à Londres d'où il peut revenir le soir même après avoir réglé ses affaires. En moins de temps qu'il n'en mettait au début de siècle pour gagner Marseille ou Bordeaux, il peut être à Manchester, Edimbourg ou Dublin. ${ }^{611}$

[A trip from France to England or Ireland does not pose any more difficulties than a journey from Paris to Chartres. Within one hour, a busy man is in London from where he can return the same night after sorting out his business affairs. In less time than it took at the beginning of the century to reach Marseille or Bordeaux, he can now be in Manchester, Edinburgh or Dublin.]

Travelling abroad and crossing the Channel were thus no longer seen as obstacles, since new ways of travelling simplified the journey. The anglophone Blue Guide to southern France not only lists the steamer services from England to France, but also various routes by air, which shows that novel methods of transportation were gradually permeating society. ${ }^{612}$ The Dutch ANWB travel guide Midden Engeland en Wales [The Midlands, East Anglia and Wales] (1975) also mentions numerous air travel routes from both Amsterdam and Rotterdam to various airports in the UK. ${ }^{613}$

A further reason for the rising numbers of travellers was no doubt the economic growth in Europe during the 1950s and 1960s. Paid holidays were introduced and progressively extended during the 1950s, and annual leave was

de vie, (2009) < http://www.credoc.fr/pdf.php?param=pdf/Rech/C269> [accessed 4 May 2015], p. 27; Hans-Werner Prahl, 'Entwicklungsstadien des deutschen Tourismus seit 1945', in Zur Sonne, zur Freiheit! Beiträge zur Tourismusgeschichte, ed. by Hasso Spode (Berlin: Verlag für universitäre Kommunikation, 1991), pp. 95-108 (pp. 99-100).

${ }^{610}$ See: <http://www.severnbridge.co.uk/history.html> [accessed 6 May 2015].

${ }^{611}$ Élisabeth Halévy, Iles Britanniques: Angleterre, pays de Galles, Écosse, Eire, Irlande du Nord, Guides bleus (Paris: Hachette, 1958), p. cxxxvii.

${ }^{612}$ Southern France with Corsica, ed. by L. Russell Muirhead, The Blue Guides, 2nd edn (London: Ernest Benn Limited, 1954), pp. xxvi-ii.

${ }^{613}$ Midden Engeland en Wales, p. 288. 
increasingly regarded as a right instead of a luxury. ${ }^{614}$ In France, a third week of paid leave was introduced in $1956,{ }^{615}$ and in West Germany there was also an extension of the minimum amount of leave (twenty-four work days per year). ${ }^{616}$ Most Dutch workers were entitled to fifteen days of paid leave per year in this period. ${ }^{617}$ Whereas the majority of tourists stayed in their home country in the 1950s, this changed during the course of the 1960s when greater numbers of travellers ventured abroad. The percentage of French tourists abroad grew from thirteen to fifteen per cent during this period, which meant a significant increase of their absolute number. Destinations primarily included France's neighbouring countries, including Great Britain. ${ }^{618}$ However, these percentages are rather low in comparison to the proportion of West German travellers who went abroad during the decades following World War II. Like the French, they mostly spent their holidays at home in the 1950s, but during the 1960s already a third of all West German tourists went across the border. During the 1970s Great Britain became progressively popular amongst these travellers due to the introduction of the hovercraft service across the Channel. ${ }^{619}$

The tourism sector was not only changing on the Continent, but also in Britain and Wales where its potential was rapidly recognised after World War II. As early as 1948, the Welsh Tourist and Holidays Board Ltd was established as an industry body that promoted tourism in Wales. This organisation was ultimately succeeded by the Wales Tourist Board, which was founded in 1969 as a result of the Development of Tourism Act. Although the international marketing of Wales remained under the control of the British Travel and Holidays Board (which later became known as the British Tourist Authority) until 1992, the Welsh Board offered suggestions about the marketing of its own country. Films about Wales with subtitles in various languages were distributed throughout the Continent to promote the country and raise its profile. Moreover, overseas parties were invited to Wales and

\footnotetext{
${ }^{614}$ For more on the development of tourism in France, Germany and the Netherlands during this period, see: Schildt; Vandewalle and Borzakian; Antonius N. F. van Egmond, Het verschijnsel toerisme: verleden, heden, toekomst (Meppel: Edu'actief, 2010); Micha Kat, 'De opkomst van het massatoerisme', Historisch nieuwsblad, 6 (2001)

<http://www.historischnieuwsblad.nl/nl/artikel/5724/de-opkomst-van-het-massatoerisme.html> [accessed 5 May 2015].

615 Vandewalle and Borzakian, p. 27.

${ }^{616}$ Schildt, p. 78.

${ }^{617}$ Kat.

618 Vandewalle and Borzakian, p. 27.

${ }^{619}$ Schildt, p. 80. Unfortunately, there are no similar figures available for Dutch tourism, but it may be assumed that comparable developments occurred there.
} 
promotional visits abroad were undertaken by board members. ${ }^{620}$ This shows that it actively attempted to attract foreign visitors to Wales and to familiarise these target groups with the country. These developments also demonstrate that tourism as an economic sector was regarded with growing interest, and the marketing of Wales as a tourist destination became an important objective which may have stimulated overseas tourism to the country.

\subsubsection{The Corpus}

The guides that form the basis of this chapter have clearly evolved compared to those examined previously. The German-language guides are still based on the description of itineraries, like their nineteenth-century predecessors, but their style has become more informal and less enumerating. Instead of being an inventory of practical information, the guides incorporate the facts into a more narrative description. Some guides even discard the impersonal narrative style, frequently regarded as an important characteristic of the genre. The Sternfahrten guidebook uses a first-person narrator, thus drawing attention to the presence of the author. For instance, he explains his motivation for letting his tour start in Aberystwyth from a personal perspective:

Trotzdem liegt für mich die Entscheidung klar auf der Hand; denn Aberystwyth, obwohl es einen kiesigen Strand hat, ist in jeglicher Hinsicht so bezaubernd und liegt zudem so ideal und zentral, daß man sich einen schöneren Sternpunkt kaum denken kann. Doch unabhängig davon gebe ich im folgenden die gewohnte Übersicht über die Badeorte, wobei ich freilich auf die Aufzählung aller Fischerhäfen verzichte. ${ }^{621}$

[Nevertheless, the decision is obvious for me since Aberystwyth, despite its pebble beach, is so charming in every way and is so ideally and centrally situated, that one can hardly imagine a more beautiful 'star point'. In the following, however, I shall provide the usual overview of seaside resorts, although I will not list all the fishing harbours.]

In contrast to the nineteenth-century guidebooks, the author is more visible and explains the choices he has made as well as his personal preferences. Even in the description of the sites, he does not refrain from expressing his own opinion.

Considering the castles of Wales, the author for example states: 'Ich werde also mit

\footnotetext{
${ }^{620}$ Lyn Howell, The Wales Tourist Board: The Early Years ([n.p.]: Wales Tourist Board, 1988), p. 10. ${ }^{621}$ Hans Eberhard Friedrich, Grossbritannien: Teil 1 - England/Wales, Sternfahrten (Opladen: Leske Verlag, 1961), pp. 600-1. The term Sternpunkt [star point] is used in this guidebook to identify the most attractive sites for the tourist.
} 
meiner Meinung nicht hinter dem Berge halten, welche zu sehen ich für unerläßlich halte, auf welche ich aber verzichten würde' [I will therefore not keep my opinion to myself, regarding which ones I believe essential to see and which ones I would forego]. ${ }^{622}$

Whereas the German guidebook genre seems to evolve relatively coherently, the French material of this period shows an evident diversification of the guidebook genre, which can be divided into two main categories. The guidebooks belonging to the first group can be classified as a continuation of the nineteenth-century guidebook style. These series, to which the Guides bleus and the Guides Nagel belong, ${ }^{623}$ focus on the description of landscape, art and medieval architecture. They endeavour to provide an exhaustive overview of the country, meticulously describing a large number of itineraries and their adjacent sights. The inhabitants of Wales, including their culture, language and history, are largely ignored and do not form any significant part of the anticipated tourist experience.

The guides belonging to the second category, on the other hand, deliberately try to distance themselves from their nineteenth-century precursors. Petite planète, Monde et voyages and Nous partons are examples of such series. By employing a more personal and narrative style, they deviate from the notions of objectivity and exhaustiveness, instead openly acknowledging the fact that the guides are idiosyncratic products. According to Chris Marker, founder of the Petite planète series, the guidebooks aimed to resemble a conversation with someone who really knows and loves the country. Moreover, the intended readership were those who rejected the superficial focus on the picturesque and who sought a more profound knowledge of a travel destination. ${ }^{624}$ In these guides, the actual description of towns, cities and landmarks becomes of secondary importance. Instead, they aspire to present the culture and customs of a specific country, as well as to highlight contemporary issues. ${ }^{625}$ In the Petite planète guidebook to Great Britain, for example, only two itineraries through Wales are described. They are outlined at the end of the chapter, whilst the rest of the section concerning Wales discusses the country's

\footnotetext{
622 Friedrich, p. 614.

${ }^{623}$ Later published as Guides Nagel: encyclopédie de voyage.

${ }^{624}$ Chris Marker, quoted in: Hervé Serry, 'Chris Marker au Seuil', <http://www.seuil.com/pagehommage-chris-marker.htm\#_ftn13>, [accessed 10 March 2015].

${ }^{625}$ See: Guilcher, 'Entre continuité et innovation', p. 14.
} 
history, culture and language. ${ }^{626}$ The description of towns and sites appears to be a compulsory supplement rather than the core of the guide. The Monde et voyages series has a similar approach and primarily focuses on what the author identifies as 'Grande étappes' [Great Trails]: the most worthwhile towns and sites of the destination. In the guide to Great Britain, merely one these 'Grande étappes' is situated in Wales, namely Caernarfon. ${ }^{627}$ This is therefore the only Welsh town that is described. In addition to the portrayal of the town, the author provides a range of related information about the castle, its history and the legends surrounding it. The description of sights therefore entails much more than it would usually do in the more traditional guidebooks, although fewer sights are described in total. Therefore, it appears as if this series adheres to the principle of quality above quantity. Finally, these guides have an informal narrative style; ${ }^{628}$ the reader is directly addressed (albeit in the vous-form), ${ }^{629}$ and personal preferences of the author are voiced. In the Petit planète guidebook, for example, the author expresses his own predilection: 'Il serait injuste de négliger le pays de Galles. Personellement, je lui trouve plus de séduction qu'à l'Écosse' [It would be unfair to neglect Wales. Personally, I find it more seductive than Scotland]. ${ }^{630}$ Instead of aiming to provide an impartial and comprehensive description of a destination, the guidebooks claim to present the country in question from a more personal, selective perspective.

\subsection{First Impressions: Wales's Growing Distinctiveness as a Travel Destination}

This section explores some preliminary observations concerning the visibility of Wales as a distinct travel destination in the guidebooks, whilst later sections of the chapter will examine the portrayal of Wales as a cultural, linguistic, ethnographic and historical entity in more detail. In Chapter 3 it was shown that the nineteenthcentury guidebooks depicted Wales primarily as an integral part of Great Britain and

\footnotetext{
${ }^{626}$ Jean Bailhache, Grande-Bretagne, Petite planète (Paris: Éditions du Seuil, 1960), pp. 105-9.

${ }^{627}$ Pierre Pierrard, L'Angleterre, l'Écosse, le pays de Galles, l'Irlande du Nord, Monde et voyages (Paris: Larousse, 1968), pp. 82-3.

${ }^{628}$ For this reason, these series will collectively be addressed as 'narrative guidebooks' in the rest of the thesis.

${ }^{629}$ Pierrard, p. 105.

${ }^{630}$ Bailhache, Grande-Bretagne (1960), p. 105.
} 
even of England with relatively little distinctiveness of its own. Even though the Baedeker guides granted Wales more attention towards the end of the century, the country continued to be portrayed as an area of little touristic interest. Between 1955 and 1975, Wales is increasingly treated as a more distinctive part of the United Kingdom. Overall, the guides show a growing interest in Wales, its culture and language, but this does not necessarily mean that Wales is no longer overshadowed by its hegemonic neighbour England.

The cover of the Große Polyglott guide speaks volumes in this respect (see Figure 5); although the title of the guide is England mit Wales [England with Wales], only the former is mentioned on the cover, which displays the Union Jack. Wales is thus invisible, both in terms of its name and symbols, and the target audience would at first sight not be able to tell that this guide deals with both England and Wales.

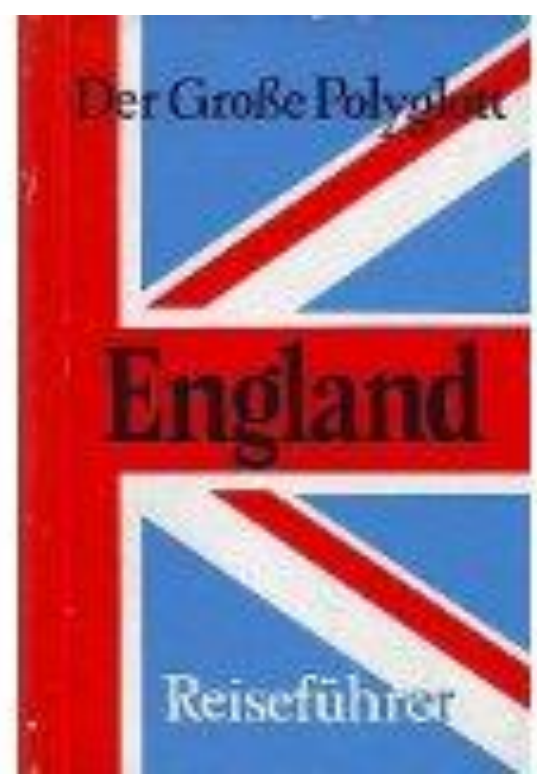

Figure 5: Neither Wales's name, nor any other national symbols appear on the cover. $^{631}$

Regarding perceptions of its touristic attractiveness, Wales also remains eclipsed by England. The guide from the Bertelsmann Reiseführer series entitled England und Wales [England and Wales] provides a list of the nineteen supposedly most worthwhile sites in these two areas, of which only one is situated in Wales

${ }^{631}$ Hans Lajta, England mit Wales, Der große Polyglott (Munich: Polyglott-Verlag, 1971). 
(Caernarfon) ${ }^{632}$ The map that is included in the French-language Guides bleus handbook provides the same impression of Wales being a relatively blank space regarding tourist sights. This map, with the telling caption 'L'Angleterre Touristique' [Touristic England], indicates where the most worthwhile sites are supposedly situated. In contrast to England, Wales appears for the largest part devoid of tourist attractions (see Maps 4 and 5). Only North Wales seems to be able to provide the tourist with some form of entertaining diversion. The touristic focus on this part of the country is a continuous characteristic throughout the guidebooks published in the twentieth and twenty-first century, and will be scrutinised in more depth later in this and the following chapter.

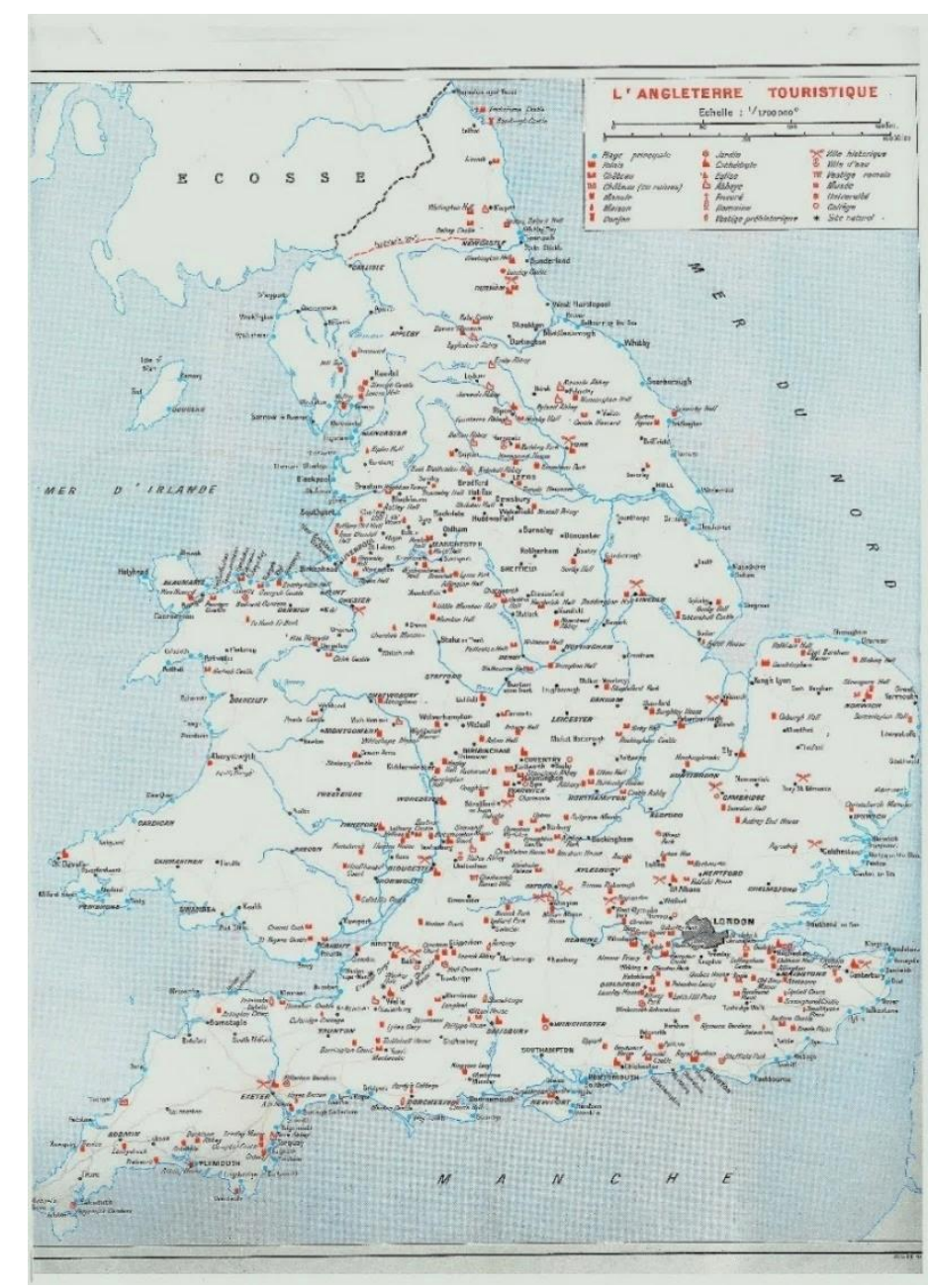

Map 4: Compared to England, most of Wales is almost devoid of tourist attractions, according to this map. ${ }^{633}$

${ }^{632}$ Wilhelm Voss-Gerling, England und Wales, Bertelsmann Reiseführer (Gütersloh: Bertelsmann, 1973), p. 3.

${ }^{633}$ Halévy, p. 386. 


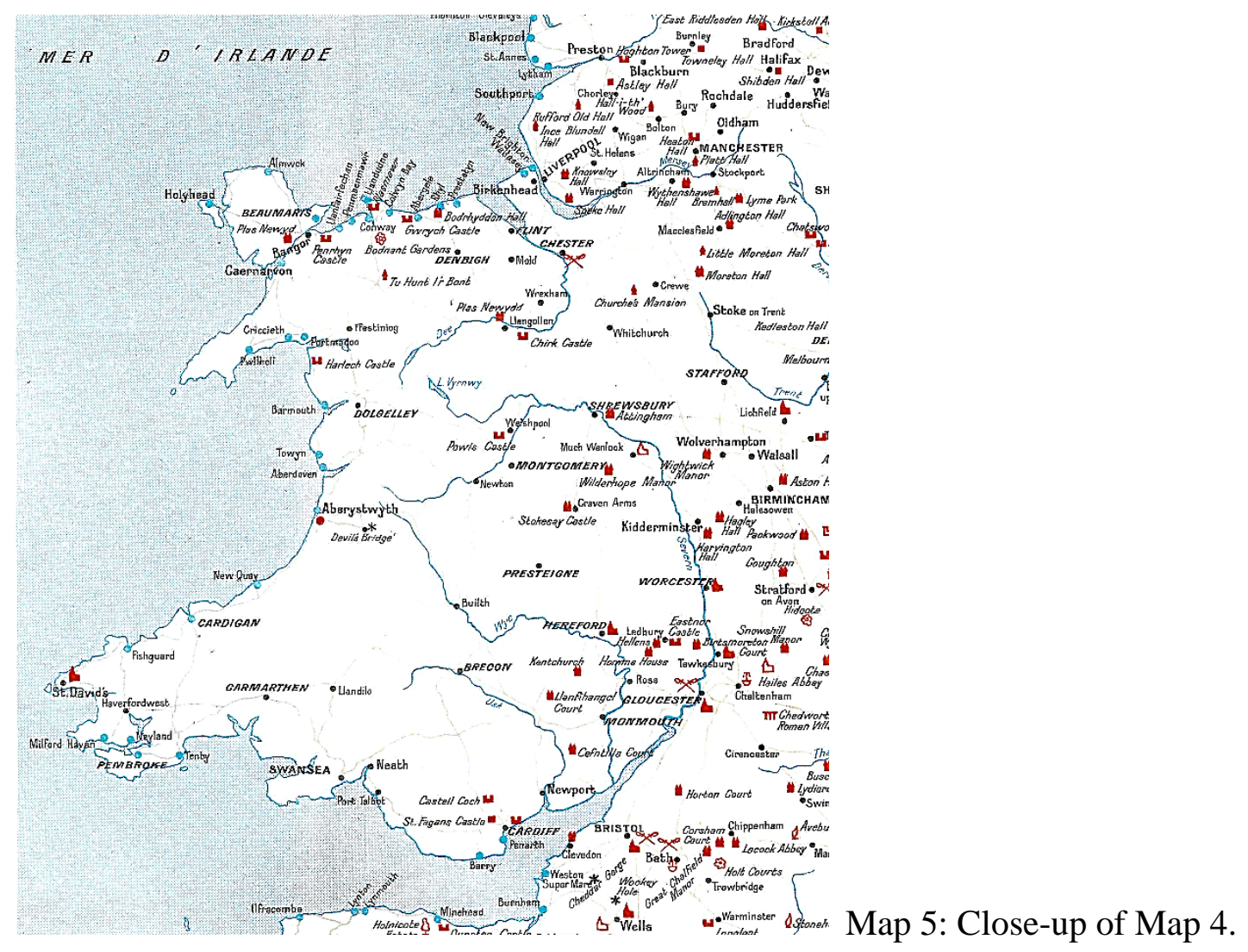

The incessant relative marginalisation of Wales, especially compared to England, can also be observed in the number of pages that are allocated to Wales. In the 1958 Guides bleus guide, the description of England covers pages 106-582, whereas Wales is allocated pages 583-621. Similarly, the Guide Nagel handbook comprises 1251 pages, of which Wales takes up a mere forty-five. ${ }^{634}$

This being said, it must also be noted that in comparison to the nineteenthcentury guidebooks, Wales has gained relative significance and prominence as a tourist destination. This growing interest is first of all indicated in the titles of the guides. The nineteenth-century guidebooks often omitted Wales from their titles and instead only mentioned England, Scotland and Ireland, presumably regarding Wales as an integral part of England. The guidebooks between 1955 and 1975 do not do this; Wales is either mentioned directly, or the guides generally refer to Great Britain. The Stauffacher guidebook is for example entitled Grossbritannien [Great Britain], whilst the Sternfahrten guide specifies this term by adding the subtitle Teil 1-

${ }^{634}$ Théo Lang, Grande-Bretagne, Nagel: encyclopédie de voyage (Geneva: Les éditions Nagel, 1975), pp. 849-94. 
England/Wales [Part 1 - England/Wales $].{ }^{635}$ The French guides show a similar tendency; Wales is either mentioned separately, or the more general term GrandeBretagne [Great Britain] is employed in the titles. This development, compared to the guidebooks' titles during the nineteenth century, seems to imply that Wales is gradually becoming a more visible entity within Great Britain which is not simply considered to be a part of England. Conclusive reasons for this growing awareness of Wales as a distinct entity within Great Britain cannot be given, but it is noticeable that this development occurs in the same period that Wales was making small steps in the direction of devolution. The post of Minister of Welsh Affairs was created in 1951, and the establishment of the post of Secretary of State for Wales and the Welsh Office followed in 1964. Moreover, Cardiff was declared capital of Wales in 1955, which gave the country a more autonomous profile in relation to London. ${ }^{636}$ These administrative and political changes might have contributed to the fact that Wales was increasingly recognised as being separated from England.

This assumption is also supported by the fact that Wales is described in a separate chapter, commonly preceded by an introduction providing background information about the country's history, customs and inhabitants. ${ }^{637}$ Moreover, various German-language guidebooks encourage the reader to undertake a prolonged journey to the country. The Stauffacher guidebook for example recommends a longer stay 'um die Schönheiten der Täler, Wasserfälle und Schluchten richtig geniessen zu können' [in order to fully appreciate the beauties of the valleys, waterfalls and gorges]. ${ }^{638}$ Even though the author of the Sternfahrten guide emphasises that the traveller does not need to see every castle, prehistoric relic or Celtic cross, and that a selection should suffice, the guide still recommends two multiple-day journeys in order to fully comprehend and discover the country. ${ }^{639}$ Most of the guides propose

\footnotetext{
${ }^{635}$ This increasing interest in Wales as a tourist destination is also exemplified by the special issue from the German-language periodical Merian Monatshefte (published in 1974) which is dedicated to Wales alone. Due to the fact that this is a travel magazine, rather than a travel guidebook, this text will not be taken into account in this thesis. Furthermore, several articles are written by British authors, which makes these unsuitable for the examination of German views of Wales. Nevertheless, the publication attests to a growing touristic interest in and awareness of Wales in Germany.

${ }^{636}$ See: Davies, A History of Wales, pp. 638-42.

${ }^{637}$ See, for example: Théo Lang, Grande-Bretagne et Irlande, Guides Nagel (Paris: Les éditions Nagel, 1953), p. 461; Halévy, pp. 583-84; Carl Heller-Merricks, Grossbritannien: Illustriertes Touristen-Handbuch für Reisen und Ferien in Grossbritannien, Stauffacher-Reiseführer (Zürich: Stauffacher-Verlag, 1955), pp. 302-3; Friedrich, pp. 596-601.

${ }^{638}$ Heller-Merricks, p. 307.

${ }^{639}$ Friedrich, p. 600.
} 
fairly exhaustive tours, dividing Wales into a southern and northern route, which the traveller could combine into one circular itinerary. ${ }^{640}$ The focus points of these routes are usually the South Wales coast and the castles of North Wales.

In the case of the Dutch material it is first and foremost noticeable that there are guidebooks to Great Britain and Wales in existence, in contrast to the lack of publications in the nineteenth century. During the period 1955-1975, a Dutch guidebook tradition to Great Britain emerges. Although the number of guides is still very low, Wales's visibility increases, and the sections about the country gradually become more substantial. However, it is not until 1975, the end of the period under examination in this chapter, that Wales is described to a considerable extent in the Dutch material. Before this, it is still perceived as a marginal region within Great Britain. In one of the first ANWB travel guides to Great Britain, ${ }^{641}$ Wales is primarily reduced to a transitional place for travellers to Ireland; the only main route through Wales leads directly from Shrewsbury to Holyhead, from where travellers could take the ferry across the Irish Sea (see Maps 6 and 7). The guide describes this itinerary as follows: 'Deze route vormt de snelste verbinding tussen Londen en Holyhead, biedt weinig belangrijks en is opgenomen voor hen, die het noordelijk deel van Wales wensen te bezoeken en die van Holyhead naar Ierland willen oversteken' [This route is the fastest connection between London and Holyhead, offers little of interest and is included for those who wish to visit North Wales and those who want to go from Holyhead to Ireland]. ${ }^{642}$ Although exploring North Wales is suggested as a possibility, the guide also implies that there is not much of interest in this area. The primary aim of this route is to enable travellers to reach Ireland.

\footnotetext{
${ }^{640}$ For examples, see: Heller-Merricks, p. 302; Friedrich, p. 608; Lajta, pp. 342-3.

${ }^{641}$ The ANWB (Algemene Nederlandse Wielrennersbond) is the Royal Dutch Touring Club which was founded in 1883 and is one of the largest and most important travellers' associations of the Netherlands: 〈http://www.anwb.nl/over-anwb/vereniging-en-bedrijf/organisatie/english-page> [accessed 25 May 2015].

${ }^{642}$ Reiswijzer voor Engeland, Wales en Schotland, ANWB reiswijzer voor het buitenland ([n.p.]: Kon. Ned. Toeristenbond A.N.W.B., 1957), p. 33.
} 


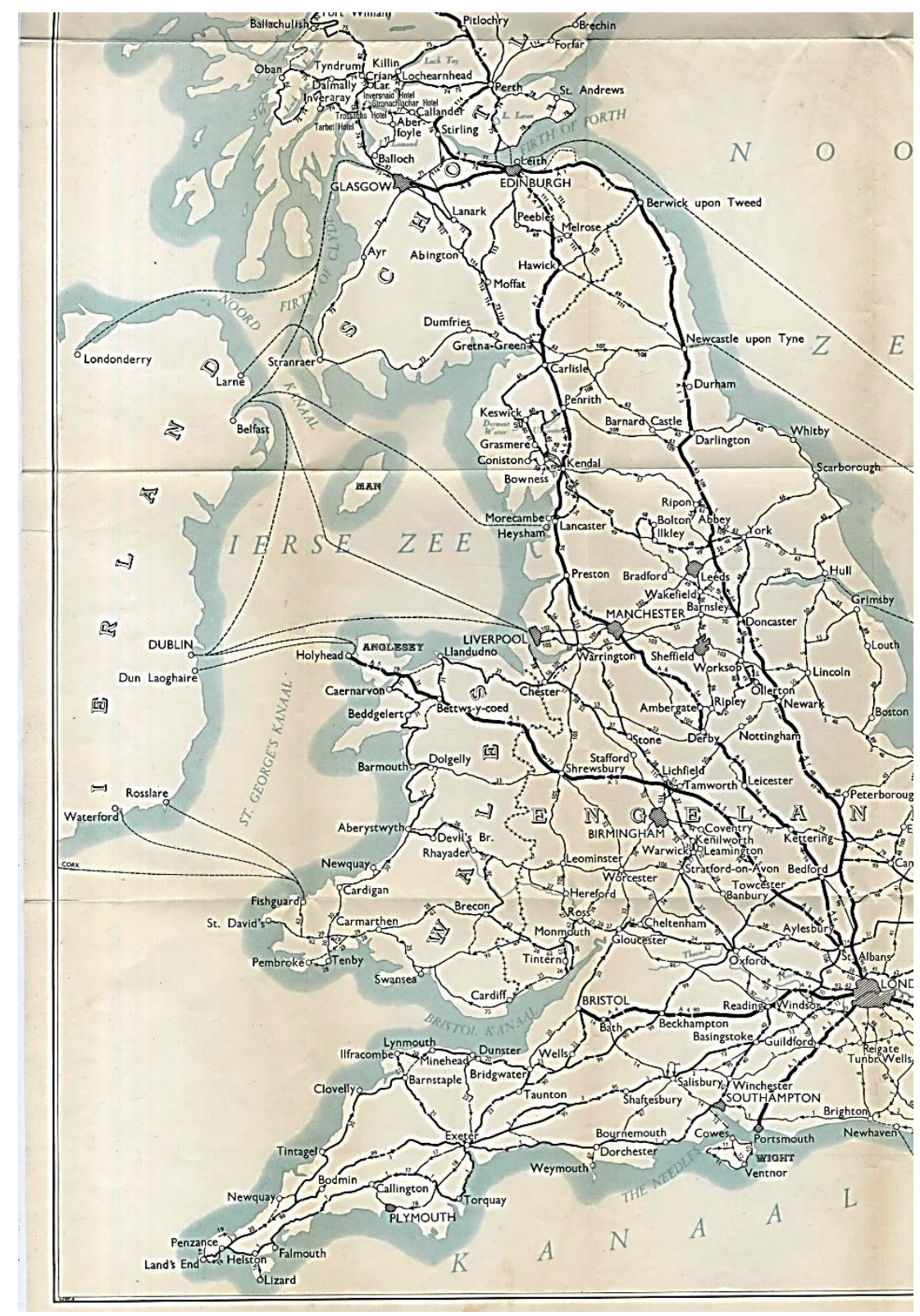

Map 6: Only one of the major routes goes through Wales, heading straight towards Ireland; Wales is primarily seen as a place of transit for the traveller. ${ }^{643}$

${ }^{643}$ Reiswijzer voor Engeland, Wales en Schotland. 


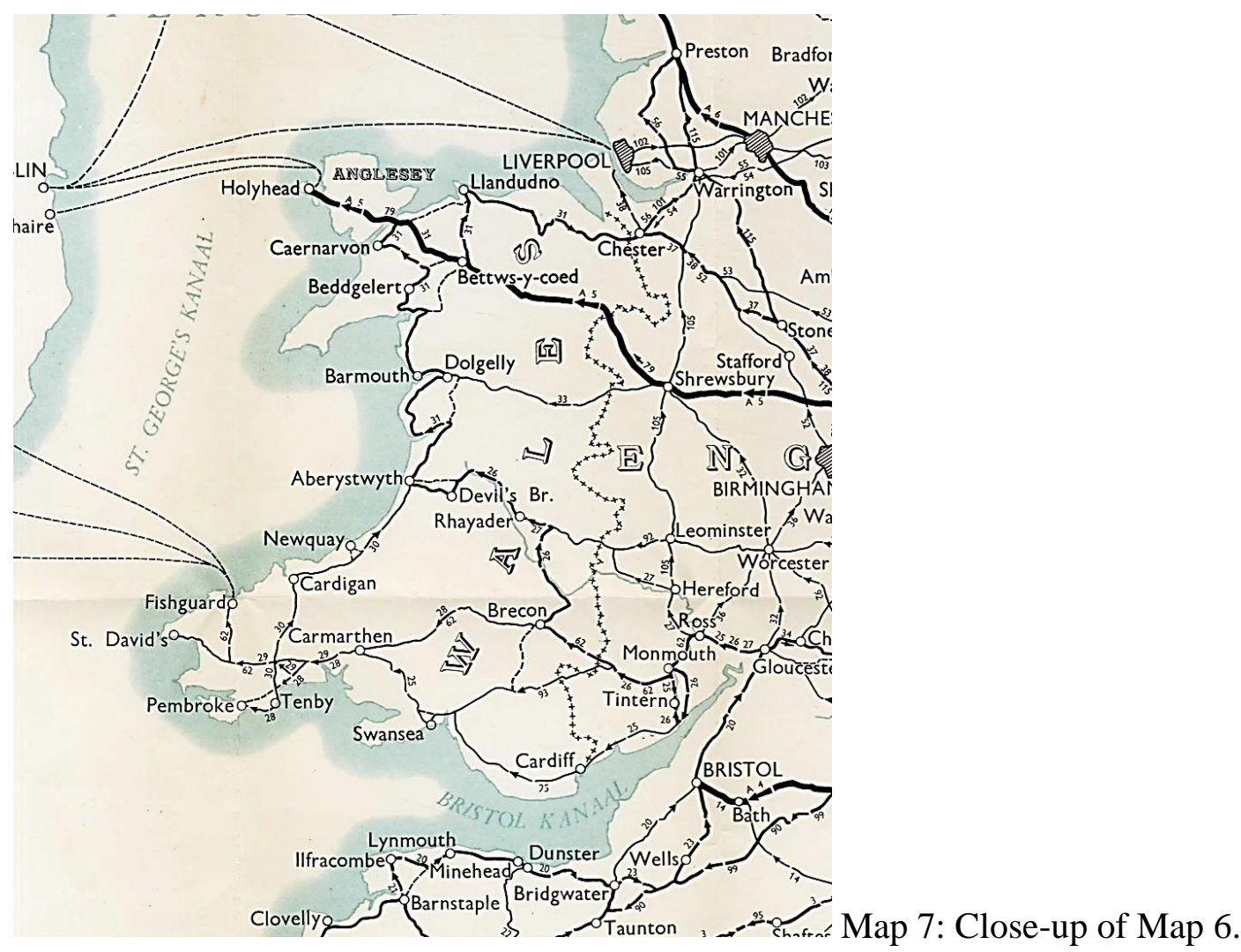

Although Wales is mentioned in the title of Allert de Lange's guide Gids voor noordelijk Engeland en Wales [Guide to Northern England and Wales], it is stated in the introduction that the focus will lie on England. The guide points out that Wales will only be described in an appendix, as the series will soon publish a separate guide to Wales. ${ }^{644}$ This indicates that there is an increasing interest in Wales, resulting in the intention to publish a single volume to the country. However, there is no evidence that this guide was indeed published, and Wales thus remains a supplement to England. The new ANWB guidebook Midden Engeland en Wales [The Midlands, East Anglia and Wales] from 1975 is the first Dutch guide to include Wales more exhaustively. In this guide, the description of Wales covers seventy out of 240 pages. As was the case with the German- and French-language guidebooks published in this period, this evolution seems to indicate a growing interest in and awareness of Wales as a travel destination. This reflects the contextual developments outlined above: a general increase of Continental tourism in Great Britain in the post-war period and

${ }^{644}$ L. van Egeraat, Gids voor noordelijk Engeland en Wales: ten noorden van Boston - Leicester Birmingham - Chester, Allert de Lange reisgidsen (Amsterdam: Allert de Lange, 1960), p. 8. 
the infrastructural developments made Wales progressively accessible and perhaps also comprehensible. As more and more tourists were visiting the UK, it might not be surprising that guidebooks were looking for regions and areas that had previously been overlooked. Within this increasing appreciation of Wales as a travel destination, the real question is how the country is evaluated, how it is characterised and how its cultural, linguistic and historical borders are created and situated. The following sections examine the guidebooks' touristic evaluation of Wales in more detail. The German material will be scrutinised first, after which a comparative analysis will be offered of the French and Dutch guidebooks.

\subsection{German Views: Aestheticising and Racialising Wales}

\subsubsection{Continuation and Development of the Nineteenth-Century Discourse: Picturesque and Industrial Landscapes}

Although significant changes in the discourse about Wales were identified in this period compared to the nineteenth century, which will be addressed later in this chapter, there are also clear similarities between the periods. The continuation of the nineteenth-century discourse is especially apparent in the appreciation of Wales's natural landscape. This had been the main reason for travelling to Wales in the nineteenth century, which also seems to have been the case in the German-language guidebooks published between 1955 and 1975. The Baedekerian tradition is still very evident; many guides divide the country into itineraries, and the focus lies on nature and historical edifices. Bertelsmann's guidebook depicts Wales as 'Land der Berge und Seen' [Land of Mountains and Lakes], and adds that the country's landscape and historical sites are the most worthwhile tourist attractions. ${ }^{645}$ Of the fourteen sights that are awarded two asterisks in the Große Polyglott guidebook, ten are towns with significant medieval remains of castles or cathedrals, such as St. David's and Caernarfon. ${ }^{646}$ The guidebook from the Stauffacher series also points out that Wales is primarily a popular travel destination because of its natural beauty, ${ }^{647}$ and even the similarities between Switzerland and Wales are brought forward again as an

\footnotetext{
${ }^{645}$ Voss-Gerling, p. 99.

${ }^{646}$ Lajta, pp. 346, 353.

${ }^{647}$ Heller-Merricks, p. 302.
} 
argument for travelling and an assurance that Wales is a worthwhile destination. ${ }^{648}$ Moreover, words like 'paradise' and 'Dorado' are used recurrently to refer to Wales's natural landscape, ${ }^{649}$ and the country's picturesque and sublime qualities are also still highlighted in the guides. ${ }^{650}$ The Sternfahrten guidebook for example describes the Wye Valley as a landscape that 'ein romantischer Landschaftsmaler im Anfang des vorigen Jahrhunderts ausgesucht haben würde, wenn er sich vorgenommen hätte, das Ideal einer zarten Idylle auf seine Leinwand zu zaubern' [at the beginning of the previous century, a Romantic landscape painter would have chosen if he had wanted to conjure up the ideal of a delicate idyll on his canvas]. ${ }^{651}$ He directly refers to Wales as the picturesque ideal, but emphasises that it is the variety of the landscape, which alternates between the picturesque and sublime, that constitutes the real beauty of Wales. ${ }^{652}$

The industrial landscape, on the other hand, an aspect of Wales that was regarded as a positive sign of progress by the nineteenth-century German-language guidebooks, has almost entirely disappeared from the guides. Apart from a trace of the industrial sublime in one of the guidebooks published during the 1950s, the industrial landscape is primarily ignored. ${ }^{653}$ The Sternfahrten and Große Polyglott guides, for example, describe South Wales only as a coastal area where many old churches and abbeys can be visited, whilst largely disregarding the industrialised Valleys. The suggested route through Wales in the latter carefully circumvents this area. ${ }^{654}$ Even though the Welsh itinerary in the Sternfahrten guidebook does run through the Valleys, the tourist gaze is quickly guided away from any signs of industrialisation, and is only pointed towards ruinous castles and churches. ${ }^{655}$ Industrial towns and cities such as Llanelli and Swansea are mentioned, only to be subsequently discounted as having nothing to offer to the traveller. ${ }^{656}$ Although the

\footnotetext{
${ }^{648}$ Friedrich, p. 596; Lajta, p. 43.

${ }^{649}$ See for example: Lajta, pp. 350-1.

${ }^{650}$ See for example: Heller-Merricks, pp. 310, 324.

${ }^{651}$ Friedrich, p. 640.

${ }^{652}$ Friedrich, p. 642.

653 The Stauffacher guidebook describes the area between Pontypridd and Merthyr Tydvil as having little to offer to the tourist, 'es sei denn, er interessiere sich für die vielen Hochöfen, deren Leuchten dem Tale bei Nacht einen eigenartigen Anstrich geben' [unless he is interested in the many blast furnaces, whose lights give the valley a peculiar lustre at night] (Heller-Merricks, p. 306).

${ }^{654}$ Lajta, pp. 342-3.

${ }^{655}$ Friedrich, pp. 636-7.

${ }^{656}$ See: Friedrich, p. 636; England und Wales, Grieben-Reiseführer (Munich: Karl Thiemig, 1965), pp. 153-4, 202-3.
} 
Stauffacher guidebook recognises Wales's industry as being of great economic importance, ${ }^{657}$ this guide also rejects it as uninteresting for the traveller. The Welsh Valleys are simply summarised as: '[eine] wenig anziehende Landschaft' [a rather unattractive landscape]. ${ }^{658}$ Noticeable in this respect is the fact that the area is not evaluated negatively per se, but is mostly simply disregarded. This observation leads to the conclusion that the industrialised side of Wales is excluded from the touristic map in these guidebooks.

This decreasing interest in industrialisation arguably reflects its declining importance in Wales. Whilst Welsh commerce had been at the forefront of European industrialisation during the nineteenth century, it had lost its glamour in the postWorld War II period. Despite short periods of growth due to the war industry, the Welsh coal trade declined sharply during the twentieth century and did not recover. ${ }^{659}$ The resulting social and economic malaise in South Wales became increasingly apparent, which probably influenced the German appreciation of this area. Moreover, a growing awareness regarding environmental issues could also explain this shifting focus of the German tourist gaze. However, it must be pointed out that the rise of environmentalism in Germany did not significantly differ from that in the rest of the Western world in the 1960s and 1970s. As Frank Uekötter describes in his book The Greenest Nation?, Germany only became a figurehead of environmental protection in the 1980s. Before this, the country essentially followed global trends concerning the issue. ${ }^{660}$ This contextualisation could therefore not explain any differences between the evaluation of industrialisation in the Germanand French-language guidebooks from the 1960s and 1970s.

\subsubsection{Moving towards the Periphery}

Although the natural landscape continues to be perceived as the main touristic asset of Wales, it can already be seen that the guidebooks' evaluation and description is evolving as the South Wales Valleys are largely excluded from the guidebooks' spatial construction of the country. The notion of Welshness is also shifting

\footnotetext{
${ }^{657}$ Heller-Merricks, p. 302.

${ }^{658}$ Heller-Merricks, p. 315.

${ }^{659}$ See: Jenkins, pp. 233-9.

${ }^{660}$ Frank Uekötter, The Greenest Nation? A New History of German Environmentalism (Cambridge, MA: MIT Press, 2014), p. 20.
} 
significantly. During the nineteenth century, Welshness had to a great extent been absent from the guidebooks; Wales was generally regarded as part of England, the innovative centre. This conceptualisation of the country changes dramatically in the period under investigation in this chapter. Instead of being spatialised in the centre, Wales and Welshness are moving towards the imaginative periphery. The various elements that contribute to this peripheralisation will be examined in the following sections.

To begin with, it is noticeable that many guidebooks immediately highlight the difference between Wales and England, whilst using the topographical border between the two countries to symbolise this. Several post-World War II Germanlanguage guidebooks bring the distinctiveness of Wales to the attention of the reader, primarily establishing this vis-à-vis England. The 1965 Grieben guidebook for example emphasises: 'Sobald man die englisch-Waliser [sic] Grenze überschritten hat, merkt man sogleich, daß man in einem anderen Lande weilt' [As soon as you have crossed the English-Welsh border you will immediately notice that you are staying in a different country]. ${ }^{661}$ This quotation firstly demonstrates that the topographical border between the two countries is highlighted and is perceived to be a sign of difference; crossing it will permit the tourist to enter another country. Secondly, it could be argued that the verb weilen has temporal connotations; it suggests a pause (eine Weile), a slower speed of the passing of time. This temporalisation of Wales will be discussed in more detail later in this chapter.

The Große Polyglott also regards the topographical border between England and Wales as a significant sign of distinction: 'Schon nach dem Überschreiten der Grenze erkennt man, daß Wales sich von England in vieler Hinsicht unterscheidet' [After crossing the border, you will instantly realise that Wales differs from England in many respects]. ${ }^{662}$ In these depictions, England is arguably taken to be the norm (i.e. the centre) from which Wales (i.e. the periphery) deviates. The following issue is then, in which different ways the guidebooks perceive Wales to deviate from the centre. In other words: what constitutes the alleged difference of Wales in these texts?

${ }^{661}$ England und Wales, p. 31.

662 Lajta, p. 42. 


\title{
4.3.2.1 Ethnographic Distinctions
}

The Stauffacher guidebook also emphasises the perceived difference between England and Wales when crossing the border. According to the guide this is noticeable due to the language (which will be discussed in more detail later in this chapter), but primarily because of Wales's alleged Celtic character:

\begin{abstract}
Beim Betreten dieses überaus anziehenden Landes merkt der Fremde sofort, dass er sich nicht mehr in England befindet, nicht nur wegen der oft schwer auszusprechenden gälischen Ortsnamen, nicht nur weil das in Wales gesprochene English eine andere Klangfärbung hat, sondern weil die Bevölkerung gewisse Eigenschaften besitzt, die allen Kelten anhaftet. ${ }^{663}$

[When entering this extremely attractive country, the foreigner will immediately notice that he is no longer in England. Not only due to the place names that are difficult to pronounce, not only due to the different intonation of the English that is spoken in Wales, but because the inhabitants have certain characteristics that can be found in all Celts.]
\end{abstract}

Here, the source of Wales's difference is therefore the Celticity of its inhabitants, which is subsequently summarised as consisting of a love of music and poetry, as well as a brave character. Other guides also base their differentiation of the various British areas on ethnographic observations, warning the tourist not to mix up the terms 'Englishman', 'Welshman', 'Irishman', and 'Scot', as these 'unterscheiden sich nicht nur in ihrer Abstammung, sondern auch in ihrer Lebensart stark voneinander' [differ not only strongly from one another in respect to their origins, but also in their way of life]. ${ }^{664}$ Whereas the English are described as friendly yet reserved and disciplined (the stereotype of the stiff upper lip), the Scots as talkative and emotional, and the Irish as religious and merry, the Welsh are characterised as 'gefühlsbetont, musikalisch and sehr ritterlich, aber auch mißtrauisch und oft streitlustig' [emotional, musical and very chivalrous, but also suspicious and often argumentative]. ${ }^{665}$ These stereotypical characteristics can be found in most Germanlanguage guidebooks from this period, especially the supposed Welsh love of music and their defiant nature. ${ }^{666}$

In some guidebooks, the ethnographic descriptions are very detailed. The Sternfahrten guidebook for example includes a whole section on the British national

\footnotetext{
${ }^{663}$ Heller-Merricks, p. 302.

${ }^{664}$ Lajta, p. 40.

${ }^{665}$ Lajta, p. 40.

${ }^{666}$ See for example: Heller-Merricks, p. 302; Friedrich, p. 597; England und Wales, p. 31.
} 
character, of which the Celtic 'type' is also regarded to be a part. ${ }^{667}$ According to this guide, the Celtic and Anglo-Saxon Erbe [heritage] together form the British national identity, yet the Welsh are also seen as a culturally and 'rassisch' [racially] different people. ${ }^{668}$ The issue of race clearly permeates this guidebook and is used to explain the perceived differences between the various regions of Great Britain. The author describes the Welsh as a typically 'keltischen Typus' [Celtic type], ${ }^{669}$ of which T.E. Lawrence is allegedly an excellent example, ${ }^{670}$ having a 'Neigung zur Isolierung, zu Mystik, zu missionarischem Berufungsglauben, schnelle Auffassungsgabe, Fröhlichkeit, Sorglosigkeit, aber auch eine eigenartige Veranlagung zur Versponnenheit' [tendency to isolation, mysticism, missionary vocation, the ability to comprehend things quickly, gaiety, carefreeness, but also a peculiar disposition to eccentricity]. ${ }^{671}$ Later in the guidebook, the Welsh are described as 'charakterfest, furchtlos und beredt [...], sangeslustig und jedem Vergnügen zugetan' [strong of character, fearless and eloquent [...], with a fondness of singing as well as every other kind of pleasure]. ${ }^{672}$ These characterisations correspond to those found in the other German-language guidebooks from this period. Noticeable in this respect, however, is the fact that this guidebook emphasises the eidgenössische [federal] attitude of the Welsh towards the English, being 'Mitglieder des englischen Staatsvolkes' [members of the English nation]. ${ }^{673}$ Ethnographically, the Welsh are thus regarded as a distinctive 'race', but this does not endanger the unity of the British nation, according to the guidebook.

It is noticeable that the characterisation of the Welsh (and the Celtic type in general) as melancholic, emotional and musical has strong similarities with the racial depiction formulated by Arnold and Renan almost a century earlier (see Chapter 2). The question thus arises why these ethnic characterisations did not emerge earlier, and only appear in the German-language guidebooks in the period following World War II. It might be expected that the horrors of this war, chiefly caused by ideas of racial superiority, would have left a negative connotation regarding the distinction

\footnotetext{
${ }^{667}$ Heller-Merricks, p. 154.

${ }^{668}$ Friedrich, p. 18.

${ }^{669}$ Friedrich, p. 22.

${ }^{670}$ Friedrich, pp. 154, 626.

${ }^{671}$ Friedrich, p. 154.

672 Friedrich, p. 597.

${ }^{673}$ Friedrich, p. 597.
} 
between different races. However, neither the term Rasse [race], ${ }^{674}$ nor the classification of a people in racial terms seem to be considered controversial by the guides. ${ }^{675}$ These findings seem to contradict the general assumption that the term Rasse became taboo after 1945 and consequentially disappeared from the public discourse. In their volume After the Nazi Racial State: Difference and Democracy in Germany and Europe, Rita Chin and others also conclude that this alleged disappearance of a racial discourse in Germany after the end of the war is an illusion and that the term 'race' merely shifted semantically. These scholars assert that the term was no longer used to refer to Jews, but became accepted in other contexts, for example when referring to people with different skin colours. ${ }^{676}$ In their research, they argue that the term is now directly associated with racism against Afro-Germans and Turkish immigrants. In the guidebooks, however, it can be assumed that it is not intended to be racist or to have any negative connotations. The opposite can even be asserted: racial and ethnographic differences are intended to enhance Wales's touristic appeal and to create a positive form of distinctiveness. In contrast to the nineteenth-century guidebooks, which primarily portrayed Wales as part of the centre, these post-World War II guidebooks are seemingly trying to present a more distinctive image of Wales. In order to achieve this, they are emphasising ethnographic (or racial) characterisations. Although no overall conclusions can be made based on these texts, it could prove fruitful for further research to examine the positive use of the term Rasse in relation to tourism in post-war Germany.

\subsubsection{Spatialising and Temporalising Welshness}

By being described as a 'pure' and 'unmixed' people, ${ }^{677}$ the Welsh are not only racialised but also spatialised and temporalised, which eventually leads to their conceptualisation on the imaginative periphery. In the guidebooks' representations of Wales, these three concepts are closely intertwined. Whereas the landscape had primarily been an aesthetic aspect in the nineteenth-century guidebooks, it is granted

\footnotetext{
${ }^{674}$ Another guidebook that uses this term is: England und Wales, p. 31.

${ }^{675}$ Noteworthy in this respect is the fact that the ladies of Llangollen are described by the Stauffacher guidebook as two 'exzentrischer arischer Fräulein' [eccentric Aryan women], a peculiar choice of adjective to describe the ladies ten years after the Nazi regime collapsed (Heller-Merricks, p. 328). ${ }^{676}$ Rita Chin and others, After the Nazi Racial State: Difference and Democracy in Germany and Europe (Ann Arbor: University of Michigan Press, 2009), pp. 6, 20.

${ }^{677}$ For example: Voss-Gerling, p. 12.
} 
a far more pivotal role in the construction of Welshness in the post-World War II guides. In these texts, the landscape is perceived to have influenced Welsh identity and is represented as closely connected to the inhabitants. The guides thus move beyond the purely aesthetic evaluation of the landscape, whilst conceptualising it as a signifier of Welshness, loaded with symbolic value.

The alleged inaccessibility of the landscape, the identity of the Welsh people and the idea of cultural continuity (in other words: timelessness) appear to be inextricably connected in the German guidebooks. Bertelsmann's guidebook notes in this respect:

[D]ie Waliser, die Einwohner von Wales, [sind] mehr oder weniger reine Nachfahren von Kelten, die in einzigen Rückzugsgebieten, so in Wales, ihr Volkstum lange Zeit ziemlich unverfälscht erhalten konnten. Brauchtum und Traditionen der Waliser sind auch heute noch lebendig [...]. ${ }^{678}$

[The Welsh, the inhabitants of Wales, are more or less pure descendants of the Celts. In some places of refuge, like Wales, they have been able to maintain their customs and traditions relatively unaltered for a long time and these are still maintained [...].]

In this sense, the Welsh landscape acted as a barrier against anglicisation; it safeguarded Welsh culture by conserving it in a timeless container. The Sternfahrten guidebook goes further, and asserts that the landscape not only passively protected Welsh culture and customs, but also actively shaped its inhabitants and their disposition. The guide provides a detailed description of how the Celts were driven back by the Anglo-Normans and eventually withdrew into the harsh, mountainous areas of Wales. Here they were finally left alone since the Anglo-Normans were allegedly not interested in these barren areas. According to the guide, it was due to these bleak surroundings that the Welsh turned into a hardened people. ${ }^{679}$ The Welsh landscape is thus directly connected to the national identity and character of its inhabitants and is arguably seen as an important reason for the exclusion of Wales from the centre on the imaginative periphery.

According to the Grieben guidebook, however, the Welsh actively pursue this seclusion themselves, thus being responsible for their own peripheralisation:

Der Bewohner dieses Landes legt seit Jahrhunderten in Lebensform, Sprache und Aussehen darauf Wert, nichts mit den anderen Rassen und Einwohnern der Insel zu tun zu haben, und

\footnotetext{
${ }^{678}$ Voss-Gerling, p. 12. Italics of original.

${ }^{679}$ Friedrich, pp. 23-24.
} 
bemüht sich seit den Zeiten der römischen Besatzung, diesen Unterschied bei jeder Gelegenheit zur Schau zu bringen. ${ }^{680}$

[For centuries, the country's inhabitants have wanted to keep the other races and occupants of the island at bay regarding their way of life, language and appearance. Ever since the Roman occupation, they have tried to demonstrate this difference on every possible occasion.]

The guide then argues that as a result of this secluded lifestyle, Wales has not changed for two and a half centuries, and that travellers will be amazed by 'all das Unerwartete, und auch noch Unentdeckte und Unbekannte' [all the unexpected, and still undiscovered and unfamiliar things] that they will encounter during their tour through Wales. Subsequently a scene of people singing in the midst of valleys, mountains and forests is described, with the comment: 'Die Waliser haben schon immer vereinzelt dahingelebt - ohne Dörfer und ohne Städte - und in dieser abgeschlossenen Traumwelt ihre Dichtungen und Lieder und Sagen und Märchen von Generation zu Generation erhalten' [The Welsh have always lived in isolation with neither villages nor cities - and in this secluded dream world they have preserved their poetry and songs and legends and fairy tales from generation to generation]. This guidebook thus links Welsh identity, which is generally reduced to a fondness for singing and poetry, to the fact that the Welsh are an 'unmixed' race, living in self-chosen isolation without ever progressing into modernity. The reader is even led to believe that the place they inhabit is not of this world (Traumwelt). This description conveys a portrayal of the Welsh as an exotic and not yet fully discovered tribe of noble savages, living outside of contemporary time, space and even reality.

\subsubsection{A Historical Sense of Difference: Aggressors, Heroes and Fair $\underline{\text { Rulers }}$}

The sense of difference in the Welsh case is also constructed through the representation of historical events. Although awareness of the Welsh historical narrative increased compared to the nineteenth-century guidebooks, it is still largely subordinate to that of the English. All the guides in this period include a separate section about English history, but only the Grieben guidebook provides something similar for Wales. But even then, this is still very brief in comparison; whereas nine

${ }^{680}$ England und Wales, p. 31. 
pages are allocated to English history, only one is devoted to Wales. ${ }^{681}$ Moreover, after the Acts of Union Welsh history is considered to be the same as that of England and is therefore not further described. ${ }^{62}$ The other guides do not provide any kind of separate section about Welsh history and only mention it when the Welsh were involved in a conflict with the English. As a result, the Welsh side of history is depicted as non-existent on its own, and is rather reduced to a set of conflicts with the English. Again, the Welsh can only be represented in relation to and in contrast with the English, merely coming into existence when confronted with the centre.

Although the Welsh historical narrative is marginal, it is within the description of specific sites, for example the Welsh castles, that the historical difference between the Welsh and English is described in more detail. Two main figures are central in this respect: Owain Glyndŵr and Edward I. In the guides, these two historical actors represent the struggles between the Welsh and the English, and therefore the depiction of Welsh history. In the light of the dichotomy of self and other, as well as the general opposition of Welsh and English, it is illuminating to see how these two actors are described.

The portrayal of Owain Glyndwrr undergoes a 360-degree change in the German guidebooks between 1955 and 1975. Following the late nineteenth-century Baedekerian representation of this historical figure, the 1955 Stauffacher guidebook describes Glyndŵr as a welsche Hauptmann [Welsh chieftain], and points out the place where his knife got stuck 'als er ihn aus Zorn über ein Zerwürfnis mit den Einwohnern gegen die Tür schleuderte' [when he hurled it against the door out of rage over an argument with the locals]. ${ }^{683}$ Owain is therefore by no means depicted as the national hero he is considered nowadays by many in Wales, ${ }^{684}$ but rather as an unpredictable and violent rebel who endangers his own people. Later guidebooks seem to have changed their views on Glyndŵr and describe him from a more positive point of view. The Sternfahrten guidebook characterises him for example as 'der große Freiheitskämpfer von Wales' [the great freedom fighter of Wales] and adds that he has remained an exemplary symbol of Welsh stubbornness. ${ }^{65}$ The Große

\footnotetext{
${ }^{681}$ England und Wales, pp. 31-41.

${ }^{682}$ England und Wales, pp. 40-41.

${ }^{683}$ Heller-Merricks, p. 320.

${ }^{684}$ See: Pitchford, pp. 59-64.

${ }^{685}$ Friedrich, p. 622.
} 
Polyglott guide similarly labels him 'Nationalhelden von Wales' [national hero of Wales]. ${ }^{686}$

Although most guidebooks describe the Edwardian castles merely from an aesthetic perspective, the Große Polyglott guidebook is a noticeable exception in this respect and seems to initiate a new way of representing Welsh history which is commonly found in more contemporary guidebooks (see Chapter 5). It is the first guide to describe the castles of Wales as relics of the struggles of the Welsh against the English: 'Alte Schlösser und Burgen künden von der einstigen Wehrhaftigkeit seiner Bewohner und erinnern an die stürmische Geschichte des Landes' [Old castles and fortresses bear witness to the former defensiveness of its inhabitants and recall the tumultuous history of the country]. ${ }^{687}$ Instead of being regarded from a purely aesthetic point of view, the Edwardian castles are now starting to be connected to Welsh history and to be perceived as symbols of Welsh resistance.

Whilst these examples show that there seems to be a tendency within the guidebooks published in this period to provide a more extensive and more balanced portrayal of Welsh history, the representation of Edward I remains remarkably similar. When he is described, it is mostly as a merciful and fair ruler, who wanted to meet the wishes of the Welsh by giving them his first son who would speak Welsh as his first language. ${ }^{688}$ The Sternfahrten guide even describes Edward I as a victim of Welsh aggression. According to the guidebook, Edward had built town walls around Caernarfon, and it was only after he was attacked by Welsh rebels that he was enraged, retook the town and built one of his most magnificent castles there. History is thus turned around, representing the Welsh as the aggressors, instead of Edward I who subjugated Wales during a military campaign. Consequently, it is implied that the Welsh are themselves to blame for their subjugation.

\subsubsection{The Welsh Language}

The language is the final aspect through which Wales's difference is constructed. Again, this aspect of Welshness is primarily represented in contrast to English and is thus turned into a marker of otherness. As has already been shown

\footnotetext{
${ }^{686}$ Lajta, p. 350.

${ }^{687}$ Lajta, p. 43.

${ }^{688}$ Heller-Merricks, p. 325. See also: England und Wales, p. 41; Lajta, p. 62.
} 
earlier in the analysis, the Stauffacher guidebook identifies the Welsh language and the English accent of the Welsh as indications that the traveller is entering a different country. ${ }^{689}$ Bertelsmann's guide also underlines that Welsh and English have nothing in common and provides a glossary to demonstrate this fact. ${ }^{690}$ Instead of depicting the Welsh language as a means of communication and as a language in which a wide range of literary and scholarly work has been published, it is limited to a sign of difference. This is especially noticeable in contrast to the depiction of the language in the nineteenth-century guidebooks, in which Baedeker considered it important to have a basic knowledge of the pronunciation of Welsh place names. In comparison, no German guidebook between 1955 and 1975 provides any kind of structured pronunciation aid.

The imprecision with which the pronunciation of Welsh place names is treated in the Große Polyglott guide exemplifies the general lack of interest in the language as anything but a sign of otherness. Although this guide provides phonemic transcriptions of place names (not exclusively the Welsh ones), these do not reflect the actual Welsh pronunciation but are rather transcriptions of a supposed English phonation. The place name 'Llanystumdwy' is for example phonetically transcribed as 'läni' Btimdui', ${ }^{691}$ thus ignoring the correct pronunciation of the phoneme /1/ whilst simplifying it as an /l/, as well as describing the Welsh /a/ sound as an anglicised $/ \varepsilon /$. In addition, the use of the symbol to indicate stress is used inconsistently; sometimes it is put in front of the actual stressed syllable and sometimes after, therefore failing to provide a well-defined and clear aid to the reader.

Glossaries are found in only two of the guides, merely enumerating words that are commonly found in place names. ${ }^{62}$ This vocabulary is intended to help the tourist understand the meaning behind geographical Welsh terms. The way the Welsh language is ignored and downplayed as a language of communication leads to its portrayal as a passive object of the tourist gaze, for example in the case of Llanfair P.G. which is described as an attraction. ${ }^{693}$ Instead of being an interactive part of the tourist experience it remains a marginal aspect, only suitable to emphasise Wales's otherness and to occasionally entertain the traveller.

\footnotetext{
${ }^{689}$ Heller-Merricks, p. 302.

${ }^{690}$ Voss-Gerling, p. 14.

${ }^{691}$ Lajta, p. 353.

${ }^{692}$ See: Heller-Merricks, p. 303; Voss-Gerling, p. 14.

${ }^{693}$ See for example: Heller-Merricks, p. 319; Friedrich, p. 623.
} 
Overall, the representations of Wales have changed drastically compared to the images of the country found in the nineteenth-century guidebooks. Rather than being constructed as part of the industrialising and innovative centre whilst largely ignoring Wales's difference as a cultural entity, the guidebooks published in the decades following World War II create a different image of the country. Although the natural landscape is still perceived as the main asset of the country, the industrialised areas in South Wales are removed from Wales's touristic map. Moreover, the country is being moved towards the imaginative periphery by stressing the difference of Wales from the centre. The topographical border is imagined as a crucial point of transition, after which the traveller enters a country where an ancient Celtic race still resides. Its otherness is primarily constructed in opposition to the English centre, and illustrated by the depictions of Welsh culture, racial characteristics, history and language.

\subsection{Diverging French Perceptions of Wales}

\subsubsection{Continuation and Development of the Nineteenth-Century Discourse: Picturesque and Industrial Landscapes}

As has been noted in Chapter 4.1.3. concerning the corpus examined in this chapter, the French material can be divided into two categories. It was argued that the Guides Nagel and the Guides bleus could be seen as direct successors of the nineteenth-century guidebooks, and for this reason they will form the focus of the current section. These two guidebook series hardly provide any information about the culture, language and inhabitants of Wales. Instead, they regard the natural landscape as the most important reason for travelling to Wales, similar to the nineteenth-century guidebooks. The Guides Nagel, for example, points out that Wales is famous for its mountains, lakes and castles, and that the most worthwhile towns are Caernarfon, Llanrwst and Betws-y-Coed due to their magnificent location amid the countryside. ${ }^{694}$ The guides clearly distinguish between the industrialised South and the rural North, preferring the latter from a touristic point of view due to its varied natural landscape, both inland and along the coast. ${ }^{695}$ The Guides bleus

${ }^{694}$ Lang, Grande-Bretagne et Irlande, p. xxxvii.

${ }^{695}$ Lang, Grande-Bretagne et Irlande, p. 481. 
express similar preferences, recommending North Wales as the most worthwhile area due to its mountainous landscape, whereas South and Mid-Wales are said to have far less to offer the tourist. ${ }^{696}$ Nineteenth-century tourist attractions such as panoramas, ruined castles and abbeys still dominate the guides. An analysis of the attractions that are awarded an asterisk in the Guides bleus shows that nine can be classified as natural features (e.g. landscapes and views), whereas the remaining five are medieval edifices, such as Conwy Castle and St. David's cathedral. In this respect, the portrayal of Wales has hardly changed compared to the descriptions found in guidebooks published almost a century earlier.

The description of the industrial areas of Wales also indicates a continuation of the style of the nineteenth-century guidebooks throughout the 1950s. However, during the following two decades this interest seems to be rapidly decreasing, which eventually leads to the omission of this aspect of Wales. The Nagel guidebook to Great Britain, published in 1953, describes industrial areas in an unprejudiced manner. Usually, they are succinctly mentioned without any further information or evaluation. ${ }^{697}$ The industrial area around Cowbridge in South Wales is for example described as: 'Région minière très active et à la population très dense' [Very active mining region with very dense population]. ${ }^{698}$ These descriptions are hardly illuminating for the tourist, but it is still noticeable that the towns are mentioned rather than simply ignored and omitted, as was the case in the German-language guidebooks published during this period. Moreover, the description of Swansea shows that industry and leisure were not considered mutually exclusive: '[G]rand centre commercial et industriel et station de vacances' [Major commercial and industrial centre, as well as holiday resort]. ${ }^{699}$

The Guides bleus handbooks from the 1950s take a more engaged stance, similar to the nineteenth-century Guides Joanne guidebooks, by paying attention to the social and economic problems of the industry sector. The guide expresses these

\footnotetext{
${ }^{696}$ Halévy, p. 583.

697 The Valleys are for example described as: 'Entre les Black Mountains, Brecknock et Glamorgan, où se trouvent toutes les vallées charbonnières importantes de la Galles du Sud, est la vallée de l'Usk' [The Usk Valley is situated between the Black Mountains, Brecknock and Glamorgan, where one can find all the important coalfields], in: Lang, Grande-Bretagne et Irlande, p. 471. Italics of original.

${ }^{698}$ Lang, Grande-Bretagne et Irlande, p. 466. ${ }^{699}$ Lang, Grande-Bretagne et Irlande, p. 468.
} 
views by quoting a section from Dudley Stamp's Le Visage de la Grande-Bretagne

[The Face of Great Britain] (1947): ${ }^{700}$

\begin{abstract}
Les carreaux de la mine couvrent le fond de la vallée et les rangées lugubres de petites maisons de mineurs, qui forment une chaîne ininterrompue de villes et de villages, sont obligées d'escalader les deux versants. Une ligne de chemin de fer, parfois deux, et une route doivent également utiliser la vallée, et c'est le même spectacle pendant des kilomètres et des kilomètres... ${ }^{701}$

[The surface facilities of the mine cover the bottom of the valley, and the gloomy rows of little miners' cottages, which form an uninterrupted chain of towns and villages, are forced to climb the two slopes. A railway line, sometimes two, and a road also have to make use of the valley, and it is the same sight for miles and miles on end...]
\end{abstract}

This quotation sketches a very cheerless impression of the South Wales Valleys, which are subsequently described as having 'cruellement souffert pendant vingt ans' [suffered cruelly for twenty years]. The description of the Swansea Valley provides a similarly grim image: '[L]e paysage donne une impression de désolation extraordinaire: les fumées des usines de cuivre, qui ne sont pas malsaines pour les hommes, ont détruit toute la végétation, à l'exception d'une sorte de camomille jaunâtre' [The landscape gives an extraordinarily desolate impression: the fumes from the copperworks, which are not unhealthy for humans, have destroyed all vegetation with the exception of a yellowish kind of chamomile]. ${ }^{702}$ Although the guide downplays the health risks of the factories for humans, the environmental effects and the living conditions of the workers are critically evaluated; the Cardiff workmen's quarters Grangetown and Butetown are described as dirty and filled with smoke. $^{703}$

This does not, however, mean that industry is considered uninteresting for the tourist. Like the nineteenth-century guidebooks, the Guides bleus still points out to the reader that slate quarries, docks and steelworks, as well as foundries and forges, can be visited. ${ }^{704}$ Especially the Cardiff Docks and the Dowlais Cardiff Steel Works are said to be genuinely worth a visit. ${ }^{705}$ Even though interest in Wales's industry has

\footnotetext{
${ }^{700}$ It is not clear whether this a translation of an English original, and from what book this would then be a translation.

${ }^{701}$ Halévy, p. 1-li.

702 Halévy, p. 609.

${ }^{703}$ Halévy, p. 616. The remark that the fumes are harmless to men is later omitted in: Robert Boulanger, Iles Britanniques: Angleterre et pays de Galles, Écosse, Irlande du Nord, Eire, Guides bleus (Paris: Hachette, 1964), p. 696.

${ }^{704}$ Halévy, pp. 603, 618-9.

705 Halévy, p. 618.
} 
decreased to some extent and is not always evaluated positively, it is nevertheless mentioned in the guides. In contrast to the German guidebooks from this period, the industrial areas of Wales are not simply ignored and erased from Wales's touristic map; in these French examples, the Valleys remain part of Wales.

During the following two decades, the guidebooks nevertheless gradually remove the area from the Welsh touristic space. In the Guides bleus edition from 1964, the visits to the Cardiff Docks and Dowlais Steel works, as well as to other industrial sites, are omitted. The tourist is now advised to avoid the area around the Docks, as well as the route between Hereford and Swansea, also known as Heads of the Valleys Road. ${ }^{706}$ In its 1975 edition, the Nagel guidebook also omits many of the references to industrial sites and towns but does mention that the National Museum of Wales in Cardiff has a section devoted to the mining industry. ${ }^{707}$ Industry is thus moving into the commodified domain of the museum, instead of being part of the landscape. In other words, for the tourist it has become part of Welsh heritage rather than of everyday reality.

\subsubsection{Contrasting Views}

The following sections examine new discourses for Wales in the Frenchlanguage guidebooks published after World War II. Although there are many similarities between the French and German portrayals of the country and its inhabitants, there are also striking differences. Key points of comparison will be the portrayal of the Welsh people, their history and language, as well as their cultural traditions. Moreover, it will become apparent that the guidebooks with a more narrative style often provide a crucially different representation of the country compared to the Guides Nagel and the Guides bleus.

\subsubsection{The Welsh Inhabitants: Manual Workers and Political Innovators}

In Section 4.2 it was argued that Wales was increasingly regarded as a distinctive travel destination since it was no longer automatically equated with England. However, it was also stressed that this growing distinctiveness was relative

\footnotetext{
706 Boulanger, pp. 691, 701.

${ }^{707}$ Lang, Grande-Bretagne, p. 852.
} 
and that Wales was still overshadowed by England in particular. An illuminating example of this is the characterisation, or rather the lack of characterisation, of the Welsh in the 1958 Guides bleus guidebook. This guide shows a growing awareness of the differences between the various people of the British Isles, which is discussed under the heading 'Rapports avec les habitants des différentes régions' [Relations with the Inhabitants of the Different Regions]. ${ }^{708}$ This section informs readers of what they might expect when they get in contact with the inhabitants of the Isles. Succinct descriptions of the English, Irish and Scottish characters are given, but the Welsh are not included. The only remark in respect to the Welsh is: '[R]ares sont les personnes qui ne renoncent pas à nouer conversation avec les paysans des villages perdus d'Irlande ou du Pays de Galles!' [There are few that will have the perseverance to strike up a conversation with the farmers in remote villages in Ireland or Wales!]. ${ }^{709}$ Later, in the introduction to Wales, the Welsh people are described in slightly more detail:

Les Gallois, pêcheurs et mineurs surtout, mais aussi cultivateurs et pasteurs, sont les descendants des vieilles populations celtiques de l'île; ils parlent et écrivent encore leur dialecte celtique, le 'gallois', appelé 'Welsh' par les Anglais, et qu'il est intéressant de rapprocher des dialectes bretons, irlandais et écossais. ${ }^{710}$

[The Welsh, mostly fishermen and miners but also farmers and shepherds, are the descendants of the old Celtic population of the island; they still speak and write their Celtic dialect, 'Gallois', which the English call 'Welsh', and it is interesting to compare this to the Breton, Irish and Scottish dialects.]

Although the Welsh are identified as descendants of an 'old Celtic population', their distinction from the rest of the inhabitants of the British Isles is primarily based on their language. Noticeable in this respect is the fact that it is termed a dialecte [dialect], which ignores the fact that Welsh is a separate language. The portrayal of the Welsh language will be discussed in more detail in Section 4.4.2.3.

Despite the association with their asserted Celtic roots, a prominent racial discourse, as was apparent in some of the German guidebooks discussed earlier, is not evident. By focusing on the alleged professions of the inhabitants, i.e. farmers, fishermen, miners or shepherds, Wales is depicted as an underdeveloped region where most people work as manual labourers. Historically, unskilled or semi-skilled

\footnotetext{
${ }^{708}$ Halévy, p. cxxxviii.

${ }^{709}$ Halévy, p. cxxxviii.

${ }^{710}$ Halévy, p. 583.
} 
manual labour has often been associated with low social status especially in comparison to intellectually skilled work. Owing to this, Wales is perceived to be in a less advanced state and its inhabitants are marginalised as an underdeveloped people. Apart from this description, neither the Guides bleus nor the Guides Nagel provide any characterisation of the inhabitants of Wales. The country thus remains largely devoid of human population in these guidebooks.

Conversely, in the narrative French-language guides from this period, the various people from the British Isles are not distinguished by their profession but rather by their origins and characteristics. In this respect, these texts resemble their German-language counterparts. The existence of an ethnographic difference is emphasised and brought to the attention of the reader. Several guides warn their readers not to use the term 'English' when addressing the Welsh or the Scots: 'Il aura vite de vous corriger, en vous donnant probablement de surcroît son opinion peu flatteuse des Anglais' [He will quickly correct you, probably on top of that voicing his unflattering opinion of the English]. ${ }^{711}$ Instead of treating the British as one people, their supposed mutual antipathy is emphasised.

Not only are the differences between the various inhabitants of the United Kingdom highlighted, the characterisation of the Welsh features more prominently than in the Guides bleus and Guides Nagel as well. Resembling the depiction of Wales found in some of the German-language guidebooks from this period, the Petite planète describes the Welsh from a 'vue racial' [racial point of view]. ${ }^{712}$ Wales is termed 'la région la plus authentiquement britannique de Grande-Bretagne' [the most authentically British region of Great Britain], ${ }^{713}$ because the oldest inhabitants of the island have allegedly lived here for centuries; a race closely connected to the Celts in Cornwall and Brittany. The idea of the Welsh as the indigenous population of Great Britain which was found in the German guidebooks is again noticeable here. Another similarity is the fact that the Petite planète considers the mountainous landscape as a crucial prerequisite for the survival and preservation of Welsh national identity. The guidebook subsequently provides a physiognomic depiction of the Welsh, 'que les

\footnotetext{
${ }^{711}$ Pierrard, p. 105. See also: François Bédarida and Renée Bédarida, Nous partons pour la GrandeBretagne, Nous partons (Vendôme: Presses universitaire de France, 1975), p. 9.

712 Bailhache, Grande-Bretagne (1960), p. 105.

${ }^{713}$ Bailhache, Grande-Bretagne (1960), p. 105.
} 
Anglais ont baptisé Taffy' [whom the English have baptised Taffy] ${ }^{714}$ as slimmer than the English, with darker hair, and a more active and lively character.

Although other guides refrain from defining the Welsh in terms of their physical appearance, their character is usually described in a way that closely resembles the characterisations found in contemporaneous German guidebooks. Musicality is mentioned by many as the most defining Welsh character trait, to which qualities such as emotional, poetic and mystical are added by the Petite planète and the Monde et voyages guidebook. ${ }^{715} \mathrm{~A}$ telling example of this is the characterisation of the Welsh in the latter: 'Ce sont des artistes, disent les Anglais en parlant des Gallois, ils ne savent pas compter, et quand ils se réunissent, c'est toujours pour chanter' [They are artists, as the English say when speaking about the Welsh, they do not know how to count, and when they come together, it is always to sing]. ${ }^{716}$ In this striking characterisation, the Welsh are portrayed as a peripheral people who do not fit in with modern society. Viewing the Welsh from an English perspective, as the guide acknowledges, it is assumed that the former do not possess the skills which are regarded to be useful in contemporary society, such as counting; instead, they sing.

The assertion made above that the narrative French guidebooks do not characterise the Welsh according to their profession must be somewhat revised. The Nous partons guidebook describes them as 'tantôt poètes, tantôt chanteurs ou joueurs de harpe' [sometimes poets, sometimes singers or harp players]. ${ }^{717}$ Instead of the image of the Welsh as relatively unskilled manual labourers, their creativity becomes their main occupation. Albeit very different representations of the Welsh and their livelihoods, both depictions can be argued to be marginalising. The conceptualisation of the Welsh as creative further contributes to their peripheralisation, as creativity and artistry are characteristics that are generally associated with the imaginative periphery (see Chapter 2.3).

\footnotetext{
${ }^{714}$ Bailhache, Grande-Bretagne (1960), p. 106. Although it remains uncertain whether the author was aware of the derogatory connotation of this 'nickname', it is nonetheless noticeable that this traditionally English sobriquet had apparently permeated the French discourse employed for Wales to some extent. It could be suggested that it had been introduced through the travelogue written by Charles Le Goffic entitled 'Chez Taffy: quinze jours dans la Galles du sud' [At Taffy's: Fifteen Days in South Wales] (1901). Nevertheless, this is the only instance of a guidebook using the term and its acceptance in French discourse should therefore not be overstated.

${ }^{715}$ Bédarida and Bédarida, p. 267; Bailhache, Grande-Bretagne (1960), p. 106; Pierrard, p. 154.

${ }^{716}$ Pierrard, p. 83.

${ }^{717}$ Bédarida and Bédarida, p. 267.
} 
So far, the depictions of the Welsh in the French-language guidebooks show clear similarities to those found in their German counterparts. A significant difference, however, is the fact that the Petite planète and the Monde et voyages guidebooks manage to connect this characterisation to modern political achievements instead of linking the Welsh national character to an allegedly desired isolationism. These two guidebooks relate their descriptions of the Welsh character to the fact that these people have brought forth so many eloquent and passionate public speakers and politicians, such as Keir Hardie, ${ }^{718}$ Lloyd George and Aneurin Bevan:

\begin{abstract}
Il n'est donc pas étonnant que le pays de Galles, avec un Robert Owen, avec un Keir Hardie, qui fonda en 1893 le Parti Indépendant du Travail, avec un Lloyd George, si fougueusement gallois, et Aneurin Bevan, son digne successeur, avec le solide électorat travailliste de ses centres miniers, ait été à la pointe du combat politique. ${ }^{719}$
\end{abstract}

[It is therefore not surprising that Wales, with Robert Owen, with Keir Hardie, who founded the Independent Labour Party, with Lloyd George, so passionately Welsh, and Aneurin Bevan, his worthy successor, and with the stable Labour electorate of its mining centres, has been at the forefront of the political struggle.]

This quotation shows how the Petite planète guidebook places the Welsh people in a contemporary setting, even spatialising them as being the centre of a so-called 'political struggle'. Whereas the previously examined guidebooks all neglected the political activity of the Welsh, the Petite planète and the Monde et voyages seem to highlight a completely different side of Wales. Instead of depicting the Welsh as secluded people that are stuck in the past and do not want to become involved with the other races of the island, they are portrayed as politically innovative. According to the Petit planète guidebook, this vitalité [vitality] of the country and its people is furthermore exemplified by their economic ventures and the fact that the Welsh have emigrated to every corner of the world. ${ }^{720}$ Due to these depictions, the image of Wales as a globalised, enterprising nation is created, which in itself forms a centre from which people, political ideas and economic forces are spreading. This image is further consolidated in the second edition of the Petite planète, in which a new section about Welsh politics is added: 'Sur le plan politique, la création en 1964 d'un

\footnotetext{
${ }^{718}$ It must be emphasised that in fact Keir Hardie was not a Welshman, but a Scot who worked as an MP in the Welsh constituency of Merthyr Tydfil and Aberdare during the beginning of the twentieth century. Taking him as a personification of Welsh national identity shows once more how constructed and imagined the characterisation of the Welsh is. The guidebooks take and omit whatever they need in order to create the desired image.

${ }^{719}$ Bailhache, Grande-Bretagne (1960), p. 106. See also: Pierrard, p. 154.

${ }^{720}$ Bailhache, Grande-Bretagne (1960), p. 107.
} 
secrétariat d'État au Pays de Galles a reconnu à ce pays un embryon d'indépendence à l'égard du gouvernement central' [On the political level, the creation of a Secretary of State for Wales in 1964 has granted the country an embryo of independence from the central government]. ${ }^{721}$ By representing Welsh independence as an embryo, the guide strongly implies that Welsh autonomy will grow during the coming years, and that this is only the beginning of a politically sovereign Wales. Although this is the only guidebook that mentions this development, it shows that Wales is gradually starting to be recognised as a political entity with a certain level of governmental independence. This is a crucial step towards perceiving Wales as a distinctive country, instead of merely as an opposite to England. The representation of the political independence of Wales will be scrutinised in more depth in the next chapter in relation to devolution.

Although this portrayal of the Welsh is an important shift compared to the depictions found so far, it must be highlighted that the Petite planète also complies with the view of the Welsh normally found in the guidebooks. After having stressed the vitality of South Wales, the guide states that North Wales is different; very peaceful with more sheep than men. It is in this area that the Welsh soul has found its perfect space, according to the guide. ${ }^{722}$ Therefore, it is not the praised vitality of the country, but rather its rurality and emptiness that truly constitutes the l'âme galloise [Welsh soul]. The connection between an allegedly empty landscape and Welshness will be further explored in Section 4.4.2.4.

In summary, it can be argued that the French material from this period provides a less consistent image of the Welsh than the German guides, which primarily focused on their Celtic background. A similar categorisation of the various people of the British Isles did not feature prominently in the French guidebooks. Even though ethnographic views were adopted on certain occasions, this did not lead to the temporalisation of the Welsh as a backward-looking, unmixed and secluded race. Instead, characteristic features of the Welsh were at times even seen as contributing to their political success and contemporary achievements. These diverging views of the Welsh could arguably have contributed to the differentiating readership of the various series. The Guides Nagel and the Guides bleus took little

\footnotetext{
${ }^{721}$ Jean Bailhache, Grande-Bretagne, Petite planète, 2nd edn (Paris: Éditions du Seuil, 1972), p. 108.

${ }^{722}$ Bailhache, Grande-Bretagne (1960), p. 107.
} 
interest in the inhabitants of the country and this appears to fit their profile as successors of the nineteenth-century guidebook series. The narrative guidebooks clearly attempt to break with the traditions of their precursors and to provide their readers with different forms of information and new points of view. According to Goulven Guilcher, who has published extensively on French guidebooks, the Petite planète series 'est une création originale tout à fait non conformiste. [...] Les problèmes sociaux et politiques du moment ne sont pas éludés, liberté en Pologne, poids de la religion en Irlande, et le ton est beaucoup plus natural qui celui des Guides-Bleus de l'époque' [is an original creation, entirely nonconformist. [...] Current social and political problems are not avoided, e.g. freedom in Poland or the influence of religion in Ireland, and the tone is much more natural than in the Guides bleus of that period]. ${ }^{723}$ This certainly also seems to be the case for their portrayal of Wales and its inhabitants, and could have resulted in a more politicised view. Although the Monde et voyages and the Nous partons series are not as politicised as the Petite planète, they are also looking for new ways of constructing the genre as they are clearly deviating from the set-up of their forerunners.

\subsubsection{A Question of Perspective: The Anglo-Normans as Subjugators or Bringers of Law and Order}

Similar to the German guidebooks from this period, the marginality of Wales is also constructed through the lack of information concerning the country in the historical overviews of the guides. Most guides base their chronology on the English (later British) dynasties, and the only detail about Wales that is consistently mentioned is the year of its subjugation by Edward I. ${ }^{724}$ Wales is thus not seen as an individual historical entity, but is again only defined in respect to its contact with the English. In the Guides bleus, the historical developments in Wales are summarised in one paragraph:

La nature du sol permit à ses habitants de résister vigoureusement aux Saxons, puis aux Normands, et ce n'est qu'en 1283 qu'Edouard ${ }^{\text {er }}$ acheva la conquête du royaume de Galles; encore faut-il attendre jusqu'en 1536 pour le voir faire partie intégrante de

\footnotetext{
${ }^{723}$ Guilcher, 'Entre continuité et innovation', p. 14.

${ }^{724}$ Lang, Grande-Bretagne et Irlande, p. xxviii; Halévy, p. lvi; Bédarida and Bédarida, p. 38.
} 
l'Angleterre (sous Henry VIII Tudor) et suivre dès lors le développement historique de celle-ci. ${ }^{725}$

[The nature of the territory made it possible for its inhabitants to vigorously resist the Saxons and the Normans, and it was not until 1283 that Edward I completed the conquest of the kingdom of Wales; it would still take until 1536 before it became an integral part of England (under Henry VIII Tudor), after which it followed the historical development of the latter.]

Wales's history is thus confined to its resistance to the Saxons, Normans and the English, whilst it supposedly has no individual history after the Acts of Union. The only way in which Wales can historically exist is therefore in opposition to England; at the moment that it becomes united with the latter, its historical individuality ceases to exist.

Within this discourse of opposition, the way in which the various sides (i.e. Anglo-Norman and Welsh) are portrayed varies greatly. Similar to the German guides from this period, the guidebooks seem to choose either the point of view of the Welsh or the Anglo-Normans. The Guides Nagel and the Guides bleus represent Welsh history from the traditional 'Anglo-Saxon' perspective: the Welsh are depicted as the assailants and the English as the protectors of Wales. The Guides Nagel, for example, summarises the reason for the construction of the Anglo-Norman fortress of Denbigh in the thirteenth century as: '[À] maintenir l'ordre dans les Galles' [To maintain order in Wales]. ${ }^{726}$ The arrival of the English and the construction of their strongholds are seen as having had a positive influence on the development of Wales, as towns like Aberystwyth and Harlech are said to have flourished under the protection of their respective castles. ${ }^{727}$ These military constructions are thus regarded as positive developments, instead of symbols of oppression. Especially in the description of Caernarfon Castle it becomes clear that the English are seen as the bringers of advancement and prosperity:

Cette ville commença à se développer dès le moment où son imposante forteresse fut érigée, c'est-à-dire sous le règne d'Edouard I ${ }^{\mathrm{er}}$, à partir de 1283. [...] Les Anglais durent faire face à plusieurs rebellions des Gallois, notamment en 1294, lorsqu'ils parvinrent à pénétrer dans le château qui n'était pas encore achevé, et en 1400, lors de l'insurrection dirigée par Owen Glendower. $^{728}$

\footnotetext{
${ }^{725}$ Halévy, p. 584.

${ }^{726}$ Lang, Grande-Bretagne et Irlande, p. 492.

${ }^{727}$ Boulanger, pp. 705, 708.

${ }^{728}$ Boulanger, p. 710.
} 
[This village started to develop from the moment its impressive castle was built, namely from 1283 onwards under the reign of Edward I. [...] The English had to withstand several Welsh rebellions, particularly in 1294, when the latter managed to enter the uncompleted castle, and in 1400 during the insurrection led by Owen Glendower.]

The Welsh are thus portrayed as the agitators, whereas the English are represented as the enforcers of law and order. Whilst towns were able to develop and grow under the reign of the Anglo-Normans, the Welsh seem to have been only capable of rebelling. This juxtaposition between positive English and negative Welsh influence is glaring and clearly illustrates the viewpoint from which Welsh history is described in the guidebooks. Furthermore, the Guides Nagel also depicts the English as victims by mentioning that Edward I was assaulted in Conway Castle by the Welsh and subsequently almost starved to death but was saved due to food supplies that were delivered by sea. ${ }^{729}$

These descriptions result from a reading of Welsh history from an 'AngloSaxon' perspective. Instead of portraying the Welsh as a subjugated people and the English as the oppressors, the former become the rebellious aggressors, whereas the latter bring order and prosperity. The narrative French guidebooks from this period provide an opposing view, showing a growing awareness of the travellee's perspective; they depict the English as the subjugators, whereas the Welsh are portrayed as courageous warriors. The Petite planète, for example, describes Wales as a country that has been defined by conflict against various other inhabitants of the island. Even though Edward I finally succeeded in conquering the country, the Welsh are portrayed as the de facto victors, since the Welsh Tudor dynasty triumphed over the Yorkists in the War of the Roses: 'Il est donc bien évident que c'est le Pays de Galles qui a conquis l'Angleterre, et non l'inverse' [It is therefore evident that it is Wales that has conquered England, and not the other way around]. ${ }^{730}$ In the guide, this unusual viewpoint on Welsh history is thus completely opposed to what was found in the more traditionalist guidebooks from the same period.

The Monde et voyages also depicts the English as the aggressors; in contrast to the descriptions of the Edwardian castles as bringers of economic prosperity, this guide clearly focuses on these constructions as signs of war and oppression. By using the famous quotation from the Welshman Thomas Pennant to describe Caernarfon

\footnotetext{
${ }^{729}$ Lang, Grande-Bretagne et Irlande, p. 495.

${ }^{730}$ Bailhache, Grande-Bretagne (1960), p. 106.
} 
Castle as "“ces merveilleux jalons de notre servitude"" ["the magnificent badge of our subjection"], ${ }^{731}$ the guide views this edifice from an opinionated Welsh perspective, rather than from a purely aesthetic one. It is emphasised that Edward I built these castles to secure his dominance over the country, which is a completely different reason than 'to secure order', as was suggested by the Guides bleus and Guides Nagel. Edward I is now clearly depicted as the villain; he is described as having dislodged Prince Llywelyn, quartered the latter's brother and slaughtered all the bards to prevent them from encouraging their countrymen to take up arms again, before installing his own son as Prince of Wales. ${ }^{732}$ Although the Nous partons guidebook does not depict Edward I as negatively as the Monde et voyages guide, it also adds that the castles are seen by the Welsh as symbols of oppression, whilst granting that these edifices are nevertheless the most worthwhile sights in Wales. ${ }^{733}$ At the same time, Llywelyn ap Gruffudd and 'Owain Glyn Dŵr' are identified as the personification of Welsh resistance to the English, and their deaths are strongly dramatised. According to the guide, Llywelyn was mourned by all the Celts and Owain Glyndŵr lived on in the memories of his compatriots. ${ }^{734}$

Comparing the German and French representations of Welsh history, it can be argued that whereas the Welsh are transformed from villains into freedom fighters during the 1960s and 1970s in the former, this transformation is not temporally bound in the latter. The difference in perspective can rather be found between the guides that are situated in the nineteenth-century tradition (i.e. the Guides bleus and the Guides Nagel) and the narrative guides. In the former, the English bring stability and progress, whereas the latter depict them as the aggressors. This difference could again be attributed to the divergent target audiences of these series. As was asserted before, the narrative guides aimed to show their destinations from a new point of view, and this could also entail providing an original historical perspective. Instead of focusing on the national history, alternative histories and the perspectives of the conquered could have been considered an excellent way of doing this. Nevertheless, in all of the guides the Welsh people are determined by conflict, which is recognised as a crucial part of their identity. As the Petite planète guidebook points out:

\footnotetext{
${ }^{731}$ Pierrard, p. 82.

732 Pierrard, pp. 82-83.

${ }^{733}$ Bédarida and Bédarida, p. 267.

${ }^{734}$ Bédarida and Bédarida, p. 268.
} 
'L'histoire du pays est d'abord une longue lutte contre les peuples qui, l'un après l'autre, tentèrent de forcer ses retranchements' [The history of the country is above all a long struggle against other peoples who, one after the other, tried to seize its strongholds]. ${ }^{735}$ The Welsh are therefore once more defined in terms of difference and opposition: only in contrast to other peoples, notably the English as both aggressors and bringers of prosperity, does Welsh history take place.

\subsubsection{The Welsh Language}

The Guides bleus and Guides Nagel hardly discuss Wales as a linguistically distinct part of Great Britain. As was already mentioned, the Guides bleus identify Welsh as a 'dialecte celtique' [Celtic dialect], ${ }^{736}$ which overlooks the fact that it is a distinctive language. Instead, it is rendered a dialect and is given no further specifications; the guide does not provide a glossary nor any pronunciation aid for the traveller. The only clear indication that another language is spoken in Wales is the remark that in Radnorshire solely English is used. ${ }^{737}$ This indirectly implies that in the rest of Wales another language, presumably Welsh, is used in addition to English. Only very rarely are Welsh place names mentioned alongside their English equivalents, ${ }^{738}$ and even these have been omitted in the 1968 edition of the Guides bleus.

The Guides Nagel do not differ significantly in this respect. In its vocabulary section, the 1953 edition emphasises that English is spoken everywhere in Great Britain, although it does make a reference to the Welsh language: 'Au Pays de Galles, un tiers de la population emploie une autre langue ayant beaucoup de force et de beauté' [In Wales, a third of the population uses another language, which is very powerful and beautiful]. ${ }^{739}$ The reader is made aware of the fact that another language is also spoken in Wales, but it remains anonymous, only referred to as une autre langue [another language]. Its place in Welsh and British society therefore remains marginalised. The 1975 edition has added a glossary of some fifty words commonly used in place names, but it would be exaggerating to see this as a major

\footnotetext{
735 Bailhache, Grande-Bretagne (1960), p. 105.

${ }^{736}$ Halévy, p. 583.

${ }^{737}$ Halévy, p. 605.

${ }^{738}$ For example: Lang, Grande-Bretagne et Irlande, pp. 471, 489; Halévy, pp. 595, 600.

${ }^{739}$ Lang, Grande-Bretagne et Irlande, p. 686.
} 
shift towards a more profound interest in the Welsh language. The listed vocabulary merely serves the purpose of understanding the meaning behind Welsh place names and does not encourage any active interaction with the language. Especially compared to the English vocabulary, which includes useful phrases for the traveller such as 'Good morning' and 'Do you speak French/German?', ${ }^{740}$ the interest in the Welsh language remains very limited and passive.

It can be contended that the Guides bleus and the Guides Nagel do not specifically use the Welsh language as a marker of difference, whilst the narrative French guidebooks have a clearly different approach to this aspect of Welshness. These guides neither provide a general description of the language nor a glossary, and Welsh place names are also left unmentioned due to the lack of systematic town descriptions. Instead, they use the language as a symbol of Welshness and directly connect it to contemporary Welsh identity and culture. The Petite planète, which stresses the vitality of Welsh political life, also points out that the Welsh language is thriving. The author informs readers that thirty per cent of the population still speaks the language and that it is taught at schools and universities. ${ }^{741}$ The vitality of the language is also noted in the Nous partons guidebook, which underlines that Welsh is alive despite seven centuries of English presence, and has a rich, though traditional and folkloric, literary tradition. ${ }^{742}$

Moreover, the language is seen as inextricably bound to its speakers and their alleged l'âme galloise [Welsh soul] ${ }^{743}$ As was already mentioned, the Petite planète guide considers North Wales as having the best environment for this so-called 'Welsh soul' due to its emptiness, and adds that the language is mainly spoken there. The connection between language and an imagined Welsh soul is furthermore based on the fact that the language is perceived as melodious and musical, thus apparently reflecting the character of a people who love music and singing. According to the guide, these national qualities typically manifest themselves in an Eisteddfod, which is described as 'une fête où s'expriment en un seul élan ancestral les aspirations religieuses, poétiques et mélomanes de ce peuple' [a festival where the people's religious, poetical and passionate musical aspirations express themselves in a single

\footnotetext{
${ }^{740}$ Lang, Grande-Bretagne, p. 1111.

${ }^{741}$ Bailhache, Grande-Bretagne (1960), p. 107.

${ }^{742}$ Bédarida and Bédarida, p. 262.

${ }^{743}$ Bailhache, Grande-Bretagne (1960), p. 107.
} 
ancestral zest]. ${ }^{744}$ In the Petite planète guidebook, the language is thus seen as a strong marker of Welsh identity which is closely linked to its speakers, their national character and topography.

The idea that the Welsh language is closely connected to the identity of the Welsh seems to prevail in the narrative French guidebook series. The Monde et voyages guide also connects the Welsh language to the national character and the alleged love of the Welsh for singing. In Section 4.4.2.1 it was described how this guidebook portrays the Welsh as a people with no practical skills, such as counting. The language is perceived to be equally ineffective, whilst at the same time adding a flavour of quaintness and otherness to the country:

\footnotetext{
Dans le Nord, surtout, ils [...] parleront [l'anglais] beaucoup plus tard, à l'école seulement, car leurs parents sont trop attachés à cette vieille langue celtique [...]. Une telle langue, c'est vrai, n'est pas faite pour faciliter les contacts, mais elle n'a jamais empêché les Gallois d'ouvrir toutes grandes leurs portes. ${ }^{745}$

[Especially in the North they [...] speak English much later, only at school, because their parents are too attached to this old Celtic language [...]. Such a language, that is true, is not made to facilitate contacts, but it has never prevented the Welsh from opening their doors.]
}

English, here understood as a functional language which can be used to establish contacts, is consequently regarded as being of little interest to the Welsh, as is the skill of counting. Instead, the Welsh irrationally hang on to their allegedly impractical language out of sentimental reasons. It could therefore be argued that the language becomes a marker of backwardness; a relic from the past which has no direct purpose in modern society. It makes both the Welsh and their language irrelevant to contemporary civilisation. As was described in Chapter 2, emotionality and sentimentality were seen as typical characteristics of peripherality. Whereas the centre is usually perceived to be practical and functional, the periphery is frequently seen as embodying the opposite. The portrayal given by the Monde et voyages guidebook can therefore be said to significantly contribute to the textual spatialisation of Wales on the imaginative periphery.

The German guidebooks from this period primarily regarded the language as a marker of difference, but overall showed little interest beyond this. Although it

\footnotetext{
${ }^{744}$ Bailhache, Grande-Bretagne (1960), p. 107.

${ }^{745}$ Pierrard, p. 83.
} 
would be exaggerating to state that the French guides use the language as more than a marker of difference, the vitality of the language is occasionally emphasised. Moreover, it is not so much used as a differentiating symbol in contrast to English, but rather as a marker of Welshness; language, national identity and culture are closely intertwined in some of the French guides. Nevertheless, a sincere interest in the language as a means of communication is not apparent in the guidebooks. It primarily remains a means to further the peripheralisation of Wales.

\subsubsection{The Landscape as a Repository of Identity and Legend}

The German guides from this period regarded the Welsh landscape and its inhabitants as inextricably linked. By describing Wales as the last refuge for the natives of the island, the country became a storehouse of the past, untouched by modernity and racial impurity. In the French narrative guidebooks, a comparable yet clearly different discourse is found. Although the Petite planète remarks that the Welsh have been protected by their mountainous surroundings, thus enabling them to conserve their national character, ${ }^{746}$ it focuses more strongly on the perceived emptiness of the country's landscape as an aspect of its identity. It was already noted that this guide regards North Wales as the ideal space for its 'Welsh soul', which is primarily based on the assumption that it is an agricultural area that 'compte presque deux fois plus de moutons que d'êtres humains' [numbers almost twice as many sheep as humans]. ${ }^{747}$ Paradoxically, the 'Welsh soul' of the inhabitants is thus connected to emptiness, apparently finding its perfect terrain de culture [living conditions] in an area which is described as chiefly populated by animals rather than humans.

The Monde et voyages guidebook presents a similar portrayal of the country's landscape in connection to its identity, labelling it terre des moutons [Land of Sheep] ${ }^{748}$ The introductory paragraph in the chapter about Caernarfon (the only Welsh town described in detail) even depicts a scene of a dog herding sheep, thus immediately asserting the importance of livestock for the country as well as its rural character. ${ }^{749}$ Whereas the German guidebooks frequently regarded the landscape as

\footnotetext{
746 Bailhache, Grande-Bretagne (1960), p. 105.

${ }^{747}$ Bailhache, Grande-Bretagne (1960), p. 107.

${ }^{748}$ Pierrard, p. 82.

${ }^{749}$ Pierrard, p. 82.
} 
secluding the country from influences from the centre, such as modernisation and racial impurity, the focus in the French guidebooks appears to lie on the emptiness of the landscape. Although clearly different, both ways of representation result in a reading of Wales as a country on the imaginative periphery, a place where the modern pace of life has not yet permeated.

Several French guidebooks also use the landscape as a repository of myths and legends. References to mythology are scarce in the Guides Nagel. ${ }^{750}$ They are more numerous in the Guides bleus, albeit still sporadic. ${ }^{751}$ In the narrative guides, the landscape is mythologised much more markedly. The description of North Wales in the Monde et voyages guidebook combines aestheticised, external descriptions of the landscape with mythological tales: 'Les montagnes y sont escarpées, les vallées étroites, les lacs nombreux, et l'un d'eux, le Llyn Llydaw, renferme toujours dans ses profondeurs Excalibur, la fameuse épée du roi Arthur' [the mountains there are steep, the valleys narrow, the lakes numerous. One of them, Llyn Llydaw, still conceals Excalibur in its depths, the famous sword of King Arthur]. ${ }^{752}$ Subsequently, the guide tells the legend of how the sword was thrown into the lake on the orders of the king. Aestheticising descriptions of the landscape are thus intertwined with mythological tales, turning the landscape into a signifier of myths and legends.

A similar reading of the landscape is especially noticeable in the Nous partons guidebook. The guide strongly mythologises and romanticises the Welsh landscape, depicting the Celtic peninsulas of Wales and Cornwall as 'terres de la romance d'Arthur' [Lands of Arthurian Tales] and '[p]ays des magiciens et des saints' [countries of wizards and saints]. ${ }^{753}$ Moreover, both are described as misty and rainy, whilst Anglesey is identified as 'centre mystérieux du druidisme' [mysterious druidic centre]. ${ }^{754}$ Snowdon, in addition, is said to be a '[1]ieu sacré du folklore gallois' [sacred place of Welsh folklore]. In the adjacent section, the guide discusses fact and fiction behind the Arthurian myth and concludes that even though Arthur was probably a historical figure, many of the tales and legends surrounding him are folkloric. ${ }^{755}$ It is noticeable that the guide points out that this image of Wales

\footnotetext{
750 One of the few references is to the legend of Rhitta Fawr, who is said to be buried on Mount Snowdon: Lang, Grande-Bretagne et Irlande, p. 490.

${ }^{751}$ For example: Halévy, pp. 602, 604, 610.

${ }^{752}$ Pierrard, p. 83. Italics of original.

${ }^{753}$ Bédarida and Bédarida, pp. 251-2.

${ }^{754}$ Bédarida and Bédarida, p. 251.

${ }^{755}$ Bédarida and Bédarida, p. 254.
} 
as 'terre de merveille' [Land of Wonders] and 'pays d'Arthur et de Merlin' [Land of Arthur and Merlin] and of its inhabitants as sorcerers and magicians is an image that was constructed by English outsiders; primarily Borrow, Shakespeare and Defoe. ${ }^{756}$ In this sense, the guide represents Wales through an English lens, whilst assuming that all travellers will agree with these Englishmen that this 'terre de légende et de poésie' [Land of Legends and Poetry] has indeed a remarkable character. ${ }^{757}$ Even though the guidebook thus exposes these mythologising images as invented constructions, it nevertheless re-uses them to create a portrayal of Wales.

In comparison to the German guidebooks discussed in this chapter, it is apparent that the interest in Welsh mythology, especially the tales relating to King Arthur, is far more prevalent in the French texts. This observation had already been made regarding the nineteenth-century material, and the difference has only become more noticeable. It can be argued that this focus primarily served the purpose of constructing Wales as an attractive tourist destination. It could be suggested that due to France's own popular Arthurian tradition, webs of familiarity were created between the two countries and their respective traditions. Wales is thus constructed as different from England, but at the same time similar to France and its literary traditions.

In general, it can be contended that both the German and French guidebooks to Wales published in the decades following World War II show an increasing awareness of Wales as a distinct entity. However, the way this distinctiveness is created differs. Whereas the German guidebooks primarily conceptualise it in relation to England (in topographical, ethnographic, historical and linguistic terms), the French guidebooks seem to present Wales in a more self-contained manner. Although the historical struggles between the English and the Welsh are highlighted, Wales is less clearly seen as a peripheral opposite to England. At times, it even forms a centre of its own: industrial areas are not omitted and some guidebooks even regard Wales as being at the forefront of political innovation. However, this does not mean that Wales is not marginalised; the language is downplayed as a useful means of communication and by viewing the landscape as a repository of myths and legends, otherworldly connotations are attached to the country.

\footnotetext{
${ }^{756}$ Bédarida and Bédarida, p. 262.

${ }^{757}$ Bédarida and Bédarida, p. 262.
} 


\subsection{A Debut: The Dutch Material}

Owing to the limited material available, this section will be more succinct than those discussing the German and French material, and will primarily focus on the ANWB handbook Midden Engeland en Wales [The Midlands, East Anglia and Wales] (1975), which is the only Dutch guide in this period that discusses Wales in more depth. The two other guidebooks which will be scrutinised first of all are an earlier edition in the ANWB series, Reiswijzer voor Engeland, Wales en Schotland [Travel Guide to England, Wales and Scotland] (1957), and a guide from the Allert de Lange series, entitled Gids voor noordelijk Engeland en Wales [Guide to Northern England and Wales] (1960). ${ }^{758}$

These two guides, both written in a markedly Baedekeresque style, discuss Wales only very briefly. Especially the 1957 ANWB edition is primarily a list of route descriptions, outlining the various suggested itineraries through the country (see Maps 6 and 7). The rest of the guide discusses a selection of English and Welsh sites in which the latter clearly form the minority. Only a handful of Welsh towns is described, most of them merely in one or two sentences. From this selection, it is evident that the preference of the guide is given to picturesquely situated seaside towns, such as Llandudno, although Cardiff and its docks are also recommended. ${ }^{759}$ The guide appears to be unaware of the fact that Wales is a distinct cultural, historical and linguistic entity, limiting itself to a superficial and aestheticising narrative.

The portrayal of Wales in the Allert de Lange guidebook does not differ significantly. The natural landscape of Wales is regarded as the main touristic appeal of the country and sites such as Snowdon and Betws-y-Coed are highly recommended for their natural features. ${ }^{760}$ The appraisal of industry has however changed. Whereas the 1957 ANWB edition still recommended a visit to the Cardiff Docks and described the industrialised areas in neutral terms, ${ }^{761}$ the Allert de Lange guidebook emphasises several times that travellers might want to exclude these parts of the country from their trips. ${ }^{762}$ The Cardiff Docks are even described as

\footnotetext{
${ }^{758}$ Reiswijzer voor Engeland, Wales en Schotland; Van Egeraat.

${ }^{759}$ Reiswijzer voor Engeland, Wales en Schotland, pp. 302-3, 271.

${ }^{760}$ Van Egeraat, pp. 178-9.

${ }^{761}$ Reiswijzer voor Engeland, Wales en Schotland, pp. 271, 309.

${ }^{762}$ Van Egeraat, p. 170.
} 
'buitengewoon vuil' [extraordinarily dirty]. ${ }^{763}$ Despite this shift, there seems to be no growing awareness of Wales as a distinct cultural, linguistic or historical entity. No references are made to features of Welshness. The only example in this respect is the description of the landscape around Strata Florida, which is said to be 'typisch Welsh, wat tevens melancholie impliceert' [typically Welsh, which also entails melancholy]. ${ }^{764}$ However, it is neither explained to the reader why feelings of melancholy are connected to Welshness and the Welsh landscape, nor what is understood by 'typically Welsh'. Although the guide thus hints at the existence of a distinctive sense of Welshness, this is left in a limbo of vagueness, leaving the reader wondering what it implies.

The ANWB guide Midden Engeland en Wales [The Midlands, East Anglia and Wales] (1975) is the first Dutch guidebook to describe Wales as a more distinctive country and provides the reader with background information about its history, culture and inhabitants. Overall, this seems to indicate a growing awareness of Wales as a travel destination with its own customs and traditions. The descriptions of towns and cities are alphabetically ordered, and the chapter about Wales is furthermore divided into a South, North and Mid-Wales section. The guide primarily focuses on the natural landscape, as well as on traditionally popular sights such as castles and churches, and it can thus be contended that the guide follows in the footsteps of its nineteenth-century precursors.

Similar to the German-language guidebooks published in this period, the 1975 ANWB handbook considers the border between Wales and England, identified as Offa's Dyke, as a significant marker of difference:

\footnotetext{
Tot op de dag van vandaag vormt de Dyke een duidelijke grens: politiek, cultureel, geologisch en etnologisch. De overgang van Engeland naar Wales is werkelijk frappant. Het duidelijkst toont ons dit het landschap. ${ }^{765}$

[Up to the present day, the Dyke forms a clear border: politically, culturally, geologically and ethnologically. The transition from England to Wales is truly striking. This is especially noticeable with regard to the landscape.]
}

The landscape is thus perceived as the most noticeable feature of dissimilarity between the two countries, which has been a recurrent theme in the guidebooks'

\footnotetext{
${ }^{763}$ Van Egeraat, p. 171.

${ }^{764}$ Van Egeraat, p. 175.

${ }^{765}$ Midden Engeland en Wales, p. 219.
} 
portrayal of Wales discussed in this chapter. However, the Dutch ANWB handbook not only understands the landscape as a geographical marker of difference, but imbues it with mythical properties. Surrounded by this landscape, the guide informs its readers, 'dringen zich gedachten aan bovennatuurlijke krachten en wezens aan ons op. Feeën en monsters, trollen en heiligen horen in dit landschap thuis. Maar ook de Welshman' [thoughts about supernatural forces and beings strike us. Fairies and monsters, trolls and saints belong to this landscape. But also the Welshman]. ${ }^{766}$ Offa's Dyke, the geographical border between England and Wales, is thus imagined as a portal to a different and mythical world, inhabited by fairy-tale creatures. As a result, Wales is spatialised as a country outside of reality, an otherworldly place, where believing in fairy tales is only a logical consequence of the aesthetic and enchanting properties of the landscape. ${ }^{767}$

As becomes clear from the quotation discussed above, the Welsh are perceived as an integral part of this landscape. By paralleling them to legendary creatures such as trolls and fairies, they too are imagined as belonging to the mythical world, instead of reality. These allegedly legendary inhabitants are said to have a Keltische geest [Celtic spirit], which has been shaped by their natural habitat; a landscape that strongly appealed to the imagination of the country's inhabitants. ${ }^{768}$ This imaginative 'Celtic spirit' expresses itself in the many Welsh legends concerning supernatural powers and magical beasts. ${ }^{769}$ On the one hand, the landscape is thus regarded as the natural habitat of fairy-tale creatures, including the Welshmen. On the other hand, however, the landscape has reinforced the imagination of the Welsh, which has resulted in a rich mythological tradition. It can therefore be argued that the Welsh are represented as both creations and creators of these myths. Landscape, a so-called 'Celtic spirit', a lively imagination and supernatural powers are considered typically Welsh and spatialise the country and its inhabitants outside of reality, on the imaginative periphery.

According to the guide, another inherent feature of the 'Celtic spirit' are the Eisteddfodau. ${ }^{770}$ In comparison, the German guidebooks from this period primarily highlight the International Eisteddfod in their description of Llangollen and hardly

\footnotetext{
${ }^{766}$ Midden Engeland en Wales, p. 219.

${ }^{767}$ See for example the description of Llyn y Fan Fach on p. 232.

${ }^{768}$ Midden Engeland en Wales, p. 15.

${ }^{769}$ Midden Engeland en Wales, p. 15.

${ }^{770}$ Midden Engeland en Wales, p. 220.
} 
connect it to the Welsh language and culture, ${ }^{771}$ whilst the French guidebooks also show only a marginal interest in this expression of Welshness, usually describing it in one or two sentences. ${ }^{772}$ However, the 1975 ANWB guide regards these festivals as emblematic for Wales and its 'Celtic spirit', in particular the singing competitions. This corresponds again to the German and French guidebooks from this period, which regarded musicality as an evident feature of Welsh national identity. Indeed, the ANWB guide also describes the art of singing as an innate Welsh characteristic, exemplified by the famous male voice choirs. ${ }^{773}$ Following this characterisation, the Welsh personality is described:

\footnotetext{
Behalve het zingen van liederen, die ook in de pub spontaan worden aangeheven, houdt de Welshman ook van praten. In de pub komt zijn openhartige, gastvrije en enigszins nieuwsgierige aard tot uiting, vooral tegenover de buitenlander die hij meteen als een vriend zal behandelen. ${ }^{774}$

[Apart from spontaneously breaking into song, which happens in the pub as well, the Welshman also loves talking. In the pub, his [sic] frank, hospitable and somewhat curious nature will emerge, especially towards the foreigner who he will immediately treat as a friend.]
}

This portrayal of the Welsh has seemingly nothing to do with their earlier depiction as belonging to the magical realm. However, it can be argued that both characterisations contribute to the spatialisation of the Welsh as a peripheral people. In their comparison to trolls and fairies, the Welsh are imagined as an otherworldly people, living beyond our reality. Even though their characterisation as a hospitable, singing people does not necessarily reinforce this view, it still creates an image of the Welsh as living in a different world; a more virtuous place in which values that are often perceived as lost in our modern society, such as honesty and hospitability, are still upheld. In this respect, Wales is imagined as a dream world in both cases.

In this guidebook, Wales and its inhabitants are thus defined as having a 'Celtic spirit', which is subsequently constructed as highly imaginative, having an aptitude for singing as well as a welcoming character. According to the guide, these character traits have been strongly influenced by the landscape, which was identified as an important marker of difference. As a result, Wales is imagined as the periphery,

\footnotetext{
${ }^{771}$ Friedrich, pp. 611-2; Lajta, p. 44.

${ }^{772}$ Lang, Grande-Bretagne et Irlande, p. 686; Bailhache, Grande-Bretagne (1960), p. 107; Pierrard, p. 105.

${ }^{773}$ Midden Engeland en Wales, p. 220.

${ }^{774}$ Midden Engeland en Wales, pp. 220-1.
} 
deviating in terms of landscape, moral values and its sense of reality. This deviation can be sought in respect to England, but this seems to be rather simplistic. Instead, it can be argued that Wales is imagined as an opposite to a far greater centre; the modernised Western world. By constructing Offa's Dyke as the gateway to a magical realm, Wales is conceived as the counterpart of modern Western society, an inverted world.

Within Wales, however, the guide also identifies a division; between the South and the North. South Wales, labelled 'het andere Wales' [the other Wales], ${ }^{775}$ is said to differ significantly from the rest of the country regarding its character, atmosphere and, crucially, its landscape. ${ }^{776}$ The latter, ostensibly a fundamental element of Welshness, is evidently not apparent in the southern part of the country. The alleged 'Celtic spirit' is associated with lonely heights, remote valleys and quiet lakes ${ }^{777}$ and not with industrialisation and urbanisation, making South Wales unfit as a space for Welshness. According to the guide, the South Wales Valleys used to be 'groene lustoorden' [green idyllic places] with wooded hills and clear rivers, ${ }^{778}$ and as such would arguably have been suitable for the 'Celtic spirit' of Wales. However, the guide describes how industry took possession of this part of the country, transforming the Valleys into a ' $k$ aal en mistroostig landschap van mijningangen, fabrieken, schoorstenen, machines en grauwe, eentonige rijen mijnwerkershuizen, die terrasvormig in lange linten tegen de heuvels gebouwd werden' [barren and gloomy landscape of mine entrances, factories, and grey, monotonous rows of miners' cottages, which are built in long terraced ribbons on the slopes of the hills]. ${ }^{779}$ It could be contended that the Valleys, with their destroyed natural landscape, could no longer be part of the 'Celtic' Wales. North Wales, however, has supposedly remained 'lonely' and 'wild', that is to say uncultivated, and therefore intact as the source of myths and legends. ${ }^{780}$ The guide for example remarks about the Llŷn Peninsula:

\footnotetext{
${ }^{775}$ Midden Engeland en Wales, p. 223.

${ }^{776}$ Midden Engeland en Wales, p. 221.

777 Midden Engeland en Wales, p. 15.

${ }^{778}$ Midden Engeland en Wales, p. 235.

${ }^{779}$ Midden Engeland en Wales, p. 235.

${ }^{780}$ Midden Engeland en Wales, p. 265.
} 
Nergens komt de oude Welshe sfeer zo goed over als op dit met sagen en legenden omweven schiereiland. [...] Sinds eeuwen is er niet veel veranderd op deze afgezonderde landtong. U reist terug in de tijd, ver van de moderne, koele, technologische wereld. ${ }^{781}$

[Nowhere else can you experience the old Welsh atmosphere so well as on this peninsula, which is shrouded in myths and legends. [...] For centuries, not much has changed on this secluded headland. You travel back in time, far away from the modern, cool, technological world.]

Welshness, it seems, can only exist in places that have been forgotten by the progress of time. According to the guidebook, such a place is located in the North of the country, particularly Snowdonia and the Llŷn Peninsula. ${ }^{782}$

The description of Wales's history is similarly spatialised. According to the guidebook, the Welsh preferred to live in remote areas, and, being 'individualistic Celts', were not able to organise themselves like the Anglo-Saxons did. As a result, the Welsh did not stand a chance in the long term. ${ }^{783}$ However, the guide subsequently asserts that the remote areas in Snowdonia were not fully conquered until the sixteenth century, just like Merlin had prophesised. In the introduction to North Wales, a perceived connection between its landscape and built environment, as well as its historical and mythical side is emphasised:

\begin{abstract}
Kastelen, ruïnes, kathedralen en kerken, bergpassen en dalen zijn verbonden met de geschiedenis van dit land, dat een lange periode van oorlogen en strijd heeft gekend, een strijd tussen de Welshmen en de binnendringende Angelsaksen en de Normandiërs. [...] Uit die tijd dateren de sagen en legendes, die mede geïnspireerd zijn door de kleurrijke geschiedenis en het eenzame, woeste landschap. ${ }^{784}$

[Castles, ruins, cathedrals and churches, mountain passes and valleys are connected to the history of this country, which has experienced a long period of war and struggle. A struggle between the Welshmen and the invading Anglo-Saxons and Normans. [...] The myths and legends date back to this time, and are partly inspired by the colourful history and the lonely, wild landscape.]
\end{abstract}

The historical distinctiveness of Wales, and therefore its role as a feature of Welshness, is again spatialised in the North of the country, and is also temporalised as an 'oud land' [old country]. ${ }^{785}$

Noticeable in this guidebook is the fact that the language is hardly thematised. In the French and German guidebooks published in this period, it was

\footnotetext{
${ }^{781}$ Midden Engeland en Wales, p. 280.

782 Midden Engeland en Wales, p. 265.

${ }^{783}$ Midden Engeland en Wales, p. 219.

${ }^{784}$ Midden Engeland en Wales, p. 265.

${ }^{785}$ Midden Engeland en Wales, p. 265.
} 
frequently used as a marker of Welshness or to emphasise the difference between England and Wales. Moreover, the French narrative guidebooks repeatedly made the connection between the asserted musicality of the Welsh and their language.

However, the 1975 ANWB guidebook does not regard the language as inherent to Welshness nor as a feature of the so-called 'Celtic spirit'. The guide does provide a brief pronunciation aid and a list of words commonly found in Welsh place names, but does not list any Welsh variants of place names, as was often, though not systematically, the case in the German- and French-language texts.

In comparison to the contemporaneous German and French guidebooks, the 1975 ANWB edition, which forms the centre of the analysis of the Dutch material in this chapter, clearly presents the most marginalising portrayal of Wales. Although the country is seen as a culturally, historically and linguistically distinctive part of Great Britain, its distinctive features are characterised by their unworldliness, creating an image of Wales as an unrealistic dreamland. The notion of Welshness, which seems to be termed 'Celtic spirit' in this guide, is spatialised in the North of the country. The uncultivated state of the landscape appears to be of crucial importance, which allows this area to be temporalised as well as imagined as a mythical space.

\subsection{Concluding Remarks}

In conclusion, it is especially conspicuous how many similar tendencies can be detected in the guidebooks to Wales in the three languages during the mid-twentieth century. First of all, Wales gained visibility as a distinct travel destination within Great Britain in virtually all the guidebooks. It was incorporated in the title of the guides, described in a separate chapter, and often introduced individually. However, this did not imply that Wales stopped being a touristically marginal region.

Especially in contrast to England, Wales remained regarded as an area of secondary interest for the tourist. Secondly, the natural landscape remained the most important reason for travelling to Wales and was identified as the country's main tourist attraction. The industrial landscape, however, was rapidly disappearing from the guides. Whereas this had been regarded as a sign of progress and modernity in many nineteenth-century guidebooks, industry was now generally considered to be detrimental to both the natural environment and the country's inhabitants. Instead of 
praising industrial development, it was rather seen as a sign of destitution. In addition, contemporary issues connected to industry, such as pollution and unemployment, were discussed in several guides.

Apart from this shifting appreciation of the landscape in aesthetic terms, it also became endowed with meaning beyond this. In a large number of guidebooks, in all three languages, the landscape became a signifier of difference, primarily between England and Wales. Crossing the topographical border between the two countries was frequently imagined as entering another world, where a different society had managed to remain unaffected by the ills of modernity. The German-language guides recurrently regarded the border as a barrier, protecting Wales from modernisation and anglicisation whilst keeping its inhabitants racially pure and secluded. The French and Dutch guidebooks, on the other hand, recurrently represented the landscape as a repository of myths and legends. In the empty landscape of Wales, magical creatures and traces of the legendary King Arthur abounded, according to the guidebooks.

Despite these differences between the languages, it can be concluded that an interest in Wales and Welshness increased significantly compared to the nineteenth century. The guides create a distinctively Welsh space for their readers in which aspects of Welshness, such as the language, culture and history are localised. Within this space, it is particularly Wales's Celtic otherness which is used to enhance the attractiveness of the country and highlight its cultural, ethnographic and historical distinctiveness. This shift in the perception of Wales in Continental guidebooks must be seen within a wider context of changing (travel) cultures after World War II. During the late nineteenth and early twentieth century, there had been a sense of optimism about the future and the capacity of technological progress, which was reflected in the guidebooks' representations of Wales during this period. Although some criticism was expressed, there was an overall tone of appreciation of industrialising developments, even within the realm of tourism. However, after World War I and the subsequent decades, this optimism declined sharply and the idea that our society had lost touch with nature became widespread. Throughout the Western world, countercultural movements, such as the hippie movement in the 1960s and New Age groups during the 1970s, were establishing themselves in 
opposition to mainstream society. ${ }^{786}$ As was already outlined in Chapter 2, it was during these decades that an interest in Celticity developed, which was conceptualised as an opposite to our modern consumer culture. This growing interest in Celticity resulted in the popularisation of the Celtic areas as holiday destinations. ${ }^{787}$ By imagining Wales as a Celtic space, several guidebook series were thus responding to changing travel cultures and target audiences. This also accounts for the diverging guidebook representations of Wales and Welshness. Innovative guidebook series such as Petite planète, written with the interests of these new travelling groups in mind, highlighted Wales's Celticity and its allegedly connected spirituality. More traditional guidebooks such as the Guides bleus, on the other hand, were writing for a readership that in many respects still closely resembled the nineteenth-century educated middle class that had primarily visited Wales for its aesthetic landscapes. It can thus be argued that the guidebooks reflect changes in the travel destination (e.g. the declining industry of Wales) but to an even greater extent mirror shifts within the society and culture in which they are produced.

Although these representations arguably tell us more about the culture in which they were produced, they do influence the way in which a certain country or area is perceived, in this case Wales. As popular distributors of practical and cultural information, guidebooks influence the image people have of a travel destination. As such, there is a complex process at work in which reflections of the home culture are projected onto the region that the guides are describing and which are subsequently disseminated through these texts. In the case of Wales, it can be maintained that the increasing celticisation of the country in Continental guidebooks is the result of expanding counter-cultural movements and the pervasive search for spirituality and socio-political alternatives during this period. Consequently, this emphasis on Wales's Celticity spatialises the country on the imaginative periphery and temporalises the country as ancient and backward. Instead of recognising Wales as a unique entity, the country is used as an empty space onto which, under the guise of Celticity, romantic visions of a spiritual society close to nature can be projected.

${ }^{786}$ For further reading on the development of these movements, see: Paul Heelas, The New Age Movement: The Celebration of the Self and the Sacralization of Modernity (Oxford: Blackwell, 1996); J. Gordon Melton, 'New Thought and the New Age', in Perspectives on the New Age, ed. by James R. Lewis and J. Gordon Melton (New York: State University of New York Press, 1992), pp. 15-29.

${ }^{787}$ Kent, p. 212. 


\section{5 - 1995-2013: The Devolved Periphery}

\subsection{Introduction}

The political structure of Wales and the UK changed dramatically when on 18 September 1997 the people of Wales voted in favour of devolution. Even though only a small majority voted 'yes', this was still a major U-turn compared to the referendum that was held almost twenty years earlier when nearly eighty per cent voted against devolution. Many scholars have attempted to determine the reasons for this changing attitude, and they generally concur that it is linked to a politicisation of Welsh national identity. ${ }^{788}$ According to John Osmond, many voters in 1979 did not see Wales as a viable political unit, and this sentiment was exploited by the No campaign: 'We do not need an Assembly to prove our nationality or our pride. That is a matter of hearts and minds, not bricks, committees and bureaucrats' ${ }^{789}$ In the course of approximately twenty years, this view changed drastically, resulting in the 'Yes' vote in 1997. Various factors simultaneously contributed to this. First of all, it has been asserted that a sense of Britishness, which could co-exist with other subnational identities, was waning. ${ }^{790}$ Accelerated by roughly twenty years of Thatcherism, which saw the decline of the welfare state and the traditional heavy industries forming the basis of the South Wales's social structure, a rift developed between Welshness and Britishness. ${ }^{791}$ It has been argued that many people in Wales started to resent the Tories and their mainly English electorate, which resulted in a growing wish for constitutional change. ${ }^{792}$ Secondly, a self-conscious Welsh identity was flourishing due to the institutionalisation of Welshness: the powers of the Welsh Office were expanded, and various Welsh organisations were created, such as the

\footnotetext{
${ }^{788}$ See, for example: Richard Wyn Jones and Dafydd Trystan, 'The Welsh Referendum Vote', in Scotland and Wales: Nations Again?, ed. by Bridget Taylor and Katarina Thomson (Cardiff: University of Wales Press, 1999), pp. 65-94; Geoffrey Evans and Dafydd Trystan, 'Why Was 1997 Different?', in Scotland and Wales: Nations Again?, ed. by Bridget Taylor and Katarina Thomson (Cardiff: University of Wales Press, 1999), pp. 95-117; Davies, 'Banal Britishness and Reconstituted Welshness'.

${ }^{789}$ Labour 'No' Campaign, 1979, quoted in: John Osmond, Welsh Politics in the New Millenium (Cardiff: Institute of Welsh Affairs, 1999), p. 4.

${ }^{790}$ David McCrone, Understanding Scotland: The Sociology of a Nation, 2nd edn (London: Routledge, 2001), p. 185.

${ }^{791}$ Davies, 'Banal Britishness and Reconstituted Welshness', p. 116.

792 Richard Wyn Jones, Roger Scully and Dafydd Trystan, 'Why Do the Conservatives Do (Even) Worse in Wales?', British Elections and Parties Review, 12 (2002), 229-45.
} 
Welsh Language Board and S4C, paradoxically all under Thatcher's rule. ${ }^{793}$ Overall, it can be asserted that a sense of Britishness declined within Wales, or at least changed, whilst a self-conscious awareness of Welshness and the desire for constitutional change grew which eventually led to the positive outcome of the 1997 referendum.

Consequently, Wales became a more autonomous political entity: the outcome brought about the Government of Wales Act 1998 and the subsequent creation of the Welsh Assembly, which was granted legislative and executive powers on a range of domestic matters. Owing to this, the country has gained significant control in managing its own affairs independently from Westminster. Although only 50.3 per cent of the Welsh population voted in favour of devolution in 1997, surveys have indicated that in the years following this referendum the support for devolution continued to rise. ${ }^{794}$ This is also demonstrated by the positive outcome of the 2011 referendum, which attests to growing Welsh support for and confidence in their National Assembly and Welsh devolution. This time, 63.5 per cent supported further devolution, thereby extending the legislative powers of the Assembly without requiring the agreement of UK parliament. An important consequence of this, as Housley, Moles and Smith have pointed out, is that these democratic institutions strengthened the political boundaries of the country, making a clearer distinction between 'who's in' and 'who's out'. 795

Apart from political borders, boundaries of identity have become clearer as well. Welsh national identity, which had become more pronounced in the decades leading up to the 1997 referendum, has been gaining visibility in the years that followed and has become increasingly contrasted with a British identity. As Bradbury and Andrews have argued in a recent study on devolution and Welsh identity, Welshness and Britishness still co-exist in Wales, but there has been a significant growth of Welsh consciousness in public life since devolution. Resulting from this, 'Welshness has become predominant over Britishness in public discourses'. ${ }^{796}$ Bradbury and Andrews refute the widely-held belief that devolution

\footnotetext{
${ }^{793}$ Jonathan Bradbury and Rhys Andrews, 'State Devolution and National Identity: Continuity and Change in the Politics of Welshness and Britishness in Wales', Parliamentary Affairs, 63 (2010), 22949 (pp. 235-6); Davies, p. 118.

${ }^{794}$ Bradbury and Andrews, p. 238.

${ }^{795}$ William Housley, Kate Moles and Robin Smith, 'Identity, Brand or Citizenship? The Case of PostDevolution Wales', Contemporary Wales, 22 (2009), 196-210 (p. 199).

${ }^{796}$ Bradbury and Andrews, p. 230.
} 
often contributes to a growing sense of regional or sub-state identity which goes at the expense of the state identity, by claiming that a sense of Britishness has not disappeared from Wales, it has only become less visible than Welshness in the public discourse. ${ }^{797}$ Their argument is primarily based on surveys undertaken between 1997 and 2007, in which inhabitants of Wales could indicate whether they felt 'Welsh not British', 'More Welsh than British', 'Equally Welsh and British', 'More British than Welsh', or 'British not Welsh'. As Bradbury and Andrews rightly point out, the division between Welsh and British identities has remained the same on average over time. However, there has been a significant increase in the percentage (from seventeen to twenty-four per cent) of people who indicate that they feel Welsh and specifically not British (the first category). ${ }^{798}$ This would indicate that the boundaries between the two identities are becoming more clear-cut. Obviously, this does not take into account any apparent differences existing within the Welsh identity. ${ }^{799}$ These issues are merely raised in order to exemplify the increasing visibility and perceived distinctiveness of Wales and Welshness. Concurringly, the former Welsh Secretary of State, Peter Hain, stated in 2009 that as a result of Welsh devolution, Wales had been 'transformed very much for the better. More self-confident. More vocal. More democratic. [...] Welsh identity is flourishing as never before'. ${ }^{800}$ Martin Johnes agrees in his pioneering work Wales since 1939 that a sense of Welsh identity is more noticeable in daily life since devolution. According to him, this can be illustrated by the term 'Cool Cymru', which gained momentum during the turn of the millennium. ${ }^{801}$ This term was used in the late 1990s as a label to reflect the success of popular Anglo-Welsh bands, such as Catatonia, Stereophonics and Super Furry Animals, as well as fashion and film. ${ }^{802}$

This chapter will examine the ways in which the guidebooks published in Dutch, German and French deal with the increased consciousness and public visibility of Welsh identity, as well as the greater political and administrative

\footnotetext{
${ }^{797}$ See, for example: Stein Rokkan and Derek W. Urwin, The Politics of Territorial Identity: Studies in European Regionalism (London: SAGE Publications, 1982); Michael Keating, The New

Regionalism in Western Europe: Territorial Restructuring and Political Change (Cheltenham: Edward Elgar, 1998).

${ }^{798}$ See the table of the survey in: Bradbury and Andrews, p. 233.

${ }^{799}$ See, for example: Haesly, p. 249.

${ }^{800}$ Peter Hain, quoted in: Martin Johnes, Wales since 1939 (Manchester: Manchester University Press, 2012), p. 427.

${ }^{801}$ Johnes, p. 427.

${ }^{802}$ See: Harris, p. 152.
} 
independence of Wales as one of the four countries within the United Kingdom. Compared to the last two chapters, it will scrutinise whether Wales is gradually being recognised as a distinctive part of the UK which is given the right to occupy its own space within the contemporary globalising world. The political, topographical, cultural, linguistic and historical boundaries that are constructed in the guidebooks will be examined again, and their shifts compared to earlier guidebooks will be highlighted. This chapter will look in particular at the representations of the modernising, devolving transformation of Wales. Does Wales remain locked up in a distant and unrealistic past, as was argued in the previous chapter, or do the guidebooks manage to portray Wales as a country that has moved into the twentyfirst century?

\subsubsection{Corpus: The Surge}

During the 1980s, there seems to have been a sudden surge of guidebook publications on Wales in German, French and Dutch. Whilst the number of Dutch guides doubled during this decade, the growth of material in German is even more noteworthy. Whereas during the 1970s twenty-two German guidebooks to Wales and Great Britain were published, this number rose to fifty-five during the course of the 1980s; an increase of exactly 150 per cent. This surge in publication activity is most noticeable during the 1980 s, but also continues during the following ten-year period. After the turn of the millennium, the growth in the number of published guidebooks seems to stabilise. ${ }^{803}$ It is also during the late 1970 s that the first original German and Dutch guidebooks solely on Wales are published. ${ }^{804}$ Although translated guidebooks to Wales were available in German ten years earlier, it is telling that it is towards the 1980s that Wales appears to become more widely recognised as a tourist destination for which it is financially viable to publish untranslated guidebooks. Several possible reasons for this sudden growth can be suggested; for example the rise of international tourism and the tourism industry in Wales, as well as the increased accessibility of Wales as a travel destination. These social and historical contextual parameters will

\footnotetext{
${ }^{803}$ These numbers are based on the total number of German, French and Dutch guidebooks to Wales or Great Britain identified in my survey. This includes material in the original languages, as well as translations from other languages, primarily English.

${ }^{804}$ Klaus Bötig and Christiane Kohls, Wales: Geschichte, Stillkunde, Strecken- und Ortsbeschreibungen, Goldstadt-Reiseführer (Pforzheim: Goldstadtverlag, 1977); P. Walma van der Molen-Meindersma, Wales, Kosmos reisgidsen (Amsterdam: Kosmos, 1978).
} 
be examined in more detail later in this chapter. Moreover, it could be contended that the predilections of the counter-cultural travel cultures from the 1960s and 1970s were starting to permeate mainstream society, thus influencing the popularisation of travel destinations.

In comparison to the surge of material in Dutch and German, the amount of French-language guides seems to lag behind. An analysis of all the located texts indicates that the number of German-language guidebooks to Great Britain and Wales more than tripled between the 1970s and 1990s, whereas the French material 'only' doubled. Moreover, it was not until 2001 that an original French guidebook specifically on Wales was published. ${ }^{805}$ These numbers and percentages are particularly surprising since France is one of Wales's most important overseas markets. ${ }^{806}$ No definite reason can be provided for this difference; financial reasons will doubtlessly play a role, as by combining England and Wales into one guidebook publishers might try to reach a larger market. However, it remains unclear what financial differences there could be between the French, Dutch and German guidebook markets that would explain the uneven growth of guidebooks in the various languages.

Moreover, it is evident that the guidebook market further diversified during this period. As was already outlined in the previous chapter, new, alternative travel cultures emerged which were looking for a different kind of guidebook that offered more than the typical Baedekerian middle-class viewpoint. Consequently, innovative series were developed, such as the Petite planète and Monde et voyages. However, these series remained too avant-garde to gain popularity with a wider audience. This changed with the arrival of the Lonely Planet series. This guide was also created to serve the young, alternative traveller looking for places off the beaten track, but (paradoxically) has by now become the most widely used guidebook series there is (see Chapter 1.1). In this period, we therefore find a wide variety of guidebooks with different target audiences that all represent Wales in ways that make the country as attractive as possible for their readers.

\footnotetext{
${ }^{805}$ Dominique Auzias and Jean-Paul Labourdette, Pays de Galles, Petit futé: country guide (Paris: Nouvelles éditions de l'université, 2001).

${ }^{806}$ Visit Britain, Trends in Visits to Different Areas of Britain, p. 7.
} 


\subsubsection{Overseas Tourism in Wales: Struggling against London- centrism}

The proliferation of guidebooks to Wales and Great Britain coincides with the upsurge of tourism. Since the 1970s, international tourism has increased significantly and has become a major global economic force. ${ }^{807}$ In Great Britain, overseas tourism has steadily expanded; whereas there were nearly seven million overseas visits to Britain in 1970, this number grew to seventeen million in $1989 .{ }^{808}$ During the $1980 \mathrm{~s}$ and 1990s, shorter trips became increasingly popular owing to the reduced costs of travelling. Cheap charter flights, for example, made overseas tourism to Britain available to a large number of travellers from the Continent. ${ }^{809}$ The improved accessibility of Great Britain and Wales in particular, along with the growing affluence of Europe's population, have doubtlessly played an important role in the growth of inbound tourism to the British Isles and Wales. In 1986, the runway of Cardiff Airport was extended and in 2008 the airport was used by 2.1 million passengers, making it the nineteenth busiest airport in the UK. ${ }^{810}$ For German, Dutch and French travellers, Cardiff Airport offers flights from, amongst other destinations, Paris, Düsseldorf, Berlin and Amsterdam, thus providing easy connections between the Continent and Wales. ${ }^{811}$ These flights are not only inexpensive, but have also considerably reduced the length of the journey. Travelling from Berlin to Cardiff, for example, would take more than twelve hours by car or train, whereas it only takes a few hours when travelling by airplane, making the journey more attractive for quick visits as well. This is not to say that all Continental air travellers use Cardiff as their place of arrival. English airports such as those in Birmingham and Bristol are also recommended by the guides as having good public transport connections to Wales and will doubtlessly also be used by Continental visitors. ${ }^{812}$ In addition to the

\footnotetext{
${ }^{807}$ Marie-Françoise Lanfant, 'International Tourism, Internationalization and the Challenge to Identity', in International Tourism: Identity and Change, ed. by Marie-Françoise Lanfant, John B. Allcock and Edward M. Bruner (London: SAGE Publications, 1995), pp. 24-43 (p. 27).

${ }^{808}$ Middleton, p. 28.

${ }^{809}$ Middleton, pp. 28-30.

${ }^{810}$ UK Airport Statistics: 2008 - annual,

$<$ http://www.caa.co.uk/default.aspx ?catid=80\&pagetype $=88 \&$ sglid=3\&fld=2008Annual $>$ [accessed 23 October 2015].

811 <https://www.cardiff-airport.com/destinations/> [accessed 29 January 2018].

${ }^{812}$ See for example: Guus Berkien, Wales, Kosmos reisgidsen (Utrecht: Kosmos-Z\&K Uitgevers, 1996), p. 123; Dominique Auzias and Jean-Paul Labourdette, Pays de Galles, Petit futé: country
} 
improved and expanded air travel services, the opening of the Second Severn Crossing in 1996 augmented the road traffic capacity from England into South Wales, whilst the re-routing of the M4 via this bridge made the journey faster and shorter. In particular the connection with the Channel Tunnel, which opened in 1994 and has since then facilitated access to the United Kingdom for 346 million passengers, ${ }^{813}$ has made travelling from the Continent to Great Britain and subsequently to Wales easier, faster and cheaper than ever before. However, despite its improved accessibility, Wales is still often regarded as a remote and isolated corner of Great Britain (see introduction).

For Wales, tourism has become an increasingly important sector of its economy, especially since the disappearance of the coal mining industry. It currently supports 80,000 jobs, which is 8.7 per cent of the total workforce in Wales. ${ }^{814}$ The majority of holiday-makers to Wales comes from within Great Britain; in 2013, some ten million domestic tourism trips were taken to Wales, during which 1.7 billion pounds were spent. ${ }^{815}$ In the same year, Wales attracted 884,000 international visitors, who spent 353 million pounds. ${ }^{816}$ Examining the absolute numbers of overseas visitors to Wales, statistics show that in 201355,000 visitors came from Germany, 33,000 from France and 24,000 from the Netherlands, thus ranking these countries amongst the top six nations that visit Wales. ${ }^{817}$

As was outlined in the introduction of the thesis, Wales is nevertheless still lagging behind other British regions in respect to tourist numbers, and has a weak overseas profile. Hence, despite the creation of a devolved UK in which Wales has attained a more separate position as a political entity that has simultaneously strengthened Welsh identity, Wales and Welshness appear to have remained largely invisible to the wider world according to tourism surveys. Moreover, the fact that

guide, 3rd edn (Paris: Nouvelles éditions de l'université, 2008), p. 307; Britta Schulze-Thulin, Wales, Reise Know-How (Bielefeld: Peter Rump, 2004), p. 25.

${ }^{813}$ Eurotunnel Group: Traffic Figures, <http://www.eurotunnelgroup.com/uk/eurotunnelgroup/operations/traffic-figures/> [accessed 23 October 2015].

814 <http://www.wales.com/business/business-sectors/tourism> [accessed 27 October 2015].

815 Visit England, The GB Tourist: Statistics 2013,

<https://www.visitengland.com/sites/default/files/gb_tourist_2013_v2.pdf> [accessed 27 October 2015], p. 15.

${ }^{816}$ Llywodraeth Cymru/Welsh Government, Latest Statistics <http://gov.wales/topics/tourism/researchmain/latest-stats/?lang=en> [accessed 27 October 2015].

817 The Irish constitute the largest proportion with 66,000 overseas visitors in 2013, followed by Germany and the USA (45,000 visitors) respectively. See: Visit Britain, Trends in Visits to Different Areas of Britain, p. 7. 
Wales has never been so easily accessible for travellers has apparently not led to a wider recognition of the country and its culture on the Continent. In other words, it lacks a distinct identity in the eyes of overseas travellers, and it is here that travel guidebooks can play an important role as they help create our understanding of places, cultures and people.

\subsection{Dutch Views: Wales as the Integral Other}

In this chapter, the Dutch material will be discussed first, as no original Dutch guidebooks to Wales or Great Britain have been published after 2000. From then onwards, the guidebooks that are published in Dutch are all translations from other languages (French, German and English), and can therefore not be taken into account in this analysis. It is also noticeable that series which formerly used original Dutch texts have switched to translations from, primarily, English guidebooks, presumably due to the fact that it is more economical to translate, rather than to produce a new Dutch text. ${ }^{818}$ This is unfortunate, since it will therefore not be possible to trace the development of the Dutch representations of Wales into the first decade of the twenty-first century, a time during which Wales re-discovered itself as a devolved nation. Nevertheless, the analysis of the guides that are available will provide insights into the Dutch approaches to the country, its culture, language and history towards the end of the twentieth century. As there is French- and German-language material available that has been published in more recent years, these languages will be scrutinised after the Dutch material, in order to fully comprehend the development of Wales's image into the new millennium. The analysis will focus on the continuation of the discourses that emerged during the decades after Worlds War II, and will also attempt to reveal new ways of imagining Wales as a socio-political entity. Devolution will be a central theme throughout the analysis, and the chapter will examine whether and how the growing autonomy of Wales as a political entity has influenced the overall Dutch perceptions of the country.

\footnotetext{
818 The Kosmos reisgidsen and the ANWB guidebooks are examples of series that switched from using original Dutch texts to translations from English.
} 


\subsubsection{The Antiquated Other}

In Chapter 4, it was argued that Wales was seen by the Dutch-language guidebooks as a Celtic fairy-tale land, inhabited by magical creatures such as trolls and monsters, but also the Welshman. This overtly fantastic image of the country has disappeared in the contemporary period under examination here, but, as will be shown in this section, the country remains temporalised as stuck in the past.

Similar to the 1975 ANWB guidebook which was scrutinised in the previous chapter, Offa's Dyke is again seen as a clear boundary between England and Wales, on the western border of which supposedly lies a completely different and undiscovered world. The new ANWB travel guide, published in 1997, for example introduces the country as follows:

\footnotetext{
Het bergachtige, altijd groene Wales verbergt zich achter de ruim $200 \mathrm{~km}$ lange Offa's Dyke, die in de $8^{\mathrm{e}}$ eeuw door de gelijknamige koning van Mercia werd opgeworpen om de weerbarstige Kelten buiten zijn rijk te houden. De geïsoleerde positie van Wales heeft ervoor gezorgd dat het 'land' veel van zijn identiteit heeft weten te bewaren. ${ }^{819}$

[The mountainous, always green Wales conceals itself behind the more than $200 \mathrm{~km}$ long Offa's Dyke. It was raised in the eighth century by a king of the same name who ruled Mercia, in order to keep the unruly Celts out of his kingdom. It is due to Wales's isolated position that the 'country' has managed to preserve much of its identity.]
}

Although not as mystified as in the 1975 ANWB edition, Wales is still represented as an 'always green' country, evoking images of a luxuriant nirvana. ${ }^{820}$ The fact that the guide spatialises Wales as 'isolated' behind Offa's Dyke further reinforces the image of the country as a secret dream world which can be found on the western periphery of Great Britain. However, the guide goes even further by implying that this peripheralisation is actively sought after by Wales ('conceals itself'), making the country into the agent of its own isolation. Wales is therefore not only peripheralised, but desires to remain secluded from the globalising, modernising world around it. Other guides also identify the landscape as a marker of distinctiveness. In its introduction, the Dominicus travel guide for example stresses that the landscape will be the first difference the traveller notices when entering Wales from England. ${ }^{821}$

\footnotetext{
${ }^{819}$ Wim Danse and Guus Berkien, Midden-Engeland en Wales, ANWB reisgids gouden serie, 2nd edn (The Hague: ANWB, 2000), p. 11. See also: Karin Schaedtler, Wales, Dominicus reeks (Haarlem: J.H. Gottmer, 1997), p. 12.

${ }^{820}$ The noticeable fact that 'country' is in inverted commas will be addressed later.

${ }^{821}$ Schaedtler, p. 11.
} 
This conceptualisation of Wales as a green paradise with abundant 'onbedorven natuurschoon' [unspoilt natural beauty], ${ }^{822}$ is seen by most contemporary Dutch guidebooks as the main reason for visiting the country. The ANWB: actief en anders guidebook summarises it aptly: 'Wales is rust en natuur' [Wales is peace and nature]. ${ }^{823}$ Other guidebooks also stress that the main tourist attractions of Wales are its nature, space and peace which make the country very suitable for active holidays: ${ }^{824}$ 'Dit is het land van de natuurvorser, de fietser, wandelaar en paardrijder' [This is the country of the naturalist, the cyclist, the hiker and the horse rider]. ${ }^{825}$ Rather than being a solely aesthetic feature, the natural landscape is now regarded as something that can be actively consumed. In the Dominicus travel guide the emptiness of the country is represented by its allegedly large amount of sheep, and an entire section about these animals is inserted: 'Het landschap van Wales is ondenkbaar zonder schapen. Er zijn er dan ook ruim tweemaal zoveel als inwoners' [You cannot imagine the landscape of Wales without sheep, of which there are twice as many as people] ${ }^{826}$ An inserted photograph shows an empty street with sheep, and the caption reads: 'Wales heeft een landelijk karakter. Regelmatig komt men kudden geiten of schapen op de weg tegen' [Wales has a rural character. Regularly, one encounters herds of goats or sheep in the middle of the road]. ${ }^{827}$ The animals embody the country's asserted rurality, and are juxtaposed with urbanisation and modernisation which are apparently lacking in Wales.

In this supposedly empty and nirvana-like country lives a people that is equally idealised. The Kosmos guide, which discusses the Welsh character in detail, is a telling example in this respect. In a rather Arnoldian fashion, the guide describes the inhabitants of the 'land van de vrienden' [Land of Friends] $]^{828}$ as romantic, with an inclination towards the mysterious and the supernatural. Although the Welsh are no longer equated with supernatural beings, as was the case in the 1975 ANWB guide, they are still perceived as being attracted to these themes. Moreover, the guide asserts that: 'Ook zijn de Welshen wars van overdreven gedoe. Ondanks de soms

\footnotetext{
${ }^{822}$ Guus Berkien, Wales, Vitamine V reisgids (Utrecht: Kosmos-Z\&K Uitgevers, 2000), p. 12.

${ }^{823}$ Ben Hummel, Wales, ANWB: actief en anders (The Hague: ANWB, 1998), p. 7.

${ }^{824}$ Danse and Berkien, p. 56.

${ }^{825}$ Danse and Berkien, p. 258.

${ }^{826}$ Schaedtler, p. 19.

${ }^{827}$ Schaedtler, p. 17.

${ }^{828}$ Berkien, Wales (1996), p. 14. This is the translation the guide gives of Cymru.
} 
grote armoede zijn ze opvallend gastvrij. Te waarderen is eveneens hun betrouwbare, eenvoudige en vooral gemoedelijk vriendelijke karakter' [The Welsh also have an aversion to exaggerated fuss. Despite the sometimes extreme poverty, they are remarkably hospitable. One can also appreciate their reliable, simple and above all friendly character $].{ }^{829}$ Similar descriptions of the Welsh as particularly hospitable, friendly and helpful can also be found in other guidebooks. ${ }^{830}$ Resulting from this characterisation, the Welsh are idealised. It is implied that they have not been compromised by the anonymity and self-centredness that is often associated with modern society. According to these guides, old-fashioned values are still upheld in Wales; the moral decline of contemporary civilisation has supposedly not yet penetrated the country.

This characterisation is also underlined in the sections concerning religion, which tend to focus on the popularity of Nonconformity in nineteenth-century Wales. Religion is a relatively new topic, which was hardly thematised in the guides published in earlier periods. However, the descriptions remain superficial and primarily add to the description of the Welsh as morally superior people, whilst opposing them to the English. The ANWB guidebook for example states: 'Anders dan de zelfgenoegzame Anglicaanse Staatskerk van die dagen legden de methodisten, die samenkwamen in eenvoudige, vaak zelfgebouwde "chapels", de nadruk op vroomheid, eenvoud en armoede' [Unlike the conceited Church of England of those days, the Methodists, who congregated in simple, often self-built 'chapels', emphasised piety, simplicity and poverty], ${ }^{831}$ which furthered their popularisation amongst the 'hardworking' miners and factory workers, according to the guide. Similar descriptions of religion in Wales can be found in the other texts. ${ }^{832}$ By omitting that Nonconformity, and Christianity in general, have declined in Wales much like in the rest of Western Europe, and that many chapels are now abandoned, the guides characterise the Welsh as a Nonconformist people that voluntarily chose a morally superior life of hardship whilst taking care of the poor, and opposed the perceived arrogance of the Church of England.

\footnotetext{
${ }^{829}$ Berkien, Wales (1996), p. 14.

${ }^{830}$ For example: Jan-Willem Driessen, Reishandboek Wales, Elmar reishandboeken (Rijswijk:

Uitgeverij Elmar, 1994), p. 26; Danse and Berkien, p. 56.

${ }^{831}$ Danse and Berkien, p. 318.

${ }^{832}$ For example: Berkien, Wales (1996), p. 15; Schaedtler, p. 23; Driessen, p. 40.
} 
The description of the language further reinforces this constructed image of Wales as what will be termed here 'the antiquated other'. Although most guidebooks include a brief glossary of Welsh words, these are mainly limited to geographical terms which help the traveller understand Welsh place names. ${ }^{833}$ There is no real sense that the language has any practical use for the traveller, and although it is occasionally mentioned that the number of speakers has stabilised, this is seen as a result of 'een hernieuwde hang naar een eigen identiteit en nationale saamhorigheid' [a new desire for their own identity as well as national solidarity]. ${ }^{834}$ Instead of regarding the stabilising number of Welsh speakers as resulting from a growing awareness of the importance of the language, it is depicted as an inward movement, a sentimental reaction against globalisation which triggered a desire to secure Wales's national identity. That the language is regarded as having hardly any contemporary relevance is even more noticeable in the other depictions of this aspect of Welshness, in which it is primarily used to reinforce the temporalisation of the country. Firstly, it is repeatedly emphasised that the language is very old. The Kosmos guide informs its readers that is was already spoken two thousand years ago, and the Dominicus and ANWB guidebook identify it as the oldest living language in Europe, whilst the former even puts living in quotation marks, implying that it is not really alive. ${ }^{835}$ Secondly, the guides assert that the language is extremely difficult to understand and pronounce, and does not resemble any other language with which the reader could be familiar. Similarly, the guide from the Elmar reishandboeken series contends that the language has no commonalities with other languages and is exceptionally hard to learn for foreigners. ${ }^{836}$ The 1998 ANWB travel guide remarks in this respect: 'De vorm van de woorden leidt vaak tot grote verwarring door de onmogelijk lijkende combinaties van medeklinkers en door de lengte van de woorden' [The structure of the words often leads to great confusion, as the combination of consonants appears to be impossible and the words are long]. ${ }^{837}$ As a result, the language is portrayed as exceptionally old, quaint and exotic, which reinforces the overall antiquation and othering of the country in general.

\footnotetext{
${ }^{833}$ For example: Schaedtler, p. 242; Bartho Hendriksen and Leo Platvoet, Wales, Odyssee (Amsterdam: Babylon-De Geus, 1997), p. 168; Danse and Berkien, p, 58.

${ }^{834}$ Berkien, Wales (1996), p. 15. See also: Danse and Berkien, p. 58.

${ }^{835}$ Berkien, Wales (1996), p. 14; Schaedtler, p. 32; Danse and Berkien, p. 55.

${ }^{836}$ Driessen, p. 28.

${ }^{837}$ Hummel, p. 121.
} 
This image is also evoked by the depictions of Welsh culture. It must be stressed that most texts show a great interest in Welsh culture, which is a significant shift compared to earlier periods when this aspect of Welshness was virtually nonexistent. There are elaborate sections about architecture, music and literature which provide the reader with an overview of these topics. ${ }^{838}$ From this perspective, there is a clearly growing interest in the cultural side of Wales, and an increasing awareness of the distinctiveness of Welsh culture, which is treated as a phenomenon deserving attention. However, when the content of these sections is scrutinised, it becomes clear that this interest is very superficial, and primarily reinforces an image of Wales as culturally conservative. Although some guidebooks refer to more contemporary artists (Dylan Thomas and R.S. Thomas, ${ }^{839}$ as well as Kyffin Williams are for example mentioned $)^{840}$ they generally focus on the cultural continuity that travellers can supposedly find in Wales.

In particular the Welsh musical tradition is significant in this respect, as it is frequently regarded as the most important element of Welsh culture. The Kosmos travel guide, for example, informs its readers: 'Wales' bijnaam "Land of Song” en "Land of Harp" en de tweede regel van het volkslied, waarin gesproken wordt van "land van dichters (bards) en zangers (minstrels)" illustreren het belang dat in het prinsdom aan muziek wordt gehecht' [Wales's nickname 'Land of Song' and 'Land of Harps' and the second line of the national anthem, which refers to the 'Land of Poets (bards) and Singers (minstrels)', illustrate the importance of music in the principality]. ${ }^{841}$ In this quotation, the rather stereotypical and out-dated view of Wales as the 'Land of Song' is reinforced by translating the Welsh terms from the national anthem beirdd with bards and cantorion with minstrels, consequentially evoking images of the Middle Ages and age-old cultural traditions for its Dutch readership. Subsequently, the guide highlights the popularity of the harp in Wales, which is said to be only rivalled by the fiddle, another traditional music instrument which does not in any way contradict the image of Welsh culture as being folkloric. The guide also draws attention to the male voice choirs, penillion (improvised

\footnotetext{
${ }^{838}$ See for example: Berkien, Wales (1996), pp. 20-22; Schaedtler, pp. 32-35; Hendriksen and Platvoet, Wales (1997), pp. 29-33.

${ }^{839}$ Berkien, Wales (1996), p. 22; Danse and Berkien, p. 56.

${ }^{840}$ Hendriksen and Platvoet, Wales (1997), p. 31.

${ }^{841}$ Berkien, Wales (1996), p. 22. The use of the term principality will be discussed later in this chapter.
} 
singing in Welsh, accompanied by a harp) and Eisteddfodau as typical elements of Welsh culture, whilst asserting that the latter are primarily held in 'het Keltisch' [the Celtic language]. ${ }^{842}$ The Celtic language, regarded as a language of the past, is thus directly connected to the culture as well, with the effect of further temporalising and ossifying Wales and Welshness.

The Kosmos travel guide is by no means an exception in this respect, and must rather be seen as an example of how most guidebooks discuss Welsh culture. The Dominicus travel guide, for instance, expresses similar views. A large section is dedicated to the Eisteddfodau, informing readers that this tradition firmly established itself in Wales eight hundred years ago and gives expression to the 'Celtic spirit' of the country's inhabitants. ${ }^{843}$ In addition, Welsh culture is said to consist of male voice choirs and harp music. ${ }^{844}$ Wales's cultural tradition is consequently rendered old-fashioned, whilst its age-long continuity is stressed to further reinforce the image of antiquated other. Even guides which do touch upon modern Welsh culture, such as the Odyssee guide, still primarily focus on its traditional aspects. For example, after having mentioned Dylan Thomas, the guide states: 'De hedendaagse Welse literatuur verschijnt veelal in dichtvorm die zich moeilijk laat vertalen in het Engels' [Contemporary Welsh literature often appears in a poetic form which is difficult to translate into English]. ${ }^{845}$ Even modern Welsh literature is thus depicted as obscure and highly poetic, exhibiting a cultural continuity from early medieval poets onwards, such as Aneirin and Taliesin. ${ }^{846}$

Other aspects of Welsh culture, which seamlessly fit in with this conceptualisation and which are highlighted by virtually every Dutch guidebook published in the period examined, are summarised in sections termed 'Welsh Folklore' and 'Welsh Symbols'. Although some guidebooks discuss these under separate headings, there is a significant overlap between the two and the themes they comprise. The Elmar travel guide, for example, includes a large chapter entitled 'Welse folklore' [Welsh Folklore], which lists a variety of themes, such as national emblems (leek and daffodil), the national anthem and the Welsh flag, but also

\footnotetext{
${ }^{842}$ Berkien, Wales (1996), p. 23.

${ }^{843}$ Schaedtler, pp. 32-33.

${ }^{844}$ Schaedtler, pp. 34-35. For similar descriptions of Welsh culture, see: Hendriksen and Platvoet, Wales (1997), p. 31; Hummel, pp. 112-3; Danse and Berkien, p. 277.

${ }^{845}$ Hendriksen and Platvoet, Wales (1997), p. 31.

${ }^{846}$ Hendriksen and Platvoet, Wales (1997), p. 29.
} 
cultural artefacts such as coracles and lovespoons. ${ }^{847}$ Other guidebooks make a distinction between 'folklore' and 'national symbols', in which the latter are usually summarised as entailing the flag, anthem and national emblems, whilst aspects such as the national costume, sheepdog trials and music are counted towards the former. ${ }^{848}$ Some only include a section about national symbols, thus focusing the attention of the reader on stereotypical, banal markers of Welshness. ${ }^{849}$ It can be argued that on the one hand, these sections emphasise the difference of Wales by highlighting national symbols and artefacts of the country. Cultural boundaries are consequently erected, thus strengthening conceptions of Welshness and reinforcing the 'imagined community' of Wales. This is a significant shift compared to the conceptualisation of Welshness in the Dutch guidebooks published in the 1960s and 1970s, which primarily constructed the country as lying outside of reality. On the other hand, however, these lists of banal Welsh concepts of nationalism as well as cultural artefacts summarise Welshness as stereotypical, superficial and old-fashioned.

\subsubsection{The Apolitical Principality}

Due to this new attention paid to expressions of Welshness and Welsh nationalism, it could be expected that Wales was gradually becoming recognised as a stateless nation with its own politics, especially after devolution was initiated in 1997. At first sight, this seems indeed to be the case, since many Dutch guidebooks have included sections about politics and the form of government in the UK. ${ }^{850} \mathrm{In}$ addition, several guides inform their readers about nationalism in Wales and the issue of (relative) autonomy. ${ }^{851}$ However, as the analysis in the following section will make apparent, the guidebooks downplay these themes and their importance for Wales as a socio-spatial entity. This ultimately leads to the marginalisation of Wales as a political space, whilst calling Wales's status as a nation into question and conceptualising the country as being on the imaginative periphery.

Although none of the guidebooks make the mistake of confusing Wales with England anymore, and the distinction between the two countries has become general

\footnotetext{
${ }^{847}$ Driessen, pp. $38-41$.

${ }^{848}$ For example: Berkien, Wales (1996), pp. 8, 22; Schaedtler, pp. 22, 248.

${ }^{849}$ Berkien, Wales (2000), p. 7; Danse and Berkien, p. 55.

${ }^{850}$ See, for example: Driessen, p. 26; Hendriksen and Platvoet, Wales (1997), pp. 24-25; Danse and Berkien, pp. 54-55.

${ }^{851}$ Berkien, Wales (1996), p. 8; Schaedtler, p. 31; Berkien, Wales (2000), p. 7.
} 
knowledge, the status of Wales within the UK and its relationship with England is still a point of uncertainty for many guidebooks. The Odyssee guidebook for example commences its introduction by posing the question: 'Wales, de achtertuin van Engeland of het trotse Cymru, het land der broederschap? Deze vraag houdt al eeuwen de Cymro and Cymraeg [sic], de bewoners van Wales, bezig' [Wales, the backyard of England or proud Cymru, land of fraternity? This question has occupied the Cymro and Cymraeg [sic], the inhabitants of Wales, for centuries]. ${ }^{852}$ Wales's relationship with England and the status of the former in relation to the latter is thus questioned: is Wales English property, or is it a distinct and separate country? The fact that even the inhabitants of Wales apparently do not know the answer to this question implies that the country's dependence on England is still accepted as a reality by many Welshmen and Welshwomen.

These blurred and questioned imagined borders form a stark contrast to the ANWB's introduction of Wales quoted earlier, in which Offa's Dyke was represented as a clear geographical boundary between England and Wales. ${ }^{853}$ However, as was already noted, this guide puts the word country in relation to Wales in inverted commas, suggesting that the term is somehow not fully applicable to Wales. Despite the erection of geographical boundaries between England and Wales, the status of the latter as a country remains a matter of uncertainty. A further example of this is the following description, published in the 1998 ANWB edition: 'Wales is een land, maar geen staat. Het heeft een hoofdstad, maar nog geen regering; een vlag, maar geen ambassades; een taal, maar nog geen eigen wetten' [Wales is a country, but not a state. It has a capital city, but not yet a government; a flag, but no embassies; a language, but not yet its own laws]. ${ }^{854}$ Although Wales is designated as a country, the lack of certain institutions such as a government, embassies and laws is perceived as contradictory. Considering its year of publication, it can be the case that this guide was written before the initiation of devolution, although the use of the word nog [yet] implies that things are changing in Wales on a political and constitutional level; whilst these institutions are not currently there, the guide hints that they might be in the near future.

\footnotetext{
${ }^{852}$ Hendriksen and Platvoet, Wales (1997), p. 9.

${ }^{853}$ Danse and Berkien, p. 11.

${ }^{854}$ Hummel, p. 7.
} 
In addition to the overall confusion of how to define Wales, most Dutch guides (including those published after the political events of 1997) use the word prinsdom [principality] to refer to Wales. ${ }^{855}$ Technically, this term refers to a sovereign state which is governed by a prince or princess with executive powers, and although this was initially the case when the title was first given to an English prince in 1301, it has been purely ceremonial since the first Acts of Union (1536). ${ }^{856}$ Confusion about how to refer to Wales regularly causes controversy in the UK as well, and the term principality generally does not go down well in Wales, especially since 1997 when the country was given a devolved status. ${ }^{857}$ After a 2010 UN report described the UK as being made up of two countries (England and Scotland), whilst defining Northern Ireland as a province and Wales as a principality, Leanne Wood, at the time Plaid Cymru Assembly Member, objected vociferously, stating that the term could damage Wales's reputation internationally and engender false impressions of the country. ${ }^{858}$ On its website www.wales.com, promoted as the official international gateway for Wales, the Welsh Government explains: 'Wales is not a Principality. Although we are joined with England by land, and we are part of Great Britain, Wales is a country in its own right' ${ }^{859}$ The fact that the Dutch guides designate Wales as a principality instead of a country indicates how Wales's status within the UK is perceived. Wales remains defined in terms of its relationship with England, in which the latter has historically occupied a hegemonic and dominating position. By using the term 'principality', this hegemonic position continues to be maintained and strengthened.

This is further accentuated by informing the tourist that the title 'Prince of Wales' is a symbol of the unification and bond between the two countries. ${ }^{860}$ Even

\footnotetext{
${ }^{855}$ For example: Hendriksen and Platvoet, Wales (1997), p. 9; Schaedtler, p. 12; Danse and Berkien, p. 52; Berkien, Wales (2000), p. 6.

856 Jenkins, p. 103.

${ }^{857}$ See for example the heated discussions after Wales was called a principality during the opening ceremony of the Commonwealth Games in 2014 which took place in Glasgow: Owen Williams, 'Wales Isn't a "Principality" - Sorry!', BBC News Wales, 24 July 2014 <http://www.bbc.co.uk/blogs/wales/entries/1fa3ef03-d94a-3a3c-a22f-093c74467401> [accessed 22 August 2015]; Lizzie Edmonds, 'Welsh Outrage as BBC's Hazel Irvine Describes their Country as a PRINCIPALITY during the Commonwealth Games Opening Ceremony', Dailymail Online, 24 July 2014 <http://www.dailymail.co.uk/news/article-2704029/> [accessed 22 August 2015].

858 'UN Report Causes Stir with Wales Dubbed "Principality", WalesOnline, 3 July 2010

<http://www.walesonline.co.uk/news/wales-news/un-report-causes-stir-wales-1906214> [accessed 21 August 2015].

${ }^{859}$ Wales/Cymru, Frequently Asked Questions <http://www.wales.com/about-wales/frequently-askedquestions\#Question_11> [accessed 17 November 2015]. Emphasis in original.

${ }^{860}$ Berkien, Wales (1996), p. 8.
} 
though surveys have indicated that the majority of the Welsh support the monarchy and want the title to continue to exist, ${ }^{861}$ there was also fierce nationalist opposition to Prince Charles's investiture as Prince of Wales in 1969 which took place in Caernarfon Castle. This antagonism is, to say the least, downplayed in the guidebook. The Welsh nationalist political party Plaid Cymru and the Welsh language organisation Cymdeithas yr Iaith (The Welsh Language Society) opposed the investiture in Caernarfon as, in their view, the ceremony commemorated the conquest of the Welsh. Moreover, two members of the group Mudiad Amddiffyn Cymru (the Movement for the Defence of Wales) were accidently killed at Abergele when they were installing bombs, apparently meant to destroy the train in which Prince Charles was travelling to Caernarfon for the ceremony. ${ }^{862}$ Therefore, the Welsh attitude towards the title of Prince of Wales can best be described as ambiguous and problematic if nationalist views are taken into account, but this is not reflected in the guidebook. This positive stance towards Wales as a principality and the country's connection to the title 'Prince of Wales', which is unique in the Dutch guides and does not feature in the French nor in the German guidebooks from this period, might be explained by the fact that of these three countries, only the Netherlands have their own royal family. Due to the relatively strong support for the monarchy in the Netherlands, ${ }^{863}$ the connection between Wales and the British royals could be regarded as a positive aspect. It could be asserted that the link to the monarchy is seen as a touristic asset for Wales which the guides use to highlight its attractiveness as a travel destination. ${ }^{864}$

On the one hand, there is an increased interest in Wales as a political entity, as the growing number of sections dedicated to topics such as politics and nationalism indicate, but on the other hand the constitutional connection between England and Wales is highlighted, causing the political boundaries to blur rather than

\footnotetext{
861 'Wales Backs Charles for King', BBC News, 25 June 1999

<http://news.bbc.co.uk/1/hi/uk/377976.stm> [accessed 24 August 2015].

862 Davies, A History of Wales, p. 646.

${ }^{863}$ Marissa van Loon and Danielle Pinedo, 'Draagvlak voor monarchie opnieuw afgenomen', NRC, 26 April 2016 <https://www.nrc.nl/nieuws/2016/04/26/draagvlak-voor-monarchie-in-nederland-flinkafgenomen-a1407639> [accessed 21 October 2016].

${ }^{864}$ Interestingly, none of the guides refer to the fact that the Dutch king, Willem-Alexander, went to school in Wales. Between 1983 and 1985 he attended the United World College of the Atlantic at St. Donat's Castle, near Llantwit Major. Most guides do not even mention St. Donat's Castle nor Llantwit Major, and even when they do it is not stated that the king has any affiliation to this place. See for example: Driessen, p. 107.
} 
to be reinforced. Moreover, when analysing the sections concerning Wales's political situation and autonomous status within the UK, it can be argued that the guidebooks marginalise the political ambitions of Wales both before and after devolution. In the guides published before the 1997 referendum, Welsh nationalism is for example discussed but subsequently dismissed as unterritorial. It is highlighted in several guides that the Welsh do not strive for autonomy, as this would supposedly be unattainable. The Kosmos guidebook remarks in this respect:

\footnotetext{
Sinds de onvrijwillige inlijving bij Engeland (1282-83) zijn er verschillende oplevingen van Welsh nationalisme geweest. Wel moet daar onmiddelijk bij aangetekend worden dat de meeste geen economische of politieke, maar een op emoties [...] gebaseerde, puur cultuurlinguïstische achtergrond hadden en in een enkel geval ook een educatief-religieuze. ${ }^{865}$

[Since the involuntary annexation by England (1282-83), there have been several revivals of Welsh nationalism. However, it should immediately be noted that most of these had no economic or political background, but were rather based [...] on emotions and were related to cultural-linguistic and in some cases also educational-religious matters.]
}

Here it becomes evident that although the political side of Wales is mentioned, it is immediately marginalised. It is rendered an emotional aspect of Welshness, rather than a force which could change the constitutional borders of the UK. Similarly, the Elmar travel guide includes a section about the history of Plaid Cymru, which is concluded by the following lines: 'Toch streeft deze partij niet naar een onafhankelijk Wales, want men weet dat Wales dit economisch niet kan bolwerken. Overigens is ook de Welse bevolking zich hier van bewust' [Nevertheless, this party does not strive for an independent Wales, since they know that Wales would economically not be able to manage this. The people in Wales are also aware of this]. ${ }^{866}$ This guidebook also highlights that although Welsh nationalism is growing, this is of no concern for the traveller since its aims are harmless; it is limited to the protection of the country's language and culture, and would at no cost endanger the political or constitutional boundaries of the country and the border between England and Wales.

This vision of Welsh nationalism and politics can also be found in the Dominicus travel guide, which was published in 1997. In the section entitled 'Opleving nationalisme' [Revival of Nationalism], the guide describes the growth of Plaid Cymru, and the disillusionment at the outcome of the 1979 referendum. The

\footnotetext{
${ }^{865}$ Berkien, Wales (1996), p. 8.

${ }^{866}$ Driessen, p. 37.
} 
guide concludes: 'De uitslag bewees dat ook deze opleving van nationalisme inmiddels alweer voorbij was: meer dan $80 \%$ zei nee. De Welshmen hangen blijkbaar meer aan hun taal en traditie dan aan een eigen regering' [The results proved that this revival of nationalism had already ended: more than eighty per cent said no. Apparently, the Welsh are more attached to their language and culture than to having their own government]. ${ }^{867}$ The 1979 referendum is thus dismissed as a nationalist whim, which had already vanished. Instead of placing the result into a meaningful socio-economic or political context, the guide marginalises it as proof that the Welsh are an apolitical people. As long as they can secure their language and culture (which were both seen as old-fashioned, as was argued earlier), the Welsh are not interested in reinforcing their political borders.

It could be expected that after the 'Yes' vote for the 1997 referendum, this image of Wales as an apolitical nation would diminish, but this is not the case. The post-devolution edition from the Odyssee series has added a small paragraph about the referendum, in which it is emphasised that only a 'minieme meerderheid' [slight majority] voted in favour of devolution, and that merely 'iets meer dan de helft van de kiezers' [little more than half of the voters] showed up to vote. ${ }^{868}$ As a result, the outcome of the referendum is downplayed, and by not further highlighting the constitutional changes that took place in its wake, the guide marginalises this political event for Wales in all respects. Several other guidebooks published after 1997 do not, or barely, mention the referendum and its outcome. The ANWB: actief \& anders does not refer to it at all, whilst the Vitamine $\mathrm{V}$ travel guide merely states that Wales has chosen its own Assembly in $1999 .{ }^{869}$ The 2000 edition of the ANWB series, published almost three years after the referendum, still only writes that Labour has promised Wales its own Assembly if they win the election. ${ }^{870}$ The guide subsequently remarks:

Van volledige autonomie willen de meeste Welshmen echter niets weten. Het - in sommige delen zeer sterke - besef tot een aparte Keltische natie te behoren, gaat niet hand in hand met de wens een eigen staat te creëren. Zelfbewustzijn is voor de Welshmen niet hetzelfde als zelfbestuur.

\footnotetext{
${ }^{867}$ Schaedtler, p. 31.

${ }^{868}$ Bartho Hendriksen and Leo Platvoet, Wales, Odyssee (Amsterdam: Babylon-De Geus, 2000), p. 138.

${ }^{869}$ Berkien, Wales (2000), p. 7.

${ }^{870}$ Danse and Berkien, p. 55.
} 
[Most Welshmen do not strive for complete autonomy. The - in some parts very strong awareness of belonging to a separate Celtic nation does not go hand in hand with the desire to establish their own state. Self-awareness is for the Welshmen not the same as selfgovernment.]

Not only does the guide remain unaware of the fact that devolution has been initiated almost three years earlier, it also reinforces the portrayal of Wales as an apolitical nation once again. According to the guide, the Welsh are satisfied with their cultural and linguistic autonomy, and are not interested in expanding this to the political realm. Moreover, by identifying Wales as a 'separate Celtic nation', associations concerning Celticity are evoked, such as backwardness, spirituality and otherness, which are indeed difficult to reconcile with the image of Wales as a political entity.

Overall, it can be concluded that the Dutch guidebooks published between 1995 and 2000 show a growing awareness of Wales as a distinctive socio-cultural entity, especially compared to the texts that were examined in the previous chapter. However, the emphasis lies on Wales's depiction as other, whilst the centuries-long continuity of its language and culture is stressed. Wales is consequently perceived as a country where time passes at a slower rate, where old-fashioned values are still upheld and where the tourist can relax in a green nirvana. Moreover, even though sections are added concerning Wales's political situation, the guides reassure their readers that Welsh nationalism and politics form no threat to the overall coherence of Great Britain, whilst perceiving the British monarchy as a uniting factor between England and Wales. Even as a devolved nation, Wales remains the apolitical, antiquated and integral other. A distinct sense of Welshness can only exist if this does not compromise the unity of Great Britain and is safely kept in the past. This tension between the perception of Wales as a cultural and political entity, and possible reasons for the various interpretations found in the Dutch-language guidebooks, will be further explored in the conclusion of this chapter.

\subsection{The German Construction of a Welsh Tryptich}

This section explores the German-language guidebooks to Wales and Great Britain that were published between 1995 and 2013. It will become clear during the course of the analysis that discursive themes which emerged during the decades after World War II have become even more prominent, although new ways of imagining 
Wales as a socio-spatial entity are also developing. On the one hand, the view of Wales as a magical country outside of modern time and space which developed during the 1960s and 1970s has become a central aspect of the German-language discourse concerning Wales. On the other hand, there is an increasing interest in the travellees' perspective, due to which Wales is gradually being recognised as a political space as well. Moreover, the modern side of Wales is also highlighted. These spaces of Welshness are strongly spatialised in the guidebooks, as will be argued in this section.

\subsubsection{The Defiant Underdog}

This section initially explores the continuation of the discourses used to describe Wales in the earlier periods. As has been asserted in the previous chapter, Wales was increasingly viewed as a distinctive ethnographic, historical and linguistic space, but this distinctiveness was primarily based on a perceived difference with England from which Wales deviated as a peripheral other. As a result, Wales was conceptualised as a country located on the imaginative periphery that had remained secluded from external influences, its inhabitants withdrawing from the world surrounding them.

This difference between England and Wales is still highlighted in the introduction of most German-language guidebooks. The Marco Polo guidebook, for example, commences its description of Wales as follows: 'Reisende nach Wales sollten auf ein Stück Großbritannien vorbereitet sein, das mit kaum einer anderen Region vergleichbar ist' [Travellers to Wales should be prepared to find a part of Great Britain which is hardly comparable to any other region], ${ }^{871}$ and subsequently attributes this difference to the landscape. Other guidebooks frequently base their first introduction to Wales and its alleged difference on the country's Celticity. The Polyglott guidebook for example states forcefully: 'Dabei ist es absurd, Wales als westliche Fortsetzung Englands zu betrachten. Denn die Vorfahren der heutigen Waliser waren die alten Briten, ein keltisches Volk, das sich in den wilden, freien Westen der Insel zurückzog' [It is absurd to regard Wales as a western continuation of England. For the ancestors of the present Welsh were the ancient British, a Celtic

\footnotetext{
${ }^{871}$ Uwe Westphal, Wales: Reisen mit Insider-Tips, Marco Polo (Ostfildern: Mairs Geographischer Verlag, 1996), p. 5.
} 
people who retreated into the wild, free west of the island]. ${ }^{872}$ This image of Wales as a Celtic country where the old inhabitants have secluded themselves strongly resembles what was argued about the representation of Wales in the Germanlanguage guidebooks from the 1960s and 1970s.

During that period, the historical struggle between the English and the Welsh, on a territorial, cultural and linguistic level, played a central role in the spatialisation of Wales on the imaginative periphery. This theme has become even more pronounced in the guidebooks published around the turn of the twenty-first century. The historically strained relationship between England and Wales remains one of the most pivotal themes in the German-language guidebooks throughout the period under investigation. Whereas the point of view chosen still differed per guide in the period after World War II, the guides now unanimously choose the side of the travellee; the Welsh. The historical struggle between the Welsh and the English is highlighted continually, and within this struggle the Welsh occupy the role of suppressed underdog and the English that of villains. The reader is told that century after century, the latter and their forebears have oppressed the Welsh culturally and linguistically, as well as territorially; Wales is '[v]on Römern regiert, von Sachsen verdrängt, von normannischen Königen annektiert, schließlich unter der englischen Eine-Insel-ein-Volk-Politik entmündigt. Und trotzdem nicht in Einerlei untergegangen' [ruled by Romans, expelled by Saxons, annexed by Norman kings and finally incapacitated by the English one-island-one-people-policy. And nevertheless not perished in [this] uniformity]. ${ }^{873}$ The Edwardian castles are regarded as the most prominent and visible pieces of evidence of this history of oppression; they are given a lot of attention due to their symbolic value and popularity as picturesque tourist attractions. This perspective had already been adopted by the Polyglott guide in 1971, but in this period the castles were still primarily considered to be merely aesthetic edifices. By now, the castles are identified as representing English domination, and it is highlighted several times that they were used to flaunt

\footnotetext{
${ }^{872}$ Franz-Josef Krücker, Wales, Polyglott Reiseführer (Munich: Polyglott-Verlag, 1999), p. 7. See also: Günter Semsek, Frank Hecker and Katrin Hecker, Schottland, England, Wales: Tiere und Pflanzen entdecken, Kosmos Naturreiseführer (Stuttgart: Kosmos, 2001), p. 100; Britta SchulzeThulin, Wales, Reise Know-How, 4th edn (Bielefeld: Peter Rump, 2010), p. 7.

${ }^{873}$ Dorothea Fröhlich-Kretzschmar, Wales, Merian Live! (Munich: Gräfe und Unzer Verlag, 1996), p. 5.
} 
English military superiority. ${ }^{874}$ In the Merian Live! guidebook, Harlech Castle is for example described as a 'Furcht einflößendes Bollwerk gegen den walisischen Widerstandsgeist' [fear-instilling bastion against the Welsh resistance spirit] ${ }^{875}$ and the Kosmos-Naturreiseführer identifies Caernarfon Castle as 'Symbol für die anglonormannische Unterdrückung des Landes' [symbol of the Anglo-Norman oppression of the country]. ${ }^{876}$ In opposition to this Anglo-Norman oppression, personified by Edward I and his iron ring of castles, the guides present Owain Glyndŵr as a national hero and freedom fighter. The 1999 Polyglott series even dedicates a whole page to this so-called 'legendary' man who attempted to liberate Wales from the English. ${ }^{877}$

This age-long oppression has, however, not led to the demise of the Welsh, their language and culture. According to the German-language guides, this involuntary role as underdog has made the Welsh a resilient people, willing to fight for their cultural and linguistic heritage; the Welsh are not a broken, demoralised underdog, they are represented as a defiant underdog. Despite 'massive attempts of the government ${ }^{878}$ to annihilate the Welsh language and culture, along with the hegemonic pressure of the English who have 'swallowed, spat out, usurped and exploited' the Welsh, ${ }^{879}$ the latter have successfully preserved their cultural and linguistic uniqueness due to their defiant character and stubbornness, so the guides inform their readers: 'Aber Wales war nie ein leichtverdaulicher Bissen, und im Lauf der Jahrhunderte kristallisierte sich eine Art kämpferische Solidarität heraus, die den Walisern im Blut liegt' [But Wales has never been an easily digestible bite, and over the centuries a kind of defiant solidarity emerged which runs in the Welsh blood]. ${ }^{880}$ The Welsh struggle against the English thus becomes a defining feature of Welshness and Welsh identity in the German guidebooks.

Some guides regard the symbol of Wales, the red dragon, as the personification of the obstinacy and contrariness of the Welsh character. In the Polyglott guide, the country is for example described as a 'small, wild country', symbolised by the 'zackig' [jagged] red dragon which has fought intruders time and

\footnotetext{
${ }^{874}$ See, for example: Uwe Westphal, Wales: Reisen mit Insider-Tips, Marco Polo, 3rd edn (Ostfildern: Mairs Geographischer Verlag, 2000), p. 34; Juling, p. 172.

${ }^{875}$ Fröhlich-Kretzschmar, p. 44.

876 Semsek, Hecker and Hecker, p. 109.

${ }^{877}$ Krücker, p. 71.

878 'massiven Versuche der Obrigkeit', Juling, p. 34.

879 'schluckte, ausspuckte, an sich riß, ausbeutete', Fröhlich-Kretzschmar, p. 7.

${ }^{880}$ Fröhlich-Kretzschmar, p. 7.
} 
again in the past. ${ }^{881}$ The contrariness of the inhabitants is furthermore exemplified by the following anecdotal characterisation of the Welsh: '[W]enn man irgendwo in Wales laut "Ja" rufen würde, gingen sofort alle Fenster auf und mindestens zehn Leute würden einem genauso laut "Nein" entgegenschreien' [If you would shout 'yes' somewhere in Wales, all the windows would open immediately and at least ten people would yell 'no' in response]. ${ }^{882}$ This representation of the Welsh as a stubborn, defiant people is definitely not seen as a negative aspect of Welshness, but rather adds to the country's appeal and sense of character. It provides the Welsh with a distinctive identity, clearly different from their neighbours the English. It can be argued that the guides, aware of the fact that Wales is a rather obscure travel destination, try to create a sense of uniqueness for Wales in respect to England. Perhaps the easiest way of doing this is by creating an identity in opposition to the English.

The Welsh language is also used as an element to highlight the oppression of the Welsh by the English, and to further reinforce the opposition between the two peoples. This is a key change in comparison to its representation in the periods previously under investigation, when the language was given only a minimal amount of attention as an aspect of Welshness. In the guides published during the period currently under scrutiny, the Welsh language is used as an element of distinction and to underpin the image of the Welsh as oppressed yet defiant underdogs. According to the guides, the linguistic oppression of Wales started after the Acts of Union (1536/1543), which condemned Wales to become a 'cultural no man's land' ${ }^{883}$ The repression of the Welsh language is discussed in many German guides and is elucidated by references to the Welsh Not; a piece of wood inscribed with the letters WN which was used as a punishment until the mid-twentieth century by being hung around the necks of schoolchildren who were found speaking Welsh. ${ }^{884}$ Despite this malicious repression, the language has survived, and it is even asserted that the number of speakers is rising. ${ }^{885}$ The survival of the language is thus used by the guides as a further attestation of the perseverance of its speakers and is seen as an

\footnotetext{
881 'kleines, wildes land', Krücker, p. 8.

882 Krücker, p. 8.

883 'kulturelle[s] Niemandsland', Fröhlich-Kretzschmar, p. 11; see also: Juling, p. 34.

${ }^{884}$ Krücker, p. 11.

${ }^{885}$ Westphal, Wales (2000), pp. 5-6; Juling, p. 37; Schulze-Thulin, Wales (2010), p. 58.
} 
expression of their character. As 'Zeichen des Widerstands' [sign of resistance], ${ }^{886}$ it becomes an integral part of the struggle against the hegemony of the English. The Merian Live! guidebook for example describes the language as the 'Rettungsanker einer Nation' [lifeline of a nation] and informs its readers how the language became the focal point in the fight against the English and their cultural domination in the 1960s, in which even militant measures were not shunned: 'Eloquente Rädelsführer begeisterten eine rebellische Jugend, und das Volk hatte seine Sprache wiedergefunden!' [enthusiastic ringleaders inspired a rebellious youth, and the people had found their language again!] ${ }^{887}$ Contemporary issues are therefore taken into account, which indicates that the guides are increasingly viewing the travel destination from the travellee's perspective. ${ }^{888}$ The language is not only used as a marker of difference, as was the case in the 1960s and 1970s guidebooks, but is seen as an inherent part of the Welsh defiant character and identified as a central topic in the Welsh-English struggles.

Another example of this is found in the Reise Know-How series, which includes a paragraph about Welsh protest graffiti that can be found on the side of roads throughout the country. The passage is part of the section 'Autofahren' [driving the car] in the chapter 'Praktische Reisetipps von A bis Z' [Practical travel tips from A to Z], and is located between advice for car troubles and information for disabled travellers. Therefore, it cannot be said that the graffiti is represented as a tourist attraction; it seems to be primarily inserted for informative purposes. The guide does not express an overly positive or negative attitude towards the phenomenon, but explains the graffiti as yet another sign of the Welsh struggle against anglicisation: 'Unterwegs begegnen dem Autofahrer immer wieder walisische Parolen. Diese sind als Protest gegen die Engländer und das Englische gemeint' [En route, motorists will frequently encounter Welsh slogans. These are meant as protests against the English and their language $].{ }^{889}$ The guide provides a list of these slogans, including their translations, so that car drivers know what they mean, but it also gives its own interpretations of their supposedly 'true' meaning.

\footnotetext{
${ }^{886}$ Krücker, p. 13.

${ }^{887}$ Fröhlich-Kretzschmar, p. 11.

888 Other contemporary Welsh issues, such as English in-migration and consequential rising house prices, and the creation of water reservoirs in Wales primarily for English consumption, are also discussed in the guides: Schulze-Thulin, Wales (2010), pp. 97, 263; Mark Schmidt, Wales selbst entdecken, Regenbogen Reiseführer (Zürich: Klaus Stromer, 1996), p. 216.

${ }^{889}$ Schulze-Thulin, Wales (2004), p. 34.
} 
The slogan 'Rhaid i'n Cymunedau fyw' is for example translated as 'Unsere Gemeinde müssen leben' [our communities must live], to which the following explanation is added: 'Engländer raus!' [English go away!]. ${ }^{890}$ Other slogans are explained similarly, thus stressing the opposition between English and Welsh and drawing the attention of the reader to contemporary issues through the medium of and with respect to the Welsh language. The language is arguably represented as a vent for wider problems within Welsh society, such as rising house prices which are caused by the popularity of the relatively cheap Welsh countryside amongst retired people and second-home owners in-migrating from England. In other words, the Welsh language becomes a protest language, a language through which the defiant character of its speakers is expressed.

\title{
5.3.2 A Refuge from Globalisation and Modernisation
}

Resulting from this idea of Wales having a culture of obstinacy, the country is imagined in the German-language guidebooks as a refuge from globalisation and modernity. Wales is conceptualised as a country that refuses to adjust to the contemporary speed of life where the tourist can instead discover 'slowness' ${ }^{891}$ The 2000 Marco Polo edition remarks in this respect:

\begin{abstract}
Aus gutem Grund zieht es heute viele Menschen aus Europa, die der Hektik und dem Stress des Alltags der Städte entfliehen wollen, in die walisische Einsamkeit. Die, so hat man immer wieder den Eindruck, ist von den Walisern gewollt. Einen großen internationalen Flughafen gibt es nicht, und auch British Rail wagt sich bloß an der Südküste ein paar Kilometer auf walisisches Gebiet vor. ${ }^{892}$

[For good reasons, the solitude of Wales attracts many people from Europe who want to escape the hustle and bustle and stress of everyday city life. Time and again, one gets the impression that this isolation is wanted by the Welsh. There is no large international airport and British Rail also only dares to enter Wales for a couple of kilometres at the southern coast.]
\end{abstract}

The increased accessibility of Wales, which was outlined in Section 5.1.2, is completely ignored in order to conjure up the desired image of the country as a safe haven from modern influences. Wales is imagined as offering the tourist an escape

\footnotetext{
${ }^{890}$ Schulze-Thulin, Wales (2004), pp. 34-35.

891 'Langsamkeit', Petra Juling and Ulrich Berger, Wales, DuMont Reise-Taschenbuch, 2nd edn (Ostfildern: DuMont Reiseverlag, 2013), p. 9. This theme of slowness is also pertinent in more literary travel writing on Wales, see for example: Birgit Jürschik-Busbach and Peter Busbach, ARAF - Slow: Auf der Suche nach dem walisischen Herzschlag (Leverkusen: Drachenmond Verlag, 2012).

${ }^{892}$ Westphal, Wales (2000), p. 5.
} 
from the real world to a place that has not yet been affected by the stress and turmoil of modernity. The fact that the guide notes that this isolation is not just a coincidence or merely the result of historical factors (such as closed borders or a long-term war) but is actively strived after by its inhabitants, again draws the attention of the reader to this asserted contrary nature of the Welsh and their unwillingness to be incorporated into the modern, (anglicised) globalising world: 'Bis heute hält man im Westen am Althergebrachten fest, in einer Kontinuität, die über Traditionsbewusstsein weit hinausgeht' [To this day, these people in the west hold on to their old ways in a continuity that goes far beyond a sense of tradition]. ${ }^{893}$

Described as having a culture of 'Widerstand und Anderssein' [resistance and being different $],{ }^{894}$ Wales is considered to have successfully resisted globalisation: 'Gerade in einer Zeit, da so vieles vereinheitlicht und gleichgeschaltet wird, tut es gut zu wissen, daß im “freien Westen” ein kleines Volk starrköpfig seine Eigenheiten verteidigt - und damit ein bißchen von der Vielfalt unserer Welt' [Especially in an era in which so much is being standardised and synchronised, it is good to know that in the 'free West' a small people is stubbornly defending its own idiosyncrasies - and thus a little piece of the diversity of our world] ${ }^{895}$ As these quotations show, the westerliness of Wales is frequently highlighted. Other examples of this are the Merian Live! guidebook which spatialises Wales as 'der Winzling im Westen Englands' [the pipsqueak to the west of England], ${ }^{896}$ and the Reise Know-How series which introduces the country as 'das kleine keltische Land im Westen Großbritanniens' [the small Celtic country in the west of Great Britain]. ${ }^{897}$ Therefore, it can be argued that the image of Wales as a defiant, secluded area is spatialised in the west. As has been asserted by Kneafsey in relation to Ireland and Brittany, Celtic otherness and westerliness are closely connected. ${ }^{898}$ This western spatialisation therefore contributes to the peripheralisation of the country. Not only is it seen as a safe haven from the modern world where traditions are still held in high esteem, it is also situated on the edge of a more central mainland. In addition to this western

\footnotetext{
${ }^{893}$ Berger and Juling, p. 8.

${ }^{894}$ Fröhlich-Kretzschmar, p. 6.

${ }^{895}$ Krücker, p. 7.

${ }^{896}$ Fröhlich-Kretzschmar, p. 4. It seems that in this quote, the topographical borders between the two countries are blurring, as Wales is described as an area in western England. However, in the rest of this guide, the boundary between the two countries is drawn firmly, especially on a cultural and historical level, as will be demonstrated in this chapter.

${ }^{897}$ Schulze-Thulin, Wales (2010), p. 7.

${ }^{898}$ Kneafsey, p. 126. See also Chapter 2.3.
} 
spatialisation, Wales is repeatedly described as a small country in the quotations above. Wales is therefore not only imagined on the western periphery, but is also perceived as unthreatening, even harmless. It is not granted any considerable substantiality, but is rather diminished as a charming little country on the imaginative periphery.

This sanctuary in the west is described as a sanctuary for 'fugitives from civilisation" 899 and an "El Dorado for "counterculturists", 900 where, according to the DuMont guide, environmentalism had already emerged during the early twentieth century and is an intrinsic part of Welsh identity. ${ }^{901}$ Again, the idealisation of Wales and its inhabitants as being more in touch with their natural surroundings becomes evident. This portrayal turns the country into a perfect travel destination for people who dismiss the contemporary world in which everything appears to be dominated by a desire for wealth and progress. The DuMont guidebook confirms this by stating that such travellers will find their ideal travel destination in Wales, where a large number of organic wholefood cafés can be found to serve their needs. ${ }^{902}$ Parallel to this, the Marco Polo guide lists the availability of meditation groups and yoga classes, which sheds light on the intended readership of these guides and their expectations of Wales. ${ }^{903}$ From this, it can be argued that the New Age and countercultural movements which discovered Wales in the 1960s and 1970s have greatly influenced the conceptualisation of Wales as a travel destination, which has now become more mainstream.

Resulting from these depictions of Wales as a refuge from modernity, the country remains secluded from the rest of the modernising world and is instead portrayed as a storehouse of the past. The Kosmos Reiseführer remarks in this respect that Wales 'ist eines jener Gebiete, in denen die Britischen Inseln aufs Ganze gesehen keltisch geblieben sind' [is one of those areas where the British Isles have generally remained Celtic], ${ }^{904}$ thus implying that Celticity is linked to a state of inactiveness; a static characteristic rather than something which can evolve and transform. Whilst other British areas are understood as having moved forward,

\footnotetext{
899 'Zivilisationsflüchtlinge', Juling, p. 33.

900 'Dorado für “Alternative"', Juling, p. 35.

901 Juling, pp. 35-37.

902 Juling, p. 50.

${ }^{903}$ Westphal, Wales (2000) p. 35.

${ }^{904}$ Semsek, Hecker and Hecker, p. 100.
} 
functioning within the processes of modernisation and change, Wales has remained Celtic. The idea that travelling to Wales equals travelling back in time is not only implicated by the suggested flight from the contemporary world, but is also unambiguously proposed as a reason for choosing Wales as a holiday destination. In Wales, travelling to the past is presented as a conceivable option; the DuMont guide for example suggests trips to various historical periods, such as to prehistory, the Roman period, as well as to the age of the Industrial Revolution. ${ }^{905}$

Wales thus remains represented as a country living in the past, where the tourist can flee from modernity and consume history. Being perceived as a country outside of modern times and globalising developments, Wales consequently becomes an otherworldly land in which concepts of ancientness and enchanting landscapes merge. Wales is described as 'Land der Mythen und Legenden' [Land of Myths and Legends] ${ }^{906}$ and 'Land des Zaubers und Magie' [Land of Enchantment and Magic]. ${ }^{907}$ The Welsh landscape is portrayed as bezaubernd [enchanting], ${ }^{908}$ and is compared to a Märchenbühne [fairy-tale stage], ${ }^{909}$ thus presenting the country as an imaginary place. The DuMont travel guide remarks in this respect: 'Überall in Wales kann man der Kraft [der] Vergangenheit nachspüren, die in Sagen und Legenden weiterlebt. Und in magischen Plätzen, die eingebettet sind in eine Landschaft zum Hinschauen' [Everywhere in Wales you can trace the power of the past that lives on in myths and legends. And in magical places, which are embedded in a landscape at which to gaze]. ${ }^{910}$ The tourist is thus indirectly urged to consume the landscape and its ascribed magical qualities.

Noticeable in this respect is that two guidebooks, the Merian Live! and Marco Polo 2000 edition, describe Wales as a land of the gods, taking the asserted otherworldliness of Wales to a new level. ${ }^{911}$ The former uses the heading 'Gott muß ein Waliser sein...' [God Has to be Welsh...], after which the natural landscape of Wales is extolled and mystified. ${ }^{912}$ Verbs and adjectives such as zaubern [to work magic] and geheimnisvoll [mysterious] are used to describe this landscape and to

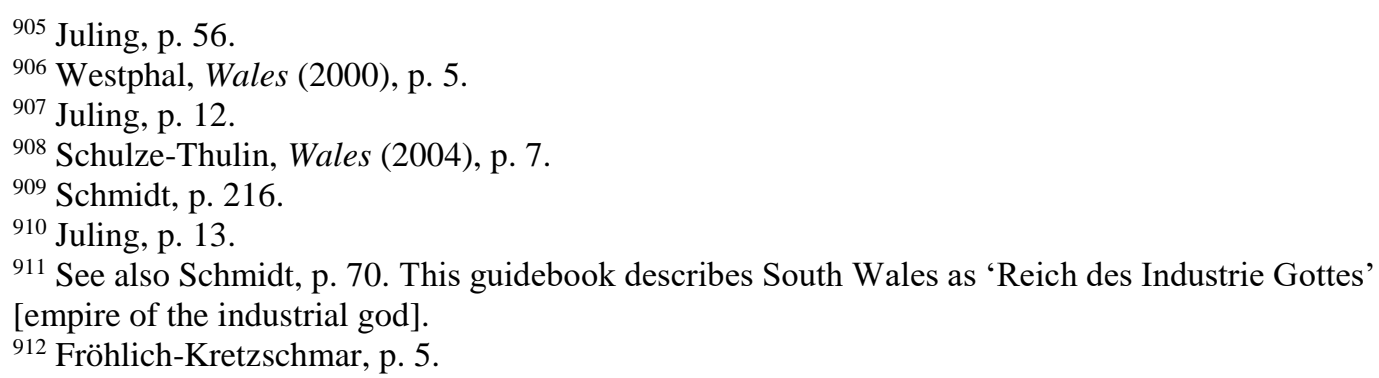


equip it with otherworldly qualities. In this guide, the landscape of Wales is imagined as created by God himself: 'Wenn Gott Waliser ist, dann hat er seine Schätze auf kleinstem Gebiet verschwenderisch verteilt' [When God is Welsh, he has lavishly distributed his treasures in a very small area]. ${ }^{913}$ However, no overly Christian connotations are connected to this, but instead a broader sense of spirituality is evoked. This is also the case in the Marco Polo guidebook, which introduces Wales as follows: 'Die Menschheit is zwar woanders entsprungen, aber die ersten Götter sind in Wales umhergewandelt' [Humanity may have originated elsewhere, but the first gods walked around Wales]. ${ }^{914}$ Again, the landscape is seen as evidence of this supposedly godly presence. Also indicative in this respect is that the landscape gardens in Wales are described as ‘Gärten von Eden' [Gardens of Eden]. ${ }^{915}$ These descriptions conceptualise Wales as a divine place, a space between heaven and earth, which has direct connections to the spiritual world. ${ }^{916}$

\subsubsection{Wales as a Political Space}

Resulting from the establishment of devolution in 1997, it could have been expected that the awareness of Wales as a political space would increase in the guidebooks. So far, the analysis has focused on the conceptualisation of Wales as a space outside modern time and reality, but in the following section the political face of Wales in the guides will be discussed. Special attention will be given to the changing attitudes of the guidebooks towards Wales as a political space before and after devolution. In general, however, it must be remarked that this interest remains relatively marginal in the guidebooks, and the overall portrayal of the country continues to be dominated by the image of Wales as an otherwordly place.

Before the 1997 referendum, the awareness of Wales as a political space is minimal, although it does permeate the guidebooks to a certain extent. The Regenbogen guidebook for example highlights that Wales is still 'im Schatten der englischen Politik' [in the shadows of English [sic] politics] and had to fight to get its own television station, mournfully concluding that '[a]uch dies ist noch längst nicht

\footnotetext{
${ }^{913}$ Fröhlich-Kretzschmar, p. 6.

914 Westphal, Wales (2000), p. 5.

915 Westphal, Wales (2000), p. 6.

${ }^{916}$ Noticeable in this respect is the fact that none of the guides refer to the Welsh language as 'Iaith $y$ Nefoedd' [The Language of Heaven], which is a popular way of referring to the Welsh language in Wales.
} 
selbstverständlich in der heutigen, doch so modernen und toleranten Welt...' [This, too, is by no means self-evident in today's modern and tolerant world...]. ${ }^{917}$ The Merian Live! guidebook, published in 1996, shows a greater attentiveness towards current affairs within Wales, which primarily reinforces the image of Wales as the defiant underdog, continually bullied by the English. The guide for example asserts that the Welsh have long been derided as 'Briten dritter Klasse' [third class Brits] and feel treated as the "'Hinterhof Englands"" ['backyard of England']. ${ }^{918}$ It is furthermore claimed that every child in England still knows the derogatory nursery rhyme 'Taffy Was a Welshman'. ${ }^{919}$ Moreover, the tension in the 1980s between the Thatcherite government and the Welsh miners, at the time termed the 'enemy within' by their own administration as the guide points out, is also emphasised. ${ }^{920}$ Again, the struggles between the Welsh and the English are central here and determine the construction of Wales as a political space: the belittled opponent of its hegemonic neighbour.

The guide thematises Welsh autonomy several times as well, highlighting that despite having their own versions of most characteristics of a nation (an anthem, library, museum, flag etc.) they do not have their own government. ${ }^{921}$ Nevertheless, a paragraph concerning politics is included, in which the governmental structure of the UK is outlined. Plaid Cymru is also mentioned in this respect; it was established to bring the anglicisation of Wales to a halt, according to the guide. ${ }^{922}$ It also refers to the failed referendum of 1979, whilst explaining the outcome as caused by fear of an economic downfall. Despite this rejection of more autonomy, the guide stresses that there is a political friction between Wales and England: 'Trotzdem hegen viele Waliser einen Groll gegen die zentralistische Regierung in London' [Nonetheless, many Welsh hold a grudge against the centralist government in London]. ${ }^{923}$ Instead of interpreting the negative vote as an indication that Wales wanted to belong to Great Britain politically, the guide considers it necessary to point out to the reader that the contemporaneous political situation is not tenable for many Welsh. Despite

\footnotetext{
917 Schmidt, p. 26.

918 Fröhlich-Kretzschmar, pp. 10, 56.

${ }^{919}$ Fröhlich-Kretzschmar, p. 10.

${ }^{920}$ Fröhlich-Kretzschmar, p. 11.

${ }^{921}$ Fröhlich-Kretzschmar, p. 12.

${ }^{922}$ Fröhlich-Kretzschmar, p. 116.

${ }^{923}$ Fröhlich-Kretzschmar, p. 116.
} 
the fact that Wales voted against devolution in 1979, Wales is still considered to be a political space, trying to stand up for its own constitutional rights.

The Marco Polo guidebook provides a completely different image of Wales as a political space, and the shifting image of Wales in this respect between the various editions is illuminating. The edition published in 1996 contends that the Welsh have remained a 'Volk für sich' [a separate people], whilst subsequently stating:

\footnotetext{
Viele Politiker aus London bemühten sich um die Gunst der Bevölkerung. Doch die insistierende Eigenheit und ein oft mangelndes Interesse der Waliser an der Enge zentraler politischer Organisationen haben diese Pläne oft scheitern lassen. ${ }^{924}$

[Many politicians from London sought the favour of the population. But the insistent peculiarity and the often lacking interest of the Welsh in the narrow parameters of central political organisations have frequently led to the failure of these plans.]
}

In this guidebook, the Welsh are portrayed as a people that wants to remain secluded from London and the rest of the world. Whilst the guide implies that Westminster has attempted to please the Welsh, seeking their approval, they have turned their backs on British politics. The reasons for this remain elusive, but it is suggested that the Welsh are generally disinclined to follow Westminster's course, as they do not feel represented by the British political system. This corresponds to the image of the Welsh as defiant; they would rather go their own way than succumbing to 'London' politics. Resulting from this description, the Welsh appear to be generally dismissive of politics, being a people that rather keeps to itself.

It is significant that this passage was omitted in the 2000 edition, which instead added the 1979 failed referendum and the establishment of the Welsh Assembly to the list of historically important dates. ${ }^{925}$ These changes suggest that during the post-devolution years, the Marco Polo series is becoming more aware of Wales as a political entity, which does not allow for a portrayal of the country as secluded and dismissive of politics. Also noticeable in this respect is the difference between the sections titled 'Nationalismus' [nationalism] in the two editions. Whereas the 1996 edition still primarily connects this to violent actions, for example the arson attacks on holiday homes, the 2000 edition has omitted these references and focuses on devolution and the electoral gains by Plaid Cymru during the last

\footnotetext{
924 Westphal, Wales (1996), p. 8.

${ }^{925}$ Westphal, Wales (2000), pp. 8-9.
} 
elections. ${ }^{926}$ It could therefore be argued that nationalism is becoming validated and justified as a political force, instead of remaining in the realm of state-undermining aggression.

After 1997, this interpretation of Welsh nationalism seems to prevail. Most guides include a section concerning devolution and Welsh nationalism, which is often linked to Plaid Cymru and their efforts for Wales, its culture and language. The DuMont travel guide, for example, provides a historical outline of Welsh nationalism, starting from the Acts of Union which unified Wales and England. The guide describes how Plaid Cymru members carried out an arson attack on an RAF bombing school in North Wales in 1936, refused to pay taxes during World War II and went on a hunger strike in order to secure a Welsh-medium television station. The guide then reassures the reader: Plaid Cymru is no longer as radical as it used to be, but is nevertheless 'wichtiger denn je' [more important than ever before] as they are now part of the opposition in the newly-created Welsh Assembly. ${ }^{927}$ Instead of being restricted to the illegal actions of a few political activists, Welsh politics has fully permeated society and has gained recognition as a governmental force. It can therefore be argued that the political boundaries between Wales and England are being recognised in the guides and are used to set the two countries apart. A quotation from the Reise Know-How guide illustrates this aptly: 'Doch die Waliser fühlen sich weniger als Briten und schon gar nicht als Engländer. Seit 1999 besitzt Wales mit der walisischen Nationalversammlung ein eigenes Parlament mit 60 Mitgliedern' [However, the Welsh do not feel British and not at all English. Since 1999, Wales has its own parliament with 60 members: The Welsh National Assembly]. ${ }^{928}$ The National Assembly is thus used to strengthen the boundary between Wales and England and their respective inhabitants. In other words, political distinctiveness is added to the list of oppositions between England and Wales; one more aspect that makes the difference between the two countries and the individuality of Wales visible.

After devolution, the political border between Wales and England has thus been strengthened in many guidebooks, and Wales is increasingly regarded as a politically distinctive space. Within Wales, however, the extent of the country's

\footnotetext{
${ }^{926}$ Westphal, Wales (1996), p. 15; Westphal, Wales (2000), p. 16.

927 Juling, pp. 34-35.

${ }^{928}$ Schulze-Thulin, Wales (2010), p. 88. Emphasis in original.
} 
politicisation is depicted as differing significantly, and appears to be strongly bound to certain topographical areas: the formerly industrialised areas of Wales, in particular the South Wales Valleys. The Merian Live! guidebook, for example, describes how England benefitted from Welsh mineral resources, accumulating its wealth whilst the Welsh colliers and quarrymen were suffering. Resulting from this inequality, the industrialised areas became politicised: 'Solidarität und Sozialismus, wortgewaltige Gewerkschaftsführer und beinharte Streiks - die Kumpels der Valleys und der Schieferbrüche im Norden waren dafür bekannt' [Solidarity and socialism, verbose union leaders and tough strikes - the miners of the Valleys and the slate quarries in the North were known for that]. ${ }^{929}$ It is in these locations that a Welsh political identity emerged, according to the guide. This spatialisation of political Welshness can be found in most other German-language guidebooks from this period as well. According to the DuMont guidebook, the Welsh are political radicals and socialists; many of them, for example Aneurin Bevan, were born and raised in South Wales, which is described as a hotbed of socialism. ${ }^{930}$ This concurs with the Polyglott's portrayal of the Rhondda Valley as 'Wiege der Arbeiterproteste' [cradle of workers' protests]. ${ }^{931}$ The Reise Know-How guidebook claims along similar lines that it was in these regions that a new feeling of national identity emerged in the nineteenth century, which was combined with strong separatist trends. It was due to the demands for home rule coming from these areas that national institutions, such as Welsh universities and a national library as well as a museum, were established in Wales during that period, the guide informs its readers. ${ }^{932}$

In addition to this politicalisation of South Wales, this area is also rediscovered as a touristic area. Various guides describe this formerly industrialised area as a space in transition. The Valleys used to be surrounded by 'versengten und geschwärzten Hügel inmitten glühend heißer, teuflischer Natur' [scorched and blackened hills amidst glowing hot, devilish nature], ${ }^{933}$ but are now turning into green spaces fit for touristic recreation and consumption. ${ }^{934}$ In addition, most guides highlight industrial sites in South Wales, which have now become tourist attractions.

\footnotetext{
${ }^{929}$ Fröhlich-Kretzschmar, p. 6.

930 Juling, p. 32.

${ }^{931}$ Krücker, p. 38.

${ }^{932}$ Schulze-Thulin, Wales (2010), p. 86.

${ }^{933}$ Fröhlich-Kretzschmar, p. 55.

${ }^{934}$ See also: Semsek, Hecker and Hecker, p. 101.
} 
Big Pit and the Rhondda Heritage Museum in particular are praised for their 'authenticity', as they give visitors an inside view of a mineworker's life. The fact that the tour guides are former Kumpel [miners] contributes considerably to their perceived authenticity. ${ }^{935}$ These sites can provide the visitor with a glimpse of the past, of the hard lives miners used to have in bygone ages: 'In Blaenavon, Welterbestätte von UNESCO, lädt das Besucherbergwerk The Big Pit [sic] zur Zeitreise in die gar nicht so ferne Vergangenheit ein - echte Kumpels, echte Kohle mit viel Authentizität' [In Blaenavon, an UNESCO World Heritage Site, the tourist mine The Big Pit [sic] takes you on a journey into the not so distant past - real miners, real coal with a lot of authenticity]. ${ }^{936}$ Compared to the earlier periods that have been scrutinised in this thesis, the representation of industrialised spaces of Wales has undergone the most drastic change in the guidebooks. During the nineteenth century, these areas were admired as spaces of innovation, examples of commercial activity which could function as models for Germany's own future. In South Wales, tourists could therefore travel into the future. However, due to the decline of industrial activity in Wales after World War II and the general degeneration of the South Wales Valleys, this area was simply erased from the touristic map in the German-language guidebooks published between 1955 and 1975. The most recently published German-language material imagines the industrialised Valleys as places where one can discover the past, travelling back in time, rather than into the future.

\subsubsection{The Modern Side of Wales}

Hitherto it has been shown that the guidebooks highlight two seemingly opposite sides of Wales and Welshness. On the one hand, there is the image of Wales as an otherworldly, isolated sanctuary from globalisation which predominates in the guidebooks to a large extent. On the other hand, however, the guides create the image of Wales as a political space. These two representations of Wales appear to contradict each other; the former suggests that Wales is a withdrawn space outside the realms of modernity where time passes more slowly than in the rest of the world,

\footnotetext{
${ }^{935}$ For example: Fröhlich-Kretzschmar, pp. 69, 71; Schmidt, pp. 59, 70; Krücker, p. 39; Juling, p. 75; Semsek, Hecker and Hecker, p. 101.

${ }_{936}$ Juling and Berger, p. 76. See also: pp. 67, 102-3.
} 
whilst the latter contends that Wales is a politicised space where radical socialist ideas thrive. However, the guides appear to have no issues switching from one representation to the other. It could be asserted that this is due to the fact that both versions of Wales inhabit clearly different topographical spaces and as such do not clash. Whereas the otherworldly secluded image of Wales is spatialised in the NorthWest, on the fringe of the British Isles, the politically engaged, socialist Welsh space is primarily located in the South Wales Valleys. Due to this topographical separation, the conceptualisations are able to co-exist and function as representations of the same country.

Moreover, different as they may seem, they both contribute to the image of Wales as the defiant underdog. The depiction of Wales as a remote refuge from modernity reflects this mainly from a historical perspective, in which the Welsh are portrayed as a people that have been oppressed for centuries. Despite this, they have been able to maintain their culture and language, primarily due to their obstinacy. The fact that the industrialised areas of Wales are politicised reinforces the country's characterisation as defiant. However, the Welsh are still seen as oppressed, for example by Thatcher and 'English' centralism. As a result of this oppression, the Welsh have adopted a radical political standpoint. Again, it is a reaction to English influences, arguably coming from the centre, which have brought about these attitudes in Wales. In both representations, therefore, Wales and Welshness are in fact created by the English.

However, a third, co-existing manifestation of Wales and Welshness is created in the guidebooks: a modern Welsh space. Within the same guidebook, Wales can be depicted as a politically radicalised, yet secluded safe haven, as well as a fashionable hotspot. First of all, some guides illustrate this contemporary side of Wales by drawing the attention of the reader to the 'Cool Cymru' phenomenon. The 2000 edition of the Marco Polo guidebook to Wales, for example, has added a section about rock music which describes Wales as having gained international recognition due to bands such as Catatonia: 'Nach weit verbreiteter Überzeugung hat die Rockmusik Wales "befreit" und dazu beigetragen, dass vor allem Jugendliche diesen kleinen Fleck auf der Landkarte entdeckt haben' [It is widely believed that rock music has 'liberated' Wales and has contributed to the fact that young people in 
particular have discovered this little spot on the map]. ${ }^{937}$ Wales is thus also perceived as having a modern and vibrant culture, and it is during the period between 1995 and 2013 that this side of Wales is increasingly highlighted. In the 2000 edition, the DuMont guidebook still describes Wales's music scene as consisting of opera singers, male voice choirs and harpists, although it is mentioned that there is a slowly emerging Welsh pop music scene as well. ${ }^{938}$ In the 2013 edition, the guide has fully revised its viewpoint on the subject, instead stating: 'Bergmannschöre?

Opernsänger? Das war gestern. Die heutige walisische Musikszene ist überraschend vielfältig, überaus munter und innovativ' [Male voice choirs? Opera singers? That was yesterday. The contemporary Welsh music scene is surprisingly diverse, very lively and innovative]. ${ }^{939}$ Bands such as the Manic Street Preachers and Super Furry Animals are discussed elaborately and are seen as representative of a new-found modern Welsh culture.

The guides locate this modern identity of Wales in the urbanised southern regions of Wales, primarily in Cardiff. The capital city is seen as the face of a new Wales which seems to have developed during the turn of twenty-first century. In the 1996 guide from the Merian Live! series, Wales is primarily described as a land of myths with landscapes steeped in legends, but the country's modernity is also brought forward: 'Wales denkt modern, tanzt Techno in den Nightclubs von Swansea und plant die Zukunft: Der Bau des neuen Opernhauses in der Marina von Cardiff wurde Zaha Hadid, einer der innovativsten zeitgenössischen Architektinnen, anvertraut' [Wales thinks modernly, dances techno in Swansea's nightclubs and plans the future: the construction of the new opera house in Cardiff Bay was entrusted to Zaha Hadid, one of the most innovative contemporary architects]. ${ }^{940}$ In this quotation it becomes clear that Wales's modern side and identity are spatialised in the two largest cities of the country, situated in the largely anglicised area of South Wales. Cardiff, as the centre of this modern Welsh space, is frequently described as innovative and cosmopolitan, and the architectural renovation of Cardiff Bay is

\footnotetext{
937 Westphal, Wales (2000), p. 18.

938 Juling, pp. 46-49.

939 Juling and Berger, p. 70.

${ }^{940}$ Fröhlich-Kretzschmar, p. 12. It should be highlighted here that Hadid's plans were never realised due to a refusal by the Millennium Commission to fund her design. The collapse of the project was finally made public in December 1995. The Merian Live! guidebook, which was published in 1996, might have already been written and edited before this was revealed.
} 
especially extolled. ${ }^{941}$ However, it is repeatedly emphasised that Cardiff is anything but the heartland of Welsh language and culture, and has actually little connection to the rest of the country. The 2000 DuMont edition, for example, stresses that Cardiff 'ist weit davon entfernt, Zentrum rein walisischer Kultur und Sprache zu sein' [is far from being the centre of pure Welsh culture and language]. ${ }^{942}$ It is even contended that Cardiff was only proclaimed capital of Wales due to the fact that it had a good infrastructural system, rather than because of its internal connection with the nation. ${ }^{943}$ It can therefore be argued that Cardiff, the modern capital of the nation, is not considered to be part of the 'real Wales', which is said to be found in the NorthWest. $^{944}$

If we take these various depictions of Welsh culture and identity in the German guides into account, a large discrepancy becomes visible in the portrayals of Wales, its culture and national identity. First, there is a predominant image of Wales as a country that is stuck in the past and that has excluded itself from the modernising world. The inhabitants are praised for their obstinacy, which is seen as the main reason for their own survival as well as that of their language and culture. This character trait has kept the country a safe haven from globalisation, cultural uniformity and anglicisation. This way, Englishness, globalisation and modernity are closely linked to each other and are apparently part of the same package. This face of Wales and Welshness is primarily spatialised as westerly. Secondly, there is the representation of Wales as a politicised space, where socialism, radicalism and nationalism seem to determine the country's identity. This version of Wales is localised in the old industrialised areas, primarily the South Wales Valleys. Both descriptions of Wales contribute to the overall image of the Welsh as a defiant people, fighting against English oppression. Thirdly, Wales is depicted as having a modern side as well, which is spatialised in the urbanised, anglicised south-eastern part of the country, especially Cardiff. The guides themselves problematize this by stating that Cardiff is not a hub of Welshness and is in this sense not representative of the nation. Especially in light of Cardiff's negative vote in the devolution referendum, it is ironic, to say the least, that the city is now the face of Wales as a

${ }^{941}$ Westphal, Wales (2000), pp. 6, 70; Fröhlich-Kretzschmar, p. 56; Juling, pp. 56-57; Schulze-Thulin, Wales (2010), p. 343; Juling and Berger, pp. 76-77.

942 Juling, p. 56.

${ }^{943}$ Schmidt, pp. 74-76.

${ }^{944}$ Schulze-Thulin, Wales (2004), p. 102. See also: Westphal, Wales (2000), p. 31. 
modern and devolved nation, being the country's capital and seat of Welsh Assembly.

Overall, it is noticeable that the three versions of Welshness that are constructed in the German-language guidebooks from this period bear strong resemblance to Balsom's so-called 'Three Wales Model', which was discussed in the introduction of this thesis. The guidebooks' location of the 'real' Wales, where the Welsh language and culture have managed to survive despite English oppression, is roughly situated in the same area as Balsom's Y Fro Gymraeg. They spatialise a political sense of Welshness in the area identified by Balsom as Welsh Wales, where they imagine the opposition to anglicisation and English centralism to be strongly present. The omnipresence of Welsh identity in the Valleys, expressed in antiEnglishness, is also something Balsom notices. According to him, it is in Y Fro Gymraeg and Welsh Wales that there is a clear sense of Welsh identity. ${ }^{945}$ British Wales, identified by Balsom as having the weakest sense of Welshness, is spatialised in South-East Wales, in particular Cardiff, and is indeed regarded by the guides as generally un-Welsh and, perhaps exactly therefore, as modern. In these recent German guidebooks, Welshness appears to be incompatible with modernity, and it is only the anglicised side of Wales and its culture that can represent the modern face of the country. Nevertheless, it can be concluded that the guidebooks show a growing recognition of the differences within Wales and Welshness, and try to highlight various facets of the country and its identity. With the slowly yet steadily increasing awareness of Wales as a tourist destination, the guidebooks might be attempting to create a Welsh space for every kind of tourist. According to the guides, the country offers travellers both an escape from modern life as well as the possibilities of an urban trip. Headings such as 'Wales heute: Mythen und Moderne' [Wales Today: Myths and Modernity] further illustrate this interpretation of the country as having both a modern side as well as one which fits in with the idea of Wales as 'Land der Kelten' [Land of Celts]. ${ }^{946}$

\footnotetext{
945 Balsom, p. 6.

${ }^{946}$ Fröhlich-Kretzschmar, p. 4.
} 


\subsection{Wales as the Celtic Colony in French-Language Guidebooks}

In contrast to the German-language material, it has already been noted that the availability of French-language guidebooks in this period is far less substantial. Whereas single-volume German guidebooks to Wales were frequently published between 1995 and 2013, in this period there is only one original French-language series, Petit futé, that published a separate guide to Wales. Other French contemporary guidebooks either describe both England and Wales together in one guide, or cover the whole of Great Britain. Within these books, Wales is normally merely described in one chapter and the introductory sections are brief if provided at all, making the material available about the country far more succinct than was the case for the German-language analysis. It is difficult to provide an explanation for this evident difference between the German- and French-language publishing situations. In the chapter's introduction it was suggested that the lack of singlevolume French-language guides to Wales might be the result of economic considerations; a guidebook which combines England and Wales has a larger target audience than two separate guidebooks. However, this would not necessarily explain the difference between the German and French publishing situation, since France is, like Germany, one of the most important overseas holiday markets for Wales. ${ }^{947}$ In the conclusion of this chapter, it will be argued that the striking difference could be explained by the interest in and acceptance of regionalism in the two countries, which might influence the overall appreciation of Wales as a distinctive travel destination.

Overall, Wales thus occupies a marginal place in the French-language guidebooks published around the turn of the twenty-first century. In the Michelin vert tourist guide to Great Britain, for example, the descriptions of Welsh sites are simply incorporated in the alphabetical enumeration of British sites without any sign of distinction, making the country rather invisible for the traveller as a separate destination. ${ }^{948}$ Although the other French-language guides do describe Wales

\footnotetext{
${ }^{947}$ Visit Britain, Trends in Visits to Different Areas in Britain, pp. 6-7.

${ }_{948}$ Manufacture française des pneumatiques Michelin, Grande-Bretagne, Michelin vert: guide du tourisme, 2nd edn (Paris: Pneu Michelin, 1997). It must however be emphasised that sights in Scotland are treated in the same way and are also listed indistinctively.
} 
separately, the introductions that are provided are usually very minimal, such as the one in the Guides mondéos to England and Wales:

\begin{abstract}
Culture celte, légendes du roi Arthur, vestiges romains, forteresses du Moyen Age, côte sauvage du Pembrokeshire, douces collines du Snowdonia Park, pays de l'ardoise et du charbon... Tel est le pays de Galles, région à part de la Grande-Bretagne qui a su préserver ses traditions et son identité. ${ }^{949}$

[Celtic culture, legends about King Arthur, Roman remains, fortresses from the Middle Ages, the wild coast of Pembrokeshire, the gentle hills of Snowdonia National Park, land of slate and coal... That is Wales, a separate region in Great Britain that has been able to preserve its traditions and identity.]
\end{abstract}

This introduction is not only very succinct, it also provides a superficial and stereotypical image of Wales. The country is clearly portrayed as the other within Great Britain, focusing on Wales as a storehouse of the past.

Despite the apparent scarcity of French material concerning Wales, some guidebooks have gradually expanded their chapters concerning the country, which in contrast demonstrates a growing awareness of the country's touristic potential. This can be exemplified by the various Guide du routard editions of its guide to the British Isles (later England and Wales only). Whereas Wales is covered in merely five pages (out of a total of 183 pages) in the 1982 guide, this is extended considerably to thirtyseven (out of 399 pages) in 1996 and to eighty (out of 759 pages) in the 2002 edition. ${ }^{950}$ The fact that between 1996 and 2002 the chapter more than doubled in length, and that the section providing background information about the history, culture and language of Wales expanded from two to six pages, attests to a growing touristic responsiveness to and interest in Wales as a holiday destination. ${ }^{951}$ Since this coincides with the devolution referendum and the subsequent establishment of the Welsh Assembly, it could be contended that these changes contributed to the growing recognition of Wales as a unique travel space within the UK with its own language, culture and history. The fact that the Petit futé series published its first

\footnotetext{
949 Marianne Peyri, Angleterre et pays de Galles, Guides mondéos (Paris: Les éditions Comex, 2004), p. 95.

${ }_{950}$ Philippe Gloaguen, Grande-Bretagne, Irlande, Guide du routard (Paris: Hachette, 1982), pp. 8387; Philippe Gloaguen, Angleterre, pays de Galles, Guide du routard (Paris: Hachette, 1996), pp. 284 319; Philippe Gloaguen, Angleterre, pays de Galles, Guide du routard (Paris: Hachette, 2002), pp. 664-744. The sections regarding Wales have not only increased in absolute page numbers, but also in terms of percentage. Whereas Wales's share of the guidebook was 2.7 per cent in 1982, this rose to 7.5 in 1996 and to 10.5 in 2002.

${ }^{951}$ Gloaguen, Angleterre, pays de Galles (1996), pp. 284-5; Gloaguen, Angleterre, pays de Galles (2002), pp. 664-71.
} 
guide dedicated solely to Wales in 2001 further supports the argument that around the turn of the millennium Wales was becoming an increasingly visible travel destination for the French.

Since Wales is principally described in combination with England or Great Britain in the French-language guidebooks from this period, it may be expected that the dynamics between Wales and the rest of the UK are represented differently when compared to the country's portrayal in, for example, the German-language material. Especially in light of devolution, it will be illuminating to see whether and how Wales's position within the UK transforms throughout the period under examination.

\subsubsection{The Familiar Celtic Other}

A continuing theme in comparison to the periods previously under examination is the foregrounded Celticity of Wales, which seems to indicate an unwillingness to change the representation of Wales. In comparison to the Germanlanguage guidebooks, which have shown a clear development in their depiction of Wales through the ages, it can be argued that there is a greater element of continuity in the French-language guidebooks. Similarly to the guidebooks published during the decades following World War II, Wales's Celtic background is frequently highlighted, especially its oral tradition and the Arthurian legends. The Guide mondéos describes Wales as 'pays de légendes' [country of legends]: 'Héritier d'une forte tradition orale celtique, le pays de Galles entretient avec dévotion ses contes et ses mythes peuplés de princes, d'animaux monstrueux et d'êtres surnaturels fascinants' [having a strong Celtic oral tradition, Wales has devotedly preserved its tales and myths inhabited by princes, monstrous animals and fascinating supernatural beings.${ }^{952}$ These legends, the guide informs its readers, are connected to the landscape and villages throughout Wales, thus spatialising the country's asserted Celticity in terms of its geography. The Petit futé recommends (re-)reading legends about 'Merlin l'Enchanteur' [Merlin the Wizard] before travelling, as this would enrich the journey through Wales. ${ }^{953}$ The guide even tells its readers that there is no point in visiting Wales if they do not appreciate mythology and fairy tales, since these are thoroughly interwoven with the country, its landscape, history and culture

\footnotetext{
952 Peyri, p. 103.

${ }^{953}$ Auzias and Labourdette, Pays de Galles (2008), p. 1.
} 
and are therefore inescapable. ${ }^{954}$ Owing to this emphasis, a tour through Wales based on an Arthurian theme is proposed, visiting towns such as Caerleon (supposedly the site of King Arthur's round table), Carmarthen (according to legend the birthplace of Merlin) and Bardsey Island (one of the sites thought to be King Arthur's burial place). ${ }^{955}$ Wales's Celticity is thus seen as one of the most important aspects of its culture for the French tourist and is used as a means to enhance the attractiveness of the country. In other words, its Celtic background is used to set Wales apart from England and to provide it with a clearly recognisable touristic identity.

Simultaneously, it is this Celtic aspect that is arguably used to enhance the closeness of Wales to France. Due to the fact that France also has a Celtic nation within its state, namely Brittany, the Celtic aspect of Wales evokes images of familiarity whilst removing any arising fears of unsettling and unknown foreignness. The guides themselves also directly highlight this and both the Guide du routard and the Petit futé discuss the Celtic connection between Wales and Brittany in relative detail. In the section 'Le pays de Galles à l'origine de la Bretagne' [Wales at the Origins of Brittany], the Guide du routard describes how the 'Bretons', supposedly the original inhabitants of the British Isles, were gradually expelled to the outskirts of the Island after the Romans had left and other invaders had free rein. According to the guide, some of these expellees, who are termed 'boat-people, ${ }^{956}$ crossed the Channel and settled in the area now known as Brittany. It is not clear why the guide has chosen the term 'boat-people' in particular, which has strong political connotations, as no other remarks are subsequently made which could additionally reinforce this historical politicisation. Although it could be argued that the term adds a contemporary dimension to the narrative of the connection between Wales and Brittany, the guide does not explore this further. It would therefore be exaggerating to assert a high level of contemporalisation of the Welsh. Instead, this term arguably emphasises the peripheralisation of the Welsh and the Bretons. They have allegedly been expelled from their original territory to the outskirts of the British Isles, and have even ventured across the Channel to settle on the fringe of France as well. Their role as dwellers at the periphery is underlined and dramatised by the term, rather than contemporalised and politicised. Moreover, the guide also inadvertently strengthens

\footnotetext{
954 Auzias and Labourdette, Pays de Galles (2008), p. 9.

955 Auzias and Labourdette, Pays de Galles (2008), pp. 17-18.

${ }_{956}$ Gloaguen, Angleterre, pays de Galles (2002), p. 668. Emphasis and English term used in original.
} 
the power dynamics between the minoritised stateless nations Brittany and Wales and their hegemonic neighbours by characterising the former as expellees who have been driven from their country by more powerful players. ${ }^{957}$

As could be expected, another important similarity between the two Celtic countries that is noticed by these guidebook series is their common linguistic ancestor. The Guide du routard for example highlights that place names in both countries have similar elements and emphasises that the languages have many commonalities in respect to their vocabulary, grammar and syntax. ${ }^{958}$ The Petit futé goes even further by remarking: 'Le breton et le gallois s'avèrent être tellement proches qu'une personne parlant breton peut se joindre sans trop de peine à une conversation en gallois!' [Breton and Welsh have proven to be so similar that a person speaking Breton can join in a Welsh conversation without too much trouble!]. ${ }^{959}$ Needless to say, this is an exaggerated view of the likeness of the two languages and does not reflect the actual linguistic relationship of Welsh and Breton. Nevertheless, by discussing the Welsh language in relative detail whilst simultaneously highlighting its connection to the Breton language, the guides on the one hand emphasise the linguistic distinctiveness of Wales regarding the other parts of the UK, whilst on the other hand creating a web of familiarity for the reader. Wales has its own language, but the similarity to the situation in Brittany is foregrounded in order for the traveller to frame Wales's distinctiveness. This closeness is further strengthened in the Guide du routard, which draws attention not only to the linguistic similarities between Welsh and Breton, but also between Welsh and French. The guide for example remarks that Welsh, like French, distinguishes between a formal and informal form of 'you' and that certain words, e.g. pont, mil and ffenestr, are also related. ${ }^{960}$

\footnotetext{
957 The Petit futé also stresses the closeness of the Welsh and the Bretons in a separate section entitled 'Bretons et Grands-Bretons' [Bretons and Great-Bretons] in which the connection between the two people is asserted to primarily manifest itself in their common history and shared Arthurian legends. See: Auzias and Labourdette, Pays de Galles (2008), p. 43.

${ }^{958}$ Gloaguen, Angleterre, pays de Galles (2002), pp. 668-9.

${ }^{959}$ Auzias and Labourdette, Pays de Galles (2008), p. 43.

${ }^{960}$ Gloaguen, Angleterre, pays de Galles (2002), p. 669.
} 


\subsubsection{Devolution: The End of Colonisation}

It could thus be argued that in many guidebooks, Wales is conceptualised as a Celtic other, spatialised within a web of familiarity. Overall, Wales is now rarely confused with England as the cultural boundaries between the two countries are generally recognised. ${ }^{961}$ Nevertheless, the position of Wales within Great Britain is still perceived to be problematic. The country is for example described as 'une nation dans la nation' [a nation within the nation] whilst at the same time being labelled 'une région' [region]. ${ }^{962}$ The depiction of Wales as 'région' is used throughout the French guides from this period and is a telling example of how Wales's position within Great Britain is perceived. ${ }^{963}$ Even though Wales is becoming 'a nation once again' towards the end of the twentieth century, ${ }^{964}$ the French guides highlight Wales's integrality within the UK and locate the country within British boundaries. Consequently, the topographical borders surrounding Wales seem to blur. Similar to the Dutch guides from this period, the Guides Marcus also openly problematises how Wales's position within the UK ought to be evaluated: 'Pays de Galles, terre des princes anglais ou terre des Gallois?' [Wales, land of English princes or land of the Welsh?]. ${ }^{965}$ The guide thus questions who is the actual owner of Wales; the Welsh or the English? In this case, the boundaries between the countries have faded and English hegemony is evidently permeating Welsh territory.

The socio-spatial position of Wales within the UK and its relationship with England is highlighted, and it can be argued that the description of this relationship is expressed through a colonial discourse. In the guide to Great Britain from the Petit futé series, the chapter about Wales is introduced by the following paragraph:

La campagne de la campagne anglaise, c'est ici. Sauvage, le pays de Galles est l'un des plus superbes joyaux de la couronne. L'expression conviendrait plutôt flatter une colonie lointaine, exotique. Eh bien nous y sommes, au pays de Galles, loin de tout, à la fois en géographie physique, avec cette personnalité des terres galloises, et en géographie humaine:

\footnotetext{
${ }^{961}$ A noticeable exception is the description of Beaumaris castle as 'le plus belle exemple de château de forme concentrique en Angleterre' [the most beautiful example of a concentric castle in England] in: Manufacture française des pneumatiques Michelin, Grande-Bretagne (1997), p. 58.

962 Abigaël Brisou-Nowik, En Angleterre et au pays de Galles, Guides visa (Paris: Hachette, 1994), p. 159.

${ }^{963}$ See for example: Peyri, p. 95; Auzias and Labourdette, Pays de Galles (2008), p. 1.

964 Johnes, p. 414.

${ }^{965}$ Abigaël Brisou-Nowik, Angleterre et pays de Galles, Guides Marcus (Paris: Éditions Marcus, 2002), p. 14.
} 
car si les Gallois peuvent aujourd'hui se considérer comme sujets de Sa Majesté, annexer ce remuant voisin de l'Ouest ne fut pas chose facile pour les Britanniques. ${ }^{966}$

[The countryside of the English countryside is here. Wild, Wales is one of the most superb 'jewels in the crown'. This expression would be more appropriate to flatter a distant, exotic colony. But here we are, in Wales, far from everything, both physically, regarding the character of the Welsh land, and anthropologically: because although the Welsh can now consider themselves subjects of Her Majesty, annexing this turbulent western neighbour was not easy for the British.]

Here, Wales is clearly depicted as English property whilst using a strongly colonial vocabulary to describe the relationship between Wales and England. Wales is peripheralised as the countryside of the English countryside; a fraction of a fraction of England, accessible as a place of leisure for the English and the French, and inclined to be consumed by these visitors. Although the expression of 'un des plus superbes joyaux de la couronne' could be read purely aesthetically as referring to Wales as one of the most attractive areas in Great Britain, the phrase has specific imperial and colonial connotations, and is usually used to refer to India. ${ }^{967}$ In this case, 'the crown' refers to its meaning as representation of the British monarchy, in which Wales is firmly assimilated. Understood in this way, Wales is seen as an aesthetic and exotic possession of the queen, rather than a devolved and distinct cultural and political entity. It is portrayed as prepared to be explored and gazed at, whilst remaining passive as well as voiceless. Although it resembles a 'distant, exotic colony', it is still nearby and easily reachable, thus offering the tourist, in Katie Gramich's words, 'accessible otherness'.968

It is noticeable that the paragraph quoted above only features in the Petit futé guide to Great Britain and is not included in the series' volume solely dealing with Wales. Even though most of the Wales chapter in the Petit futé to Great Britain corresponds to sections from the Wales edition, the authors apparently thought the passage quoted above would be a suitable addition to the former. Here, we therefore see a discrepancy in the way Wales is regarded individually and in combination with the other parts of Great Britain. In the Petit futé to Great Britain, the exoticisation of Wales is much more emphatic, and especially the language is used to set Wales apart from the rest of the state: '[C]'est d'abord elle [la langue] qui vous fera pénétrer un

966 Auzias and Labourdette, Grande-Bretagne, p. 448.

${ }^{967}$ See, for example: Paul Scott, The Jewel in the Crown (London: Panther, 1977).

968 Katie Gramich, "Evvery Hill has its History, Every Region its Romance”: Travellers' Constructions of Wales, 1844-1913', in Travel Writing and Tourism in Britain and Ireland, ed. by Benjamin Colbert (Basingstoke: Palgrave Macmillan, 2012), pp. 147-63 (p. 147). 
monde aux consonances étranges, voire étrangères' [It is first of all this [the language] that will open up a world for you of strange, or even foreign sounds]. ${ }^{969}$ The language is thus seen as the most evident aspect of Wales's distinctiveness; it functions as a portal to a different, foreign world even though the country is situated within the topographical borders of Great Britain. In the Petit fute to Wales, which will shortly be discussed in more detail, the country is exoticised to a much lesser degree. It can therefore be argued that it is the combination in the guidebook of Wales and the other parts of Great Britain that leads to the apparent need to establish Wales as an other, a 'foreign' part within the state, even designating it as a 'colony'. As a result, a sense of otherness is achieved, whilst keeping Wales integrated within the borders of the UK.

The Michelin vert guidebook, which also discusses the whole of Great Britain, differs significantly in this respect. As was noted before, the 1997 edition of this guide lists Welsh sites amongst those located in other parts of the country without any sign of cultural nor topographical distinctiveness, although it must be added that later editions do have a separate Wales chapter. The most probable explanation for this disparity between the Petit futé and the Michelin vert series is their different target audience. Whereas the Michelin vert is particularly directed towards the educated middle class (though no longer exclusively car drivers), the Petit futé is written for the same kind of backpacker tourist as is targeted by guides such as the Lonely Planet and the Guide du routard. It could be asserted that the readers of these latter series are more open to cultural differences within countries than the audience of the Michelin vert, who might be primarily interested in the aesthetic qualities rather than the social dynamics of their travel destination.

To come back to the description of Wales as a colony, it is noticeable that this is a recurring theme throughout the French guides, although most use it as a way of describing Wales as an oppressed and ransacked country rather than a possession of the crown. Wales is for example described as historically 'opprimé, possédé par de grands seigneurs anglais, sans droit ni justice pour la population locale' [oppressed, possessed by great English lords, with neither rights nor justice for the local population]. ${ }^{970}$ The reader is informed that these Englishmen came to Wales attracted

\footnotetext{
${ }^{969}$ Auzias and Labourdette, Grande-Bretagne, p. 448.

${ }^{970}$ Brisou-Nowik, En Angleterre et au pays de Galles, p. 162.
} 
by the rich mineral resources that they wanted to exploit. ${ }^{971}$ The English exploitation of Wales during the Industrial Revolution is also underlined, when Wales allegedly became 'une source inépuisable de richesse pour la Grande-Bretagne' [an inexhaustible source of wealth for Great Britain]. ${ }^{972}$ These quotations evoke the image of Wales as a colonised area, whose resources have been used by the English for their own gain. Due to this image, it might not be surprising that the guides show a significant amount of interest in Wales's industrial past. The Guide Visa, for example, includes a two-page-long section about 'Les vallées industrielles' [The Industrial Valleys], in which the industrialisation of Wales is described, whilst focusing on the terrible living and working conditions of the miners:

Les ouvriers entassés dans des maisons construites les unes sur les autres souffrent de la pollution de l'eau et d'une hygiène déplorable; typhus, typhoïde, choléra, mortalité infantile, heures de travail d'une longeur inhumaine, accidents au fond de la mine déciment les populations. Le salaire, payé en jetons, n'est pas dépensable que dans les magasins des compagnies. ${ }^{973}$

[The workers were crowded in houses built on top of each other, suffering water pollution and poor hygiene; typhus, typhoid, cholera, infant mortality, inhumanly long working hours, accidents at the bottom of the mine decimated the population. The salary, paid in tokens, could only be spent in the company's shops.]

This extreme, albeit accurate, description of life in the industrialised Welsh Valleys contributes to the image of Wales as a plundered and oppressed colony. The guide highlights that these conditions led to fierce protests by the workers against the ruling classes, and although their circumstances gradually improved, it is asserted that Wales is still a deprived area with a high percentage of unemployment. ${ }^{974}$

This interest in the social history of Wales and the fate of the working classes has been a recurring theme throughout the French-language guidebooks to Wales from the nineteenth century onwards. Overall, these texts show a greater engagement with the socio-historical situation in Wales than the other two languages do. It could be suggested that this is the result of France's own historical developments, in which the struggle between the working and ruling classes has occupied a central place. This reinforces the assertion that the French guides show a greater continuity in their

\footnotetext{
${ }^{971}$ Brisou-Nowik, En Angleterre et au pays de Galles, p. 161.

972 Auzias and Labourdette, Pays de Galles (2008), p. 33; see also: Peyri, p. 31.

${ }^{973}$ Brisou-Nowik, En Angleterre et au pays de Galles, p. 172.

${ }^{974}$ Brisou-Nowik, En Angleterre et au pays de Galles, pp. 172-3. For similar descriptions of Wales's industrial past, see: Auzias and Labourdette, Pays de Galles (2008), p. 36.
} 
representation of Wales than for example the German-language guidebooks, in which the country's conceptualisation passes through some significant changes. It is furthermore noticeable that only the French-language guidebooks use a colonial discourse to conceptualise Wales and its relationship with England. A plausible explanation for this is that the French have themselves engaged with their postcolonial heritage for decades, and the struggle regarding this legacy has been part of French public discourse. ${ }^{975}$ Moreover, France has its own minoritised Celtic nation, Brittany, which has long been viewed through a colonial prism, even though this has only recently been acknowledged by postcolonial studies. ${ }^{976}$ In the 1960s and 1970s, Bretons were also starting to describe themselves from a postcolonial perspective. ${ }^{977}$ It could therefore be argued that in France, the public is already used to the idea of a postcolonial Celtic other, and this point of view is used to conceptualise Wales in a familiar, relatable way. This is obviously not the case for the Dutch- and Germanlanguage material. These societies do not have a postcolonial Celtic other on which they can base their conceptualisations of Wales. Moreover, Germany and the Netherlands have only fairly recently started to come to terms with their colonial heritage. In the case of Germany, scholars have even used the term Amnesie [amnesia] to describe the postcolonial memory in the public, collective memory. ${ }^{978}$ In the Netherlands, it has been said that the debate pertaining to Dutch postcolonial history is still primarily concerned with shame and nostalgia. ${ }^{979}$ In short, the

\footnotetext{
975 Emile Chabal, 'Whose Postcolonialism? The French and their Colonial Past', $<$ https://moderncontemporarybham.wordpress.com/2015/10/05/whose-postcolonialism-the-frenchand-their-colonial-past/\#_ftn1> [accessed 4 May 2017]. Although it has been argued that the postcolonial debate has been largely absent in France's academic discourse, Chabal asserts that this can be explained by the fact that the French, unlike the British, deal with their post-colonial history from a political and governmental point of view, rather that a social and literary theory perspective. Cf.: Charles Forsdick and David Murphy, 'Introduction: The Case for Francophone Postcolonial Studies', in Francophone Postcolonial Studies: A Critical Introduction, ed. by Charles Forsdick and David Murphy (London: Hodder Education, 2003), pp. 1-17 (pp. 7-8).

976 See: Williams, Postcolonial Brittany, pp. 17-18.

977 Williams, Postcolonial Brittany, p. 18.

${ }^{978}$ Reinhart Kössler, 'Kolonialherrschaft: Auch eine deutsche Vergangenheit', in Kolonialismus und Erinnerungskultur: Die Kolonialvergangenheit im kollektiven Gedächtnis der deutschen und niederländischen Einwanderungsgesellschaft, ed. by Helma Lutz and Kathrin Gawarecki (Münster: Waxmann, 2005), pp. 23-40 (p. 23); Lora Wildenthal, "Notes on a History of "Imperial Turns" in Modern Germany', in After the Imperial Turn: Thinking with and through the Nation, ed. by Antoinette Burton (Durham, NC: Duke University Press, 2003), pp. 144-56 (p. 145).

${ }^{979}$ Alice Smits, 'Niet willen weten: Nederland in postkoloniaal perspectief', Metropolis M, 5 (2011) $<$ http://framerframed.nl/nl/dossier/niet-willen-weten-nederland-in-postkoloniaal-perspectief/> [accessed 27 April 2017].
} 
postcolonial view is not an inherent part of German and Dutch identity and is therefore not used in relation to Wales either.

Arising from this portrayal of Wales as a colonised and plundered country, devolution is repeatedly described as the beginning of the end of English oppression, thus highlighting it as a significant catalyst for change in Wales. In the Guides Marcus guidebook, devolution is considered to have freed Wales and Scotland from English domination, which unfortunately still weighs heavy on Northern Ireland. The guide subsequently adds that after having been exploited by England for a long time, Wales is now slowly regaining its economic, as well as emotional balance. ${ }^{980}$ Devolution is therefore seen as the end of English dominance, the beginning of Welsh freedom and the moment that the Welsh 'commencent enfin à prendre en main leur destin' [finally start to take control of their destiny]. ${ }^{981}$ Within this perception of devolution as having 'liberated' Wales from English oppression, some guides define the period before the 1997 referendum as a time of a fierce lutte [struggle]. ${ }^{982}$ Like the contemporaneous German-language guidebooks, the perspective of the travellee is becoming increasingly important and evident. In the context of this asserted struggle, violent actions are seen as having brought about devolution. The Guides mondéos for example remarks in this respect: 'Des actes terroristes viendront renforcer les revendications nationalistes. Finalement, en 1997, un référendum est organisé: 50,3\% des Gallois se prononcent en faveur d'une Assemblée galloise' [Terrorist acts came to strengthen nationalist claims. Finally, in 1997, a referendum is organised: 50.3 per cent of the Welsh declare that they are in favour of a Welsh Assembly]. ${ }^{983}$ The Guide Marcus provides a similar image, describing the period before devolution as an era determined by the deliberate burning down of English holiday homes in Wales and the 'terrible' miners' strikes of the 1980s. ${ }^{984}$ These acts of violence correspond to the image of Wales as a subjugated colony that had to fight to regain its relative independence which was finally achieved after 1997. Devolution thus becomes a crucial turning point in the

\footnotetext{
980 Brisou-Nowik, Angleterre et pays de Galles, p. 14.

981 Auzias and Labourdette, Pays de Galles (2008), p. 36.

982 Auzias and Labourdette, Pays de Galles (2008), p. 38; Brisou-Nowik, En Angleterre et au pays de Galles, p. 161.

${ }^{983}$ Peyri, p. 27. Although viendront is a form of the future tense of the verb venir and could be translated with 'will come to', a future tense is used here to narrate an event that took place in the past, a grammatical construct which can be used in French. See: Monique L'Huillier, Advanced French Grammar (Cambridge: Cambridge University Press, 1999), p. 110.

${ }^{984}$ Brisou-Nowik, Angleterre et pays de Galles, p. 14.
} 
uneven relationship between the Welsh and the English, framed in terms of colonial rule and violent uprisings.

After the establishment of devolution, most French-language guidebooks devote a brief section to the political situation in Wales. ${ }^{985}$ This attention is only minimal compared to the German-language guidebooks from this period, but this can be explained by the fact that Wales is merely covered in one chapter in the Frenchlanguage guidebooks. This assertion is confirmed by the only single-volume guide to Wales, from the Petit futé series, which included a relatively large section about Welsh politics. It covers three pages and discusses the major political developments in Wales during the twentieth century, whilst describing the structure of the Welsh National Assembly and providing an overview of the political parties in Wales. ${ }^{986}$ The guide also describes the process of devolution within the framework of Welsh struggles against English domination, explaining the no-vote during the 1979 referendum as caused by the large number of English people in Wales who were not concerned with the survival of the Welsh language. The guide thus considers this group of English immigrants as solely responsible for the negative outcome of the referendum in that year. But, even after this defeat, the guide remarks, 'the struggle went on' ['la lutte continue']. ${ }^{987}$ This contrasts sharply with the explanations given by the Dutch guides, which frequently described the no-vote as an indication that Welsh nationalism was merely cultural and not territorial nor political. According to the Petit futé, it was the resurgence of the Welsh language and culture that led to the yes-vote in $1997 .{ }^{988}$ Devolution is therefore strongly associated with Welshness (it is also emphasised that Welsh speakers especially voted in favour of devolution) and the struggle against the English as well as anglicisation.

Resulting from this, the Petit futé identifies devolution as a momentous change for Wales which has significantly influenced its distinctiveness as a separate nation and political space:

Le pays de Galles est considéré comme une nation. [...] Au niveau politique, le pays de Galles possède sa propre Assemblée nationale depuis 1999. Elle est compétente dans de

\footnotetext{
985 See for example: Peyri, p. 27; Nadia Bosquès, Angleterre, pays de Galles, Michelin guide vert (Paris: Michelin cartes et guides, 2007), p. 107; Gloaguen, Angleterre, pays de Galles (2002), p. 665.

${ }^{986}$ Auzias and Labourdette, Pays de Galles (2008), pp. 37-39.

987 Auzias and Labourdette, Pays de Galles (2008), p. 38.

988 Auzias and Labourdette, Pays de Galles (2008), p. 36.
} 
nombreux domaines: agriculture, culture, industrie, santé publique, routes nationales, éducation. ${ }^{989}$

[Wales is considered a nation. [...] On a political level, Wales has its own National Assembly since 1999, which is responsible for various matters: agriculture, culture, industry, public health, national highways, education.]

The fact that Wales has its own Assembly and is responsible for its own internal political affairs thus contributes to the status of the country as a nation; the political distinctiveness of Wales and its national borders are gradually being recognised and reinforced. Other political changes are also highlighted as important milestones for Wales's transition into a nation. The proclamation of Cardiff as capital city is said to have contributed to the idea of Wales being 'un petite nation' [a small nation] ${ }^{990}$ and 1951, the year that the post of Minister of Welsh Affairs was created, is celebrated as 'une grande année pour le pays de Galles' [a great year for Wales], but that decade is also identified as the beginning of 'nombreuses reprises par des terroristes gallois' [numerous incidents by Welsh terrorists], thus again linking politicisation to violence. $^{991}$

The connection between 'Welsh terrorism' and devolution is frequently made in the French-language guidebooks from this period, and the image of the Welsh as a defiant people is thus something the French and German guidebooks have in common. However, the overall interpretation of this aspect of Welshness varies in the two languages. Whereas the German guidebooks portray the friction between the English and the Welsh as a matter of national character which contributes to Wales's charm and attractiveness as a distinct travel destination, the French guidebooks frequently associate the tension between the two nations with violence framed within a colonial discourse. The French represent Welsh violence as much more extreme, which does not necessarily add to the touristic appeal of the country as a quaint destination. These instances of terrorist aggression are detached from the general characterisation of Wales and the Welsh, and remain isolated cases.

Instead of the overall characterisation of the defiant underdog, the French guidebooks create an image of Wales as a country of abundant natural beauty

\footnotetext{
989 Auzias and Labourdette, Pays de Galles (2008), p. 11.

${ }^{990}$ Auzias and Labourdette, Pays de Galles (2008), p. 36.

${ }^{991}$ Auzias and Labourdette, Pays de Galles (2008), p. 38. The guide refers to the attacks that were carried out as acts of protest against the flooding of the Tryweryn Valley; a plan which had been passed by parliament in 1957 despite the fact that no Welsh MP had voted in favour. See: Davies, $A$ History of Wales, p. 640.
} 
inhabited by hospitable, friendly people. As a result, the political aspect of Wales and its people is moved to the margins of society. It can be asserted that in the Frenchlanguage guidebooks, the politicised Welsh space is a peripheral phenomenon rather than something mainstream that is inherently imbedded in the country and its people. A telling example is the concise introduction of Wales provided by the Guide $\mathrm{du}$ routard: 'Mer, montagnes et châteaux: voilà ce que vous trouverez au pays de Galles' [Sea, mountains and castles: that is what you will find in Wales]. ${ }^{992}$ In contrast to the German guidebooks, Welsh identity is not constructed through the idea of rebelliousness and what was termed the mentality of the defiant underdog. Instead, the French guidebooks stereotype the Welsh as 'un peuple joyeux' [a happy people] ${ }^{993}$ and 'conteurs, poètes, chanteurs, acteurs' [storytellers, poets, singers, actors] who will always answer the tourist with a smile. ${ }^{994}$ Music, myths and rugby are regarded as the centre of Welsh life. ${ }^{995}$ In addition, the assumed hospitality of the inhabitants of Wales is praised, as well as their sense of humour and love of good food and drink. ${ }^{996}$ Resulting from this, the Welsh are turned into innocuous and good-humoured objects of the tourist gaze, and the tourist is reassured; even though the Welsh have committed acts of violence within the perceived framework of colonialisation and oppression, these acts were directly aimed at the English and were exceptions rather than inherent to the Welsh character. Rebelliousness is not part of the general characterisation of the Welsh (as was the case in the Germanlanguage guidebooks) and the traveller has therefore nothing to fear.

\subsubsection{The Modern Side of Wales}

Defiance and obstinacy are not regarded as defining character traits of Wales's inhabitants, and Wales is therefore not seen as opposed to globalisation and modernisation as a matter of principle, as was the case in the German-language guidebooks. However, even though Wales is not depicted as openly anti-modern, its modern side is not highlighted either. By focussing on Wales as a land of Celtic myths, legends and male voice choirs, the country is not brought into the twenty-first

\footnotetext{
992 Gloaguen, Angleterre, pays de Galles (2002), p. 664.

${ }^{993}$ Peyri, p. 104.

${ }^{994}$ Gloaguen, Angleterre, pays de Galles (2002), pp. 670, 711.

995 Gloaguen, Angleterre, pays de Galles (2002), p. 671; Peyri pp. 96, 103-4.

996 Auzias and Labourdette, Pays de Galles (2008), pp. 25, 44; see also: Brisou-Nowik, Angleterre et pays de Galles, p. 14.
} 
century. Overall, the guides tend to concentrate on Wales's past, especially the Edwardian conquest and the Industrial Revolution, and its mountainous landscape which is frequently connected to the Arthurian legends. ${ }^{997}$ In comparison to the German-language guidebooks from this period, which did not significantly highlight the modern side of Wales either, most French-language guides ignore it altogether.

Only a few guidebook series take Wales into the present-day; the Michelin vert, the Guide du routard and the Petit futé. Like the German-language guidebooks from this period, the modern face of Wales is primarily spatialised in the two largest cities of Wales; Cardiff and Swansea. ${ }^{998}$ The changing evaluation of Cardiff before and after the establishment of devolution is particularly illuminating in this respect. Whereas the 1993 Michelin vert edition presents Cardiff with quite a lukewarm appraisal, giving it only one star out of three, the renewed 2007 edition gives it a top score of three stars, whilst stating that the modern and renovated city of Cardiff will take visitors by surprise. ${ }^{999}$ The Guide du routard shows a similar reappraisal of Cardiff during the years following the 1997 devolution referendum. In the 2002 edition, the description of Cardiff has been considerably expanded whilst highlighting the modernity and national importance of the city: 'Depuis quelque temps, Cardiff s'affirme. Elle n'est plus cette ville moyenne de Grande-Bretagne, elle devient capitale d'une nation. Le changement, est visible partout; la ville est devenue jeune et attirante' [Recently, Cardiff has been asserting itself. It is no longer that average British town, it is becoming the capital of a nation. This change is visible everywhere; the city has become young and attractive]. ${ }^{1000}$ Although this changing evaluation of Cardiff cannot be directly linked to the introduction of devolution, it is noticeable that the city is asserted to have gone through a positive change 'recently' whilst it has become 'the capital of a nation', and it could thus be argued that devolution and the modernisation of Cardiff are regarded as connected developments. Moreover, Cardiff Bay has by now been given its own separate entry, praising it as the 'vitrine technologique et culturelle du pays de Galles'

\footnotetext{
997 Peyri, p. 103; Auzias and Labourdette, Pays de Galles (2008), p. 17.

998 Bosquès, pp. 568, 602; Auzias and Labourdette, Pays de Galles (2008), pp. 78-79, 139; Gloaguen, Angleterre, pays de Galles (2002), pp. 682, 692.

${ }^{999}$ Manufacture française des pneumatiques Michelin, Grande-Bretagne, Michelin vert: guide du tourisme (Paris: Pneu Michelin, 1993), p. 87; Bosquès, p. 568.

${ }^{1000}$ Gloaguen, Angleterre, pays de Galles (2002), p. 682.
} 
[technological and cultural showcase of Wales] ${ }^{1001}$ and linking it to the commencement of Wales as a modern nation.

As the Petit futé is the only original French series that has published a singlevolume guidebook to Wales in the period under examination, it is justifiable to examine this guide in more detail. The quotations and descriptions in the previous sections of this chapter have shown that this guide, like the others, tends to focus on Wales as a Celtic, unthreatening other, a land of Arthurian legends and smiling inhabitants. However, a fair amount of attention is also given to the modern side of Wales. Being a single-volume guidebook to Wales enables it to be more detailed, and to describe the country from multiple angles and points of view. In addition to the focus on the country's rich heritage (primarily castles and industrial sites), Celtic culture and varied natural landscapes, this guide seems to depict Welshness in a similar way to the German guides: in opposition to Englishness. The animosity between the two people is highlighted frequently, and the attitude of the Welsh towards the English is summarised as follows:

Ennemi juré des Gallois, tout ce qui vient d'Angleterre est méprisé, voire, dans certains cas, haï. Les Gallois fonctionnent selon un postulat assez simple:

- Les Anglais sont X, donc nous ne sommes pas X.

- Les Anglais aiment Y, donc nous n'aimons pas Y.

- Les Anglais détestent Z, donc nous aimons Z. ${ }^{1002}$

[Sworn enemy of the Welsh, anything that comes from England is scorned, sometimes even hated. The Welsh operate on a fairly simple premise:

- The English are X, therefore we are not X.

- The English love Y, therefore we do not love Y.

- The English hate Z, therefore we love Z.]

The differences between the Welsh and the English are thus emphasised and this simplistic Welsh-English opposition is repeated throughout the guide as a leitmotif. ${ }^{1003}$ It is noticeable that the only single-volume French-language guidebook to Wales has apparently felt the need to construct Wales and Welshness in opposition to England and Englishness, similarly to the German-language guidebooks from this period. It could be asserted that this tendency is elicited by the fact that Wales is

${ }^{1001}$ Gloaguen, Angleterre, pays de Galles (2002), p. 690.

1002 Auzias and Labourdette, Pays de Galles (2008), p. 24. Emphasis in original.

1003 See, for example: Auzias and Labourdette, Pays de Galles (2008), pp. 26, 33, 39, 42, 44. 
discussed separately. Perhaps the Petit futé found it necessary to construct Wales in opposition to something else, because it was feared that readers would otherwise not have the means to conceptualise the country as a distinctive entity. In the guides that discuss England and Wales together, focussing on the relative integrality of the UK might be considered more desirable.

The Petit futé bases the opposition of Welshness and Englishness on various aspects, such as the language, culture, descent and national character. However, the process of contrasting the Welsh with the English does not, as was the case in the German guides, lead to the portrayal of the Welsh as a rebellious people averse to modernity and globalisation. According to the Petit futé guide, the contemporary attitude in Wales is pro-European Union and most Welsh would be in favour of extending the powers of Brussels. ${ }^{1004}$ This is in contrast to the English, who are said to be generally opposed to the European Union: 'Les Gallois restent beaucoup plus pro-européens que leurs voisins anglais: il est en effet dans leur intérêt que Londres perde de son pouvoir en faveur de Bruxelles!' [The Welsh remain much more proEuropean than their English neighbours: it is in their interest that London loses its power in favour of Brussels!]. ${ }^{1005}$ The guide stresses that the Welsh economy has benefitted from modern European infrastructure, due to which foreign companies have been able to settle in Wales, providing work for the local population. ${ }^{1006}$ In this guide, Wales is thus represented as turning towards globalisation and more European collaboration, whereas England is regarded as having an anti-European attitude. In other words, the Welsh welcome globalisation whilst the English are represented as resisting international collaboration, thus becoming the recluses. This interpretation of Wales can only be found in the Petit futé guidebook, and this is therefore an exceptional, yet illuminating, view of Wales in the French-language guides from this period. Firstly, it could be contended that this is due to the fact that it is the only single-volume French-language guidebook to Wales; the Petit futé has the space to highlight various sides of Wales. Secondly, the guide is primarily directed towards younger travellers on a budget, who might be more interested in the political, rather than solely the aesthetic landscape of the country they are visiting. Nevertheless, this

\footnotetext{
${ }^{1004}$ It is of course highly ironic in this respect that the majority of the electorate in Wales (52\%) voted in favour of Brexit in June 2016.

1005 Auzias and Labourdette, Pays de Galles (2008), p. 39.

1006 Auzias and Labourdette, Pays de Galles (2008), pp. 39-40.
} 
does not explain the difference between the general German view of Wales as having an aversion to modernisation, and this French view of Wales turning towards globalisation. Perhaps the Petit futé considers its readership to be more politically engaged than is the case for the German-language guidebooks.

Another important difference between the German and French views of modern Wales is that even though they both locate it in Cardiff and Swansea, the French guidebooks do not regard these cities to be un-Welsh. The Petit futé even designates Cardiff as explicitly Welsh: '[O]n y est gallois et fier de l'être, on cultive ses traditions tout en s'adaptant au modernisme' [the people here are Welsh and are proud of it, they cultivate their traditions whilst adapting to modernity]. ${ }^{1007}$ Cardiff and its associated modernity are therefore not, as was the case in the German guides, rejected as non-Welsh, but are seen as directly connected to the nation and its identity.

\subsection{Concluding Remarks}

Overall, Wales has become more visible as a tourist destination and political entity in Continental guidebooks since the end of the twentieth century. Chapters about the country have been extended, single-volume guidebooks published and sections about Welsh politics added. Although conclusive proof cannot be presented, it can be stated with relative certainty that this growing awareness is related to Wales's devolved status and growing profile as a distinct country within the UK. Practically every French, German and Dutch guide devotes a few lines or a whole paragraph to the Welsh referendum in 1997 and to the establishment of the Welsh Assembly, including details about the percentage of the population that voted in favour of devolution, the turnout at the referendum and the political parties active in the Assembly. The fact that this information is included shows that these political events are regarded as noteworthy, and that the guides' editors find it necessary to inform the tourist in this respect.

Nevertheless, Wales remains described as an other in comparison to England, and its relationship with its eastern neighbour is a central theme throughout the guides, even though this is assessed differently in the various languages. To

1007 Auzias and Labourdette, Pays de Galles (2008), p. 79. 
summarise very briefly, it was argued that the German guides primarily depict Wales as the fierce underdog in relation to the supposedly malevolent England, the French guides represent Wales as a colonised yet innocuous country whilst in the Dutch material Wales is portrayed as the quaint Principality, emphasising the country's bond with England and its integrality within the UK, particularly in relation to the British monarchy. In my view, these rather striking differences in representation should be seen in light of the respective French, German and Dutch attitudes towards the existence of regional identities. The way in which regions with distinct cultural identities are generally valued within these countries seems to correspond to the guides' respective approaches to Wales as an ethnically, culturally and politically distinct area in Great Britain.

In Germany, being a federal state, the existence of multiple simultaneous identities is widely accepted. As Maiken Umbach asserts in her edited volume German Federalism: Past, Present, Future, federalism is a focal point in German national memory. It reconciles regional and national feelings of allegiance, thus allowing the existence of a plurality of identities. ${ }^{1008}$ Due to its belated unification in comparison to other European countries, the only way for Germany to become one state was to adopt a federal structure. Otto von Bismarck, the Prussian statesman who united the German Länder at the end of the nineteenth century, was aware of the fact that only by using such a structure would he achieve his goals. ${ }^{1009}$ Moreover, the concept of federalism and its openness to regionalism were used after World War II and German reunification in 1990 to evoke a positive sense of German belonging which lacked connotations of nationalist totalitarianism. ${ }^{1010}$ As a result, regional identities are generally acknowledged and widespread in Germany, and many Germans will first call themselves Bavarian or Saxon, and only then German. ${ }^{1011}$ It could then be asserted that in the German perspective, regional distinctiveness does not pose a threat to national coherence, and the representation of the Welsh as a clearly distinct and anti-English, yet not per se anti-British, people rather adds to the

\footnotetext{
${ }^{1008}$ Maiken Umbach, 'Introduction: German Federalism in Historical Perspective', in German Federalism: Past, Present, Future, ed. by Maiken Umbach (Basingstoke: Palgrave, 2002), pp. 1-14 (pp. 4-5).

${ }_{1009}$ Alon Confino, 'Federalism and the "Heimat" Idea in Imperial Germany', in German Federalism: Past, Present, Future, ed. by Maiken Umbach (Basingstoke: Palgrave, 2002), pp. $70-90$ (p. 72). ${ }^{1010}$ Umbach, p. 12.

${ }^{1011}$ John Newhouse, 'Europe's Rising Regionalism', Foreign Affairs (1997)

<https://www.foreignaffairs.com/articles/europe/1997-01-01/europes-rising-regionalism> [accessed 11 September 2015].
} 
country's attractiveness as a tourist destination. In the German view, regionalism and a diversity of identities are seen as cultural richness.

France, on the contrary, was one of the first European states that introduced a strongly centralised government and has therefore had a long tradition of state supremacy. In her article 'Debating Cultural Difference in France', Catherine Wihtol de Wenden traces the French approaches to cultural diversity and maintains that ever since the Third Republic, the French state has been 'an enterprise of national amalgamation blurring internal borders and [...] differences' ${ }^{1012}$ Even though regional identities are still celebrated locally, for example on Corsica and in Brittany, and the languages of these cultures are at times recognised and taught at school, ${ }^{1013}$ the state still denies the existence of a Corsican or Breton people. In the eyes of the state, there is only one people in France and that is the French. ${ }^{1014}$ The French ideal of 'one country, one people' and the assimilation of minority and regional identities into a national community, unified by shared values, continues to be prevalent. As Catherine Audard remarks:

To value diversity as such is perceived as a possible threat to national unity and to the values of equality and the neutrality of the state that, since the French Revolution, have been at the heart of what it means to be a French citizen and a democrat. ${ }^{1015}$

Malcolm Chapman also recognises a French unwillingness to celebrate diversity. He attributes this to the fact that since the Revolution, there has not been a stable French centre, with the state transitioning from absolute monarchy, empire, through five republics, and a Vichy government. Chapman concludes: 'In the concern of the centre with its own survival, there was no comfortable political space that a minority could occupy'. 1016

\footnotetext{
${ }^{1012}$ Catherine Wihtol de Wenden, 'Debating Cultural Difference in France', in The Construction of Minority Identities in France and Britain, ed. by Gino G. Raymond and Tariq Modood (Basingstoke: Palgrave Macmillan, 2007), pp. 48-58 (p. 50).

${ }^{1013}$ However, France has still not ratified the Charter for Regional and Minority Languages, which was adopted by the Council of Europe in 1992 to protect as well as promote lesser-used and endangered European languages. In comparison, the Netherlands ratified the charter in 1996 and Germany followed only two years later. See: <http://www.coe.int/de/web/conventions/full-list//conventions/treaty/148/signatures> [accessed 10 November 2015].

${ }^{1014}$ Wihtol de Wenden, pp. 51-52.

${ }^{1015}$ Catherine Audard, 'The French Republic and the Claims of Diversity', in Cultural Identity and the Nation-State, ed. by Carol C. Gould and Pasquale Pasquino (Lanham: Rowman \& Littlefield, 2001), pp. 85-108 (p. 85).

${ }^{1016}$ Chapman, The Celts, p. 134.
} 
Despite this deeply centralised French vision, tourism, as an important economic force, is generating a re-appreciation of diversity. In order to stimulate regional tourism, internal cultural differences in France are being celebrated and emphasised in order to distinguish tourist regions and increase their attractiveness. ${ }^{1017}$ France's own Celtic minority, Brittany, is indeed a popular domestic tourist destination which is especially valued for its distinct culture. ${ }^{1018}$ The connection between Brittany and Wales could therefore be highlighted by some French-language guidebooks to increase the touristic attractiveness of Wales as a culturally interesting travel destination. However, it can be asserted that this otherness needs to remain unthreatening to the national identity of France. Cultural differences are only allowed and appreciated when they can be turned into tourist commodities. As such, they may be quaint and interesting, yet harmless objects of the tourist gaze. This appraisal of cultural differences corresponds to what has been argued about the French representation of Wales in the guidebooks during the turn of the twenty-first century.

In respect to the Netherlands, it has been asserted that they are one of the few countries in which the construction of a national identity actually preceded the creation of the state. Even during the time of the Dutch Republic (1581-1795), when the Netherlands were still a confederation of seven largely independent provinces, there was a strong sense of Dutch national identity although concurrent regional identities were also clearly apparent. ${ }^{1019}$ After the defeat of Napoleon, the Netherlands were politically constructed on the French centralist model. Whereas in France it was the existence of multiple languages and cultures that was considered a threat to the country's national coherence, ideological discord played a much more important role in the Netherlands where this led to verzuiling [pillarisation]: the segregation of society according to different religions or ideologies, rather than class or locality. ${ }^{1020}$ Daniël Broersma, however, points out in his study on regional consciousness in Groningen that pillarisation sometimes also led to a growing sense of local identity; this most noticeably happened in the Catholic provinces of Brabant

\footnotetext{
1017 Wihtol de Wenden, p. 52.

${ }^{1018}$ See: <http://www.bretagne.bzh/jcms/TF071112_5061/fr/tourisme> [accessed 11 September 2015].

1019 Pauline Meurs and others, Identificatie met Nederland (Amsterdam: Amsterdam University Press, 2007), p. 67.

${ }^{1020}$ Meurs and others, pp. 69-70.
} 
and Limburg, where religion was closely linked to the region. ${ }^{1021}$ Even though some religious or ethnical groups, such as the Frisians who also have their own language, felt a clear sense of regional belonging, they were nevertheless aware of the fact that they were Dutch. This awareness of a duality of identities is labelled by Broersma as the early twentieth-century Dutch ideal of 'eenheid in verscheidenheid' [unity in diversity]. ${ }^{1022}$ After World War II and the subsequent decline of pillarisation, internationality became an important aspect of Dutch national identity. In the Netherlands, regionalism is often associated with narrow-mindedness, since the focus of Dutch society now lies on looking across borders rather than focussing on them. ${ }^{1023}$ Nevertheless, as long as regional identities do not clash with a sense of Dutch belonging, they are socially acceptable.The representation of Wales as an apolitical and integral part of Great Britain (or even England) seems to mirror this Dutch stance on regionalism; Wales is regarded as a clearly different, yet politically unthreatening region which is firmly connected to England and Great Britain.

It is especially in the evaluation of Wales's political autonomy and cultural distinctiveness that the representations of the country differ in the German, French and Dutch guides. Nevertheless, however its relationship with England is described, this thesis contends that in all three languages Wales remains a minoritised country. It is only in its portrayal as other alongside or in contrast to England that Wales can be defined, thus making its relationship with its historically hegemonic neighbour the chief identifying feature of Wales. Without this, it seems, Wales cannot exist. An important recurring theme in this portrayal as a 'minoritised' country is Wales's supposed remoteness, both in time (as a country stuck in the past) and in space (as an isolated area).

If it is concluded that the representations of Wales in the various language guidebooks are influenced by prevailing views about regionalism, cultural diversity and the existence of plural identities, this raises questions about the role and influence of the guidebook author. Their individuality and authority cannot simply be disregarded. Philippe Gloaguen, founder of the Guide du routard series, is for example a native of Brittany, ${ }^{1024}$ and because of his background it may be expected

\footnotetext{
${ }^{1021}$ Daniël Broersma, Het wonderland achter de horizon: Groninger regionaal besef in nationaal verband 1903-1963 (Assen: Koninklijke Van Gorcum, 2005), p. 19.

1022 Broersma, p. 202.

${ }^{1023}$ Meurs and others, p. 80.

${ }^{1024}$ Rauch, p. 103.
} 
that his view of Wales, a Celtic sibling of his homeland, is portrayed differently. It could for example be assumed that more attention would be given to Wales's status as a 'minority' nation which it shares with Brittany. However, the analysis has shown that the representation of the Guide du routard does not differ structurally from the portrayals of Wales provided by other French guides. This could be explained by the fact that contemporary guidebooks are frequently written by teams, rather than by single authors. In the case of the Guide du routard, for example, Philippe Gloaguen is listed as 'directeur de collection et auteur' [collection's director and author], but the guides are actually written by a team of some twenty permanent staff members who are aided by more than eighty freelance travel writers. ${ }^{1025}$ Other popular series, such as the Petit futé, use a similar strategy for the production of their guidebooks. ${ }^{1026}$ This is what Foulke means when he asserts that contemporary guidebooks are 'manufactured rather than written'. ${ }^{1027}$ In these cases, personal viewpoints or the (un)conscious bias of individual authors are likely to be removed from the text during the process of collective editing and revising.

There are also guidebooks on the market that are clearly written by one or two specific authors, making these texts more idiosyncratic products than guidebooks that are compiled by editorial teams. The guidebook to Wales in the Reise KnowHow series is for example written by Britta Schulze-Thulin. She holds a doctorate in Welsh philology, and her expertise regarding Wales is emphasised in a separate section of the guide. ${ }^{1028}$ The names of the authors Bartho Hendriksen and Leo Platvoet are also clearly presented on the cover of the Odyssee guide to Wales, thus highlighting their authorial presence. Apart from these references to the authors, however, the expression of their individuality and authorial freedom appears to be decidedly restrained, as it is generally expected of guidebook authors to present the destination in a straightforward, uncritical manner whilst aiming for objectivity. ${ }^{1029}$

\footnotetext{
1025 See: 'La FAQ du Routard' <http://www.routard.com/planete_coulisse/page/faq.htm> [accessed 12 November 2015].

1026 See: 'Les atouts du Petit futé' <http://www.petitfute.com/information/societe.html> [accessed 12 November 2015].

${ }^{1027}$ Robert Foulke, 'The Guidebook Industry', in Temperamental Journeys: Essays on the Modern Literature of Travel, ed. by Michael Kowalewski (Athens: University of Georgia Press, 1992), pp. 93 108 (p. 93).

1028 Schulze-Thulin, Wales (2010), p. 407.

${ }^{1029}$ Dybiec, p. 69.
} 
Although this does not mean that personal preferences are omitted altogether, ${ }^{1030}$ it does imply that subjective views countering prevailing notions about a destination are exceptional in guidebooks. This is corroborated by the portrayals found in the various language guidebooks which present Wales in a largely unanimous manner.

Moreover, guidebook series are always written for a specific audience, and authors are expected to adjust the style and content of the guide accordingly. ${ }^{1031}$ The fact that target audiences can influence representations of the travel destination became clear in this chapter, especially for example in the differences between the Michelin guide vert and the Petit futé series. Whereas the latter is primarily directed towards middle-class travellers looking for aesthetic experiences, the Petit futé aims its guides specifically at the backpacker-type tourist who is perhaps more openly interested in political and cultural diversity within nation-states. Nevertheless, such evident differences in representation are the exception rather than the rule. In the analysis it has become clear that there are generally many similarities in the guidebooks' representations of Wales in the respective languages.

A striking illustration of this is the fundamental similarity between the representation of Wales in the DuMont and the Reise Know-How guidebook series, despite the fact that both guidebooks have different target audiences. The website for the former describes its intended readership as follows: 'Unsere Reiseführer sind nicht für Low Budget-Reisende konzipiert, wohl aber für Preisbewusste, die gelegentlich auch mal über die Stränge schlagen (möchten)' [Our guides are not written for low-budget but for price-conscious travellers, who occasionally also (want to) go wild]. ${ }^{1032}$ Moreover, the emphasis lies on art and culture, giving the series an "“Aura der Kultiviertheit"” ['cultivated aura']. This contrasts sharply with the intended readership of the Reise Know-How series which is clearly directed towards the tourist on a budget and which was established under similar circumstances as - for example - the Lonely Planet series (due to a lack of suitable guides, the founder decided to write his own). ${ }^{1033}$ Despite these very divergent target

\footnotetext{
${ }^{1030}$ Britta Schulze-Thulin, for example, shows a great interest in Celtic remains and prehistoric sites which feature abundantly in her guidebooks to Wales.

1031 See: Steinecke, pp. 18-22.

$1032<$ http://www.dumontreise.de/magazin/ueber-den-dumont-reiseverlag.html> [accessed 1 November 2016].

1033 <https://www.reise-know-how.de/verlag/ueber-uns-42799> [accessed 1 November 2016].
} 
audiences, the representation of Wales in the two series does not crucially differ from one another. 


\section{Conclusions}

Wales: according to Continental guidebooks an integral part of the British Empire, an industrialising frontrunner, the 'countryside of the English countryside', but also a secluded fairy-tale land inhabited by trolls, King Arthur and the Welsh, an ideal travel destination for yoga-practising counter-culturists. The representations of Wales and Welshness described in this thesis are wide-ranging, but consistent threads were nevertheless detected which will form the basis of this study's final conclusions. The aim of this thesis was to provide an in-depth comparative textual analysis of the perceptions of Wales and Welshness in French-, German- and Dutchlanguage guidebooks published between 1850 and 2013. In the analysis, the diachronic and cross-linguistic differences and developments were scrutinised, critically discussed, contextualised and interpreted. The research questions as formulated in the introduction of the thesis were: how is Wales spatially conceptualised in Continental guidebooks published during the period 1850 to 2013 ? Which borders, geographical as well as cultural, historical, ethnographic and linguistic, are constructed around Wales in the guides? In order to answer these questions, the analysis of the primary material was conducted within the framework of 'imaginative peripheries', primarily based on the work of Edward Said and Rob Shields, in which it was argued that guidebooks play a crucial role in the sociospatial conceptualisation of travel destinations.

The diverging translinguistic conceptualisations of Wales were frequently explained as reflections of the respective societies in which they were created, and had therefore more to do with transforming travel cultures on the Continental mainland than with internal changes in Wales in this period. Different target audiences influenced the representation of Wales to a certain degree, but overall the guidebooks of the respective languages constructed a largely comparable image of the country. It could therefore be argued that prevalent discourses concerning a topographical area affect its conceptualisation to a far more significant extent than the diverging target audiences of the texts. Due to this factor, guidebooks are illuminating sources when examining discursive formations. Whereas most literary travel writers view a certain destination from a personal and idiosyncratic point of 
view, guidebooks create as well as reflect stereotypes and reinforce existing beliefs. It is in their position as compact 'manuals' for seeing a destination that they are able to shed light on what Fendl and Löffler call 'die Wahrnehmungskultur der Herkunftsregion' [the perception-culture of the region of origin]. ${ }^{1034}$

The conceptualisation of Wales offered illuminating insights into the three Wahrnehmungskulturen examined. To name a few of the most remarkable distinctions; in the nineteenth century, many cultured middle-class travellers wanted to visit 'their future'. This was especially noticeable in the German-language guidebooks, which showed a keen interest in Wales's industrialisation. It was suggested that this was a result of Germany's own relatively belated industrialisation which triggered a curiosity concerning the industrial developments in other European countries. A recurring theme in the French-language guidebooks was their awareness of the social situation in Wales; the conditions of the working class were discussed and at times also criticised. This was arguably a result of France's history of class struggles and the ideal of egalité which rejected the class divisions within British society. Furthermore, France's relationship with its own Celtic other, Brittany, framed its conceptualisation of Wales as well. Celtic folklore, the connection between the Celtic languages, but also a familiarity with a colonial discourse to describe this internal difference, shimmered through the French representations of Wales. In the Dutch guidebooks, a positive stance towards their own monarchy was reflected in the fact that Wales was frequently imagined as having strong ties to the British royal family. Moreover, in Chapter 5 it was contended that general attitudes towards regionalism and cultural diversity considerably influenced the guidebooks' depictions of Wales and its relationship with England and Great Britain in all three languages.

The diachronic changes that were discovered in the analysis are perhaps even more illuminating than the cross-linguistic differences. In summary, it can be maintained that during the period under examination, Wales has increasingly been spatialised on the imaginative periphery. During the nineteenth century, Wales was frequently conceptualised as an integral part of an industrialising centre; in Wales the traveller could visit the future. The seed of a growing awareness of Wales as a

${ }^{1034}$ Elisabeth Fendl and Klara Löffler, "“Man sieht nur, was man weiß”: Zur Wahrnehmungskultur in Reiseführern', in Tourismus-Kultur Kultur-Tourism, ed. by Dieter Kramer and Ronald Lutz (Münster: LIT, 1993), pp. 55-77 (p. 56). 
disctinctive cultural entity was sown towards the end of this period and blossomed during the second half of the twentieth century. The idea of recuperation and getting away from urbanisation became increasingly important, and Wales was regarded as being able to offer this to the traveller. Reflecting the predilections of the changing travel cultures, the guidebooks started to conceptualise Wales on the imaginative periphery by highlighting the country's Celtic roots, its perceived otherness (primarily in relation to England), secluded geographical position and temporal remoteness. For the counter-cultural movements of the 1960s and 1970s, Wales, perceived as the oppressed peripheral underdog, seemed an excellent escape from the post-World War II consumer society. Towards the end of the twentieth century, Wales had become a more mainstream travel destination, and its otherness and Celticity were foregrounded less markedly than in some guidebooks published during the previous decades. However, its socio-cultural, geographical and temporal position on the imaginative periphery had by now permeated practically every Continental guidebook, and had thus become a vital component in the dominant discourse for Wales as a Continental travel destination. In other words; by the twenty-first century, Wales's position on the imaginative periphery has become firmly consolidated.

Concurrently, Wales has gained visibility as a travel destination. This is suggested by the fact that there has been a clear surge in the number of guidebook publications concerning Wales (see Figure 2) and that various guidebooks show an interest in the perspective of the travellee. Moreover, in these texts there is an increasing awareness of the country as a distinctive cultural, historical, linguistic and even political entity. The more Wales is placed on the imaginative periphery, the more visible the country becomes as a separate space. Resulting from these conclusions, the link between peripherality and invisibility or marginality needs to be revisited. In the introduction to this thesis, the work of Botterill and others was cited, in which peripherality was linked to invisibility and it was claimed that 'to be peripheral is to be marginalised' ${ }^{1035}$ However, during the course of the research at hand, it has become apparent that this link between peripherality and invisibility is not so straightforward. Paradoxically, it could even be asserted that peripherality causes visibility, instead of invisibility. At first sight, this might seem like a positive

${ }^{1035}$ Brown and Hall, p. 1. 
development for Wales, and it has indeed been claimed in other studies that peripherality can become a profitable tourist commodity and a key to touristic success. ${ }^{1036}$ The most recent Visit Wales campaign, 'Find your Epic', also highlights the peripherality of Wales as a secluded land of untamed nature and fairy tales, ${ }^{1037}$ and these characteristics must therefore be considered by this organisation as lucrative and beneficial for the attraction of visitors, both domestic and overseas. ${ }^{1038}$

Nevertheless, the desirability of the use of peripheralisation to increase visibility can be contested, as it might have far-reaching, unintentional consequences. Inherent to the construction of centres and peripheries is the existence and creation of borders; without borders no distinction can be made between centre and periphery. It is useful here to draw on Debbie Lisle's seminal work The Global Politics of Contemporary Travel Writing, in which she explores the political aspect of travel writing in our globalised society. Lisle contends that travel and travel writing need borders, as these are markers of difference and without difference travel writers would have nothing to write about. ${ }^{1039}$ She discusses two ways of constructing this difference. Firstly, there is a spatial dimension: 'national, cultural and civilisational differences are guaranteed by spatial difference, and the farther one travels away from home, the more significant these differences become'. ${ }^{1040}$ Although Lisle takes this spatial difference quite literally (the greater the distance from home, the more significant differences appear to be), it can be argued that this spatialisation can also be imaginative, as was illustrated in this thesis. Although Wales is topographically not far from the Continent, its spatial remoteness was constructed in the texts by highlighting its westerliness, its secluded position and its otherworldliness. Secondly, as Lisle points out, difference can also be constructed through temporalisation. ${ }^{1041}$ Not only is the travel destination described as spatially remote, it is also imagined as being in the past. This was also the case in the Continental representations of Wales,

\footnotetext{
1036 Kneafsey, p. 137.

${ }^{1037}$ See for example the 2017 TV advert for the 'Find your Epic' campaign: <http://www.visitwales.com/legends/tv-advert-2017> [accessed 4 May 2017].

${ }^{1038}$ See also the German website of Visit Wales, which tries to promote Wales by highlighting the country's magical qualities: '2017 feiern wir unser sagenhaftes Land, unsere Mythen und Legenden und unsere jahrhundertealte Geschichte' [In 2017, we celebrate our legendary land, our myths and legends and our age-old history], <http://www.visitwales.com/de> [accessed 4 May 2017]. Similar texts can be found on the French version of the website.

${ }^{1039}$ Debbie Lisle, The Global Politics of Contemporary Travel Writing (Cambridge: Cambridge University Press, 2006), pp. 9-10.

${ }^{1040}$ Lisle, p. 42.

${ }^{1041}$ Lisle, pp. 42-43.
} 
which described the country as quaint, old-fashioned and having an age-old cultural and linguistic tradition.

It can be asserted that the active construction of imagined borders and differences is particularly pressing in our age of globalisation. In a globalising world, places are more closely connected than ever before; most areas are linked through infrastructural networks, modern media can inform us about events taking place on the other side of the globe in mere seconds, and the internationalisation of enterprises has ineradicably changed our economic models. Due to this eradication of borders on a global scale, the role of and the need perceived by tourism to strengthen boundaries has only become more persistent, as it can be maintained that without them, the concept of travel would be obsolete. This is also noted by Lisle, who maintains that the construction of temporal and spatial difference is particularly pressing in the age of globalisation, as our 'linear understanding of temporality is constantly being threatened by the forces of globalisation'. ${ }^{1042}$ In other words, it seems that globalisation necessitates peripheralisation. In an era in which there are arguably no places left on Earth that have not been touched by humanity and the progress of time, the search for out-of-the-way places, both spatially and temporally, is more evident than ever before. In the words of Svetlana Boym, there is a 'global epidemic of nostalgia' in our contemporary post-modern society, which is characterised by 'a longing for continuity in a fragmented world'. ${ }^{1043}$ Driven by society's apparent need for peripheral areas, guidebooks create bordered spaces that offer us an escape from our own world; they become facilitators of our fantasies.

Following Lisle, it must be emphasised that borders, and the subsequent division of the world into centres and peripheries, are more than markers of difference; they also entail presuppositions of power. Drawing on post-colonial theories, Lisle discusses how borders and differences are often left unproblematised by travel writers, and are thus presented as natural and gradually become part of the dominant discourse. ${ }^{1044}$ As a result, uneven power dynamics are created, even when these differences are evaluated positively; the so-called 'cosmopolitan view' which Lisle juxtaposes to the 'colonial view'. According to Lisle, it is the cosmopolitan view, the positive evaluation of difference in travel writing, that is the most alarming,

\footnotetext{
1042 Lisle, p. 25.

1043 Svetlana Boym, The Future of Nostalgia (New York: Basic Books, 2001), p. xiv.

${ }^{1044}$ Lisle, pp. 12-13.
} 
as writers 'smuggle in equally judgemental accounts of otherness under the guise of equality, tolerance and respect for difference'. ${ }^{1045}$ Lisle argues that these positive views actually rearticulate colonial perspectives, and construct new global hegemonies, whilst pretending to celebrate differences.

Drawing on this line of thought, the gradual spatialisation of Wales on the imaginative periphery can be explained as reflecting, but also constructing, globally shifting power relationships. The Netherlands, Germany and France are three prominent players on the international economic market and, as part of the Western power block, have long dominated the world ideologically and economically. However, the hegemony of the West is slowly decreasing; its economic primacy is waning in favour of new emerging economies, such as Brazil, India and China, whilst its perceived ideological superiority, advocating secular democracy and industrial capitalism, is also increasingly questioned. This shift of power away from the West is accepted by many scholars, although there is no real consensus on the exact geographical distribution of future hegemony. ${ }^{1046}$ The awareness that the West has perhaps not emerged from globalisation as the great victor is gradually permeating society and can be seen as an important prerequisite for the growing appeal of populism in the Western world. ${ }^{1047}$ Political parties that advocate protectionism and isolationism are on the rise throughout Europe. ${ }^{1048}$ The outcomes of the Brexit referendum and the 2016 US election are the most evident examples of these tendencies. And even though the Dutch and French election results in 2017 have for now averted a political nationalistic dominance in these countries, ${ }^{1049}$ the

\footnotetext{
${ }^{1045}$ Lisle, p. 10. Italics in original.

1046 See: Charles Kupchan, No One's World: The West, the Rising Rest, and the Coming Global Turn (Oxford: Oxford University Press, 2012); Kishore Mahbubani, The New Asian Hemisphere: The Irresistible Shift of Global Power to the East (New York: Public Affairs, 2008); Martin Jacques, When China Rules the World: The End of the Western World and the Birth of a New Global Order (New York: Penguin, 2009); Ian Morris, Why the West Rules-For Now: The Patterns of History, and What They Reveal about the Future (New York: Farrar, Straus and Giroux, 2010).

${ }^{1047}$ See, for example: Duane Swank and Hans-Georg Betz, 'Globalization, the Welfare State and Right-Wing Populism in Western Europe’, Socio-Economic Review, 1 (2003), 215-45.

1048 John Wight, 'Across Europe Nationalism Is on the Rise', Huffington Post, 26 July 2014 <http://www.huffingtonpost.co.uk/john-wight/nationalism-europe_b_5393841.html> [accessed 1 May 2017]. This is also illustrated by the mottos of various populist campaigns which all convey the message that their respective countries should be put first again. For example; Republican Donald Trump's slogan 'Make America Great Again' and his repetitive use of the phrase 'America First', whilst UKIP leader Nigel Farage used the motto 'We Want Our Country Back' during the 2016 Brexit campaign. The official slogan of the Dutch populist Partij voor de Vrijheid party during the 2017 election campaign was also 'Nederland weer van ons' [The Netherlands Ours Again]. ${ }^{1049}$ Unfortunately, it was impossible to include the 2017 German election results which are due after this thesis is printed. However, it is certain that either the SPD or the CDU/CSU will become the
} 
rise of such Euro-sceptic, protectionist parties illustrates the overall tensions and anxieties experienced by many people in the Western world regarding globalisation and the disappearance of borders in the European Union.

Resulting from these frictions and concerns, there seems to be a growing need for the construction of an imaginative periphery. Secluded spaces, untouched by reality and modernity, which resist the 'madness of globalisation', ${ }^{1050}$ are becoming increasingly alluring. It could even be asserted that by constructing imaginative peripheries, societies are also attempting to strengthen their own centrality. By imagining a specific area, in this case Wales, as a utopian yet peripheral dream world, the centrality and (albeit imperfect) authenticity of the societies in which these images were constructed are consolidated. This brings us back to the Foucauldian conceptualisation of discourse, which underlies the work of Said and therefore also this thesis, which is based on the principle that knowledge constitutes power. Discourses are man-made and dominant discourses can become accepted as true forms of knowledge, thus creating and influencing relations of power between self and other. Through discourses, an other is created, but the self is also simultaneously endorsed and empowered whilst being spatialised as central and authoritative.

The assertion that guidebooks uphold 'old' power relations, as was argued in some studies discussed in Chapter 1, must consequently be revised. Although this contention can still be sustained, it must be added that guidebooks can also construct new power dynamics, playing an active, 'performative' role ${ }^{1051}$ in the conceptualisation of our contemporary society and the structuralisation of its relationships. In the guidebooks discussed in the above chapters, the relationship between Wales as a minoritised nation and England as a hegemonic centre was largely maintained on a textual level. As a result, the guides supported this old discourse of unbalanced authority. However, when the textual limitations of the guides are transcended, the impact of the guidebooks is arguably much more extensive. These texts could be read as constructing the relationship between the nation-states of France, Germany and the Netherlands and the stateless nation Wales,

\footnotetext{
largest party. According to the latest polls, the right-wing populist AfD can count on no more than nine per cent of the votes, which would nevertheless make it the third largest party in Germany <http://www.wahlrecht.de/umfragen/> [accessed 18 June 2017].

1050 Phrase borrowed from Tim Morgan's book Life after Growth: Tim Morgan, Life after Growth: How the Global Economy Really Works and Why 200 Years of Growth Are Over, 2nd edn (Hampshire: Harriman House, 2016).

${ }^{1051}$ See: Jack and Phipps, p. 283.
} 
creating new power relations. In other words, the minoritisation of Wales has shifted to a global level. In our post-colonial and globalising world, relationships of hegemony and unbalanced power dynamics have shifted and may have become less clear-cut and more oblique. Whilst peripheralisation initially seemed to be linked to a heightened awareness of Wales's distinctiveness and to the creation of a more visible profile of the country, it could ultimately be concluded that it reinforces the country's marginalisation and minoritisation. This thesis has thus exposed the ostensibly harmless discourse of imaginative peripheries as a powerful way of creating new imbalanced power relations in which Wales is once again minoritised.

Naturally, the conclusions drawn in this thesis are not definitive, and should be seen as incentives for future research. As the study at hand is a textual analysis, a first step to take its outcomes further is by examining reader responses to the guidebooks. As was discussed in the introduction, tourism surveys have indicated that many Continental visitors do not have a clear understanding of Wales. An emerging question, therefore, is how the responses to Wales differ between tourists that do and do not use guidebooks to frame their journeys. Such a study could be particularly useful for tourism organisations, for example Visit Wales, which could subsequently adjust their portrayal of the country in overseas campaigns. The conclusions of this thesis regarding peripheralisation and its consequences could also be taken into account by tourism and governmental organisations, as well as private businesses, when marketing Wales abroad.

Moreover, the spatialisation of our globalising world into imaginative centres and peripheries needs to be explored further. The framework of imaginative peripheries could function as a basis for future studies, examining the representation of other minoritised, stateless nations in guidebooks and travel writing. In relation to the research at hand, an investigation into the spatialisation of the Celtic siblings of Wales on the imaginative periphery could be illuminating in this respect. Are Scotland, Ireland and Brittany spatialised similarly? What differences can be detected between the construction of the imaginative periphery between these nations? Does the emphasis on Celticity evoke the same images of backwardness, seclusion and spirituality in the case of Ireland and Scotland, for example? Are all these countries reduced to a similar Celtic mix of picturesque nature and age-old tradition, or are they recognised as distinct cultural entities? An examination of pluricultural, -linguistic or -ethnic states such as Spain, Switzerland or former Yugoslavia 
investigating how such countries are and have been conceptualised in terms of centres and peripheries might also prove revealing in this respect.

The framework of imaginative peripheries could also be of interest to other academic fields, and is therefore not limited to travel writing studies or even literary and cultural studies. Tourism studies, for example, could benefit from it, particularly when investigating the popularisation of certain destinations, as well as the future developments of global tourism and their implications for the area in question as well as its inhabitants. The perception of travel destinations, but also their branding could be viewed from the prism of imaginative peripheries, which could alter the way in which smaller stateless nations are advertised as tourist destinations. Moreover, the framework could help our understanding of the uneven development of tourism in larger topographical areas, consequently also involving academic fields such as social geography and economics. It could furthermore be applied in research on uneven employment opportunities, infrastructural development and demographics.

The future of overseas tourism in post-Brexit Wales is uncertain. Although it has been argued that the decision to leave the European Union could have benefits for Welsh tourism, mainly due to the decreasing value of the pound which makes travelling to the UK financially attractive for visitors from the Continent, there are also threats facing the industry, as borders are being strengthened and travel regulations might become stricter. ${ }^{1052}$ Perhaps Prime Minister Theresa May's Freudian slip that the UK will 'lead the world in preventing tourism' will one day become true. ${ }^{1053}$ In any case, it is certain that Welsh overseas tourism is facing a period of change. Whilst borders are rapidly disappearing on a global scale, the UK, and thus also Wales, is attempting to re-erect its frontiers. It will be exciting to see how guidebooks will adjust to this process, and how this will affect the conceptualisation of centres and peripheries within the British Isles in relation to the Continent in the near future.

\footnotetext{
${ }^{1052}$ Dylan Jones-Evans, 'How Tourism Can Be a Shining Star in the Welsh Economy Post Brexit', WalesOnline, 5 May 2017 <http://www.walesonline.co.uk/business/business-opinion/how-tourismcan-shining-star-12991526> [accessed 21 July 2017].

${ }^{1053}$ Adam Bienkov, 'Theresa May Says She Wants Britain to "Lead the World in Preventing Tourism", Business Insider, 25 April 2017 <https://www.businessinsider.nl/theresa-may-in-walesbritain-to-lead-the-world-in-preventing-tourism-2017-4/?international=true\&r=UK> [accessed 21 July 2017].
} 


\section{Bibliography}

\section{Primary Material}

Auzias, Dominique, and Jean-Paul Labourdette, Grande-Bretagne, Petit futé, 6th edn (Paris: Nouvelles éditions de l'université, 2006)

— l'université, 2001)

— éditions de l'université, 2008)

Baedeker, Karl, Belgien: Handbuch für Reisende, nach eigener Anschauung und den besten Hülfsquellen bearbeitet, 5th edn (Koblenz: Karl Baedeker, 1854)

—, Grossbritannien: England (ausser London), Wales, Schottland und Irland, Baedeker Handbuch für Reisende, 3rd edn (Leipzig: Karl Baedeker, 1899)

— London nebst Ausflügen nach Süd-England, Wales und Schottland sowie Reiserouten vom Continent nach England, Baedeker Handbuch für Reisende, 2nd edn (Koblenz: Karl Baedeker, 1866)

— London nebst Ausflügen nach Süd-England, Wales und Schottland sowie Reiserouten vom Continent nach England, Baedeker Handbuch für Reisende, 7th edn (Leipzig: Karl Baedeker, 1881)

- London und seine Umgebung nebst Reiserouten vom Continent nach England und zurück, Baedeker Handbuch für Reisende (Koblenz: Karl Baedeker, 1862)

Bailhache, Jean, Grande-Bretagne, Petite planète (Paris: Éditions du Seuil, 1960) — Grande-Bretagne, Petite planète, 2nd edn (Paris: Éditions du Seuil, 1972) Bédarida, François, and Renée Bédarida, Nous partons pour la Grande-Bretagne, Nous partons (Vendôme: Presses universitaire de France, 1975) Berkien, Guus, Wales, Kosmos reisgidsen (Utrecht: Kosmos-Z\&K Uitgevers, 1996) —, Wales, Vitamine V reisgids (Utrecht: Kosmos-Z\&K Uitgevers, 2000) Bosquès, Nadia, Angleterre, pays de Galles, Michelin guide vert (Paris: Michelin cartes et guides, 2007) 
Bötig, Klaus, and Christiane Kohls, Wales: Geschichte, Stillkunde, Strecken- und Ortsbeschreibungen, Goldstadt-Reiseführer (Pforzheim: Goldstadtverlag, 1977)

Boulanger, Robert, Iles Britanniques: Angleterre et pays de Galles, Écosse, Irlande $d u$ Nord, Eire, Guides bleus (Paris: Hachette, 1964)

Brisou-Nowik, Abigaël, Angleterre et pays de Galles, Guides Marcus (Paris: Éditions Marcus, 2002)

_

Danse, Wim, and Guus Berkien, Midden-Engeland en Wales, ANWB reisgids gouden serie, 2nd edn (The Hague: ANWB, 2000)

Darcy, William, Nouveau guide général du voyageur: en Angleterre, en Écosse et en Irlande, Guides Garnier frères (Paris: Garnier frères, 1864)

Defoe, Daniel, A Tour through the Whole Island of Great Britain, ed. by Philip Furbank, Bob Owens and Anthony Coulson (Yale: Yale University Press, 1991)

De la Bourdonnais, A. Mahé, 'Le pays de Galles et Monmouth', in Voyage dans l'île de Man et le pays de Galles en 1890 avec des réflexions sur l'histoire des habitants: notes des voyages (Paris: Jeande, 1894), pp. 187-203

Driessen, Jan-Willem, Reishandboek Wales, Elmar reishandboeken (Rijswijk: Uitgeverij Elmar, 1994)

England und Wales, Grieben-Reiseführer (Munich: Karl Thiemig, 1965)

Erny, Alfred, 'Voyage dans le pays de Galles', Le Tour de Monde, 15 (1867), 25788

Esquiros, Alphonse, Itinéraire descriptif et historique de la Grande-Bretagne et de l'Irlande, Collection des Guides-Joanne (Paris: Hachette, 1865)

Friedrich, Hans Eberhard, Grossbritannien: Teil 1 -England/Wales, Sternfahrten (Opladen: Leske Verlag, 1961)

Fröhlich-Kretzschmar, Dorothea, Wales, Merian Live! (Munich: Gräfe und Unzer Verlag, 1996)

Gilpin, William, Observations on the River Wye, and Several Parts of South Wales, Etc. Relative Chiefly to Picturesque Beauty; Made in the Summer of the Year 1770 (London: R. Blamire, 1782) <http://archive.org/details/cu31924104096304> [accessed 15 April 2014] 
Gloaguen, Philippe, Angleterre, pays de Galles, Guide du routard (Paris: Hachette, 1996)

—

$\longrightarrow$, Grande-Bretagne, Irlande, Guide du routard (Paris: Hachette, 1982)

Gourdault, Jules, L'Europe pittoresque: Pays du nord (Paris: Hachette, 1892)

Halévy, Élisabeth, Iles Britanniques: Angleterre, pays de Galles, Écosse, Eire, Irlande du Nord, Guides bleus (Paris: Hachette, 1958)

Heller-Merricks, Carl, Grossbritannien: Illustriertes Touristen-Handbuch für Reisen und Ferien in Grossbritannien, Stauffacher-Reiseführer (Zürich: Stauffacher-Verlag, 1955)

Hendriksen, Bartho, and Leo Platvoet, Wales, Odyssee (Amsterdam: Babylon-De Geus, 1997)

— Wales, Odyssee (Amsterdam: Babylon-De Geus, 2000)

Hummel, Ben, Wales, ANWB: actief en anders (The Hague: ANWB, 1998)

Juling, Petra, Wales, DuMont Reise-Taschenbuch (Cologne: DuMont Buchverlag, 2000)

Juling, Petra, and Ulrich Berger, Wales, DuMont Reise-Taschenbuch, 2nd edn (Ostfildern: DuMont Reiseverlag, 2013)

Jürschik-Busbach, Birgit, and Peter Busbach, ARAF - Slow: Auf der Suche nach dem walisischen Herzschlag (Leverkusen: Drachenmond Verlag, 2012)

Krücker, Franz-Josef, Wales, Polyglott Reiseführer (Munich: Polyglott-Verlag, 1999)

Lajta, Hans, England mit Wales, Der große Polyglott (Munich: Polyglott-Verlag, 1971)

Lang, Théo, Grande-Bretagne, Nagel: encyclopédie de voyage (Geneva: Les éditions Nagel, 1975)

$\longrightarrow$, Grande-Bretagne et Irlande, Guides Nagel (Paris: Les éditions Nagel, 1953)

Le Goffic, Charles, 'Chez Taffy: quinze jours dans la Galles du sud', La Revue hebdomadaire, 5 (1901), 448-68, 22-50, 229-50, 369-95, 520-47

McLachlan, Gordon, The Rough Guide to Germany, 6th edn (London: Rough Guides, 2004)

Manufacture française des pneumatiques Michelin, Grande-Bretagne, Michelin vert: guide du tourisme (Paris: Pneu Michelin, 1993) 
$\longrightarrow$, Grande-Bretagne, Michelin vert: guide du tourisme, 2nd edn (Paris: Pneu Michelin, 1997)

Midden Engeland en Wales, ANWB reisgidsen voor het buitenland ([n.p.]: ANWB, 1975)

Muirhead, L. Russell, ed., Southern France with Corsica, The Blue Guides, 2nd edn (London: Ernest Benn Limited, 1954)

Murray, John, Hand-book for Travellers in France: Being a Guide to Normandy, Brittany; the River Loire, Seine, Rhône, and Garonne; the French Alps, Dauphiné, Provence, and the Pyrenees (London: Murray, 1843)

—_, A Handbook for Travellers in France: Being a Guide to Normandy, Brittany; the River Loire, Seine, Rhône, and Garonne; the French Alps, Dauphiné, Provence, and the Pyrenees; the Island of Corsica, \&c., \&c., \&c.; their Railways and Roads, 8th edn (London: Murray, 1861) -, A Handbookfor Travellers in North Wales, 2nd edn (London: Murray, 1864)

— - A Handbook for Travellers on the Continent: Being a Guide to Holland, Belgium, Prussia, Northern Germany, and the Rhine from Holland to Switzerland, 9th edn (London: Murray, 1853)

Nouveau guide à Londres, dans ses environs, en Angleterre, en Écosse, en Irlande, Bibliothèque du voyageur (Paris: Napoléon Chaix, 1862)

Peyri, Marianne, Angleterre et pays de Galles, Guides mondéos (Paris: Les éditions Comex, 2004)

Pierrard, Pierre, L'Angleterre, l'Écosse, le pays de Galles, l'Irlande du Nord, Monde et voyages (Paris: Larousse, 1968)

Ravenstein, Ernst Georg, London, England, Schottland und Irland, ed. by H.J.

Meyer, Meyers Reisebücher, 3rd edn (Leipzig: Bibliographisches Institut, 1876)

—, Reisehandbuch für London, England und Schottland, Meyers Reisebücher (Hildeburghausen: Bibliographisches Institut, 1870)

Reiswijzer voor Engeland, Wales en Schotland, ANWB reiswijzer voor het buitenland ([n.p.]: Kon. Ned. Toeristenbond A.N.W.B., 1957)

Richard, J.B., and Adolphe Joanne, Itinéraire descriptif et historique de la GrandeBretagne, Guides Richard (Paris: Éditeur des Guides-Richard, 1853) 
Richardson, Dan, The Rough Guide to Egypt (London: Rough Guides, 2013),

Google ebook

- The Rough Guide to Moscow, 5th edn (London: Rough Guides, 2009)

Schaedtler, Karin, Wales, Dominicus reeks (Haarlem: J.H. Gottmer, 1997)

Schmidt, Mark, Wales selbst entdecken, Regenbogen Reiseführer (Zürich: Klaus

Stromer, 1996)

Schulze-Thulin, Britta, Wales, Reise Know-How (Bielefeld: Peter Rump, 2004)

—, Wales, Reise Know-How, 4th edn (Bielefeld: Peter Rump, 2010)

Scott, Paul, The Jewel in the Crown (London: Panther, 1977)

Semsek, Günter, Frank Hecker and Katrin Hecker, Schottland, England, Wales:

Tiere und Pflanzen entdecken, Kosmos Naturreiseführer (Stuttgart: Kosmos, 2001)

Van der Molen-Meindersma, P. Walma, Wales, Kosmos reisgidsen (Amsterdam: Kosmos, 1978)

Van Egeraat, L., Gids voor noordelijk Engeland en Wales: ten noorden van Boston

- Leicester - Birmingham - Chester, Allert de Lange reisgidsen (Amsterdam:

Allert de Lange, 1960)

Voss-Gerling, Wilhelm, England und Wales, Bertelsmann Reiseführer (Gütersloh:

Bertelsmann, 1973)

Westphal, Uwe, Wales: Reisen mit Insider-Tips, Marco Polo (Ostfildern: Mairs

Geographischer Verlag, 1996)

— Wales: Reisen mit Insider-Tips, Marco Polo, 3rd edn (Ostfildern: Mairs

Geographischer Verlag, 2000)

\section{Secondary Material}

Aaron, Jane, and Chris Williams, Postcolonial Wales (Cardiff: University of Wales, 2005)

Adamson, David L., Class, Ideology and the Nation: A Theory of Welsh Nationalism (Cardiff: University of Wales Press, 1991)

Aitchison, Cara, Nicola E. Macleod and Stephen J. Shaw, Leisure and Tourism Landscapes: Social and Cultural Geographies (London: Routledge, 2000) 
Allen, Esther, "'Money and Little Red Books": Romanticism, Tourism and the Rise of the Guidebook', LIT, 7 (1996), 213-26

Anderson, Benedict, Imagined Communities: Reflections on the Origin and Spread of Nationalism (London: Verso, 1991)

Andrews, Malcolm, The Search for the Picturesque: Landscape Aesthetics and Tourism in Britain, 1760-1800 (Aldershot: Scolar Press, 1989)

Andsager, Julie, and Jolanta Drzewiecka, 'Desirability of Differences in Destinations', Annals of Tourism Research, 29 (2002), 401-21

Antonescu, Andreea, and Mathis Stock, 'Reconstructing the Globalisation of Tourism: A Geo-Historical Perspective', Annals of Tourism Research, 45 (2014), 77-88

Arnold, Matthew, On the Study of Celtic Literature (London: Smith, Elder and Company, 1867)

Ashbee, Jeremy A., Conwy Castle and Town Walls (Cardiff: Cadw Welsh Assembly Government, 2007)

Audard, Catherine, 'The French Republic and the Claims of Diversity', in Cultural Identity and the Nation-State, ed. by Carol C. Gould and Pasquale Pasquino (Lanham: Rowman \& Littlefield, 2001), pp. 85-108

Bagwell, Philip S., The Transport Revolution from 1770 (London: Batsford, 1974) Balsom, Denis, 'The Three Wales Model', in The National Question Again: Welsh Political Identity in the 1980s, ed. by John Osmond (Llandysul: Gomer, 1985), pp. 1-17

Barrie, Derek S. M., South Wales, ed. by David St John Thomas and J. Allan Patmore, A Regional History of the Railways of Great Britain, 12 (Newton Abbot: David \& Charles, 1980)

Barry, Sion, 'Wales' Financial Services Sector is the Fastest Growing in the UK', WalesOnline, 29 January 2016 <http://www.walesonline.co.uk/business/business-news/wales-financialservices-sector-fastest-10808675> [accessed 16 March 2016]

Barthes, Roland, 'Le "Guide Bleu", in Mythologies, by Roland Barthes (Paris: Éditions du Seuil, 1957), pp. 113-7

Baughan, Peter E., North and Mid Wales, ed. by David St John Thomas and J. Allan Patmore, A Regional History of the Railways of Great Britain, 11 (Newton Abbot: David \& Charles, 1980) 
Baumgartner, Karin, 'Travel, Tourism, and Cultural Identity in Mariana Starke's "Letters from Italy" (1800) and Goethe's "Italienische Reise” (1816-17)', Publications of the English Goethe Society, 83 (2014), 177-95

Beaudry, Paul, and Franck Portier, 'The French Depression in the 1930s', Review of Economic Dynamics, 5 (2002), 73-99

Beller, Manfred, 'Perception, Image, Imagology', in Imagology: The Cultural Construction and Literary Representation of National Characters - a Critical Survey, ed. by Manfred Beller and Joseph Leerssen (Amsterdam: Rodopi, 2007), pp. 3-16

Bender, Jennifer, Bob Gidlow and David Fischer, 'National Stereotypes in Tourist Guidebooks: An Analysis of Auto- and Hetero-Stereotypes in Different Language Guidebooks about Switzerland', Annals of Tourism Research, 40 (2013), 331-51

Bergman, Bosse, 'Guides to a Geography of Tourism', Belgeo, 3 (2012), 1-12 <http://belgeo.revues.org/7176> [accessed 3 July 2015]

Bhattacharyya, Deborah, 'Mediating India: An Analysis of a Guidebook', Annals of Tourism Research, 24 (1997), 371-89

Bienkov, Adam, 'Theresa May Says She Wants Britain to "Lead the World in Preventing Tourism"”, Business Insider, 25 April 2017 <https://www.businessinsider.nl/theresa-may-in-wales-britain-to-lead-theworld-in-preventing-tourism-2017-4/?international=true\&r=UK> [accessed 21 July 2017]

Bishton-Hemingray, Tamsin, 'Are Mobile Travel Apps a Bit Crap?', Travelblather (2011) <http://www.travelblather.com/2011/11/mobile-travel-appsreview.html> [accessed 18 March 2016]

Black, Jeremy, The British Abroad: The Grand Tour in the Eighteenth Century (Bridgend: Sutton Publishing, 2003)

Blunt, Alison, Travel, Gender and Imperialism: Mary Kingsley and West Africa (New York: Guilford Press, 1995)

Blunt, Alison, and Gillian Rose, ed., Writing Women and Space: Colonial and Postcolonial Geographies (New York: Guilford Press, 1994)

Bohata, Kirsti, Postcolonialism Revisited (Cardiff: University of Wales Press, 2004) Bonney, Nathalie, 'Smartphone vs. Guidebook: Which Works Better Abroad?', Good Housekeeping (2015) <http://www.goodhousekeeping.co.uk/consumer- 
advice/technology-made-easy/smartphone-vs-guidebook-which-works-betterabroad> [accessed 18 March 2016]

Boorstin, Daniel, The Image or What Happened to the American Dream (Harmondsworth: Penguin Books, 1963)

Botterill, David, Nicola Foster and others, 'Perceptions from the Periphery: The Experience of Wales', in Tourism in Peripheral Areas: Case Studies, ed. by Frances Brown and Derek Hall, Aspects of Tourism, 2 (Clevedon: Channel View Publications, 2000), pp. 7-38

Bowman, Marion, 'The Commodification of the Celt: New Age/Neo-Pagan Consumerism', in The Marketing of Tradition: Perspectives on Folklore, Tourism and the Heritage Industry, ed. by Teri Brewer, Folklore in Use: Applications in the Real World, 2 (Enfield: Hisarlik, 1994), pp. 143-52

— by Amy Hale and Philip Payton (Exeter: University of Exeter Press, 2000), pp. 69-91

Boym, Svetlana, The Future of Nostalgia (New York: Basic Books, 2001)

Bradbury, Jonathan, and Rhys Andrews, 'State Devolution and National Identity: Continuity and Change in the Politics of Welshness and Britishness in Wales', Parliamentary Affairs, 63 (2010), 229-49

Bradley, Margaret, and Fernand Perrin, 'Charles Dupin's Study Visits to the British Isles, 1816-1824', Technology and Culture, 32 (1991), 47-68

Bravo, Michael T., 'Precision and Curiosity in Scientific Travel: James Rennell and the Orientalist Geography of the New Imperial Age (1760-1830)', in Voyages and Visions: Towards a Cultural History of Travel, ed. by Jas Elsner and JoanPau Rubiés (London: Reaktion, 1999), pp. 162-83

Brennan, Emily, 'A Lonely Planet Founder Looks Back', New York Times, 7 June 2013 <http://www.nytimes.com/2013/06/09/travel/a-lonely-planet-founderlooks-back.html?_r=0> [accessed 21 March 2016]

British Tourist Authority, Tourism in the UK: The Broad Perspective (London: The British Tourist Authority, 1981)

Broersma, Daniël, Het wonderland achter de horizon: Groninger regionaal besef in nationaal verband 1903-1963 (Assen: Koninklijke Van Gorcum, 2005) 
Brown, Frances, and Derek Hall, 'The Paradox of Peripherality', in Tourism in Peripheral Areas: Case Studies, ed. by Frances Brown and Derek Hall, Aspects of Tourism, 2 (Clevedon: Channel View Publications, 2000), pp. 1-6 Brown, Terence, ed., Celticism (Amsterdam: Rodopi, 1996)

Bruce, David, 'Baedeker: The Perceived "Inventor" of the Formal Guidebook - A Bible for Travellers in the 19th Century', in Giants of Tourism, ed. by Richard Butler and Roslyn Russell (Wallingford: CABI, 2010), pp. 93-110

Buzard, James, The Beaten Track: European Tourism, Literature, and the Ways to 'Culture' 1800-1918 (Oxford: Clarendon Press, 1993)

_ ' 'The Grand Tour and After (1660-1840)', in The Cambridge Companion to

Travel Writing, ed. by Peter Hulme and Tim Youngs (Cambridge: Cambridge University Press, 2002), pp. 37-52

Campbell, Mary B., Wonder \& Science: Imagining Worlds in Early Modern Europe (Ithaca: Cornell University Press, 1999)

Carroll, Clare, and Patricia King, ed., Ireland and Postcolonial Theory (Notre Dame: University of Notre Dame Press, 2003)

Casson, Lionel, Travel in the Ancient World (London: Allen and Unwin, 1974; repr. Baltimore: The John Hopkins University Press, 1994)

Chabal, Emile, 'Whose Postcolonialism? The French and their Colonial Past', $<$ https://moderncontemporarybham.wordpress.com/2015/10/05/whosepostcolonialism-the-french-and-their-colonial-past/\#_ftn1> [accessed 4 May 2017]

Chandler, David, 'Walter Savage Landor and Wales in the 1790s', in Wales and the Romantic Imagination, ed. by Damian Walford Davies and Lynda Pratt (Cardiff: Cardiff University Press, 2007), pp. 141-60

Chapman, Malcolm, The Celts: The Construction of a Myth (Basingstoke: Macmillan, 1992)

—, The Gaelic Vision in Scottish Literature (London: Croom Helm, 1978)

Chard, Chloe, Pleasure and Guilt on the Grand Tour: Travel Writing and Imaginative Geography 1660-1830 (Manchester: Manchester University Press, 1999) Chin, Rita, and others, After the Nazi Racial State: Difference and Democracy in Germany and Europe (Ann Arbor: University of Michigan Press, 2009) Clark, Steve, 'Introduction', in Travel Writing and Empire: Postcolonial Theory in Transit, ed. by Steve Clark (London: Zed Books, 1999), pp. 1-28 
Cohen, Erik, 'The Tourist Guide: The Origins, Structure and Dynamics of a Role', Annals of Tourism Research, 12 (1985), 5-29

Colbert, Benjamin, ed., Travel Writing and Tourism in Britain and Ireland

(Basingstoke: Palgrave Macmillan, 2012)

Confino, Alon, 'Federalism and the "Heimat" Idea in Imperial Germany', in German Federalism: Past, Present, Future, ed. by Maiken Umbach (Basingstoke:

Palgrave, 2002), pp. 70-90

Constantine, Mary-Ann, 'Beauty Spot, Blind Spot: Romantic Wales', Literary

Compass Online, 5 (2008), 577-90 <DOI: 577-9010.1111/j.1741-

4113.2008.00546.x>

—_, "Impertinent Structures": A Breton's Adventures in Neo-Gothic Wales', Studies in Travel Writing, 18 (2014), pp. 134-47

__, 'La "Sainte Terre de Cambrie": La Villemarqué et le romantisme gallois', in Au-delà du 'Barzaz Breiz': Théodore Hersart de la Villemarqué, ed. by Nelly Blanchard and Fañch Postic (Brest: Centre de recherche bretonne et celtique, 2016), pp. 209-28

__, “Viewing Most Things thro' False Mediums": Iolo Morganwg (1747-1826) and English Perceptions of Wales', in Romanticism's Debatable Lands, ed. by Claire Lamont and Michael Rossington (Basingstoke: Palgrave Macmillan, 2007), pp. 27-38

Coupland, Nikolas, Hywel Bishop and Peter Garrett, 'One Wales? Reassessing Diversity in Welsh Ethnolinguistic Identification', Contemporary Wales, 18 (2006), 1-27

Cronin, Michael, Translation and Identity (London: Routledge, 2006)

Cunliffe, Barry W., The Ancient Celts (London: Penguin, 1999)

Curtis, Tony, ed., Wales: The Imagined Nation (Bridgend: Poetry Wales Press, 1986)

Dallas, Gregor, 1815: The Roads to Waterloo (London: Pimlico, 2001)

Dann, Graham, The Language of Tourism: A Sociolinguistic Perspective (Wallingford: CABI, 1996)

_ _ 'Travelogs and the Management of Unfamiliarity', Journal of Travel Research, 30 (1992), 59-63

Davies, Andrew, "Redirecting the Attention of History": Antiquarian and Historical Fictions of Wales from the Romantic Period', in Wales and the Romantic 
Imagination, ed. by Damian Walford Davies and Lynda Pratt (Cardiff:

University of Wales Press, 2007), pp. 104-21

Davies, Daniel, 'Row over Budget to Attract Overseas Tourists to Wales', BBC News,

13 January 2013 <http://www.bbc.co.uk/news/uk-wales-politics-20989259>

[accessed 17 November 2015]

Davies, Hywel M., 'Wales in English Travel Writing 1791-8: The Welsh Critique of

Theophilus Jones', The Welsh History Review, 23 (2007), 65-93

Davies, John, A History of Wales, 2nd edn (London: Penguin Books, 2007)

Davies, Rebecca, 'Banal Britishness and Reconstituted Welshness: The Politics of

National Identities in Wales', Contemporary Wales, 18 (2006), 106-21

Day, Graham, Making Sense of Wales: A Sociological Perspective (Cardiff: University of Wales Press, 2010)

—_, 'The Sociology of Wales: Issues and Prospects', Sociological Review, 27 (1979), 447-74

-, 'Wales, the Regional Problem and Development', in Poverty and Social

Inequality in Wales, ed. by Gareth Rees and Teresa L. Rees (London: Croom Helm, 1980), pp. 230-51

Day, Graham, and Richard Suggett, 'Conceptions of Wales and Welshness: Aspects of Nationalism in Nineteenth-Century Wales', in Political Action and Social Identity, ed. by Gareth Rees (Basingstoke: Macmillan, 1985), pp. 91-115

De Beer, Esmond Samuel, 'The Development of the Guide Book until the Early Nineteenth Century', The Journal of the British Archaeological Association, 15 (1952), 35-46

De Certeau, Michel, The Practice of Everyday Life (Berkeley: University of California Press, 1984)

Dijkstra, Anna-Lou, 'Marginalizing and Exoticizing Wales: Shifting Representations in Translated Guidebooks', Translation Studies, 9 (2016), 198-211

Duffy, Cian, “"One Draught from Snowdon's Ever-Sacred Spring”: Shelley’s Welsh Sublime', in Wales and the Romantic Imagination, ed. by Damian Walford Davies and Lynda Pratt (Cardiff: Cardiff University Press, 2007), pp. 180-98 Dybiec, Joanna, Guidebook Gazes: Poland in American and German Travel Guides 1945-2002 (Münster: LIT, 2004)

Edmonds, Lizzie, 'Welsh Outrage as BBC's Hazel Irvine Describes Their Country as a PRINCIPALITY During the Commonwealth Games Opening Ceremony', 
Dailymail Online, 24 July $2014<$ http://www.dailymail.co.uk/news/article2704029/> [accessed 22 August 2015]

El Daly, Okasha, Egyptology: The Missing Millennium. Ancient Egypt in Medieval Arabic Writings (London: ECL Press, 2005)

Evans, Geoffrey, and Dafydd Trystan, 'Why Was 1997 Different?', in Scotland and Wales: Nations Again?, ed. by Bridget Taylor and Katarina Thomson (Cardiff: University of Wales Press, 1999), pp. 95-117

Ewert, Alan, and Stacy Taniguchi, 'The Motivations and Satisfactions Attendant to Mountaineering', in Mountaineering Tourism, ed. by Ghazali Musa, James Higham and Anna Thompson-Carr (Abingdon: Routledge, 2015), pp. 156-80 Fairclough, Norman, Critical Discourse Analysis: The Critical Study of Language (London: Longman, 1995)

Fendl, Elisabeth, and Klara Löffler, “"Man sieht nur, was man weiß”: Zur Wahrnehmungskultur in Reiseführern', in Tourismus-Kultur Kultur-Tourism, ed. by Dieter Kramer and Ronald Lutz (Münster: LIT, 1993), pp. 55-77

Fevre, Ralph, and Andrew Thompson, 'Social Theory and Welsh Identities', in Nation, Identity and Social Theory: Perspectives from Wales, ed. by Ralph Fevre and Andrew Thompson (Cardiff: University of Wales Press, 1999), pp. $3-24$

Fischer, Tilman, Reiseziel England: Ein Beitrag zur Poetik der Reisebeschreibung und zur Topik der Moderne (1830-1870) (Berlin: Erich Schmidt Verlag, 2004)

Forsdick, Charles, and David Murphy, 'Introduction: The Case for Francophone Postcolonial Studies', in Francophone Postcolonial Studies: A Critical Introduction, ed. by Charles Forsdick and David Murphy (London: Hodder Education, 2003), pp. 1-17

Foucault, Michel, Power/Knowledge: Selected Interviews and Other Writings, 19721977, ed. by Colin Gordon (Harlow: Prentice Hall, 1980)

Foulke, Robert, 'The Guidebook Industry', in Temperamental Journeys: Essays on the Modern Literature of Travel, ed. by Michael Kowalewski (Athens: University of Georgia Press, 1992), pp. 93-108

Francon, Marc, 'L’Univers Touristique Michelin', in Les Guides imprimés du XVIe au XXe siècle: villes, paysages, voyages, ed. by Gilles Chabaud and others (Paris: Belin, 2000), pp. 113-20

Franklin, Adrian, Tourism: An Introduction (London: SAGE Publications, 2003) 
Franklin, Caroline, 'Wales as Nowhere: The Tabula Rasa of the "Jacobin" Imagination', in 'Footsteps of Liberty and Revolt': Essays on Wales and the French Revolution, ed. by Mary-Ann Constantine and Dafydd Johnston (Cardiff: University of Wales Press, 2013), pp. 11-33

Furlough, Ellen, 'Making Mass Vacations: Tourism and Consumer Cultures in France, 1930s to 1970s', Comparative Studies in Society and History, 40 (1998), 24786

Fussell, Paul, Abroad: British Literary Traveling between the Wars (Oxford: Oxford University Press, 1980)

Gerbod, Paul, Les Voyageurs français à la découverte des îles Britanniques du XVIIIème siècle à nos jours (Paris: L'Harmattan, 1995)

GfK Consumer, Tipping Point Research: Stage 2 the Netherlands, Power Point Presentation ([n.p.]: Growth from Knowledge, 2006)

_ _ Tipping Point Research Germany, Power Point Presentation ([n.p.]: Growth from Knowledge, 2006)

Gibbons, Luke, Transformations in Irish Culture (Cork: Cork University Press, 1996)

Gilbert, David, “"London in All its Glory - or How to Enjoy London”: Guidebook Representations of Imperial London', Journal of Historical Geography, 25 (1999), 279-97

Glencross, Michael, Reconstructing Camelot: French Romantic Medievalism and the Arthurian Tradition (Cambridge: Brewer, 1995)

Gorsemann, Sabine, Bildungsgut und touristische Gebrauchsanweisung: Produktion, Aufbau und Funktion von Reiseführern (Münster: Waxmann, 1995)

Gramich, Katie, “"Every Hill has its History, Every Region its Romance”: Travellers' Constructions of Wales, 1844-1913', in Travel Writing and Tourism in Britain and Ireland, ed. by Benjamin Colbert (Basingstoke: Palgrave Macmillan, 2012), pp. 147-63

Grenier, Katherine, Tourism and Identity in Scotland, 1770-1914: Creating Caledonia (Aldershot: Ashgate, 2005)

Gruffudd, Pyrs, 'Prospects of Wales: Contested Geographical Imaginations', in Nation, Identity and Social Theory: Perspectives from Wales, ed. by Ralph Fevre and Andrew Thompson (Cardiff: University of Wales Press, 1999), pp. $149-67$ 
_ , 'Tradition, Modernity and the Countryside: The Imaginary Geography of Rural Wales', Contemporary Wales, 6 (1994), 33-47

Gruffudd, Pyrs, David T. Herbert and Angela Piccini, “"Good to Think”: Social Constructions of Celtic Heritage in Wales', Environment and Planning D, 17 (1999), 705-21

_ - 'In Search of Wales: Travel Writing and Narratives of Difference, 1918-50', Journal of Historical Geography, 26 (2000), 589-604

Guelke, Leonard, and Jeanne Kay Guelke, 'Imperial Eyes on South Africa:

Reassassing Travel Narratives', Journal of Historical Geography, 30 (2004), $11-31$

Guilcher, Goulven, 'Entre continuité et innovation: les guides touristiques en langue française de 1900 à 1960', in Les Guides de voyage: au fil du Rhin et ailleurs. Actes de la journée d'études du 19 mars 2004, ed. by Martine Breuillot and Thomas Beaufils (Strasbourg: Université Marc Bloch, 2005), pp. 9-16

-, 'Les Guides européens et leurs auteurs: clef de lecture', In Situ. Revue des patrimoines, 15 (2011), 2-23 <http://insitu.revues.org/499> [accessed 23 September 2013]

__ , 'Les Guides Michelin 1900-1914', La Lettre du marché du livre ancien et d'occasion, 38 (1994), 6-7

__ 'Les Guides Richard (1824-1836)', La Lettre du marché du livre ancien et d'occassion, 54 (1997), 4-6

__ ' 'Naissance et développement du guide de voyage imprimé: du guide unique à la série, une stratégie de conquête des lecteurs?', in Les Guides imprimés du XVIe au XXe siècle: villes, paysages, voyages, ed. by Gilles Chabaud and others (Paris: Belin, 2000), pp. 81-93

—_ 'La Rivalité Chaix-Hachette pour la conquête du marché de la lecture ferroviaire en France 1846-1865', Revue d'histoire des chemins de fer, 3 (1992), 279-305

Haesly, Richard, 'Identifying Scotland and Wales: Types of Scottish and Welsh National Identities', Nations and Nationalism, 11 (2005), 243-63

Hagglund, Betty, 'Gendering the Scottish Guidebook: Sarah Murray's “Companion and Useful Guide", Women's Writing, 17 (2010), 129-46

Hale, Amy, and Philip Payton, New Directions in Celtic Studies (Exeter: University of Exeter Press, 2000) 
Hancock, Claire, Paris et Londres aux XIXe siècle: représentations dans les guides et récits de voyage (Paris: CNRS Éditions, 2003)

Harp, Stephen L., Marketing Michelin: Advertising \& Cultural Identity in TwentiethCentury France (Baltimore: Johns Hopkins University Press, 2001)

Harris, John, 'Cool Cymru, Rugby Union and an Imagined Community', International Journal of Sociology and Social Policy, 27 (2007), 151-62

Hauenstein, Werner, Wegweiser durch Meyers Reisebücher: 1862 - 1936

(Stadtoldendorf: Verlag Ursula Hinrichsen, 1993)

Hechter, Michael, Internal Colonialism: The Celtic Fringe in British National Development (London: Routledge, 1975; repr. New Brunswick: Transaction Publishers, 1999)

Heelas, Paul, The New Age Movement: The Celebration of the Self and the Sacralization of Modernity (Oxford: Blackwell, 1996)

Hellegouarc'h-Bryce, Anne, 'Le pays de Galles: ni vu, ni connu', in Pays de Galles: quelle $(s)$ image $(s) ?=$ What Visibility for Wales?, ed. by Anne Hellegouarc'hBryce, Gerry German and Jean-Yves Le Disez (Brest: Centre de recherche bretonne et celtique, Université de Bretagne Occidentale, 2009), pp. 251-65 Hinrichsen, Alex, Baedeker-Katalog: Verzeichnis aller Baedeker-Reiseführer von 1832-1987 mit einem Abriß der Verlagsgeschichte (Holzminden: Ursula Hinrichsen Verlag, 1988)

__ ' 'Zur Entstehung des modernen Reiseführers', in Zur Sonne, zur Freiheit! Beiträge zur Tourismusgeschichte, ed. by Hasso Spode (Berlin: Verlag für universitäre Kommunikation, 1991), pp. 21-32

Housley, William, Kate Moles and Robin Smith, 'Identity, Brand or Citizenship? The Case of Post-Devolution Wales', Contemporary Wales, 22 (2009), 196-210

Howell, Lyn, The Wales Tourist Board: The Early Years ([n.p.]: Wales Tourist Board, 1988)

Hughes, George, 'Tourism and the Semiological Realization of Space', in Destinations: Cultural Landscapes of Tourism, ed. by Greg Ringer (London: Routledge, 1998), pp. 17-32

Hughes, William John, Wales and the Welsh in English Literature: From Shakespeare to Scott (Wrexham: Hughes and Son, 1924)

Huggan, Graham, Extreme Pursuits: Travel/Writing in an Age of Globalization (Ann Arbor: University of Michigan Press, 2009) 
Jack, Gavin, and Alison Phipps, 'On the Uses of Travel Guides in the Context of German Tourism to Scotland', Tourist Studies, 3 (1996), 281-300

Jacobson, Jens Kristian Steen, and M.S. Graham Dann, 'Images of the Lofoten Islands', Scandinavian Journal of Hospitality and Tourism, 3 (2003), 24-47 Jacques, Martin, When China Rules the World: The End of the Western World and the Birth of a New Global Order (New York: Penguin, 2009)

James, Simon, The Atlantic Celts: Ancient People or Modern Invention? (Wisconsin: University of Wisconsin Press, 1999)

Jenkins, Geraint H., A Concise History of Wales (Cambridge: Cambridge University Press, 2007)

Johnes, Martin, Wales since 1939 (Manchester: Manchester University Press, 2012)

Jones, Kathryn N., 'Locating "Pays de Galles" in the Twenty-First Century: Dynamic Model or Forgotten World?', Studies in Travel Writing, 18 (2014), 187-98

Jones, Merfyn, The North Wales Quarrymen, 1874-1922 (Cardiff: University of Wales Press, 1981)

Jones, Rhys, and Carwyn Fowler, Placing the Nation: Aberystwyth and the Reproduction of Welsh Nationalism (Cardiff: University of Wales Press, 2008)

Jones, Richard Wyn, and Dafydd Trystan, 'The Welsh Referendum Vote', in Scotland and Wales: Nations Again?, ed. by Bridget Taylor and Katarina Thomson (Cardiff: University of Wales Press, 1999), pp. 65-94

Jones, Richard Wyn, Roger Scully and Dafydd Trystan, 'Why Do the Conservatives Do (Even) Worse in Wales?', British Elections and Parties Review, 12 (2002), $229-45$

Jones-Evans, Dylan, 'How Tourism Can Be a Shining Star in the Welsh Economy Post Brexit', WalesOnline, 5 May 2017 <http://www.walesonline.co.uk/business/business-opinion/how-tourism-canshining-star-12991526> [accessed 21 July 2017]

Kaschuba, Wolfgang, 'Erkundung der Moderne: Bürgerliches Reisen nach 1800', Zeitschrift für Volkskunde, 87 (1991), 29-52

Kat, Micha, 'De opkomst van het massatoerisme', Historisch nieuwsblad, 6 (2001) <http://www.historischnieuwsblad.nl/nl/artikel/5724/de-opkomst-van-hetmassatoerisme.html> [accessed 5 May 2015]

Keating, Michael, The New Regionalism in Western Europe: Territorial Restructuring and Political Change (Cheltenham: Edward Elgar, 1998) 
Keitz, Christine, 'Die Anfänge des modernen Massentourismus in der Weimarer Republik', Archiv für Sozialgeschichte, 33 (1993), 179-209

$\longrightarrow$, Reisen als Leitbild: die Entstehung des modernen Massentourismus in Deutschland (Munich: Deutscher Taschenbuch Verlag, 1997)

_ 'Reisen zwischen Kultur und Gegenkultur: "Baedeker" und die ersten Arbeitertouristen in der Weimarer Republik', in Zur Sonne, zur Freiheit! Beiträge zur Tourismusgeschichte, ed. by Hasso Spode (Berlin: Verlag für universitäre Kommunikation, 1991), pp. 47-60

Kemp, Tom, Industrialization in Nineteenth-Century Europe, 2nd edn (London: Longman, 1985)

Kent, Alan M., 'Celtic Nirvanas: Constructions of Celtic in Contemporary British Youth Culture', in Celtic Geographies: Old Culture, New Times, ed. by David C. Harvey and others (London: Routledge, 2002), pp. 208-26

Kirkpatrick, John, 'The Praise of Baedeker', Pall Mall Gazette, 30 August 1889, Correspondence Section, p. 2

Kneafsey, Moya, 'Tourism Images and the Construction of Celticity in Ireland and Brittany', in Celtic Geographies: Old Culture, New Times, ed. by David C. Harvey and others (London: Routledge, 2002), pp. 123-38

Koshar, Rudy, German Travel Cultures (Oxford: Berg, 2000)

__, "What Ought to Be Seen": Tourists' Guidebooks and National Identities in Modern Germany and Europe', Journal of Contemporary History, 33 (1998), $323-40$

Kössler, Reinhart, 'Kolonialherrschaft: Auch eine deutsche Vergangenheit', in Kolonialismus und Erinnerungskultur: Die Kolonialvergangenheit im kollektiven Gedächtnis der deutschen und niederländischen Einwanderungsgesellschaft, ed. by Helma Lutz and Kathrin Gawarecki (Münster: Waxmann, 2005), pp. 23-40

Kupchan, Charles, No One's World: The West, the Rising Rest, and the Coming Global Turn (Oxford: Oxford University Press, 2012)

Kuszynski, Ingrid, 'Ins gelobte Land der Freiheit und des Wohlstands: Reisen nach England', in Reisekultur: Von der Pilgerfahrt zum modernen Tourismus, ed. by Hermann Bausinger, Klaus Beyrer and Gottfried Korff (Munich: C.H. Beck, 1991), pp. 237-43 
Laderman, Scott, 'Shaping Memory of the Past: Discourse in Travel Guidebooks for Vietnam', Mass Communication and Society, 5 (2002), 87-110

Lanfant, Marie-Françoise, 'International Tourism, Internationalization and the Challenge to Identity', in International Tourism: Identity and Change, ed. by Marie-Françoise Lanfant, John B. Allcock and Edward M. Bruner (London: SAGE Publications, 1995), pp. 24-43

—_, 'Introduction', in International Tourism: Identity and Change, ed. by MarieFrançoise Lanfant, John B. Allcock and Edward M. Bruner (London: SAGE Publications, 1995), pp. 1-23

Lauterbach, Burkhart, 'Baedeker und andere Reiseführer: Eine Problemskizze', Zeitschrift für Volkskunde, 85 (1989), 206-34

Leask, Nigel, 'Fingalian Topographies: Ossian and the Highland Tour, 1760-1805', Journal for Eighteenth-Century Studies, 39 (2016), 183-96

Leerssen, Joep, 'Celticism', in Celticism, ed. by Terence Brown (Amsterdam: Rodopi, 1996), pp. 1-20

Lew, A., 'Place Representation in Tourist Guidebooks: An Example from Singapore', Singapore Journal of Tropical Geography, 12 (1991), 124-37

Ley, David, 'Behavioral Geography and the Philosophies of Meaning', in Behavioral Problems in Geography Revisited, ed. by Kevin R. Cox and Reginald G. Golledge (New York: Methuen, 1981), pp. 209-30

L'Huillier, Monique, Advanced French Grammar (Cambridge: Cambridge University Press, 1999)

Lichtenwalner, Shawna, Claiming Cambria: Invoking the Welsh in the Romantic Era (Newark: University of Delaware Press, 2008)

Lisle, Debbie, The Global Politics of Contemporary Travel Writing (Cambridge: Cambridge University Press, 2006)

Lister, William B.C., and John R. Gretton, A Bibliography of Murray's Handbooks for Travellers and Biographies of Authors, Editors, Revisers and Principal Contributors (Dereham: Dereham Books, 1993)

Löfgren, Orvar, On Holiday: A History of Vacationing (Berkeley: University of California Press, 2002)

Lord, Peter, The Visual Culture of Wales: Industrial Society (Cardiff: University of Wales Press, 1998) 
Lovering, John, 'The Theory of the Internal Colony and the Political Economy of Wales', Review of Radical Political Economics, 10 (1978), 55-67

Lowerson, John, 'Celtic Tourism: Some Recent Magnets', Cornish Studies, 2 (1994), $128-37$

MacCannell, Dean, The Tourist: A New Theory of the Leisure Class (New York: Schocken Books, 1976, repr. Berkeley: University of California Press, 1999)

McCormack, W.J., From Burke to Beckett: Ascendency, Tradition and Betrayal in Literary History, 2nd edn (Cork: Cork University Press, 1994)

McCrone, David, Understanding Scotland: The Sociology of a Nation, 2nd edn (London: Routledge, 2001)

McEwan, Cheryl, Gender, Geography and Empire: Victorian Women Travellers in West Africa (Aldershot: Ashgate, 2000)

McGregor, Andrew, 'Dynamic Texts and Tourist Gaze: Death, Bones and Buffalo', Annals of Tourism Research, 27 (2000), 27-50

Mackenzie, John M., 'Empires of Travel: British Guide Books and Cultural Imperialism in the 19th and 20th Centuries', in Histories of Tourism: Representation, Identity and Conflict, ed. by John K. Walton, Tourism and Cultural Change, 6 (Clevedon: Channel View Publications, 2005), pp. 19-38

Mahbubani, Kishore, The New Asian Hemisphere: The Irresistible Shift of Global Power to the East (New York: Public Affairs, 2008)

Mahn, Churnjeet, 'Romantic Horizons: Fact and Fiction in the Guidebook to Scotland', in Re-Visioning Scotland: New Readings of the Cultural Canon, ed. by Lyndsay Lunan, Kirsty MacDonald and Carla Sassi (Frankfurt a.M.: Peter Lang, 2008), pp. 1-12

Martin, Alison, 'Celtic Censure: Representing Wales in Eighteenth-Century Germany', Studies in Travel Writing, 18 (2014), 122-33

Mason, Rhiannon, 'Nation Building at the Museum of Welsh Life', Museum and Society, 2 (2004), 18-34

Maurer, Michael, Wales: Die Entdeckung einer Landschaft und eines Volkes durch deutsche Reisende (1780-1860) (Frankfurt a.M.: Peter Lang, 2014)

Mee, Catharine, Interpersonal Encounters in Contemporary Travel Writing: French and Italian Perspectives (London: Anthem Press, 2015) 
Melton, J. Gordon, 'New Thought and the New Age', in Perspectives on the New Age, ed. by James R. Lewis and J. Gordon Melton (New York: State University of New York Press, 1992), pp. 15-29

Mendelson, Edward, 'Baedeker's Universe', Yale Review, 74 (1985), 386-403

Meurs, Pauline, and others, Identificatie met Nederland (Amsterdam: Amsterdam University Press, 2007)

Middleton, Victor T. C., British Tourism: The Remarkable Story of Growth (Oxford: Butterworth-Heinemann, 2007)

Mills, Sara, Discourses of Difference: An Analysis of Women's Travel Writing and Colonialism (London: Routledge, 1991)

Morgan, Marjorie, National Identity and Travel in Victorian Britain (Basingstoke: Palgrave, 2001)

Morgan, Nigel, and Annette Pritchard, 'Culture, Identity and Tourism Representation: Marketing Cymru or Wales?', Tourism Management, 22 (2001), 167-79

_ Management, 12 (2005), 17-33

Morgan, Prys, The Eighteenth Century Renaissance (Swansea: Christopher Davies, 1981)

—, 'From a Death to a View: The Hunt for the Welsh Past in the Romantic Period', in The Invention of Tradition, ed. by Eric Hobsbawm and Terence Ranger (Cambridge: Cambridge University Press, 1992), pp. 43-100 -, 'Wild Wales: Civilizing the Welsh from the Sixteenth to the Nineteenth Centuries', in Civil Histories: Essays Presented to Sir Keith Thomas, ed. by Peter Burke, Brian Harrison and Paul Slack (Oxford: Oxford University Press, 2000), pp. 265-84

Morgan, Tim, Life after Growth: How the Global Economy Really Works and Why 200 Years of Growth Are Over, 2nd edn (Hampshire: Harriman House, 2016)

Morlier, Hélène, Les Guides-Joanne: genèse des guides-bleus. Itinéraire bibliographique, historique et descriptif de la collection de guides de voyage, 1840-1920 (Paris: Les Sentiers débattus, 2007)

— , 'Les Guides Joanne: invention d'une collection', In Situ. Revue des patrimoines, 15 (2011), 2-23 <http://insitu.revues.org/524> [accessed 16 September 2013] 
Morris, Ian, Why the West Rules - For Now: The Patterns of History, and What They Reveal about the Future (New York: Farrar, Straus and Giroux, 2010) Mullen, Richard, and James Munson, 'The Smell of the Continent': The British Discover Europe 1814-1914 (London: Pan Macmillan, 2009)

Murray III, John, ‘The Origin and History of Murray's Handbooks for Travellers', Murray's Magazine, 6 (1889), 623-9 (repr. in John Murray IV, John Murray III 1808-1892: A Brief Memoir (New York: Alfred A. Knopf, 1920), pp. 39-49)

Nairn, Tom, The Break Up of Britain: Crisis and Neo-Colonialism (London: New Left Books, 1977)

Nelson, Velvet, 'The Construction of Slovenia as a European Tourism Destination in Guidebooks', Geoforum, 43 (2012), 1099-110

Newhouse, John, ‘Europe's Rising Regionalism', Foreign Affairs (1997) $<$ https://www.foreignaffairs.com/articles/europe/1997-01-01/europes-risingregionalism> [accessed 11 September 2015]

Nishimura, Sachiko, Robert Waryszak and Brian King, 'The Use of Guidebooks by Japanese Overseas Tourists: A Quantitative Approach', Journal of Travel Research, 45 (2007), 275-84

Nordman, Daniel, 'Les Guides-Joanne: ancêtres des guides bleus', in Les Lieux de mémoire II: la nation, ed. by Pierre Nora, 3 vols (Paris: Gallimard, 1986), I, pp. 529-67

Nunley, Gayle R., Scripted Geographies: Travel Writings by Nineteenth-Century Spanish Authors (Lewisburg: Bucknell University Press, 2007)

Oettermann, Stephan, The Panorama: History of a Mass Medium, trans. by Deborah L. Schneider (New York: Zone Books, 1997)

Ogilvie, Frederick Wolff, The Tourist Movement: An Economic Study (London: P.S. King \& Son, 1933)

Osmond, John, Welsh Politics in the New Millenium (Cardiff: Institute of Welsh Affairs, 1999)

Paasi, Anssi, 'Region and Place: Regional Identity in Question', Progress in Human Geography, 27 (2003), 475-85

Palmer, Catherine, 'Tourism and the Symbols of Identity', Tourism Management, 20 (1999), 313-21 
Palmowski, Jan, 'Travels with Baedeker: The Guidebook and the Middle Classes in Victorian and Edwardian Britain', in Histories of Leisure, ed. by Rudy Koshar (Oxford: Berg, 2002), pp. 105-30

Parsons, Nicholas T., Worth the Detour: A History of the Guidebook (Thrupp: Sulton Publishing, 2007)

Peel, Victoria, and Anders Sørensen, Exploring the Use and Impact of Travel Guidebooks, Tourism and Cultural Change, 48 (Bristol: Channel View Publications, 2016)

Peters, Anja, “"Mein beschränkter Raum zwingt mich, auf das Selbstschauen zu verweisen.” Adele Schopenhauers Florenz-Reiseführer', German Studies Review, 37 (2014), 487-506

Pitchford, Susan, Identity Tourism: Imaging and Imagining the Nation, Tourism Social Science Series, 10 (Bingley: Emerald, 2008)

Pittock, Murray, Celtic Identity and the British Image (Manchester: Manchester University Press, 1999)

Prahl, Hans-Werner, 'Entwicklungsstadien des deutschen Tourismus seit 1945', in Zur Sonne, zur Freiheit! Beiträge zur Tourismusgeschichte, ed. by Hasso Spode (Berlin: Verlag für universitäre Kommunikation, 1991), pp. 95-108

Pratt, Lynda, 'Southey in Wales: Inscriptions, Monuments and Romantic Posterity', in Wales and the Romantic Imagination, ed. by Damian Walford Davies and Lynda Pratt (Cardiff: Cardiff University Press, 2007), pp. 86-103

Pratt, Mary Louise, Imperial Eyes: Travel Writing and Transculturation, 2nd edn (London: Routledge, 2008)

Prescott, Sarah, Eighteenth-Century Writing from Wales: Bards and Britons (Cardiff: University of Wales Press, 2008)

_ Elizabeth Spence', Studies in Travel Writing, 18 (2014), 107-21

Pritchard, Annette, and Adam Jaworski, 'Introduction: Discourse, Communication and Tourism Dialogues', in Discourse, Communication and Tourism, ed. by Adam Jaworski and Annette Pritchard, Tourism and Cultural Change, 5 (Clevedon: Channel View Publications, 2005), pp. 1-16

Pritchard, Annette, and Nigel Morgan, 'Mythic Geographies of Representation and Identity: Contemporary Postcards of Wales', Journal of Tourism and Cultural Change, 1 (2003), 111-30 
Rapley, John, The Britannia \& Other Tubular Bridges: And the Men Who Built Them (Charleston: Tempus Publishing, 2003)

Rauch, André, 'Du Joanne au Routard: le style des guides touristiques', in Les Guides imprimés du XVIe au XXe siècle: villes, paysages, voyages, ed. by Gilles Chabaud and others (Paris: Belin, 2000), pp. 95-112

Renan, Ernest, 'La Poésie des races celtiques', Revue des deux mondes, 5 (1854), 473 506

Ringer, Greg, 'Introduction', in Destinations: Cultural Landscapes of Tourism, ed. by Greg Ringer (London: Routledge, 1998), pp. 1-13

Roberts, Brian, 'Welsh Identity in a Former Mining Valley: Social Images and Imagined Communities', in Nation, Identity and Social Theory: Perspectives from Wales, ed. by Ralph Fevre and Andrew Thompson (Cardiff: University of Wales Press, 1999), pp. 111-28

Robinson, Mike, 'Narratives of Being Elsewhere: Tourism and Travel Writing', in $A$ Companion to Tourism, ed. by Alan Lew, Colin Hall and Allan Williams (Oxford: Blackwell, 2004), pp. 305-15

Rokkan, Stein, and Derek W. Urwin, The Politics of Territorial Identity: Studies in European Regionalism (London: SAGE Publications, 1982)

Saarinen, Jarkko, "Destinations in Change": The Transformation Process of Tourist Destinations', Tourist Studies, 4 (2004), 161-79

Said, Edward, Culture and Imperialism (London: Chatto and Windus, 1993; repr. London: Vintage Books, 1994)

— Orientalism (London: Routledge and Kegan Paul, 1978; repr. London: Penguin Books, 1995)

Schildt, Axel, “"Die kostbarsten Wochen des Jahres": Urlaubstourismus der Westdeutschen (1945-1970)', in Goldstrand und Teutonengrill: Kultur- und Sozialgeschichte des Tourismus in Deutschland 1945 bis 1989, ed. by Hasso Spode (Berlin: Verlag für universitäre Kommunikation, 1996), pp. 69-85

Schivelbusch, Wolfgang, The Railway Journey: The Industrialization of Time and Space in the 19th Century (Berkeley: University of California Press, 1986) Schott, Hendrik, 'Niederländische Reiseliteratur des 19. Jahrhunderts: Geschichte, Umfeld und Vielfalt einer Literaturgattung' (unpublished doctoral thesis, Philologische Fakultät der Universität Köln, 1990) 
Scott, Paul, 'Guidebooks: Prewar to Postwar Imaging', Journal of Intercultural Studies, 25 (1998), 89-106

Scully, Roger, and Richard Wyn Jones, 'Still Three Wales? Social Location and Electoral Behaviour in Contemporary Wales', Electoral Studies, 31 (2012), 656-67

Seaton, A.V., 'Tourism as Metempsychosis and Metensomatosis: The Personae of Eternal Recurrence', in The Tourist as Metaphor of the Social World, ed. by Graham Dann (Wallingford: CABI, 2002), pp. 135-68

Selwyn, Tom, ed., The Tourist Image: Myth and Myth Making in Tourism (Chichester: Wiley, 1996)

Serry, Hervé, 'Chris Marker au Seuil', <http://www.seuil.com/page-hommage-chrismarker.htm\#_ftn13>, [accessed 10 March 2015]

Sharp, Joanne P., Geographies of Postcolonialism: Spaces of Power and Representation (London: SAGE Publications, 2009)

Sherrington, Emlyn, 'How Do You Sell a Nation?', Journal for the Study of British Cultures, 11 (2004), 183-94

Shields, Rob, Places on the Margins: Alternative Geographies of Modernity (London: Routledge, 1992)

Simmons, Jack, The Railway in England and Wales, 1830-1914 (Leicester: Leicester University Press, 1978)

Simmons, Jack, and Gordon Biddle, ed., The Oxford Companion to British Railway History: From 1603 to the 1990s (Oxford: Oxford University Press, 1999)

Sims-Williams, Patrick, 'Celtomania and Celtoscepticism', Cambrian Medieval Celtic Studies, 36 (1998), 1-35

Singer, Rita, 'Project Report: Teithwyr Ewropeaidd i Gymru, 1750-2010/European Travellers to Wales, 1750-2010', Journal of Tourism History, 8 (2016), 85-91

Smith, Dai, Wales! Wales? (London: Allen \& Unwin, 1984)

Smits, Alice, 'Niet willen weten: Nederland in postkoloniaal perspectief', Metropolis $M, 5$ (2011) <http://framerframed.nl/nl/dossier/niet-willen-weten-nederland-inpostkoloniaal-perspectief/> [accessed 27 April 2017]

Smits, De oude Heer, 'Brief over het reizen. Van den ouden Heer Smits, aan zijn kleinzoon', De Nederlandsche Spectator, 2 (1861), 190-1

Stagl, Juston, Apodemiken: Eine räsonnierte Bibliographie der reisetheoretischen Literatur des 16., 17. und 18. Jahrhunderts (Paderborn: Schöningh, 1983) 
Steegman, John E.H., and Iorwerth C. Peate, 'Richard Wilson', Dictionary of Welsh Biography <http://wbo.llgc.org.uk/en/s-WILS-RIC-1713.html> [accessed 12 December 2014]

Steinecke, Albrecht, Der bundesdeutsche Reiseführer-Markt: Leseranalyse Angebotsstruktur - Wachstumsperspektiven (Starnberg: Studienkreis für Tourismus, 1988)

Stevens, Christine, 'Welsh Costume: The Survival of Tradition or National Icon?', Folk Life, 43 (2004), 56-70

Suzuki, Koshiro, and Yoshiki Wakabayashi, 'Cultural Differences of Spatial Descriptions in Tourist Guidebooks', in Spatial Cognition IV: Reasoning, Action, Interaction, ed. by Christian Freska and others (Berlin: Springer Verlag, 2004), pp. 147-64

Swank, Duane, and Hans-Georg Betz, 'Globalization, the Welfare State and RightWing Populism in Western Europe', Socio-Economic Review, 1 (2003), 215-45 Sweney, Mark, 'BBC WorldWide Criticised for Sale of Lonely Planet at "Significant Loss", Guardian, 19 March 2013, <http://www.theguardian.com/media/2013/mar/19/bbc-worldwide-criticisedlonely-planet-sale> [accessed 18 March 2016]

Tavares, David, and Marc Brosseau, 'The Representation of Mongolia in Contemporary Travel Writing: Imaginative Geographies of a Travellers' Frontier', Social \& Cultural Geography, 7 (2006), 299-317

Teague, Ken, 'Representations of Nepal', in Tourists and Tourism: Identifying with People and Places, ed. by Simone Abram, Jacqueline D. Waldren and Donald V.L. Macleod (Oxford: Berg, 1997), pp. 173-95

Teng, Emma Jinhua, Taiwan's Imagined Geography: Chinese Colonial Travel Writing and Pictures, 1683-1895 (Cambridge, MA: Harvard University Press, 2004) Therkelsen, Anette, and Anders Sørensen, 'Reading the Tourist Guidebook: Tourists' Ways of Reading and Relating to Guidebooks', Journal of Tourism Studies, 16 (2005), 48-60

Thomas, M. Wynn, 'Studying Wales Today: A Microcosmopolitan Approach', The Annual Lecture of the Learned Society of Wales and the Honourable Society of Cymmrodorion (2016), 1-13 <https://www.cymmrodorion.org/wpcontent/uploads/2017/01/STUDYING-WALES-TODAY-M-W-THOMAS-6DECEMBER-2016-compressed.pdf> [accessed 19 April 2017] 
Thompson, Andrew, and Graham Day, 'Situating Welshness: "Local" Experience and National Identity', in Nation, Identity and Social Theory: Perspectives from Wales, ed. by Ralph Fevre and Andrew Thompson (Cardiff: University of Wales Press, 1999), pp. 27-47

Titscher, Stefan, and others, Methods of Text and Discourse Analysis (London: SAGE Publications, 2000)

Towner, John, An Historical Geography of Recreation and Tourism in the Western World 1540-1940 (Chichester: John Wiley \& Sons, 1996)

Tristram, Hildegard L.C., 'Einleitung: 150 Jahre deutsche Hibernistik', in Deutsche, Kelten und Iren: 150 Jahre deutsche Keltologie - Gearóid Mac Eoin zum 60. Geburtstag gewidmet, ed. by Hildegard L.C. Tristram (Hamburg: Buske Verlag, 1990), pp. 11-53

Tully, Carol, 'The Celtic Misconnection: The German Romantics and Wales', Angermion, 2 (2009), 127-41

—, 'Out of Europe: Travel and Exile in Mid-Twentieth-Century Wales', Studies in Travel Writing, 18 (2014), 174-86

Uekötter, Frank, The Greenest Nation? A New History of German Environmentalism (Cambridge, MA: MIT Press, 2014)

Umbach, Maiken, 'Introduction: German Federalism in Historical Perspective', in German Federalism: Past, Present, Future, ed. by Maiken Umbach (Basingstoke: Palgrave, 2002), pp. 1-14

Urry, John, The Tourist Gaze, 2nd edn (London: SAGE Publications, 2002)

Vandewalle, Isabelle, and Manouk Borzakian, 'Le Tourisme durable à l'étranger ou la possibilité d'un autre voyage', Centre de recherche pour l'étude et l'observation des conditions de vie, (2009) <http://www.credoc.fr/pdf.php?param=pdf/Rech/C269> [accessed 4 May 2015]

Van Egmond, Antonius N. F., Het verschijnsel toerisme: verleden, heden, toekomst (Meppel: Edu'actief, 2010)

Van Loon, Marissa, and Danielle Pinedo, 'Draagvlak voor monarchie opnieuw afgenomen', NRC, 26 April 2016 $<$ https://www.nrc.nl/nieuws/2016/04/26/draagvlak-voor-monarchie-innederland-flink-afgenomen-a1407639> [accessed 21 October 2016] 
Vaughan, John, The English Guide Book c. 1780-1870 (Newton Abbot: David \& Charles, 1974)

Visit Britain, Overseas Visitors to Britain: Understanding Trends, Attitudes and Characteristics (2010) <http://www.etoa.org/resources/reports/2010-overseasvisitors-to-britain-understanding-trends-attitudes-and-characteristics-byvisitbritain> [accessed 17 November 2015]

— $<$ https://www.visitbritain.org/nation-region-county-data> [accessed 21 August 2015]

Walford Davies, Damian, and Lynda Pratt, 'Introduction: Devolving Romanticism', in Wales and the Romantic Imagination, ed. by Damian Walford Davies and Lynda Pratt (Cardiff: University of Wales Press, 2007), pp. 1-12

— Press, 2007)

Walton, John K., 'British Tourism between Industrialization and Globalization: An Overview', in The Making of Modern Tourism: The Cultural History of the British Experience, 1600-2000, ed. by Hartmut Berghoff and others (Basingstoke: Palgrave, 2002), pp. 109-31

Watkins, John, 'Wales and France', The Transactions of the Honourable Society of Cymmrodorion, 2 (1967), 179-202

Watson, John Richard, 'Wordsworth, North Wales and the Celtic Landscape', in English Romanticism and the Celtic World, ed. by Gerard Carruthers and Alan Rawes (Cambridge: Cambridge University Press, 2003), pp. 85-102

Welsh Government, 'News and Alerts: Visit Wales Germany Marketing Campaign', <http://content.govdelivery.com/accounts/UKWALES/bulletins/e80dd2> [accessed 16 March 2016]

Welsh Government: Stats Wales, 'Iron and Steel Production by Year, Measure and Area' <https://statswales.wales.gov.uk/Catalogue/Business-Economy-andLabour-Market/Economic-Indices/Indices-of-Production-andConstruction/ironandsteelproduction-by-year-measure-area> [accessed 16 March 2016]

Wight, John, 'Across Europe Nationalism Is on the Rise', Huffington Post, 26 July 2014 <http://www.huffingtonpost.co.uk/john-wight/nationalismeurope_b_5393841.html> [accessed 1 May 2017] 
Wihtol de Wenden, Catherine, 'Debating Cultural Difference in France', in The Construction of Minority Identities in France and Britain, ed. by Gino G. Raymond and Tariq Modood (Basingstoke: Palgrave Macmillan, 2007), pp. 4858

Wildenthal, Lora, 'Notes on a History of "Imperial Turns" in Modern Germany', in After the Imperial Turn: Thinking with and through the Nation, ed. by Antoinette Burton (Durham, NC: Duke University Press, 2003), pp. 144-56 Williams, Eddie, 'Language Attitudes and Identity in a North Wales Town:

“Something Different about Caernarfon"?', International Journal of the Sociology of Language, 195 (2009), 63-91

Williams, Gwyn A., When Was Wales?: A History of the Welsh (Harmondsworth: Penguin Books, 1985)

Williams, Heather, 'Cymru trwy lygaid Rousseau (ac eraill)', Y Traethodydd, 168 (2013), 241-54

— Studies, 2 (Bern: Peter Lang, 2007)

- ' 'Views and Visions of Wales in French Nineteenth-Century Travel Writing', Swansea University seminar, Swansea, 16 November 2015 <https://www.academia.edu/27794506/Views_and_visions_of_Wales_in_ninet eenth-century_French_travel_writing_talk_> [accessed 14 December 2016] Williams, Owen, 'Wales Isn't a "Principality” - Sorry!', BBC News Wales, 24 July 2014 <http://www.bbc.co.uk/blogs/wales/entries/1fa3ef03-d94a-3a3c-a22f093c74467401> [accessed 22 August 2015]

Withey, Lynne, Grand Tours and Cook's Tours: A History of Leisure Travel, 1750 to 1915 (London: Aurum Press, 1997)

Wong, Chak Keung Simon, and Fung Ching Gladys Liu, 'A Study of Pre-Trip Use of Travel Guidebooks by Leisure Travelers', Tourism Management, 32 (2011), $616-28$

Young, Tamara, 'Framing Experiences of Aboriginal Australia: Guidebooks as Mediators in Backpacker Travel', Tourism Analysis, 14 (2009), 155-64 Zaring, Jane, 'The Romantic Face of Wales', Annals of the Association of American Geographers, 67 (1977), 397-418 
Zillinger, Malin, 'The Importance of Guidebooks for the Choice of Tourist Sites: A Study of German Tourists in Sweden', Scandinavian Journal of Hospitality and Tourism, 6 (2006), 229-46

Zimmer, Stefan, 'Julius Rodenberg and Ferdinand Walter: Deutsche Annäherungen an Wales im 19. Jahrhundert', in 150 Jahre 'Mabinogion': Deutsch-walisische Kulturbeziehungen, ed. by Bernhard Maier and Stefan Zimmer (Tübingen: Max Niemeyer, 2001), pp. 253-64 